\title{
Requests by Australian learners of Indonesian
}

\author{
Tim Hassall
}

December 1997

A thesis submitted for the degree of Doctor of Philosophy of the Australian National University 


\section{DECLARATION}

Except where otherwise acknowledged, this thesis is my own work.

Tim Hassall 


\section{ACKNOWLEDGEMENTS}

I especially wish to thank my supervisor Tony Liddicoat for his invaluable help, suggestions and detailed comments on successive drafts of this thesis. I am also very grateful to my co-supervisors and advisors, past and present: Yohanni Johns, Robert Parbs and George Quinn, for their time and helpful comments on the direction of my work.

I am indebted to the Indonesians who acted as informants throughout this project, especially Ira Armstrong, Prapti McLeod, Wayan Pastika, and Emmy Oey, for the huge amount of time they spent discussing pieces of data with me and answering my questions. Other informants who provided very helpful comments on various aspects of the data are Tommy Christomy, Bambang Hudayana, Rina Marnita, Safnil, and Supomo Suryohudoyo.

I am grateful to Tina, Tommy, and Yudi, who generously offered to help distribute questionnaires to Indonesian informants on campus, and so saved me a lot of trouble.

I also wish to thank all the Australian students and the Indonesians who participated in the role plays and completed the questionnaires which provided the data for this study.

Finally, I would like to thank the linguistics staff at the University of Sydney for providing a wonderful MA program in Applied Linguistics in 1990-1991, which inspired my interest in second language research. 


\section{CONTENTS}

Acknowledgements

Table of contents iv

List of tables $\quad$ xiii

Conventions $\quad x v$

Abbreviations $\quad$ xvi

INTRODUCTION 1

Notes to introduction $\quad 3$

CHAPTER 1. LITERATURE REVIEW 4

1.1 Introduction 4

1.2 Pragmatic competence and communicative competence 4

1.2.1 Canale \& Swain's model of communicative competence 5

1.2.2 Bachman's model of communicative ability 6

1.2.3 Pragmalinguistic and sociopragmatic competence 8

1.2.4 Relationship between pragmatics and discourse 9

1.2.5 Definition of pragmatic competence 10

$\begin{array}{lll}1.3 \text { Speech acts } & 10\end{array}$

1.3.1 Notion of a speech act 10

1.3.2 Usefulness of 'speech act' as a category to analyse speech 12

$\begin{array}{lll}1.4 & \text { Theories of linguistic politeness } & 14\end{array}$

1.4.1 Conversational-maxim theory of politeness 15

1.4.2 Face-saving theory of politeness 17

1.4.3 Criticisms of Brown \& Levinson's model of politeness 21

$\begin{array}{ll}1.5 & \text { Universality of pragmatics }\end{array}$ 
1.6 Interlanguage pragmatics $\quad 29$

1.6.1 Introduction 29

1.6.2 What learners do in ILP 30

1.6.2.1 Issue of a pragmatic norm 30

$\begin{array}{lll}\text { 1.6.2.2 Previous studies } & 31\end{array}$

1.6.2.3 Features of learner pragmatics . $\quad 32$

1.6.3 How learners do ILP 36

1.6.3.1 Use of universal pragmatic knowledge 36

1.6.3.2 L1 transfer 37

1.6.3.3 Generalisation from the IL 39

1.6.3.4 Use of knowledge from instruction $\quad 40$

1.6.3.5 Relationship of processes 42

1.6.4 Development of pragmatic competence 44

$\begin{array}{lll}1.7 & \text { Notes to Chapter } 1 & 48\end{array}$

CHAPTER 2. METHODOLOGY 54

2.1 The subjects $\quad 54$

2.1.1 Learner subjects $\quad 54$

2.1.1.1 Low group of learners 55

2.1.1.2 High group of learners 55

2.1.2 Indonesian native speaker subjects 55

2.2 Choice of speech act to be investigated 56

2.3 Method of data elicitation $\quad 57$

2.4 The role play situations $\quad 60$

2.5 Assessment of the role play situations according to social variables 61

2.6 Judgements of appropriacy and pragmatic effect 62

2.7 Procedure for conducting role play sessions 63 
2.8 Method of data analysis $\quad 64$

2.9 Notes to Chapter $2 \quad 65$

CHAPTER 3. REQUESTING: AN INTRODUCTION 67

3.1 The speech act of requesting 67

3.2 Components of a request 68

$\begin{array}{llr}3.3 & \text { Request strategies } & 69\end{array}$

$\begin{array}{lll}\text { 3.3.1 Direct sub-strategies } & 70\end{array}$

3.3.2 Conventionally indirect (CI) sub-strategies 73

3.3.3 Non-conventionally indirect (Non-CI) sub-strategies $\quad 77$

$\begin{array}{lll}3.4 & \text { Request perspective } & 79\end{array}$

$\begin{array}{ll}3.5 \text { Asking vs requesting } & 81\end{array}$

3.6 The notion of 'interactional value' 83

$\begin{array}{lll}3.7 & \text { Notes to Chapter } 3 & 87\end{array}$

CHAPTER 4. REQUESTS: THE HEAD ACT 93

$\begin{array}{lll}4.1 & \text { Results } & 93\end{array}$

4.1.1 Choice of head act strategy: BI native speakers 93

4.1.1.1 Direct requests 93

4.1.1.2 Conventionally indirect (CI) requests 95

4.1.1.3 Non-conventionally indirect (Non-CI) requests 96

4.1.1.4 Choice of head act strategy by BI native
speakers: Summary

4.1.2 Choice of head act strategy: Learners 97

4.1.2.1 Direct requests 97

4.1.2.2 Conventionally indirect $(\mathrm{CI})$ requests $\quad 103$

4.1.2.3 Non-conventionally indirect (Non-CI) requests 106

4.1.2.1 Choice of head act strategy by learners:

Summary 108 
4.1.3 Situational variation in selection of request strategy 109

4.1.3.1 Selection of imperatives: BI native speakers

109

4.1.3.2 Selection of imperatives: Learners

4.1.3.3 Selection of Want statements: BI native speakers 113

4.1.3.4 Selection of Want statements: Learners

4.1.3.5 Selection of QP modal requests: BI native speakers

4.1.3.6 Selection of QP modal requests: Learners

4.1.3.7 Selection of hints: BI native speakers

4.1.3.8 Selection of hints: Learners

4.1.3.9 Situational variation in selection of request strategy: Summary

4.1.4 Appropriacy of learners' choice of strategy

4.1.5 Discourse considerations in strategy selection

4.1.6 Choice of request perspective

4.1.6.1 QP modal requests: BI native speakers

4.1.6.2 QP modal requests: Learners

4.1.6.3 Imperatives: BI native speakers

4.1.6.4 Imperatives: Learners

4.1.7 Other aspects of head act realisation by learners

4.1.7.1 Phrasing of request goal

4.1.7.2 Negotiation of request goal

4.1.7.3 Realisation of head act formulas

4.1.7.4 Inappropriate pronoun selection by learners

4.1.7.5 Intonation on head acts by learners 
4.1.9 Asking 143

4.1.9.1 Choice of Asking strategy: BI native speakers $\quad 143$

4.1.9.2 Choice of Asking strategy: learners 145

4.1.9.3 Choice of Asking strategy: Summary $\quad 146$

4.1.9.4 Situational variation in selection of Asking
strategies

4.1.9.4.1 Direct questions: BI native speakers 147

4.1.9.4.2 Direct questions: Learners 148

4.1.9.4.3 Situational variation in selection of direct questions:Summary $\quad 148$

4.1.9.5 Additional features of Asks by learners $\quad 149$

4.1.10 Request head act findings: Summary $\quad 150$

$\begin{array}{ll}4.2 \text { Discussion } & 152\end{array}$

4.2.1 Introduction 152

4.2.2 Frequency of QP modal requests by learners 152

4.2.3 Choice of modal verb in QP requests by learners 154

4.2.4 Frequency of imperatives by learners 157

4.2.5 Frequency of Want statements by learners 160

4.2.6 Range of direct sub-strategies by learners 163

4.2.7 Frequency of statement hints by learners 164

4.2.8 Variation in request strategy selection by learners 168

4.2.9 Frequency of impersonal perspective by learners 171

4.2.10 Performance in discourse-aspects of requesting
by learners

4.2.11 Intonation on requests by learners 176

4.2.12 Frequency of direct questions by learners 178

4.3 Request head acts: Summary and conclusion 180

$\begin{array}{ll}4.4 & \text { Notes to Chapter } 4 \\ & 184\end{array}$ 
$\begin{array}{lll}5.1 \text { Introduction } & 190\end{array}$

$\begin{array}{lll}5.2 \text { Results } & 191\end{array}$

5.2.1 Internal modification of QP modal requests $\quad 191$

5.2.1.1 BI native speakers $\quad 192$

$\begin{array}{lll}\text { 5.2.1.2 Learners } & 199\end{array}$

5.2.1.3 Situational variation in selection of $\mathrm{IM}$ in QP modal requests 202

5.2.1.4 Internal modification of QP modal requests: Summary

203

5.2.2 Internal modification of (full) imperatives 204

5.2.2.1 BI native speakers 204

5.2.2.2 Learners 207

5.2.2.3 Situational variation in selection of IM on imperative requests 209

5.2.2.4 Internal modification of imperatives: Summary 209

5.2.3 Internal modification of direct questions 210

5.2.3.1 BI native speakers 210

5.2.3.2 Learners 213

5.2.3.3 Situational variation in use of IM on direct
questions

5.2.3.4 Internal modification of direct questions:
Summary

5.2.4 Appropriacy of internal modification by learners 214

5.2.5 Internal modification of requests: Summary 215

$\begin{array}{lll}5.3 \text { Discussion } & 216\end{array}$

5.3.1 Frequency of internal modification by learners 216

5.3.2 Frequency of the modifier -lah by learners 220

5.4 Internal modification of requests: Summary and conclusion 222

$\begin{array}{lll}5.5 & \text { Notes to Chapter } 5 & 224\end{array}$ 
CHAPTER 6. EXTERNAL MODIFICATION AND ALERTERS

$\begin{array}{lll}6.1 & \text { External modification } & 227\end{array}$

$\begin{array}{ll}\text { 6.1.2 Introduction } & 227\end{array}$

$\begin{array}{lll}6.1 .3 & \text { Results } & 227\end{array}$

6.1.3.1 External modification of QP modal requests 227

6.1.3.1.1 BI native speakers 227

6.1.3.1.2 Learners 235

6.1.3.1.3 External modification of QP modal requests: Summary

6.1.3.1.4 Situational variation in selection of $\mathrm{EM}$ in QP modal requests

6.1.3.2 External modification of imperatives 243

6.1.3.3 External modification of direct questions 244

6.1.3.3.1 BI native speakers 244

6.1.3.3.2 Learners 247

6.1.3.3.3 Situational variation in selection of
EM on direct questions

6.1.3.3.4 External modification of direct questions: Summary 250

6.1.3.4 External modification of requests: Summary 250

$\begin{array}{ll}\text { 6.1.4 Discussion } & 251\end{array}$

6.1.4.1 Frequency of external modification by learners 251

6.1.4.2 Frequency of Prefaces by learners 253

6.1.4.3 Learner-specific features of Grounders 254

6.1.5 External modification: Summary and conclusion 261

6.2 Relationship between internal and external modification 263

6.2.1 QP modal requests 263

$\begin{array}{ll}\text { 6.2.2 Imperatives } & 264\end{array}$

6.2.3 Direct questions 265

6.2.4 Relationship between internal and external
modification: Summary 265 
$\begin{array}{lll}6.3 & \text { Alerters on requests } & 265\end{array}$

$\begin{array}{ll}\text { 6.3.1 Introduction } & 265\end{array}$

$\begin{array}{lll}6.3 .2 & \text { Results } & 266\end{array}$

6.3.2.1 BI native speakers 266

$\begin{array}{lll}\text { 6.3.2.2 Learners } & 268\end{array}$

6.3.2.3 Alerters on requests: Summary 270

6.3.2.4 'Scattering' of kinship TOAs by BI native
speakers 271

$\begin{array}{ll}\text { 6.3.3 Discussion } & 272\end{array}$

6.3.3.1 Frequency of native-like Alerters by learners 272

6.3.3.2 Frequency of kinship TOAs on Alerters
by learners

6.3.4 Alerters: Summary and conclusion 275

6.4 Notes to Chapter 6

CHAPTER 7. CONCLUSION 280

$\begin{array}{lll}7.1 & \text { Summary of findings } & 280\end{array}$

7.2 Implications for causes of learner pragmatic behaviour 282

7.3 Implications for development of pragmatic competence 287

7.4 Implications for teaching of L2 pragmatics 291

7.5 Implications for methodology in ILP studies 294

7.6 Implications for cross-cultural pragmatics 296

$\begin{array}{lll}7.7 & \text { Notes to Chapter } 7 & 298\end{array}$

$\begin{array}{ll}\text { APPENDICES } & 299\end{array}$

Appendix A: List of role play situations 299

Appendix B: Proportion of subjects who use each sub-strategy
in each situation

Appendix C: Assessment of social variables in each situation by
BI native and Australian learner informants 
Appendix D: Role play cues for Australian learner subjects

Appendix E: Role play cues for partners of Australian learner subjects

Appendix F: Excerpt from questionnaire on values of social variables in each role play situation

REFERENCES 


\section{List of tables}

page

Table 1: Request strategies used by subjects in order of directness

Table 2: Proportion of different request strategies used by BI native speaker subjects

Table 3: Proportion of different request strategies used by learner and BI native speaker subjects

Table 4: Proportion of QP modal requests with each perspective

Table 5: Proportion of (full) imperative requests with each perspective

Table 6: Proportion of different Asking strategies used by learner and BI native speaker subjects

Table 7: Proportion of QP modal requests by BI native speaker subjects which are internally modified

Table 8: Proportion of QP modal requests by learner and BI native speaker subjects which contain each type of internal modifier

Table 9: Description of kinship terms of address used by learner and BI native speaker subjects

Table 10: Proportion of QP modal requests by learner and BI native speaker subjects which are internally modified

Table 11: Proportion of (full) imperative requests by learner and BI native speaker subjects which are internally modified

Table 12: Proportion of (full) imperative requests by learner and BI native speaker subjects which contain each type of internal modifier

Table 13: Proportion of direct questions by learner and BI native speaker subjects which are internally modified 


\section{List of tables (cont.)}

page

Table 14: Proportion of direct questions by learner and BI native speaker subjects which contain each type of internal modifier

Table 15: Proportion of QP modal requests by learner and BI native speaker subjects which are externally modified

Table 16: Proportion of QP modal requests by learner and BI native speaker subjects which contain each type of external modifier

Table 17: Proportion of direct questions by learner and BI native speaker subjects which are externally modified

Table 18: Proportion of direct questions by learner and BI native speaker subjects which contain each type of external modifier

Table 19: Proportion of requests by learner and BI native speaker subjects which contain an Alerter

Table 20: Proportion of Alerters by learner and BI native speaker subjects which consist of each type of formula 


\section{Transcription conventions}

full stop denotes falling intonation

question mark denotes rising intonation

ellipsis denotes omitted material

(.)

pause of less than one second

pause of at least one second and less than two seconds

o-o-r

repeated vowel denotes drawn out syllable

yester/

dash denotes abruptly halted speech

(laughs)

brackets enclose comments of transcriber

YES

upper case denotes loudness

empty brackets enclose unintelligible talk

please

underlining denotes a segment of talk highlighted for the reader's attention

then [I

Did]

square brackets enclose overlapping speech 


\section{List of abbreviations used}
AE Australian English
BE British English
BI Bahasa Indonesia

BI NS Bahasa Indonesia native speaker

D social distance

EM external modification

FL foreign language

FTA face-threatening act

$\mathrm{H}$ hearer

IL interlanguage

ILP interlanguage pragmatics

IM internal modification

IMP imperative marker

INT interrogative marker

L learner

L1 first language

L2 second language

lit. literally

NS native speaker

$\mathrm{P}_{1} \quad$ power

$\mathrm{P}_{2} \quad$ partner

QP query preparatory

$\mathrm{Rx}$ imposition

S speaker

SLA second language acquisition

TOA term of address

W weightiness of threat to face 


\section{INTRODUCTION}

This study is an investigation of how Australian learners perform requests in Bahasa Indonesia in everyday situations.

Bahasa Indonesia (henceforth BI, or Indonesian), is the national language of Indonesia, and is spoken by the majority of Indonesians (cf. Nababan 1991). For most speakers it is learned as a second language, either formally at school, or informally through the community. However, there is an increasing trend for Indonesians to speak BI as a first language (cf. Nababan 1991). While speakers of BI vary in proficiency, Indonesians who have finished high school are fully proficient in the language, and for most speakers it is "the language of ordinary, everyday communication" (Worsley 1993: 7). ${ }^{1}$

The main objectives of this study are as follows: to provide a detailed preliminary description of the requesting behaviour of Australian learners and native speakers of BI in everyday situations, to offer explanations for the similarities and differences between the behaviour of the two groups, and to determine what the behaviour of these learners tells us about how learners perform requests, and speech acts more widely, in a second language (L2). ${ }^{2}$

These objective are worthwhile for several reasons. Firstly, while L2 speech act performance has been examined in many studies, relatively few of these studies focus on learners of 'exotic' languages, including Asian ones (see 1.6.2.2), so the present study will help to determine the extent to which findings from other studies are valid cross-linguistically. Secondly, while studies of L2 speech act behaviour frequently focus on requests, few studies provide detailed analyses of modification of requests (cf. Trosborg 1995: 293), so this study will contribute to relatively scant knowledge about learner behaviour in this respect. Thirdly, a great deal remains to be learned about the factors which produce L2 speech act behaviour, so studies are needed which closely examine the likely causal factors, their relative importance, and the way they interact. Lastly, this study is useful for the purposes of Indonesian teaching. Bahasa Indonesia is a language studied extensively at both school and university level in Australia, and proficiency in this foreign language is of growing importance economically, culturally, and strategically (cf. Worsley 1993). Therefore, empirical descriptions of how everyday speech acts are performed by $\mathrm{BI}$ native speakers are needed, to allow teaching materials to reflect 
reality; and descriptions of how learners of BI perform such speech acts are useful to make teachers aware of the specific difficulties that students may have.

This thesis is divided into seven chapters. Chapter 1 provides a review of research relevant to the present study. Chapter 2 explains the methodology used to carry out the study. Chapter 3 clarifies the notion of a 'request', and outlines the framework used to analyse request utterances. Chapters 4,5 and 6 describe and discuss the data on requests. The concluding chapter, Chapter 7 , provides a summary of the findings and explains their importance. 


\section{Notes to Introduction}

${ }^{1}$ For this reason, in accordance with general usage, all Indonesians who are fully proficient in BI are called 'native speakers' in the present study, regardless of whether they learned BI as a first language.

2 In accordance with convention, the term 'second language' (L2) in this study will be used "as a cover term for any language other than the first language learned by a given learner or group of learners a) irrespective of the type of learning environment and b) irrespective of the number of other non-native languages possessed by the learner" (Sharwood Smith 1994: 7, original emphasis). 


\section{CHAPTER 1. LITERATURE REVIEW}

\subsection{Introduction}

This chapter provides a background to the present paper by examining relevant research, both theoretical and empirical, in order to demonstrate why the present study is important, to clarify certain notions and frameworks on which it relies, and show the current state of knowledge in the field to which it contributes.

Firstly, the notion of pragmatic competence will be explored, in order to show that the ability to make requests is a manifestation of this vital component of communicative language ability. Secondly, the notion of a 'speech act' is discussed, as this notion is central to studies of pragmatic competence, including the present study. Thirdly, theories of linguistic politeness will be examined, in order to clarify the theoretical framework on which this study of pragmatic competence is based. Fourthly, the extent to which pragmatics are universal across languages will be discussed, to order to evaluate how much pragmatic learning has to be done by learners of a foreign language. Lastly, the research field of learner pragmatics will be surveyed, to allow the findings and conclusions of this thesis to be evaluated within the context of similar research.

\subsection{Pragmatic competence and communicative competence}

This study of how learners perform requests in Indonesian is an investigation of their 'pragmatic competence'. This notion (which will be defined shortly) is closely tied to that of 'communicative competence', as it was the development of the latter notion which allowed pragmatic competence to be recognised as a part of language ability.

The notion of communicative competence developed in response to Chomsky's (1965) narrow view of language competence as consisting exclusively of knowledge of the rules of grammar. Hymes (1972a) was one of the first ${ }^{1}$ to point out that knowledge of grammar was not sufficient to enable a speaker to communicate successfully, observing that there are "rules of use without which the rules of grammar would be useless" (Hymes 1972a: 278). Hymes (1972a) argued further that these rules of use - which tell a speaker what utterance can 
appropriately be issued in a given context - are not merely grafted onto rules of grammar but have equal status with them as a basis for language competence. He proposed a notion of 'communicative competence', which entails knowledge of both types of rules.

This notion of communicative competence, and the expanded understanding of language ability which it has brought, have greatly influenced the goals and methods of language teaching, by prompting "a shift of the focus of attention from the grammatical to the communicative properties of language" (Allen \& Widdowson 1979: 124). ${ }^{2}$ These insights have also led to a shift in the direction of language testing, towards the development of tests to assess communicative rather than merely grammatical competence. ${ }^{3}$ And from a theoretical point of view, these insights have culminated in the development of comprehensive models of communicative language competence and language ability. The best known and most influential of these models are those of Canale and Swain (1980; modified by Canale 1983) and of Bachman (1990). An examination of these two models will help to clarify what pragmatic competence is and how it relates to other components of language competence. ${ }^{4}$

\subsubsection{Canale and Swain's model of communicative competence}

According to this theoretical framework, a speaker's language competence consists of three main components (Canale \& Swain 1980: 29-30). The first is grammatical competence. This is very similar to Chomsky's (1965) notion of language competence. It includes knowledge of phonology, morphology, syntax, and lexis.

The second component is sociolinguistic competence. This, essentially, is the 'pragmatic competence' component of the model. It consists of a) sociocultural rules of use; that is, knowledge of how appropriate various forms, propositions and communicative functions are in a given context, and b) rules of discourse: knowledge of how propositions and communicative functions are combined to produce texts which are cohesive and coherent (Canale \& Swain 1980: 30).

The third component of Canale and Swain's (1980) model is strategic competence. This is a compensatory component. It involves use of communication strategies to compensate for potential breakdowns in communication, due for example to 
inadequate linguistic knowledge, or to performance limitations (such as lapses of memory).

This model of Canale and Swain (1980), above, was refined by Canale (1983). Most importantly, Canale (1983) proposed a change to the component 'sociolinguistic competence'. He narrowed this component to exclude knowledge of the rules of discourse, which, he suggested, should be regarded instead as a competence in its own right ('discourse competence').

Canale (1983:10-11) also proposed an extension of the notion of 'strategic competence'. He suggested that it includes the use of strategies not only with "compensatory" function (i.e. to solve problems) but also with "enhancement" function (i.e. to enhance the rhetorical effect of utterances).

Several useful points emerge from the above. Firstly, and crucially, it is recognised that communicative competence requires more than grammatical knowledge; knowledge of appropriacy of language to context is regarded as a vital component. Secondly, the status of knowledge about discourse appears as potentially problematic, the question being whether it is closely related to knowledge of appropriacy of language to context, or quite separate from it. Thirdly, an expanded role can be observed for strategic competence, beyond its original compensatory function. Lastly, the idea of 'competence' in the model above is used to refer to knowledge only; it does not include ability to use knowledge. 5 This distinction is important for theory of how learners acquire the pragmatics of a second language, as discussed later in this chapter (1.6.3).

\subsubsection{Bachman's model of communicative language ability}

A crucial difference between the model outlined above and that of Bachman (1990) is that Bachman's is broader in scope. His model is one of communicative language ability - which thus includes both competence (knowledge) and capacity to use this competence. As Bachman (1990) says,

Communicative language ability (CLA) can be described as consisting of both knowledge, or competence, and the capacity for implementing, or executing that competence in appropriate, contextualised communicative language use (Bachman 1990: 84, original emphasis). 
In simplified terms, Bachman's (1990) model is as follows. He proposes three main elements 6 in a model of communicative language ability: language competence, strategic competence, and physiological mechanisms.

The first of these elements, language competence, is the set of knowledge components that are employed in using language. Language competence, in turn, has two major components: organisational competence and pragmatic competence. Organisational competence consists of grammatical competence: knowledge of grammatical elements and how to combine them together; and textual competence: knowledge of how to combine sentences and utterances together into cohesive, properly structured texts. Pragmatic competence consists of illocutionary competence: knowledge of what linguistic forms are used to perform what linguistic acts; and sociolinguistic competence: knowledge of what linguistic forms can appropriately be used to perform a speech act in a given context.

While language competence, above, is purely a knowledge component, the other two components of Bachman's (1990) model account for the speaker's ability to use language knowledge. Strategic competence is the mental capacity for implementing the language knowledge described above. It gives the speaker the ability to assess the situation (e.g. assess what information needs to be conveyed in order to achieve the communicative goal, taking into account what $\mathrm{H}$ already knows), the ability to verbally plan an utterance (i.e. select relevant linguistic items from language knowledge), and the ability to execute the utterance (i.e. to actually say it out loud). The final component, psychophysiological mechanisms, are those mechanisms (such as neuromuscular skills) used to execute the utterance.

Several points should be noted about Bachman's (1990) model. Most importantly, in this model, too, knowledge of the relation between language and context is regarded as a vital component of language knowledge. While Canale and Swain (1980) called this component 'sociocultural competence', Bachman (1990), who conceives of it in essentially similar terms, calls it 'pragmatic competence'.

Secondly, Bachman (1990) vastly expands the role of 'strategic competence' from its role in the model examined earlier. Instead of regarding it as a component that speakers use only in certain circumstances, Bachman (1990) places this component in the centre of his model for communication, regarding it as crucial for the process of linguistic production. 
Lastly, Bachman's model reinforces the impression that the role of discourse competence is somehow problematic for theoretical models. While Canale and Swain (1980) regarded this component as part of sociolinguistic competence, and Canale (1983) revised its role, placing it out on its own, as a separate type of knowledge from any other; Bachman (1990) re-positions it once again, this time as part of 'organisational competence' and, hence, as more closely related to grammatical competence than to any other type of language knowledge.

\subsubsection{Pragmalinguistic vs sociopragmatic competence}

An observation should be made here about the pragmatic component of the two models above: knowledge of the relation of language to context. Both models emphasise the more linguistic aspect of this knowledge: knowledge of the social meanings carried by different language forms. However, knowledge of the relation of language to context necessarily has a more social aspect as well: knowledge of the relevant features of the social context itself. At this point, Thomas (1983) is helpful. She identifies two distinct types of pragmatic competence needed by learners: pragmalinguistic competence, and sociopragmatic competence. ${ }^{7}$ The former, more linguistic aspect is knowledge of the relationship between the form of utterances and the pragmatic force assigned to these utterances. The latter, more social aspect is knowledge of the size of the relevant social factors affecting choice of linguistic form; for example, the relative power and status of speaker and hearer, the social distance between speaker and hearer, and their relative rights and obligations in the situation (Thomas 1983: 99-105).

An example may be helpful to clarify the difference between these two types of pragmatic knowledge. If a student wanted to ask a lecturer (in English) to lend a copy of a hard-to-obtain and expensive textbook which the student needed as an essay reference, the student might consult his or her sociopragmatic knowledge in order to know that (e.g.) the hearer has high power in this situation relative to the speaker, and that the imposition on the hearer in this situation is considerable; together with his or her pragmalinguistic knowledge in order to know that (e.g.) asking a question about the speaker's permission to borrow the book is one appropriate strategy for making this request, and that the form "Do you think I could borrow....?" is one appropriate realisation of this strategy. 


\subsubsection{Relationship between pragmatics and discourse}

A point should also be made about the problematic position of discourse competence relative to other components evident from the models above. This reflects an important issue in cross-cultural and learner pragmatics: the relationship between pragmatics and discourse. Do all the 'rules of speaking' of a speech community (cf. Hymes 1972b; Wolfson 1983) fall within the ambit of pragmatics? Or are some rules of speaking, such as the rules of turn-taking in conversation, matters of discourse instead? Kasper (1992: 206) observes disagreement in the literature on this question. She suggests that the realisation of speech acts can be regarded as the 'pragmatic end' of rules of speaking, while conversational management exemplifies the 'discourse end'; however, importantly, she emphasises that many aspects of rules of speaking cannot be neatly classified as one or the other. For example, she points out that greetings and leave-takings "are illocutions and hence pragmatics, but since they happen in patterned exchanges and particular phases of encounters, conversations and the like, they are matters of discourse" (Kasper 1992: 206).

Similarly, Aston (1995) points out that speech acts are sometimes selected for their role in managing the conversation; an expression of thanks, for example, may function as a device to help close a service encounter. Moreover, as Kasper (1992) observes, the expression of pragmatic meaning itself may be highly dependent on the development of discourse. The illocutionary intent of the speaker at the time of speaking often cannot be identified (for example, because the speaker expressed his or her intent unclearly, or had more than one intent), and in such cases "pragmatic meanings might only make themselves available through interlocutors' negotiations and conversational outcomes" (Kasper 1992: 206-07).

The present study takes into account the highly interdependent nature of pragmatics and discourse. Features of linguistic performance associated with a speaker's ability to manage conversation are analysed when these features are clearly part of the speaker's requesting behaviour, and hence, of pragmatic importance. 


\subsubsection{Definition of pragmatic competence}

Based on the discussion above, a definition of pragmatic competence is proposed for the present study. The definition is: knowledge of what linguistic forms can be used, and are appropriate to use, in a given context; and the capacity to implement that knowledge to perform linguistic action.

Things to bear in mind about this definition are as follows. Firstly, the carrying out of 'linguistic action' can encompass both production and comprehension of language. However, the main focus of the present study is on spoken production of linguistic patterns and strategies by learners, rather than comprehension (which reflects the primary emphasis of ILP research to date). ${ }^{8}$ Therefore it is useful for present purposes to regard 'linguistic action' as referring to production of speech. Secondly, this definition encompasses not only Bachman's (1990) 'pragmatic competence', but also the relevant 'strategic competence' ("the capacity to implement that knowledge"). Thirdly, the knowledge referred to can usefully be regarded as having a more linguistic aspect (pragmalinguistic) as well as a more social aspect (sociopragmatic). Lastly, this pragmatic competence may involve ability to construct discourse jointly with the interlocutor; that is, the ability to manage conversation .

\subsection{Speech acts}

The notion of a speech act is closely tied to that of pragmatic competence. Pragmatic competence is manifested through the performance of speech acts, and studies of learner pragmatics (including this one) typically focus on the performance of one or more such acts. This makes it important to clarify what a speech act is, and to evaluate the validity of the notion of 'speech act' as an analytical tool in studies of this kind.

\subsubsection{The notion of a speech act}

Austin (1955/1976) introduced the notion of a speech act to modern linguistic theory ${ }^{9}$ with his observation that in producing an utterance, speakers are not only saying something, but performing an act at the same time. He identified several 
types of acts a speaker performs in saying something, of which the most important for speech act theory is the illocutionary act. ${ }^{10}$ Every time a speaker utters words with a certain sense and reference, Austin (1955/1976) asserted, the speaker is performing an illocutionary act, such as "asking or answering a question, giving some information or an assurance or a warning, announcing a verdict or an intention..." (Austin 1955/1976: 98).

Searle $(1969,1971 / 1990)$ further developed this notion of a speech act. $\mathrm{He}$ explicitly claimed for the speech act a central place in language use, asserting that

all linguistic communication involves linguistic acts. The unit of linguistic communication is not, as has generally been supposed, the symbol, word or sentence ... but rather the production or issuance of the symbol, or word or sentence in the production of the speech act (Searle 1969: 16). ${ }^{11}$

Searle (1969) also proposed a system of rules by which speech acts are performed. He claimed that a speech act is carried out if an utterance satisfies a set of conditions for performing that speech act: preparatory conditions, a sincerity condition, and an essential condition. For example, the conditions for the performance of a request are as follows:

i) The propositional content is a postulated future act A by the hearer

ii) The preparatory conditions include: that the hearer is able to do the act, and that it is not obvious to the speaker $(\mathrm{S})$ and the hearer $(\mathrm{H})$ that $\mathrm{H}$ will do the act in the normal course of events, of his/ her own accord.

iii) The sincerity condition is that $\mathrm{S}$ wants $\mathrm{H}$ to do $\mathrm{A}$.

iv) The essential condition, that makes it a request, is that the act counts as an attempt to get $\mathrm{S}$ to do A. (Searle 1969: 66 table)

Based on this notion of a speech act as developed by Austin (1955/1976) and Searle (1969), speech act theory has developed into a dynamic and fast-growing field of language study (cf. Verschueren 1985: 5), and has generated a great deal of controversy among linguists. 12 


\subsubsection{Usefulness of 'speech act' as a category to analyse speech}

Of particular relevance to this study are criticisms levelled at the adequacy of the notion of 'speech act' itself, such as those of Leech (1983). The theoretical validity of the category of 'speech act' rests on the assumption that utterances can be assigned an illocutionary force, and as Leech (1983) points out, assigning such a force to utterances may often be more difficult than Searle (1969) suggests. The system of rules that Searle (1969) sets out for performing speech acts (specifying propositional content, preparatory conditions, and so forth ) seems to assume a neat match of illocutionary force to utterance; or, as Leech puts it, "a taxonomic decision: either an utterance counts as [for example] a warning, or it does not" (Leech 1983: 23). ${ }^{13}$ In fact, Leech argues, such clear-cut interpretations of utterances in fact only exist in a few cases, and therefore Searle's (1969) system of rules represents "an unrealistic and unsubtle view of what communication by means of language is like" (Leech 1983: 23). In fact, Leech (1983: 174) goes further, arguing that as illocutionary forces are a part not of grammar, but of pragmatics, they are indeterminate by their very nature. ${ }^{14}$ This, if true, would make it theoretically impossible to assign illocutionary force to utterances.

In addition, certain practical problems associated with using the category of speech act as a tool for empirical analysis of speech have been noted. Olshtain and Cohen (1983: 20) remark on the failure of theoretical work such as Searle's to provide an operational definition; in other words, "a good working definition", of what a speech act is. As they point out, the key problem is that identified by Schmidt and Richards (1980); namely, the fact that a speech act, being essentially an act, cannot be equated to any particular unit of speech, whether it be a sentence, an utterance, or a turn.

Another potential problem with using the notion of speech act to analyse discourse is that, as studies in the field of conversational analysis have shown (e.g. Merritt 1976; Schegloff \& Sacks 1973; Sacks, Schegloff \& Jefferson 1974; Schegloff 1980; Psathas 1991; Sacks 1992), the illocutionary force of an utterance may depend heavily on the conversational context. In fact the illocutionary force may sometimes only be derived as a result of the role of the utterance in the discourse (see 1.2.4). Levinson (1983: 285) gives the example of the utterance "I bet you...", which requires uptake by the hearer in order to achieve status as the act of betting; and suggests that in the light of this kind of phenomenon, the concept of 
illocutionary force itself can perhaps be largely replaced by that of conversational function.

However, the criticisms above do not invalidate the use of the category of 'speech act' as a basis for analysis of spoken discourse. Firstly, on the theoretical level, it is doubtful whether illocutionary forces are indeterminate. Wierzbicka (1991) argues convincingly that this supposed indeterminacy "is largely an artefact of inadequate ... analyses" (Wierzbicka 1991: 199). She asserts that illocutionary forces are a part of grammar; specifically, of semantics, and demonstrates how they can be rigorously described by semantic analysis. ${ }^{15}$ She also challenges Leech's (1983) assertion that a speaker's intentions can only rarely be identified, arguing that when we listen to other people, we "more often than not" do know the intended force of the utterance (Wierzbicka 1991: 199).

Similarly, Kasper (1989: 41) - who regards the notion of speech act as having a central place in pragmatic theory - defends the adequacy of the notion of a speech act both as a theoretical category and as an analytic tool. She points out, firstly (like Wierzbicka above), that for a great many utterances a clear-cut illocutionary force can be assigned; and secondly, that instances of unclear or or multiple illocutionary force do not invalidate the notion of a speech act itself, any more than (say) the occurrence of semantic ambiguity invalidates the notion of a lexical item.

As for the practical usefulness of the category of 'speech act' in analysing discourse, this is evident from the undiminished frequency with which it is used for this purpose in empirical studies of both cross-cultural pragmatics and (as we will see shortly) of learner pragmatics. Importantly, the speech act as an analytical tool has proved adaptable to the realities of empirical data. Olshtain and Cohen (1983) for their study of apologies expanded the notion to fit their data by positing the notion of a 'speech act set'; that is, a set of semantic formulas which can be used, singly or in combination, in the execution of a speech act (e.g. for the speech act of Apology, the speech act set contains such formulas as 'expression of apology', 'acknowledgement of responsibility', and 'promise of forbearance'). This expanded notion of a speech act set has also been used successfully to describe the speech acts of complaining (Olshtain \& Weinbach 1987) and thanking (Eisenstein \& Bodman 1986).

The potential problem posed by the fact that many utterances have contextdependent illocutionary force can also be dealt with satisfactorily within a speech 
act framework. This insight into the nature of speech acts can be used to provide a more sensitive analysis of illocutionary force in many cases; for example, by assigning illocutionary force to a speech act on the basis of the status achieved by the utterance in the discourse; as a result of negotiation between the interlocutors (see 3.6).

On the whole, while the notion of speech act may be criticised as a category for the analysis of speech, it is adequate as a descriptive tool and is certainly the most useful descriptive category there is. This is well illustrated by a remark of Brown and Levinson (1987) who, when expressing reservations about their heavy reliance on speech act categories in their earlier (1978) study of discourse, concluded that this means of analysis was one "which, were we to try again today, would still be hard to avoid" (Brown \& Levinson 1987: 11).

\subsection{Theories of linguistic politeness}

The analytical framework and key concepts of this study of pragmatic competence of learners are derived largely from well-known theories of linguistic politeness. This study draws to a certain extent on the 'conversational-maxim' theory, of which the best -known proponents are Lakoff (1973) and Leech (1983); and to a considerable extent on the 'face-saving' theory of Brown and Levinson (1978; 1987). ${ }^{16}$ The former theory will be outlined briefly, in order to highlight those insights relevant to the present study; and the latter will be examined in some detail.

Both the theories to be discussed are based on Grice's (1975/1989) general principles of discourse. Grice observed that verbal interactions are cooperative efforts; that participants have a common purpose or set of purposes which guide the interaction. This leads him to postulate a general principle for conversation, the Cooperative Principle, which stipulates: "make your conversational contribution such as is required, at the stage at which it occurs, by the accepted purpose or direction of the talk exchange in which you are engaged" (Grice 1975/1989: 26). This Cooperative principle has four major maxims, which (in simplified terms) are as follows: 
A. Quantity: say as much as required, and no more than is required.

B. Quality: say only what you believe to be true.

C. Relevance: say only what is relevant.

D. Manner: be clear ( for example, by being brief, and being orderly, in speech)

(Grice 1975/1989: 26-31)

Grice (1975/1989) claims that speakers in general can be assumed to participate in conversation according to the above principles because the central goals of communication (such as giving and receiving information, influencing and being influenced by others) in which all reasonable, rational persons can be assumed to share an interest can only be achieved by talk conducted in general accordance with these principles (Grice 1975/1989: 29-30).

\subsubsection{The 'conversational-maxim' theory of politeness}

In Lakoff's (1973) version of this theory of politeness, there are two basic rules governing a speaker's pragmatic behaviour. These rules are the rules of pragmatic competence: i) Be clear and ii) Be polite. Being clear means obeying Grice's four conversational rules. Being polite means following the rules"'Don't impose", "Give options", and "Be friendly" (Lakoff 1973: 298-302).

Lakoff (1973) notes that the first rule of politeness, "Don't impose", seems to be mutually contradictory to the third rule of politeness, "Be friendly," in that an essentially different kind of politeness is entailed in these two rules.

She also notes that these two rules "Be clear" and "Be polite" are often in apparent conflict, in which case one or the other, depending on circumstances, will prevail. When a speaker's main goal is to convey propositional content, the speaker's main concern will be clarity, so the first rule "Be clear" will take precedence. However, when the speaker's main goal is to negotiate the relations between speaker and hearer, then the rule "Be polite" will take precedence instead (Lakoff 1973: 296297).

Another important observation of Lakoff (1973: 303) is that being clear can be a means of being polite. In situations where conveying the message is the important thing, then the rule of clarity can be regarded as a sub-case of rule 1 of politeness: 
"Don't impose". The purpose of the rule of clarity is get the message communicated in the shortest time with the least difficulty: that is, to avoid imposition on the hearer by wasting the hearer's time, or by confusing the hearer and making him or her look bad.

Leech (1983) reinforces a basic premise of this theory as propounded by Lakoff (1973). Like Lakoff, he asserts that Grice's Cooperative Principle interacts with a politeness principle, and that in being polite one is often faced with a clash between the two, so one has to choose how far to trade one off against the other (Leech 1983: 83).

Leech (1983) also elaborates on the theory. He conceives of the politeness principle as consisting of four maxims. The most important of these is the Tact maxim. It has two elements: a) "minimise cost to other" and b) "maximise benefit to other." The first of these elements is more important than the second. This illustrates a general principle that 'negative politeness' (avoidance of discord) is a more weighty consideration than 'positive politeness' (seeking concord).

Leech (1983) also asserts that several different scales are relevant to the operation of the Tact maxim. The way these various scales influence tact are as follows: the greater the cost of the proposed action to $\mathrm{H}$, the social distance between $\mathrm{H}$ and $\mathrm{S}$, and the power (authority) of $\mathrm{H}$ with respect to $\mathrm{S}$; the greater the need for optionality, and correspondingly, for indirectness, in the expression of an impositive speech act, if $S$ is to observe the tact maxim (Leech 1983: 127).

The 'conversational-maxim' view of politeness above, as propounded by Lakoff (1973) and Leech (1983), yields several insights important for the present study. The first is that 'clarity' and 'politeness' are potentially competing elements; that speakers may choose to give priority to one over the other. The second is that a useful distinction may be drawn between 'negative' politeness (i.e. not imposing, avoiding discord) and 'positive' politeness (i.e. being friendly, seeking concord). The third is that the scalar value, or weighting, of a contextual factor can influence a speaker's linguistic choices in performing a speech act such as a request; in particular, it can affect how directly the speaker performs the act. 


\subsubsection{The 'face-saving' theory of politeness}

The 'face-saving' view of politeness, proposed by Brown and Levinson (1978, 1987 ) is the best-known theory of linguistic politeness and the most influential one in the area of empirical studies of pragmatics. The following account of this theory is (except where otherwise stated) based closely on Brown and Levinson's own description $(1978,1987)$.

This model of politeness is based on Grice's Cooperative Principle in one essential respect, ${ }^{17}$ namely, that "there is a working assumption by conversationalists of the rational and efficient nature of talk" (Brown \& Levinson 1987: 4). Because of this assumption, politeness phenomena appear to the hearer as deviations, as instances of apparent irrationality or inefficiency. The hearer seeks a rational explanation for these deviations from the Cooperative Principle - and finds it in considerations of politeness.

The essential argument of Brown and Levinson's $(1978,1987)$ theory is as follows. All people (Model Persons, or MPs) have positive and negative face, and are rational agents, who will choose means to satisfy their ends. 'Negative face' is the want of every MP that his or her actions be unimpeded by others, while 'positive face' is the want of every MP that his or her wants be desirable to at least some others (including the desire to be understood, approved of, liked or admired). It is in the mutual interest of two MPs to maintain each other's face.

Some acts are intrinsically face-threatening acts (FTAs). Brown and Levinson $(1978,1987)$ distinguish between different kinds of FTAs: firstly, between those which primarily threaten negative face and those which primarily threaten positive face; and secondly, between acts which primarily threaten the face of the hearer $(\mathrm{H})$ and those which primarily threaten the face of the speaker (S). The speech act focused on in the present study, the request, is an act which primarily threatens H's negative face. By putting some pressure on $\mathrm{H}$ to do a certain future act, it indicates that $\mathrm{S}$ does not intend to avoid impeding H's freedom of action. Therefore, in the present discussion, the concept of an FTA may usefully be conceived of as an act threatening to H's negative face, specifically.

When performing an FTA, $S$ will want to minimize the face threat of the FTA. Therefore the more an act threatens H's face, the more $S$ will want to choose a 
strategy involving increasingly minimised risk to H's face - which means an increasingly higher numbered strategy from the following:

1.On-record: baldly

2. On record: with positive politeness

3. On record: with negative politeness

4. Off-record

5. Don't do the FTA at all.

To go 'on-record' as doing the FTA means to do it in such a way that the one's communicative intention is unambiguously clear to the participants. An advantage of going on record is that $\mathrm{S}$ can avoid the danger of being misunderstood, and avoid the danger of being seen as a manipulator.

In going on-record, one may perform the act 'baldly', without redress (Strategy 1 above). This means doing it in the most direct, clear, unambiguous and concise way possible. Alternatively, one may perform the act on-record but with 'redressive action'. This is action that gives face to $\mathrm{H}$; that attempts to counteract the potential face damage of the FTA by indicating that no such face threat was intended or desired.

Redressive action may take the form of positive politeness (Strategy 2). Positive politeness is oriented towards the positive face of $\mathrm{H}$; the positive image that $\mathrm{H}$ claims for him or herself. Advantages of using positive politeness are that one can minimize the threat to face conveyed by an act by assuring $\mathrm{H}$ that $\mathrm{S}$ likes him or her, and 'wants H's wants'; and that one may also minimize the debt implications of FTAs such as requests; for example, by referring implicitly to the on-going relationship between $S$ and $H$.

Redressive action may also take the form of negative politeness (Strategy 3). Negative politeness is oriented towards H's negative face; his or her basic want to maintain claims of territory and self-determination. An advantage of using negative politeness is that $\mathrm{S}$ can show that he or she has $\mathrm{H}$ 's face in mind by giving $\mathrm{H}$ a 'way out', either a real one or a conventional one (the notion of 'conventionality' is discussed in more detail shortly).

To minimise the risk to face still further, one may instead perform the FTA 'offrecord' (Strategy 4). This means doing the act in such a way that there is more than 
one attributable intention to the actor, so that the actor cannot be held to have committed him or herself to one particular intent. An advantage of going off-record is that $S$ can get credit for being tactful and non-coercive, and can avoid responsibility for the potentially face-damaging interpretation.

If the act is assessed by $S$ as involving an even higher risk to face, $S$ may choose the safest strategy of all, which is that of not performing the FTA (Strategy 5). The advantage of this strategy is that $\mathrm{S}$ can avoid offending $\mathrm{H}$ at all with this particular FTA.

Brown and Levinson $(1978,1987)$ argue that any rational agent will tend to choose the same type of strategy as anyone else in the same situation. This is because each strategy above intrinsically has certain advantages, and in each situation one of those advantages can be seen as more important than any other.

Brown and Levinson $(1978,1987)$ add another important component to their framework by explaining how speakers assess the seriousness of an FTA, and hence, how they select which strategy to use. A speaker calculate the weightiness of the threat to face (W) on the basis of his or her assumptions of three variables. These variables are:

1. The 'social distance' (D) between $\mathrm{S}$ and $\mathrm{H}$. This means, essentially, the degree of social familiarity between $\mathrm{S}$ and $\mathrm{H}$. The assessment of social distance is likely to be "based on an assessment of the frequency of interaction and the kinds of material or non-material goods (including face) exchanged between S and H..." (Brown \& Levinson 1978: 81-2).

2. The relative power $(\mathrm{P})$ of $\mathrm{S}$ and $\mathrm{H}$. 'Power', here means "the degree to which $\mathrm{H}$ can impose his own plans and his own self-evaluation (face) at the expense of S's plans and self-evaluation" (Brown \& Levinson 1978: 82).

3. The ranking of impositions $(\mathrm{Rx})$ in the particular culture. This means the degree to which a specific act, for example the future act of $\mathrm{H}$ postulated in a request, "is considered to interfere with an agent's wants of self-determination or of approval" (Brown \& Levinson 1978: 82).

The seriousness, or weightiness, of an FTA is calculated by adding the value of these three variables together: $\mathrm{W}=\mathrm{D}+\mathrm{P}+\mathrm{Rx}$. Brown and Levinson $(1978,1987)$ 
argue that while these factors of $\mathrm{D}, \mathrm{P}$ and $\mathrm{Rx}$ are not the only factors used by speakers to assess the danger of FTAs, they subsume all other factors.

Brown and Levinson $(1978,1987)$ provide examples of realisations of each of their proposed politeness strategies. Selected examples are as follows.

\section{Strategy 1: Bald on record}

The archetypal realisation of this strategy is the imperative request. The imperative is used where other demands override face concerns; for example, where maximum efficiency is very important (eg "Stop stop!" to a driver about to hit a pedestrian), or where S's want to satisfy H's face is small because $S$ is powerful and does not fear H's non-cooperation (eg to a house servant, "Fetch my slippers").

\section{Positive politeness}

One example is the use of in-group identity markers: eg slang, dialect, or ellipsis. These markers all rely on shared knowledge between $\mathrm{S}$ and $\mathrm{H}$, and so convey the message that $\mathrm{S}$ and $\mathrm{H}$ belong to the same group. A second example is presupposing familiarity with $\mathrm{H}$; that is, speaking as if it were mutually assumed that you and $\mathrm{H}$ have a familiar relationship (e.g.by using familiar address forms to strangers, such as English "mate", or "luv").

\section{Negative politeness}

One important example is the strategy of being conventionally indirect. This is a strategy used for performing an 'indirect speech act' - a speech act which has an illocutionary force different from that indicated by the grammatical form of the utterance (cf. Verschueren 1985: 5). The speech act is performed indirectly by referring to certain preconditions necessary for its performance, using the conventions that obtain in a given language (Blum-Kulka 1989: 47). These conventions consist of conventions of means (e.g. the convention that a request can be made by questioning the hearer's ability to do the act in question), and conventions of form (e.g. the convention that hearer's ability is questioned by the form "can you" rather than "are you able to" (Blum-Kulka 1989: 41). ${ }^{18}$

Speakers have a conflict between the want to be direct, in order to minimise the imposition on $\mathrm{H}$ by coming directly to the point; and the want to be indirect, in 
order not to coerce $\mathrm{H}$. Being conventionally indirect is a compromise means of partly satisfying both wants. When an indirect speech act realisation is fully conventionalised as a way of performing an FTA (as in the case of "can you?" as a way of performing a request in English), then the speech act is no longer 'offrecord'. So using this kind of realisation enables the speaker to go on record but at the same time to indicate his or her desire to have gone off- record.

Another means of negative politeness is being pessimistic. This means explicitly expressing doubt that the conditions for the appropriateness of S's speech act obtain. An example is making a request in English with a conditional modal verb (e.g "could you?", or "would you?"), to make the possibility of the condition being fulfilled seem more remote.

A final example of negative politeness is giving deference to $\mathrm{H}^{19}$. This is done either by humbling self, or raising $\mathrm{H}$ : in both cases, the result is to indicate that $\mathrm{H}$ is of a higher status than S. The archetypal deference strategy is the use of honorifics, including polite words for 'you', and polite terms of address (e.g."Sir" or "Madam" to strangers).

\section{Off-record strategies}

The strategy of 'giving hints' is the most important off-record strategy for present purposes. The basic mechanism of hints, as Brown and Levinson $(1978,1987)$ observe, is that they violate the maxim of relevance, and so invite $\mathrm{H}$ to search for an interpretation of possible relevance. Examples of hints are "It's cold in here" as a request for someone to close the window; or "I missed the lecture on Friday", as a request to borrow a classmate's lecture notes (request hints are discussed in more detail in Chapter 3).

\subsubsection{Criticisms of Brown and Levinson's model of politeness}

Certain general criticisms can be made of the model outlined above. Both its precision and its falsifiability are open to some doubt - as Brown and Levinson themselves acknowledge and discuss in their reassessment of their model (Brown \& Levinson 1987: 11-12). Also, and particularly relevant to this study, the claim for universality of the model is open to serious question (as discussed in the following section). Apart from such general criticisms, one specific component of 
the model is worth examining critically. This is Brown and Levinson's claim that the weightiness of the threat to face entailed in a speech act is calculated by adding the values of the variables of power, social distance + imposition (i.e. on the basis of the formula $P+D+R x=W$ ).

It appears from empirical research that the three variables of power, distance and imposition together cover the contextual factors influencing linguistic choices of speakers fairly well. While certain studies have revealed factors which may not be adequately subsumed under these three variables (cf. Brown \& Levinson 1987: 16; see also Kasper 1990: 204); it seems that on the whole these three variables together manage to account for a great deal of the variation by speakers.

However, what has received little research attention is the difficulty of operationalising the formula $P+D+R x=W$ for empirical studies; specifically, the difficulty of manipulating or calculating the size of each variable independently from that of the other two, in order to determine the role of each in influencing linguistic choices. This difficulty lies in the fact that the three variables may not be independent from each other, as claimed by Brown and Levinson $(1978,1987)$. Doubts have been implicitly expressed by certain researchers about the mutual independence of the factor of social distance from power 20; perhaps more surprising is the fact that the factor of imposition may not be independent of power.

Brown and Levinson argue for the independence of their three variables with reference to requests for 'free goods' (cf. Goffman 1967); that is, those goods and services which all members of the public may ask from each other (like a match, or telling the time, or giving directions). They claim that in such requests the factor of imposition is held constant, as small, while the factors of power and social distance can vary, depending on who the hearer is (Brown \& Levinson 1978: 85). However (even presuming that the example is meant to apply to English-speaking culture specifically) there seems to be a basic problem with this claim; namely, that that the size of the imposition $(\mathrm{Rx})$ entailed in a request is likely to increase in size when the value of power $(\mathrm{P})$ of the hearer relative to speaker increases in size.

An example is this: if a lowly clerk in a small section of one branch of a vast organisation asks an equal ranking colleague (i.e. one equal in power to $S$ ) for the time, and if the same lowly clerk asks the CEO of the whole organisation (i.e. one higher in power than S), who happens to be paying a rare visit to that branch, for the time as he or she passes; the imposition $(\mathrm{Rx})$ will be perceived as higher in the 
second case. This is because of a fact that Brown and Levinson themselves recognise in their (1987) reassessment of their model; namely, that (in some cultures at least) a superior's time is assessed as intrinsically valuable, and a superior's "mere co-presence in an interaction" (Brown \& Levinson 1987: 19) is perceived as intrinsically demanding. Brown and Levinson (1987) acknowledge that this fact has important consequences for another part of their model (their claim that off-record strategies are the most polite strategy for an FTA) ${ }^{21}$. However, it also seems to have obvious implications for their claim that the variables of power $(\mathrm{P})$ and imposition $(\mathrm{Rx})$ are independent, and means that in empirical studies, the influence of power or imposition alone may be difficult to assess.

The independence of the two variables of $\mathrm{P}$ (power) and $\mathrm{Rx}$ (imposition) may also be compromised by a more fundamental problem; the fact that these two variables, at least as they are generally understood by empirical researchers, seem to be composed of some of the same contextual factors.

At first glance, the two notions of power and imposition entailed in an FTA seem safely distinct from each other. Blum-Kulka (1991) states that context- external factors "have to do with institutionalised role constellations, such as degree of social power ..." (Blum-Kulka 1991: 259, original emphasis). So power here is explicitly classified as a context-external factor. Moreover, Blum-Kulka states that context-internal factors are "the variables specific to the requestive situation, such as the speaker's estimated legitimacy in issuing the request, or other situational prerequisites for compliance, such as ability and willingness to comply" (BlumKulka 1991: 259, original emphasis). These context-internal factors she mentions: legitimacy of the request, which refers to the rights and obligations of the interlocutors; and ability and willingness to comply, are precisely the factors which constitute imposition (cf. S. Takahashi 1996: 197-198). So it would appear that power is composed of 'context-external' factors and imposition is composed of 'context-internal' ones. ${ }^{22}$

However, the problem lies in the fact that the value of power is determined to some extent by context- internal factors as well. ${ }^{23}$ This creates a potential for the same factors to contribute to the value of both imposition and power. And indeed, two such factors, rights and obligations, seem to influence both. As well as being two of the factors which determine the size of the imposition on the hearer (cf. S. Takahashi 1996), these factors have been found in a study by Blum-Kulka and 
House (1989) to help determine the relative power of the interlocutors (Blum-Kulka \& House 1989: 142, see also 131ff). So the values of power and of imposition, to a certain extent, seem to be composed of the same factors, which places their mutual independence in doubt.

In conclusion, the theories of linguistic politeness outlined above, in particular that of Brown and Levinson (1978; 1987), provide a valuable theoretical framework for analysing politeness phenomena in speech. However, Brown and Levinson's model of how speakers vary their choice of linguistic features according to situation when performing face-threatening speech acts may be more difficult to apply to practical analysis of speech than is always acknowledged, and these difficulties should be kept in mind when carrying out and interpreting studies within this framework. 24

\subsection{Universality of pragmatics}

The issue of to what extent pragmatic phenomena are universal vs culture- and language-specific has very important implications for learner pragmatics, as it determines how much learners already know of the pragmatics of the L2 and how much of it they have to learn.

Strong claims for universality of pragmatic phenomena have been made. Searle $(1969,1975)$ claims universality for the essential rules governing performance of speech acts. He claims that the rules stating the propositional content, and the conditions, for an utterance to count as the felicitous and successful performance of a particular speech act are the same across languages (Searle 1969: 39-40); and moreover, that we can state precisely what strategies will be available in all languages to make indirect speech acts, because the realisation of these speech acts is systematically linked to those preconditions (Searle 1975: 64).

This claim of Searle is formalised by Gordon and Lakoff (1971) as a set of 'conversational postulates', or principles for performing indirect speech acts; which they believe are very likely to be universal (Gordon \& Lakoff 1971: 64, 81ff). An example of these postulates is as follows: that one can make a request either by asserting a speaker-based sincerity condition or by questioning a hearer-based sincerity condition. Thus, one could make a request either by asserting the 
condition that the speaker wants $\mathrm{H}$ to perform the act (e.g. by saying "I want you to...") or by questioning the condition that the hearer is able to perform the act (e.g. by asking "Can you...?"). Brown and Levinson $(1978,1987)$ support this claim of Gordon and Lakoff (1971) for the universality of these conversational postulates on the basis of their own data, saying that "all the evidence we have confirms that the underlying principles [of indirect speech acts] are the same across languages and cultures" (Brown \& Levinson 1978: 145). 25

Fraser (1978), similarly, claims that the strategies for performing speech acts are "essentially the same across languages" (Fraser 1978: 19). He claims some empirical support for this, in the form of an "informal survey" of 14 diverse languages, in which native speakers of each language affirmed that each of 18 English request strategies presented to them was available in that language (Fraser 1978: 19).

Fraser, Rintell and Walters (1980) make a claim for universality in particularly strong terms. They assert that the equivalence of strategies across languages is limited only when one language does not have the grammatical means of encoding some details of a strategy. For example, they claim, every language should be able to request by the same strategy as the English question "Why don't you do that now?," because all languages will have the grammatical means to construct this question. However, some languages will not have the elliptical version of the same request form which English has in "Why not do that now?," because their grammatical system cannot tolerate the construction of why + negative marker + bare infinitive (Fraser, Rintell \& Walters 1980: 79).

Fraser and Nolan (1981) extend claims for universality in one more respect. They claim that strategies for speech acts, as well as being the same across languages, also convey the same level of deference relative to the other strategies across languages. They base this claim on a study where native speakers of both English and Spanish were required to rank the same 14 translationally-equivalent request forms for deference, and agreed very closely on the rank ordering of these 14 sentences - suggesting, Fraser \& Nolan (1981) argue, that the relation between these linguistic forms and level of deference conveyed (relative to other forms) was perceived in essentially the same way across the two languages.

All the research outlined above suggests, as Fraser and Nolan (1981) put it, that "learning how to use a second language involves the grammatical code much more 
than acquiring any new pragmatic abilities" (Fraser \& Nolan 1981: 107). However, on the whole, empirical evidence does not seem to bear out such strong claims for universality of pragmatic phenomena as the claims above. The case against such claims can best be demonstrated concisely by outlining two studies carried out with the explicit goal of assessing speech act universality, by Blum-Kulka (1983, 1989). 26

Blum-Kulka (1989) examined a large corpus of data on requests in four languages (Hebrew, Canadian French, Argentinian Spanish, and Australian English) to determine the extent to which the phenomenon of 'conventional indirectness' is universal. She found that all these languages display request strategies that meet the criteria for conventional indirectness (see 1.4.2), such that the phenomenon of conventional indirectness, as distinct from non- conventional indirectness, appears to be universal (Blum-Kulka 1989: 47). She also found some shared basic properties of conventionally indirect request strategies in all the languages; for example, that the strategies used with high frequency by subjects were shared across languages (such as the strategy of making requests by questioning the hearer's ability, as in English "Can you....?”).

However, important cross-linguistic differences were found within Blum-Kulka's (1989) data. Most importantly, certain request strategies were not shared by languages. For example, while some languages conventionally employed the strategy of questioning the hearer's willingness (cf. English "Do you want to give me a hand?"), and the strategy of making a suggestion by questioning the reason for not doing something (cf. English “Why don't you clean that mess up?"); other languages did not appear to use these strategies to make requests.

Within shared strategies, as well, significant differences existed between languages. For example, when questioning the hearer's ability, a shift to past tense (cf. English "Could you...?") resulted in loss of potential requestive force in some languages but not in others. In addition, it was found that the social meanings carried by the same strategy; for example, the degree of coerciveness the strategy conveyed, sometimes differed across languages.

Blum-Kulka (1989) concludes that Searle's (1969, 1975) claims about universality of indirect speech act realisations are only partly supported by the data. While his basic claim that all languages make requests by reference to contextual preconditions necessary for the performance of the act is borne out, his assertion 
(Searle 1975) that a systematic link exists between these preconditions and speech act strategies, such that the precise strategies used in every language can be specified on the basis of preconditions for the performance of the act, is not confirmed by her results.

Blum-Kulka (1983) examined another corpus of request data, this time from native speakers of Canadian English and Hebrew - with similar results to her study above. A systematic comparison of requests in the two languages revealed that Searle's (1975) proposed mechanisms underlying speech act performance could be called universal "only if "mechanisms" are defined in the most general terms..." (Blum-Kulka 1983: 37). Blum-Kulka (1983) specifically found Gordon and Lakoff's (1971) claim for universal conversational postulates to be disconfirmed; for example, these postulates wrongly predicted that a request can conventionally be made in Hebrew, as in English, by asking if the hearer is going to perform a future act (cf. English "Will you...?"). Blum-Kulka (1983) concluded from this study that the essential similarity in speech act strategies across languages proposed by Fraser (1978) "is illusory and tends to disappear on close analysis" (BlumKulka 1983: 39).

Another line of research which casts doubt on the universality of pragmatic phenomena investigates the universality of the theoretical frameworks which, supposedly, generate these phenomena. Most of this reseach has focussed on a central tenet of Brown and Levinson's $(1978,1987)$ theory; namely, their notion of 'face', and questions its applicability in non-Western cultures.

Matsumoto (1988) argues convincingly that Brown and Levinson's $(1978,1987)$ notion of 'face' as consisting of two kinds of wants: positive and negative face wants, does not adequately describe the notion of 'face' relevant to politeness in Japanese culture. The notion of 'negative face', in particular, is inappropriate, having as its essence "the notion of an individual who desires to defend his/her own territory from the encroachments of others" (Matsumoto 1988: 405). Matsumoto argues that :

[T] his notion of individuals and their rights..... cannot be considered as basic to human relations in Japanese culture and society. ... [W] hat is of paramount concern to a Japanese is not his/her own territory, but the position in relation to others in the group and his/her acceptance by those others. Loss of face is associated with the perception by others that one has not comprehended and acknowledged the structure and hierarchy of the group (Matsumoto 1988: 405). 
This concept of face, she points out, is qualitatively different from that proposed by Brown and Levinson $(1978,1987)$, and therefore calls into question the universality of this core concept of their framework (Matsumoto 1988: 405).

Matsumoto (1988) illustrates how applying Brown and Levinson's $(1978,1987)$ notion of face leads to a mistaken interpretation of certain politeness phenomena in Japanese. Deferential honorifics, Brown and Levinson $(1978,1987)$ claim, are used with strategic intent, to reduce threat to the hearer's negative face. However, Matsumoto (1988) argues that deferential honorifics are not used in Japanese with strategic intent at all. Instead, they are 'relation-acknowledging' devices; they are used to show recognition of one's position vis a vis the hearer - regardless of whether the speech act is intrinsically face-threatening (Matsumoto 1988: 409-411).

Ide (1989), in fact, argues that this use of 'relation-acknowledging devices' such as honorifics in Japanese constitutes a whole dimension of politeness that is not captured by Brown and Levinson $(1978,1987)$; namely, that of 'Discernment'. Discernment is the use of politeness features not as interactional strategy, but as adjustments to the social context, which are carried out almost automatically by interlocutors. And it is Discernment, Ide (1989) argues, which is the major motivating force behind politeness in some cultures - not strategic reduction of threat to face (especially negative face), as Brown and Levinson $(1978,1987)$ assume. 27

In summary, empirical studies reveal considerable cross-cultural variation in strategies and in realisations of strategies for performing speech acts; moreover, a theoretical notion thought to be central to the linguistic enactment of politeness, that of 'face', seems to vary substantially between cultures. All of this casts doubt on the validity of strong claims for universality of pragmatics. We may conclude, then, that L2 learners have a certain amount of learning of L2 pragmatics to do. However, it is equally important to note that (as demonstrated by a number of empirical studies examined above) there are strong similarities in ways of encoding politeness across many languages. As a result, we may expect that learners will possess at least some pragmatic knowledge, either universal or from their native language, that they can use in performing pragmatics in the $\mathrm{L} 2$ - as discussed in the next section. 


\subsection{Interlanguage pragmatics}

\subsubsection{Introduction}

As an investigation of the pragmatic competence of learners of Indonesian, demonstrated through their performance of requests; this study lies within a relatively new field of second language (L2) research known as 'interlanguage pragmatics' (hereafter ILP). The term 'interlanguage' was first proposed by Selinker $(1969,1972)$ to refer to the separate linguistic system possessed by the learner of an L2, which differs from both the learner's first language (L1) system and from the target L2 system. In ILP research, this notion of 'interlanguage' has been extended to the pragmatic component of learners' language system, based on the observation that "second language learners seem to develop an interlanguage of speech-act performance, which differs from both first and second language native usage" (Blum-Kulka 1983: 47, original emphasis).

ILP has been defined as:

"the study of nonnative speakers' use and acquisition of linguistic action patterns in a second language..." 28 (Kasper \& Blum-Kulka 1993: 3), and as:

"the study of the development and use of strategies for linguistic action by nonnative speakers..." (Kasper \& Schmidt 1996: 150).

Certain things are worth noting from the two definitions above. Firstly, the notion of 'linguistic action' in both definitions delimits the field to the study of the pragmatic component of interlanguage. It shows that ILP is concerned with the performance of speech acts; with utterances intended to achieve a communicative goal.

Secondly, an important distinction is made in both definitions above between use of linguistic action patterns or strategies, on the one hand; and the development, or acquisition, of these patterns or strategies, on the other. As Kasper and Schmidt (1996) point out, ILP research differs from mainstream research on second language acquisition (SLA) in that the main focus has been on the use of language by learners, rather than the acquisition of language. This is because the research field of ILP has developed as an offshoot of cross-cultural pragmatics, rather than 
of SLA, and so it shares the research focus of the former rather than the latter discipline (Kasper \& Schmidt 1996: 150). As a result, ILP is concerned largely with the task of identifying the strategies and linguistic means by which learners perform certain speech acts, and describing how learners vary their selection of these strategies and linguistic means according to context.

However, as Kasper and Schmidt (1996) point out, ILP research has one concern in common with mainstream SLA research: a strong interest in the role of transfer from the first language. So, although ILP is concerned mainly with language use and SLA with language development, both disciplines share a concern with the processes underlying learners' linguistic performance. ${ }^{29}$

The present study broadly reflects the main focus of ILP research as outlined above. It is mainly concerned with learners' use of linguistic action patterns, it is also concerned with the processes underlying the production of these patterns, and to a lesser extent, only, it is concerned with the development of ability to produce these patterns. To reflect this focus, previous research on L2 learners' productive pragmatic performance will be discussed with regard to:

i) what learners do (i.e. a 'product-level' description);

ii) how learners do it (i.e. a 'process-level' description, of the psycholinguistic processes underlying $\mathbb{I L}$ knowledge and performance), and

iii) how learners develop the ability to do it (an acquisitional perspective, discussing developmental stages learners may go through).

\subsubsection{What learners do in ILP}

\subsubsection{The issue of a pragmatic norm}

An important issue to clarify before attempting to describe learner pragmatics is the question of what norm to apply as a yardstick. While an L2 native pragmatic norm seems the obvious choice, it might not in fact be appropriate as a norm for learners, for a number of reasons. ${ }^{30}$ One is that L2 learners may not even aim for L2 native pragmatic performance. They may well choose to diverge to some extent from native speaker (NS) pragmatic norms, in order to preserve, and assert, their cultural identity (cf. Blum-Kulka 1991: 269; Kasper \& Shmidt 1996: 156). Another reason is that L2 native speakers may not want learners to exhibit NS pragmatic behaviour. 
They may regard total convergence with NS pragmatic norms by learners as inappropriate to their status as outsiders; as a claim to membership of a group to which they do not belong (cf. Janicki 1986; Blum-Kulka 1991: 269; Kasper 1995a: 26).

As Faerch and Kasper (1989) argue, given our lack of certainty about what pragmatic norms should be used to assess learners' pragmatic performance, it is best at the present simply to describe learner pragmatic performance (as far as possible) in non-judgemental terms, rather than evaluating how 'well' or 'badly' learners perform. And in formulating such a description of learner pragmatics, a native speaker norm can usefully be employed as a yardstick for comparison.

\subsubsection{Previous studies}

Empirical studies in ILP usually focus on the performance of one or more speech acts by learners. Studies to date have covered a range of speech acts, performed by learners from a wide variety of L1 backgrounds. As Kasper and Blum-Kulka (1993: 7) note, the range of languages studied as the L2 is still small, with most studies focussing on English as the L2. However, ILP studies are increasingly reflecting a range of target languages as well.

The most frequently researched speech act in ILP studies is requesting. While English is the target language in many of these studies of requests (e.g. Rintell 1981; Zimin 1981; Scarcella \& Brunak 1981; Cook 1985; House \& Kasper 1987; Tanaka 1986, 1988; House 1989; Béal 1990; X. Nguyen 1990; Bilbow 1995, Trosborg 1995), other studies focus, for example, on requests by learners of Hebrew (Blum-Kulka 1982, 1983, 1991; Blum-Kulka \& Olshtain 1986; BlumKulka \& Levenston 1987; Weizman 1993), of Spanish (Koike 1989; le Pair 1996), of German (Kasper 1989; Faerch and Kasper 1989), and of French (Harlow 1990).

Another speech act which have received considerable attention in ILP research is apologising (e.g. Zimin 1981; Cohen \& Olshtain 1981; Olshtain \& Cohen 1983; Cohen, Olshtain \& Rosenstein 1986; Harlow 1990; Bergman \& Kasper 1993; Trosborg 1995). 
The two speech acts above, requesting and apologising, are the focus of the largest and best-known ILP study to date: the CCSARP (Cross-Cultural Speech Act Realisation Project). This study examined requests and apologies by learners and native speakers of a range of languages. A large number of the studies cited above are based on various data collected in the CCSARP.

Other speech acts which have received considerable attention in ILP studies are complaining (e.g. Olshtain \& Weinbach 1987, 1993; Trosborg 1995); and thanking -notably the studies of Eisenstein and Bodman $(1986$; 1993) and Bodman and Eisenstein (1988), also those of Cook (1985), Harlow (1990), T. Nguyen (1990), Hinkel (1994), and Hassall (1996).

A wide variety of other speech acts have also been examined. These include suggesting (Rintell 1981; Bardovi-Harlig \& Hartford 1990), rejecting suggestions (Bardovi-Harlig \& Hartford 1990), inviting (Scarcella \& Brunak 1981), disagreeing and giving embarrassing information (Beebe \& T. Takahashi 1989), correcting (T. Takahashi \& Beebe 1993), refusing (Beebe, T. Takahashi \& UlissWeltz 1990), greeting and leave-taking (Cook 1985).

In addition, there have been several ILP studies which examine learner pragmatic behaviour more generally, where the focus is not restricted to the performance of specific speech acts; notably the Bochum Project (cf. Edmondson, House, Kasper \& Stemmer 1984), and that of House (1996).

\subsubsection{Features of learner pragmatics}

From studies such as those above, certain features of $\mathrm{IL}$ pragmatics can tentatively be identified, across target and first languages.

One consistent finding of ILP studies is that learners tend to display 'verbosity' in pragmatic behaviour: they produce lengthy speech act realisations, compared to native speakers. This finding is particularly clear in relation to requests. Learners of a variety of L1 backgrounds have been found to support their requests by lengthy justifications and explanations (Blum-Kulka \& Olshtain 1986; House \& Kasper 1987; Faerch \& Kasper 1989; Blum-Kulka 1991), and have also been found to formulate lengthy request hints (Weizman 1993: 132-133). Learner 'verbosity' has 
also been observed in performance of complaints (Olshtain \& Weinbach 1993) and even, as Kasper (1989: 54) points out, in performance of speech acts which do not involve an inherent threat to face, but rather the expression of referential meaning. 31

The usual explanation for learners' verbosity in speech act performance is that they lack confidence in their linguistic ability, and so they use a lot of words to make sure that they succeed in conveying their message (cf. Blum-Kulka \& Olshtain 1986; Faerch \& Kasper 1989). This can be described as a strategy of 'playing it safe', which appears to be characteristic of intermediate learners particularly (Faerch \& Kasper 1989: 245). A plausible complementary explanation is also suggested by Faerch and Kasper (1989): that learners at intermediate level may use a lot of words to assert their linguistic competence; "to mark themselves as distinct from beginning learners", who lack the linguistic ability to produce lengthy utterances (Faerch \& Kasper 1989: 245). So this feature may serve the psychologically important need for self-assertion.

Another closely related feature of learner pragmatics is an emphasis on clarity in speech act performance. When performing L2 speech acts, learners tend to choose "explicit, transparent, unambiguous means of expression...." (Faerch \& Kasper 1989: 233). For example, Danish learners of English and German overuse the politeness markers "please" and bitte as a means of mitigating their requests, and it is suggested that they favour these particular mitigators because of their explicitness: as well as being highly transparent markers of politeness, they explicitly mark the utterance as being a request (Faerch \& Kasper 1989: 232-233). Similarly, learners of English in the Bochum study showed a general tendency to propositional explicitness, performing an offer, for example, with "Would you like to drink a glass of wine with me?," instead of a more elided form a native speaker might use, such as "Like a glass of wine?" (Kasper 1982). This emphasis by learners on explicitness and transparency, like their tendency towards verbosity, can be regarded as part of an emphasis on clarity. This norm of clarity is attained by explicitness as well as by lengthiness in speech act performance.

An important question related to this is: do learners emphasise clarity at the cost of politeness? In other words, do they invest less linguistic effort in being polite, because of a more pressing concern to express their meaning clearly? Koike (1989) claims that learners do just that. She found that English learners of Spanish used inappropriately blunt and direct strategies to make a request whose propositional 
goal was difficult to express and concluded that faced with this linguistically challenging situation, learners had disregarded the need for politeness and concentrated instead on making their meaning clear to the hearer.

In the Bochum study (Edmondson et al 1984), similarly, learners were found to convey illocutionary and propositional meaning adequately in their speech acts, but to invest little effort in politeness. Specifically, they did not observe the 'hearersupport' maxim in performing speech acts, tending to perform inherently facethreatening acts (such as requesting, complaining and rejecting offers) directly and without mitigation, while performing inherently face-saving acts (like offering, thanking, apologising and accepting offers) more indirectly and with mitigation. It was concluded that these learners seemed to follow the principle of "minimal communicative requirements" (Edmondson et al 1984: 122). They seem to assess relational and expressive functions as less important than illocutionary and propositional meaning, and so often did not mark their speech acts for the former functions. 32

Beebe and T. Takahashi (1989) implicitly make the same claim as Edmondson et al (1984) about learner speech act performance. They characterize the highly direct and harsh expressions of disagreement used by Japanese learners of English in their study as a 'minimalist' type of response, which they claim to be characteristic of ESL learners. They also suggest that the learners may be focussing singlemindedly on conveying their propositional message, without giving any attention to considerations of politeness (Beebe \& T. Takahashi 1989: 120).

However, it would be rash to claim that learners do not invest linguistic effort in being polite. Firstly, and most generally, it should be remembered that being clear is a means of being polite (cf. Lakoff 1973: see 1.4.1). L2 learners are likely to be aware of their limited linguistic competence, and hence, of the likelihood of annoying their listeners, confusing them, or wasting their time by unclear expression of their ideas. It may well be that in many cases the considerable efforts learners go to to be clear, through choice of explicit linguistic features and by lengthy speech act realisations, are motivated by this awareness, and hence, should properly be interpreted as a type of courtesy: a form of hearer- support during interaction.

Secondly, in the performance of FTAs specifically, verbosity may certainly be interpreted as a politeness strategy. As Brown and Levinson $(1978,1987)$ observe, 
the choice of a lengthy formulation of a speech act which inherently threatens H's face is per se a form of transparent face-work: it demonstrates to $\mathrm{H}$ the considerable effort that $\mathrm{S}$ is going to avoid damage to H's face. House and Kasper (1987) interpret the overuse by learners of reasons and justifications to support their requests consistently with this notion. They claim that learners may be overdoing these hearer-supportive moves on requests partly from uncertainty about their social competence; that is, from fear of being insufficiently polite, learners are investing 'too much' effort in their own idiosyncratic form of politeness enactment.

On the whole, then, despite evidence that learners may pay less attention than NSs to politeness as conveyed by relational and expressive functions, it might be useful to regard learners' enactment of politeness as different to that of NSs rather than as deficient. Learner politeness, rather than being neglected for the sake of propositional clarity and explicitness, may tend to be expressed through this propositional clarity and explicitness.

Another general feature of learner pragmatics to note is that learners tend to display highly non-native performance with regard to the 'discourse end' of rules of speaking; that is, when their pragmatic performance depends on skill in conversational management. House, for example, finds even very advanced German learners of English to show "a remarkable deficiency in producing pragmatically appropriate responding moves" in conversation (House 1996: 240). These learners' responses were often "non-aligned" to the initiating move by the interlocutor; for example, they were not the second pair part which the speaker had intended them to be (e.g."Don't ask me how I'm doing" --> "I'd like to borrow your car for the weekend "), or they were oriented to a first pair part that the interlocutor had not supplied (e.g. "What's up?" --> "Oh yes I'm fine ") (House 1996: 240-243). In the Bochum project (Edmondson et al 1984: 21), advanced learners of English were observed to have similar difficulty in responding appropriately to contributions by the interlocutor. 33

Difficulty in conversational management ability is also evident in the inability of advanced learners of English to express gratitude adequately, as observed by Bodman and Eisenstein (1988) and Eisenstein and Bodman (1993). Learners in these studies were unable to align their reponses to the interlocutor's contributions in order to jointly construct thanking sequences with the giver across a number of turns, by responding to comments, prompts and reactions by the giver; and thus were unable to construct thanking sequences of sufficient length for gratitude to be 
adequately conveyed. Furthermore, the interactional demands of face-to-face conversation make it hard for learners to produce appropriate initiating moves as well as responding moves. Trosborg (1995) found that advanced learners of English produced considerably fewer requesting and complaining moves than English native speakers, and argues that this is because these speech acts occur mainly as initiating moves in discourse, while learners lack "the capacity to take the initiative in interaction" (Trosborg 1995: 425).

Other general features of learner pragmatics will be mentioned only briefly. Firstly, learners frequently perform speech acts in a given situation with a different level of directness from NSs. As Kasper and Blum-Kulka (1993) observe, however, there is no consistent trend for learners to be either more or less direct than NSs; in some studies learners are more direct than NSs, while in others they are less so. Secondly, learners consistently display a small range of pragmalinguistic resources compared to native speakers. This limited repertoire is revealed by use of a smaller range of pragmalinguistic forms to realise particular strategies, as well as a smaller range of modifiers to mitigate or intensify pragmatic force, on a range of speech acts. It has been observed in a number of studies (e.g. Edmondson et al 1984; Eisenstein \& Bodman 1986; House \& Kasper 1987; Trosborg 1995) and appears to be a characteristic feature of learner speech act performance (cf. Kasper \& BlumKulka 1993: 8).

\subsubsection{How learners do ILP}

In the above description of ILP, we touched briefly on how social-psychological factors (such as learners' anxiety about their linguistic or social competence, or their wish to 'disidentify' themselves with the L2 culture) may influence learners' pragmatic performance. In the next section, we will attempt to understand the psycholinguistic processes underlying the acquisition of $\mathbb{L}$ pragmatic knowledge and the production of $\mathrm{IL}$ linguistic action. A number of specific processes play an important role, as discussed below.

\subsubsection{Use of universal pragmatic knowledge}

Firstly, it appears that learners consult universal pragmatic knowledge to some extent in learning and performing pragmatics in the L2. Blum-Kulka, for example, 
claims on the basis of her examination of requests by learners of Hebrew that learners use a "non-language-specific pragmatic competence" (Blum-Kulka 1983: 49), or "general pragmatic knowledge-base" (Blum-Kulka 1991: 262), when communicating in the L2. Blum-Kulka (1991) attempts to define the extent of the general pragmatic knowledge that learners appear to be equipped with, as follows:

[B]asic notions associated with the use of language in context, such as the ability to infer communicative intentions from indirect utterances, the ability to realise speech acts in non-explicit ways and a general sensitivity to contextual constraints in the choice of modes of performance (Blum-Kulka 1991: 255).

Kasper (1992), moreover, argues that universal pragmatic knowledge can be conceived of in more specific terms than those of Blum-Kulka (1991) above. Empirical evidence from ILP studies, Kasper (1992) claims, shows that by virtue of universal pragmalinguistic knowledge, learners have access to the same range of strategies for performing speech acts in the L2 as native speakers do. For example, when requesting, learners will be able to vary the level of directness, vary the request perspective, and to use both internal and external modifiers to either mitigate or aggravate their pragmatic force (these elements of the request speech act are discussed in Chapter 3). Furthermore, Kasper (1992: 221) claims that learners, by virtue of universal sociopragmatic knowledge, possess a sensitivity towards both types of relevant contextual features: context -external factors (such as power and social distance) and context-internal factors (such as degree of imposition on the hearer). So while we do not yet know how much or what kind of pragmatic knowledge is universal (cf. Kasper 1992), it appears that a considerable amount of it may be, and that L2 learners are likely to draw upon it as part of the process of forming IL pragmatic knowledge.

\subsubsection{L1 transfer}

Another important psycholinguistic process underlying $\mathrm{IL}$ pragmatic knowledge and performance is transfer of pragmatic knowledge from the L1. Selinker (1972) claims that transfer from the L1 is one of the "central processes" in formation of interlanguage knowledge, and a large number of empirical studies (examples are discussed shortly) attest to its influence on IL pragmatics specifically. 
A suitable definition of pragmatic transfer for the purposes of the present study is: the influence exerted by learners' pragmatic knowledge of the L1 language and L1 culture on their production and learning of L2 pragmatic information (cf. Kasper 1992: 207). This conception of transfer as "influence" from the L1 permits a broad interpretation. Most importantly, it means that avoidance of a given feature in the L2 can be called 'transfer', if this avoidance is motivated by L1 influence. 34

A useful distinction can be made between 'positive' and 'negative' pragmatic transfer. When a learner uses a pragmatic feature with native-like form, function, and distribution in the $\mathrm{L} 2$ because of influence from a parallel element in the L1, this is positive (or 'successful') transfer from the L1. However, when a learner uses a pragmatic feature with non -native form, function or distribution in the L2 because of L1 influence, this is negative (or 'unsuccessful') transfer from the L1 (Kasper 1995a: 15).

Positive pragmatic transfer has generally received little attention from researchers; partly, Kasper (1992) suggests, because of the difficulty in distinguishing it from other underlying processes (see 1.6.3.5). However, positive transfer by learners has been observed (cf. Kasper 1992: 212), and this process may have an important influence on $\mathrm{IL}$ pragmatic knowledge and performance, as demonstrated later in the present study.

Negative transfer, on the other hand, has been noted in a large number of ILP studies (e.g. Blum-Kulka 1983; Olshtain \& Cohen 1983; Edmondson et al 1984; House \& Kasper 1987; Beebe \& T. Takahashi 1989; Faerch \& Kasper 1989; Robinson 1992; Bergman \& Kasper 1993; House 1996). In some cases the transfer is pragmalinguistic; for example the use of formulaic, ritualized expressions of thanks in English by Japanese learners (Beebe \& T. Takahashi 1989); or the use of negation as a means of mitigating requests in German by Danish learners (Faerch \& Kasper 1989). In other cases, the transfer is sociopragmatic; for example, the assessment of certain contexts as less appropriate for an apology by Hebrew learners of English than by native speakers (Olshtain \& Cohen 1983), or the greater sensitivity to the hearer's social status in selecting a refusal strategy by Japanese learners of English than by native speakers (Beebe, T. Takahashi \& Uliss-Weltz 1990). In other studies it is hard to classify the transfer with certainty as one type or the other. 35 
The relationship between pragmatic transfer and lingustic proficiency is complex. Both a positive correlation and a negative correlation of pragmatic transfer with linguistic proficiency have been suggested, but no consistent evidence has emerged to support the existence of either relationship ${ }^{36}$. Furthermore, it appears (cf. S. Takahashi 1996) that learners' perceptions of transferability of L1 pragmatic features may not vary significantly with language proficiency at all. However, as Kasper (1995a: 19-20) points out, actual transfer does appear to correlate with language proficiency in several ways, certain of which are relevant here. Firstly, low level learners sometimes do not transfer L1 pragmatic features to the L2 because they lack the linguistic competence to do so. Secondly, learners at higher levels of proficiency sometimes do not transfer L1 pragmatic features to the L2 because they believe, rightly or wrongly, that such transfer would be unsuccessful (this kind of 'avoidance' of pragmatic transfer has been observed, for example, by Olshtain \& Cohen 1983; House \& Kasper 1987; Bodman \& Eisenstein 1988; Robinson 1992; Bergman \& Kasper 1993; and House 1996).

A last point about $\mathrm{L} 1$ transfer is that learners sometimes may not transfer an $\mathrm{L} 1$ pragmatic feature because they lack awareness of this feature in the L1 itself. Learners may use a pragmatic feature more or less automatically in the L1, with only a low awareness of its pragmatic function or even its existence, and because of this failure to notice the feature in the L1 they may perform L2 speech acts without this feature or a functional equivalent. ${ }^{37}$ For example, Kasper (1979) attributes the lack of downgrading modifiers on complaints by German learners of English to lack of awareness of the modal particles used for this purpose in the L1, and Trosborg (1995) attributes the lack of both downgrading and upgrading modifers on complaints by Danish learners of English to the same cause.

\subsubsection{Generalisation from the IL}

Another important psycholinguistic process underlying ILP acquisition and performance involves the use by learners not of universal pragmatic knowledge, or of $\mathrm{L} 1$ pragmatic knowledge, but of existing $\mathrm{IL}$ knowledge. In this process, the learner generalises II knowledge gained in one context to another context. Selinker (1972) claims that 'overgeneralisation' (i.e. unsuccessful generalisation leading to error) is one of the central processes in formation of IL knowledge. An important role for overgeneralisation has been claimed in ILP empirical studies as well. In the 
Bochum project, in fact, the majority of pragmatic errors were attributed "hypothetically" to the process of generalisation (Edmondson et al 1984: 122). ${ }^{38}$

An example of the process of overgeneralisation can be found in Blum-Kulka and Levenston's (1987) study. Here, US English learners of Hebrew overgeneralised the use of the L2 politeness marker bevaqaša "please" on requests in several ways. They inappropriately extended its pragmatic function, using it as an attention-getter (while native-speakers used slixa "sorry" for this purpose). They also overgeneralised the use of the request form bevaqaša + infinitive to situations where its pragmatic effect is inappropriate. This formula conveys a "formal, aggravated tone" (Blum-Kulka \& Levenston 1987: 164) and so has situationally restricted use; however, learners used it in a variety of request situations (e.g. as well as using it appropriately as a police officer asking a motorist to move an illegally parked car, they used it inappropriately as a student asking a classmate to lend them their lecture notes). 39

\subsubsection{Use of knowledge from instruction}

Another important process underlying learning and performance of $I L$ pragmatics is the use of pragmatic knowledge gained through formal instruction in the L2. Selinker (1972: 216 ) calls this process "transfer-of-training," and regards it as a central psychological process in the formation of IL knowledge. ${ }^{40}$ Formal instruction, too, can be usefully regarded as having either a positive or a negative role in learner pragmatics, depending on whether it results in native-like or nonnative- like pragmatic behaviour.

It appears that instruction may have a strong positive role in enabling L2 learners to ácquire and perform L2 pragmatics. Schmidt (1993) points out that teaching of pragmatic information can be an efficient means of helping learners to experience the crucial 'noticings' which are necessary for input to become part of IL knowledge, and, as Kasper and Shmidt (1996) state, "[T]here is every reason to suspect that pragmatic knowledge should be teachable" (Kasper \& Schmidt 1996: 160). The slim empirical evidence to date supports the claim that formal pragmatic instruction can produce more native-like pragmatic behaviour from learners (e.g. Olshtain \& Cohen (1990; cited in Cohen 1996: 261-262) on the learning of apologies; and House (1996) on the learning of various aspects of pragmatic performance). 
Kasper and Schmidt go further, arguing that instruction may even be necessary for successful learning of L2 pragmatics. They point out that

learners who are not instructed at all will have difficulty in acquiring appropriate language use patterns, especially in foreign language or classroom settings where opportunities for the full range of human interactions are limited (Kasper \& Schmidt 1996: 160).

As for the type of pragmatic instruction which is most beneficial, the few findings available are suggestive. House (1996), in a study of teaching conversation to advanced German learners, found that a combination of a rich input of pragmatic routines (on written handouts) and communicative practice was sufficient to improve pragmatic performance in both groups of learners studied. She also found that the group who in addition received explicit pragmatic instruction, in the form of metapragmatic information and opportunities for systematic reflection on their own performance in the light of this information, made superior gains in pragmatic performance. So House's (1996) study suggests that implicit pragmatic instruction and communicative practice together are beneficial, while activities which focus learners' attention closely on pragmatic input provide additional benefits. ${ }^{41}$ This finding seems borne out by research generally, Kasper and Schmidt concluding from examination of the few relevant empirical studies that "focusing on aspects of pragmatic knowledge through consciousness-raising activities and communicative practice seems highly facilitative" (Kasper and Schmidt 1996: 160). ${ }^{42}$

A negative influence of instruction in learning and performing L2 pragmatics has also been observed in the research. For example, House and Kasper (1987) attribute the inappropriate use of the formula "Would you be so kind as to...?" by German learners of English to the heavy emphasis given to this request form in the teaching they received at school. And most notably, in the Bochum project data, one third of learners' pragmatic errors are apparently influenced by the teaching they had received (Kasper 1982). Based on the Bochum data, Kasper (1982:102) suggests two ways in which instruction can result in learner-specific pragmatic features:

i) by 'primary teaching induction'. In this case, the learner is presented with deviant (i.e. wrong) input, and he or she forms $\mathrm{LL}$ - specific rules directly from this input. (An example of deviant input is this: learners might be explicitly told by their teacher or in their textbook that an older man is always addressed as "Sir". in 
English, or else they might be presented with textbook dialogues in which the term of address "Sir" is used with unnatural frequency).

ii) by 'secondary teaching induction'. In this case, the learner is presented with L2 input which is correct, but which is organised or practised in such a way that it causes the learner to form $\mathbb{I}$ specific rules. (An example is this: in a textbook the expression "thanks" might occur only in conversations between friends, while in service encounters the expression "thank you" is always used instead. Even though all this input is corrrect, as far as it goes, it might lead the learner to conclude wrongly that the expression "thanks" is not appropriate for use in service encounters).

\subsubsection{Relationship of processes}

An important fact must be emphasised about the role of the processes discussed above in ILP pragmatics. These processes are thought to operate together (either simultaneously or consecutively) to produce a given instance of IL pragmatic behaviour, so that ILP phenomena typically have a pluricausal explanation (cf. Kasper 1982). ${ }^{43}$ Thus, ILP researchers typically suggest that a certain psycholinguistic process may be one of the causes for a certain ILP feature, rather than the sole cause. Examples are these: Beebe and T. Takahashi (1989) claim a role for influence of formal instruction, transfer, and overgeneralisation in the overly harsh refusals of Japanese learners of English; Kasper (1982) claims that the influence of formal instruction interacts with processes such as transfer and generalisation to account in the pragmatic errors in the Bochum study, and S. Takahashi (1996) suggests a primary role of transfer and a secondary role for instruction (and possibly generalisation) in the acquisition of pragmatic knowledge about requesting by Japanese learners of English.

Claims for a pluricausal explanation for ILP based on observational data, such as those above, seem to be supported by the limited introspective data available as well. Robinson (1992) finds through retrospective interviews with Japanese learners of English that they sometimes produce a speech act using, for example, both L1 transfer and IL knowledge (Robinson 1992: 60-61), or IL knowledge gained from more than one source (Robinson 1992: 62-63). 
Another important point is that it is often difficult to identify which process or processes underlie a particular ILP feature. ${ }^{44}$ Kasper (1992) points out that positive transfer of pragmatic knowledge from the $\mathrm{L} 1$ is frequently hard to distinguish from the application of universal pragmatic knowledge (particularly as we often do not know if a certain item of pragmatic knowledge is universal or not). Additionally, as observed by Beebe, T. Takahashi and Uliss-Weltz (1990), the process of positive transfer from the $\mathrm{L} 1$ is hard to distinguish from successful acquisition without transfer; that is, from consultation of 'correct' $I L$ knowledge, without drawing on L1 knowledge at all. 45

It is also difficult to distinguish the process of negative transfer from the $\mathrm{L} 1$ from the process of overgeneralisation from IL knowledge.This is evident from the following example. Blum-Kulka (1983) finds that English-speaking learners of Hebrew make L2 requests using "could you?" questions, not only in situations where L2 native speakers use this strategy, but also in a situation where this strategy would not be used by NSs and in fact would not be interpreted as carrying requestive force (a wife asking a husband to attend a meeting in her place). BlumKulka (1983) offers this interpretation:

“...the process operating here is one of overgeneralization: the learner extends the use of ability questions (as requests) to contexts where native speakers prefer a different strategy" (Blum-Kulka 1983: 51).

However, it appears that the underlying process in the above example could just as well be $\mathrm{L} 1 \mathrm{transfer}$. Instead of proceeding on the basis of $\mathrm{IL}$ knowledge that ability questions can be used in Hebrew to make requests in certain contexts, and generalizing from that knowledge to other contexts (as Blum-Kulka (1983) assumes), the learners might instead proceed directly from L1 knowledge that ability questions can be used in the 'meeting' situation above, and transfer this knowledge to the L2.

Because of the complex interaction between the different processes underlying ILP behaviour, and the difficulties in identifying the relevant processes, explanations for ILP phenomena made from observable data are generally tentative. Nevertheless, the many ILP studies which have attempted to explain learner behaviour in terms of the processes at work have demonstrated that this approach can contribute a great deal to the understanding of learner pragmatics. 


\subsubsection{Development of pragmatic competence}

Bialystok (1993) offers a theoretical processing model of how learners acquire L2 pragmatic competence. Applying her earlier model of how L2 learners acquire language proficiency in general (cf. Bialystok 1991) to ILP specifically, she claims that the process of acquiring pragmatic competence entails two separate cognitive components: that of acquiring knowledge, in the form of an increasingly explicit understanding of L2 pragmatic features, and that of acquiring control over attention to this knowledge; that is, automaticity in use of this knowledge. The second of these components, Bialytok (1993) believes, is the crucial process for adult L2 learners. Generally speaking, they produce pragmatically inappropriate L2 utterances not because of deviant pragmatic knowledge but because they are unable to draw on their pragmatic knowledge when they need it; they cannot access it rapidly enough to produce appropriate utterances in real time. This contention of Bialystok (1993) that control over knowledge is the key component that L2 learners need to acquire for pragmatic competence will be evaluated in the light of findings from this study.

Empirical studies with a developmental focus, investigating acquisition of pragmatic competence by learners over time, are few in number. Findings so far (notably Schmidt 1983 and Ellis 1992) suggest that learners start to perform L2 speech acts by means of a few formulaic routines (for instance, they may perform English requests only with the formulaic phrase "Can I have...?" and with imperatives). As their pragmatic ability develops, learners begin to modify these initial routines (for example, they may sometimes use "Could I...?" as a variant of their initial formula "Can I...?"), and also begin to increase their range of strategy types (for example, they may start to use the form "I want/ I'd like...." as well). Sawyer (1992), studying development of acquisition of the modal particle $n e$ by learners of Japanese, made similar findings: learners begin by using this modal particle in formulaic expressions only, in fixed, chunk-like phrases, and then gradually come to use it in more productively, in a greater range of contexts.

Claims about developmental stages in L2 pragmatic competence are conservative in scope. As Kasper and Schmidt (1996:159) state, it appears unlikely that a fixed order of acquisition of different pragmatic features will be discovered, founded on some notion of 'pragmatic complexity', comparable to claims made for acquisition of morphosyntax. However, it seems that the development of pragmatic 
competence may be closely tied to development of grammatical competence. To what extent the former depends on the latter is not yet clear (cf. Bardovi-Harlig \& Hartford 1996: 184). Trosborg (1995) suggests that the extent may be considerable, ${ }^{46}$ by invoking the 'complexification hypothesis' (cf. Clahsen 1984). This hypothesis claims that there is a stable order of development in the acquisition of structures, and that they are acquired in order of increasing complexity, the complexity of a structure depending on the cognitive difficulty the learner has in processing it. Trosberg states that "[I]t is only reasonable to expect that the same phenomenon plays a role in the acquisition of pragmatic functions" (Trosborg 1995: 428). By this, she implies that the processing constraints on acquisition of formal structures will logically apply to structures used to convey social meanings as well; that is, to conventions of form for carrying out speech acts, or "pragmatic structures" (Trosborg 1995: 429); and that this will affect the order in which pragmatic features are acquired.

Given the likely importance of structural complexity in determining whether a pragmalinguistic form can be acquired readily by learners, 47 it is tempting to explain learners' use or non-use of a given pragmatic feature by appealing to its 'complexity'. However, while these explanations can be valuable, it should be remembered that claims in SLA research about the processing complexity of various morpho-syntactic structures are based on precise identification of the formal operations; that is, the kinds of "reorderings and restructurings... of underlying linguistic units" (Clahsen 1984: 221) entailed in using those structures- and that the results of this approach may not always consistent with casual intuitions about complexity based on observation only (e.g. it may not be immediately obvious that the use of the English third person singular 's' morpheme, as in "He eats too much" involves a high level of processing complexity48). Therefore, ILP explanations based on notions of formal complexity should be made tentatively, until they can be formulated with comparable rigour to the claims in SLA morphosyntactic research.

No attempt appears to have been made to bring acquisition of various items of sociopragmatic knowledge within the concept of a developmental sequence. This is not surprising: there is no reason to expect, for example, that learners would learn to assess the value of certain contextual factors before others (such as power before social distance, or context-external factors before context-internal factors) in performing L2 speech acts, on the basis of developmental principles operating across cultures and languages. 
Neither has much attention been paid to the question of whether pragmalinguistic or sociopragmatic competence is acquired first. It seems likely that the two components would develop in tandem to some extent, but their relative order of acquisition is little discussed. The exception is Blum-Kulka's (1991) study of learners of Hebrew, in which she suggests that sociopragmatic competence may be acquired after pragmalinguistic competence, by postulating a late stage of development of pragmatic competence at which learner's speech act performance may have become acceptable pragmalinguistically, but will still be unacceptable from a "socio-cultural" standpoint (Blum-Kulka 1991: 270). The validity of this claim is hard to assess. It is based on Blum-Kulka's attribution of a number of ILspecific features in her data (such as use of very direct request strategies in certain situations) to deviant sociopragmatic knowledge, when it seems these features could plausibly be attributed to deviant pragmalinguistic knowledge instead. ${ }^{49}$ Nevertheless, this is an interesting claim, which awaits empirical validation.

One more developmental issue should be mentioned; the question of ultimate attainment: how far towards native-speaker pragmatic competence can adult L2 learners go? It seems likely that $\mathrm{L} 2$ learners are unable to achieve native-speaker pragmatic competence. A persistent finding of ILP empirical studies is that even advanced proficiency learners show non-native pragmatic performance in many respects (e.g. Edmondson et al 1984; Eisenstein \& Bodman 1986; Faerch \& Kasper 1989; Blum-Kulka 1991; Trosborg 1995). 50 This finding appears to bear out the claim by Kasper that, possibly, "early and sustained contact with the target language culture is required in order to attain native pragmatic competence and skill..." (Kasper 1995a: 25). Evidence that familiarity with the L2 culture may be a vital requirement for highly native-like pragmatic competence is offered by the studies of Beebe and T. Takahashi (1989) and of S. Takahashi (1996), in which this factor, rather than linguistic proficiency, is found to correlate with native-like pragmatic knowledge and/ or performance by learners.

The relevant empirical findings and theoretical claims discussed above can be summarised as follows. In developing the ability to perform L2 speech acts, learners rely heavily on prefabricated 'chunks' in the early stages, and then extend their range and variety of pragmatic forms (Kasper \& Schmidt 1996: 163). This development may be closely linked to development of grammatical competence. 51 However, there is a limit to how far grammatical competence will enable learners to develop pragmatic competence (cf. Bardovi-Harlig \& Hartford 1996: 184), such 
that for highly native-like pragmatic performance, prolonged exposure to the target culture may be an essential ingredient. 


\subsection{Notes to Chapter 1}

1 Campbell and Wales (1970), like Hymes (1972a), observed early that knowledge of appropriacy as well as of grammar was crucial to language ability. An overview of how the notion of communicative competence developed is provided by Canale and Swain (1980: 1-26).

2 For a comprehensive introduction to communicative language teaching see especially Littlewood 1981, and also Brumfit and Johnson (1979); for a concise overview see Stern (1982: 258-263) and Brown (1987: 212-215).

3 For an introduction to communicative language testing, see Carroll (1980) and Morrow (1979); for a relatively recent overview of developments in the field of language testing, see Skehan (1989a, 1989b).

4 It is important to note that these two models (Canale and Swain 1980, Canale 1983; and Bachman 1990) apply to communication in writing as well as in speech, and to comprehension of language as well as production. However, for the sake of descriptive clarity these models are outlined above with reference to production of spoken language only.

5 While Canale \& Swain (1980) consider the proposal by Hymes (1972a) that the notion of 'competence' should refer not only to knowledge but also to ability to use it, they decide against extending their own notion of competence in this way.

6 Two other elements in Bachman's (1990) framework of CLA, not mentioned above for the sake of descriptive clarity, are "knowledge structures" ( knowledge of the world), and "context of situation" (e.g. the extent of shared knowledge existing between speaker and hearer, and the language resources (such as mother tongue or foreign language) available to the interlocutors).

7 Thomas (1983) makes this distinction in distinguishing between two types of pragmatic error, 'pragmalinguistic failure' and 'sociopragmatic failure'. In so doing, she acknowledges her debt to Leech (1983:10-11) for her use of the term 'sociopragmatic'.

8 For a brief summary of ILP research to date on comprehension by learners, see Kasper and Blum-Kulka (1993: 4-6).

9 Wierzbicka (1991: 197) offers a brief account of the evolution of the notion of a speech act before the work of Austin (1955/1976). 
10 Austin (1955/1976: 94-102) famously distinguishes between three types of acts: locutionary, illocutionary, and perlocutionary.

11 Leech (1983), incidentally, attacks this claim of Searle (1969) that all language is a matter of performing acts. He seizes on a remark of Searle that "of course, for most purposes, in the science of linguistics it is not necessary to speak of acts at all. One can just discuss morphemes, sentences, phonemes, etc" (Searle: 1969: 21), and points out that this is not the trivial admission that Searle seems to believe. Instead it points to a basic overstatement in speech act theory. It demonstrates that while "there are things that can be done with language, ... that does not mean that language is all a matter of doing" (Leech 1983: 21).

12 see Verschueren (1985: 6-11) for a summary of the main controversies in speech act theory.

13 Searle does, however, acknowledge briefly (Searle 1969: 70) that an utterance need not have a single illocutionary force.

14 Leech makes this point when criticising Searle's (1971/1990) taxonomy of speech acts. He points out that Searle's classification of speech acts (like that of Austin 1955/1976) is actually a classification of speech act verbs, and argues that this is inevitable; that the very endeavour of categorising speech acts is doomed, because of the indeterminacy of illocutionary forces (Leech 1983:174).

15 Wierzbicka (1991) describes the illocutionary force of speech acts by means of Natural Semantic Metalanguage, a system of postulated universal semantic primitives.

16 This very useful classification of theories into a 'conversational-maxim view' and a 'facesaving view' is adopted from Fraser 1990 (who also discusses two other perspectives on politeness: a 'social-norm view' and a 'conversational-contract view').

17 In fact, as Brown and Levinson point out, their framework also rests on another notion of Grice, his idea that communication is "a special kind of intention to be recognised by the recipient...." (Brown \& Levinson 1987: 7; emphasis added). This means it can be assumed "that what agents do is related systematically to their intents, and thus that intentions of actors are reconstructable by observers or recipients of actions" (Brown \& Levinson 1987: 7).

18 Blum-Kulka (1989) acknowledges her debt to Clark (1979) for this distinction between conventions of means and conventions of form. 
19 In fact, all Brown and Levinson's negative politeness strategies could arguably be subsumed under this single strategy of 'giving deference'. This is suggested by the fact that as one realisation of the strategy of 'giving deference', Brown and Levinson $(1978,1987)$ propose: communicating a wish not to impinge on $\mathrm{H}$. However, it would seem that the essence of all negative politeness strategies - from the very terms in which Brown and Levinson $(1978,1987)$ conceive of 'negative politeness' and 'negative face' - is the communication of a wish not to impinge on $\mathrm{H}$.

20 Fraser (1990), in describing Brown and Levinson's (1978, 1987) model, remarks that he will not address the question of "whether Distance and Power are truly independent" (Fraser 1990: 230ff). Trosborg (1995), in constructing her study of speech act performance, omits the role constellation of "+ Power" and "- Distance", because she suspects that the presence of a power differential between the interlocutors will automatically create social distance as well.

21 The fact that a superior's time and/ or attention is assessed as intrinsically valuable by participants suggests that off-record strategies such as hints may not be highly polite after all, especially to hearers with high power. This is because off-record strategies demand time from $\mathrm{H}$ to calculate the illocutionary force, and so may increase the size of the imposition and hence, the weightiness of the FTA.

22 This distinction made in empirical studies between context-external and context-internal factors is adapted from Brown \& Fraser's (1979) distinction between internal and external context of speech.

23 This fact that the value of the variable $P$ (power) is determined to some extent by contextinternal factors is acknowledged by Brown and Levinson in their $(1978,1987)$ model.

24 The difficulty of operationalising P, D and Rx is compounded by some inconsistency in the literature about whether rights and obligations are best regarded as part of imposition or not. Kasper (1989: 50) refers to "context-external factors pertaining to the request situation such as the interlocutors'......rights and obligations, and context-internal factors relating to the degree of imposition associated with the request goal [etc] ...". This would appear to place rights and obligations outside the notion of imposition — in contrast to Blum-Kulka \& House (1989) and S. Takahashi (1996) above; and also in apparent contrast to Blum-Kulka (1991: 259).

25 At another point Brown and Levinson $(1978,1987)$ hedge a little on this question, stating that indirect speech acts "for the most part are probably constructed in essentially similar ways in all languages" (1978: 147, emphasis added). 
26 For further support of the view that indirect speech acts are not universal see Sadock (1974) and Green (1975); see also Wierzbicka $(1985,1991)$ for a particularly vigorous rejection of claims for universality, both of strategies for performing speech acts and for types of speech acts themselves.

27 for other criticisms of the applicability of Brown and Levinson's $(1978,1987)$ notion of 'face' to non-Western cultures, see Gu (1990), Nwoye (1992), and Mao (1994).

28 Actually, Kasper and Blum-Kulka (1993: 3) suggest that restricting notions of LP to nonnative speakers or language learners may be too narrow. They believe that research into the "intercultural style of speaking" which may be developed by bilingual speakers, and used regardless of which language they are speaking (cf. Blum-Kulka \& Scheffer's (1993) study of the intercultural style of American-Israeli families), can also legitimately be regarded as a domain of ILP.

29 For a summary of the domains of interlanguage pragmatics and the research on each domain, see Kasper and Blum-Kulka (1993: 4-13).

30 See Kasper (1995a: 24-27) for a summary of problems associated with positing a native speaker norm for learner pragmatics.

31 For example, Bongaerts et al $(1987: 191,194)$ found Dutch learners of English to use more words than English native speakers to describe non-conventional shapes to an interlocutor, in a matching task.

32 cf. the finding of Cohen et al (1986) that advanced learners of English do not use "expressive" devices (interjections and curses) in their apologies.

33 It is interesting to note, however, that learners in the Bochum project generally appeared to cope worse in initiating than in responding roles (Edmondson et al 1984: 122). This is because they were forced by cue instructions to perform initiating acts in discourse opening phases of roleplays, even though they lacked the necessary linguistic resources for these acts. When they were able to leave the performance of initiating moves to NSs and restrict themselves to responding (as they were in the closing phases of discourse), they had a much lower rate of pragmatic errors. 
34 While the term 'cross-linguistic influence' rather than 'transfer' might thus be theoretically more accurate, Kasper (1992) follows Odlin (1989; cf. also Sharwood-Smith 1994) in asserting that the term 'transfer' is already too well-established in the literature to be replaced with another term; and in the present study, too, the term 'transfer' is used for the sake of consistency with previous research.

35 cf. Kasper (1992) on the difficulty of distinguishing pragmalinguistic from sociopragmatic transfer.

36 for a summary of the evidence for a positive and for a negative correlation of pragmatic transfer with linguistic proficiency, see S. Takahashi 1996.

$37 \mathrm{cf}$. Schmidt's (1993) claim that 'noticing' input is of crucial importance for acquiring pragmatic knowledge.

38 However, as Edmondson et al (1984) give no examples of generalisation by learners, it is difficult to assess the validity of this claim.

${ }^{39}$ For further instances of pragmatic overgeneralisation, see Blum-Kulka (1983) and Beebe and T. Takahashi (1989).

40 Alternatively, instruction can be regarded as an environmental factor (the "learning environment"), which interacts with psycholinguistic processes such as transfer and generalisation (cf. Kasper 1982: 101).

41 At the same time, this study of House (1996) (as the author herself points out) indicates the limitations of classroom instruction in pragmatics, her findings suggesting that learners need heavy exposure to a wide range of conversational contexts in order to acquire the skill in conversational management required for native-like pragmatic performance.

42 Bardovi-Harlig et al (1991), similarly, emphasise the value of both consciousness-raising activities (such as reflection on and discussion of L1 speech act behaviour) and active communicative practice (such as role play) in the teaching of L2 pragmatics. Crozet (1996) stresses the potential effectiveness of a rich input of pragmatic information combined with active communicative practice; and Crozet and Liddicoat (1997) argue for the importance of pragmatic metaknowledge by learners. 
43 This feature is not peculiar to pragmatic interlanguage: cf. Selinker (1972), who acknowledges the likelihood of the "central processes" in interlanguage operating consecutively or simultaneously, and Sharwood Smith (1994), who observes that learners tend to draw on diverse sources simultaneously in their linguistic performance in general.

44 cf. Selinker (1972: 221) on the difficulty of identifying the central processes at work in interlanguage; see also Sharwood Smith (1994: 38-40) for discussion of this problem.

45 See Rintell (1981:16-17) for an example of this difficulty.

46 cf. Koike (1989: 286), who also proposes a major role for grammatical competence in the development of $L 2$ pragmatics.

47 Bardovi-Harlig and Hartford (1996) point out that limited grammatical competence can impede learners' pragmatic development not only by limiting their capacity to produce linguistic action, but also by limiting the value of pragmatic input, by preventing learners from noticing certain pragmatic features which are grammatically too complex.

48 This claim is made by Pienemann and Johnston 1987; cited in Larsen-Freeman and Long (1991: 276).

49 Kasper's (1992) remarks on the fuzzy distinction between sociopragmatics and pragmalinguistics are enlightening in this regard.

50 But see Cohen, Olshtain and Rosenstein (1986) for near-native apology performance by advanced learners.

51 An interesting exception to the tendency to link claims for pragmatic development exclusively to grammatical development is Scarcella's (1983) study. She hypothesises a sequence for the acquisition of L2 conversational management devices which seems to be founded on criteria other than (or additional to) grammatical complexity (greetings and closings are acquired before introductions, which are in turn acquired before pre-closings and requests for clarification), and finds confirmation of this sequence in her data. However, Scarcella does not suggest what the criteria for this sequence might be. 


\section{CHAPTER 2. METHODOLOGY}

\subsection{The subjects}

\subsubsection{Learner subjects}

The group of learner subjects selected for this study consists of 20 undergraduate students, undertaking a degree program in Bahasa Indonesia at the Australian National University. Thirteen of the twenty subjects were female, and seven were male. All except one were in the 18-24 age group (the remaining subject was approximately 35 years old).

Most of the subjects (13/20) were in 3rd year of the degree program, while the rest $(7 / 20)$ were in 2 nd year. Most of them $(11 / 20)$ had previously studied Indonesian at high school, for periods ranging from two years to four years. While no test of language proficiency was undertaken on the subjects, based on their performance in data elicitation sessions and on the informal assessment of their two classroom teachers, their oral proficiency can be characterised as intermediate, with considerable range in proficiency from lower to upper intermediate.

All of the learner subjects except two had visited Indonesia, several on more than one occasion, to travel or undertake a short (one-month) language course; however, no subjects had spent more than two months in Indonesia on any one occasion. The median time subjects had spent in Indonesia was one month. Therefore, it can be assumed that their Indonesian has largely been learned through formal instruction, at university and, in the case of some subjects, at high school previously.

It was decided to select all learner subjects from a university population as this permits a group of subjects which is fairly uniform in social variables such as level of education, socio-economic status, and age. As far as possible an equal number of males and female subjects were used; however, because a large majority of the students studying Indonesian was female, the proportion of genders in the sample group reflects this bias to some extent.

While this study is not developmental in focus, it was thought useful nevertheless to compare the performance of requests by learners at different levels of proficiency, to see whether learners improve with increased proficiency with respect to certain request features. This group of learner subjects includes a number 
whose spoken performance (as evidenced in data elicitation sessions) made them highly conspicuous for either low or high linguistic ability, and these learners were selected to be compared throughout the study with respect to various request features.

\subsubsection{Low group of learners}

Three of the second year subjects, two male and one female, stood out very clearly as possessing low linguistic proficiency. These three can be assessed as at barely low intermediate proficiency, and were close to the threshold level of competence for participation in oral roleplays of the kind in this study, being barely proficient enough to participate. The interlanguage of these three subjects was characterised by consistently halting and hesitant delivery, long pauses when 'stuck' for essential vocabulary, frequent serious errors in morpho-syntax, frequent serious lexical errors, and poor listening comprehension. These three learners will be referred to as the Low group in subsequent discussion: and the individual members as Low-1 (female), Low-2 (male), and Low-3 (male).

\subsubsection{High group of learners}

Two of the third year learners, both female, were clearly conspicuous for their relatively high linguistic proficiency. They can be assessed as clearly upperintermediate in oral proficiency. Their interlanguage was characterised by consistently fluent and smooth delivery compared to other learner subjects, wide range of sentence patterns and of lexis, scarcity of serious lexico-grammatical errors, and apparent lack of difficulty with comprehension. These two learners will be referred to as the High group; and the two individuals, as High-1 and High-2 respectively. The remaining 15 learners in the study, not selected as Low or High, when referred to, will be called the Middle group.

\subsubsection{Indonesian native speaker subjects}

The Bahasa Indonesia native speaking subjects (henceforth BI NSs) consisted of 18 students, 14 postgraduate and four undergraduate, studying degree programs in a range of disciplines, at the same university as the learner subjects. Half of the subjects were male and half were female. Most (14/18) were aged from 25-35; the 
others were somewhat younger (18-24). ${ }^{1}$ None of the subjects had been in Australia for a period longer than three years.

The BI NS subjects were from various regions in Indonesia. ${ }^{2}$ Most (12/18) were from the main island of Java and had always lived in one part of Java or another (Jakarta, Western Java, or Central Java); most others (4/18) had spent a large part of their life (either their childhood or adulthood) in Java and the rest of it elsewhere in Indonesia (Sumatra or Kalimantan).

The decision not to include native speakers of Australian English as a third group of subjects was made after careful consideration. As Selinker (1972) points out, three sets of data are relevant to understanding the psycholinguistic processes which underlie interlanguage behaviour: data from the learners' native language, from the learners' interlanguage, and from the target language. As part of this study, only the latter two types of data are gathered. However, the first type of data, in this case on requests by native English speakers, is available in large quantities from previous empirical studies; including a considerable amount on requests in Australian English specifically. These data provide an adequate basis on which to draw conclusions about the likely influence of the learners' first language (in the form of processes such as transfer) on various features of the learners' requests in the present study. ${ }^{3}$

\subsection{Choice of speech act to be investigated}

It was decided to investigate subjects' pragmatic competence through their performance of one speech act: the request. This speech act was chosen for several reasons. Firstly, it is a very common speech act in everyday interaction, which makes it important for learners to know how to perform it appropriately. Secondly, it is both a complex speech act, as it can be performed by a variety of strategies, each of which conveys its own pragmatic force (cf. Fraser, Rintell \& Walters 1980: 80), and a 'sensitive' speech act, as it threatens the hearer's face (cf. Brown \& Levinson 1978, 1987); so performing this speech act provides ample opportunity for subjects to demonstrate the extent of their pragmatic competence. Lastly, the request is commonly chosen as the focus of empirical studies into pragmatics (see 1.6.2.2), which means that a well-developed analytical framework exists within which the data can be described, and that many relevant findings from other studies are available for comparison with those of the present study. 


\subsection{Method of data elicitation}

The data were collected by means of interactive oral roleplay, which is a method frequently employed in empirical studies of pragmatics (cf. Kasper and Dahl 1991; Aston 1995). The decision to use oral roleplay data can most clearly be explained by briefly discussing other methods of data collection first.

As Labov (1972) observes, the ideal target of linguistic investigation is language produced by speakers during normal conversation when they are not being observed (and the problem that conversational data can only be obtained by systematic observation constitutes the 'observer's paradox'). Given the impossibility of obtaining these ideal data, the obvious next choice, as Blum-Kulka et al (1989: 13) note, would appear to be data recorded by observers as it occurs during natural interaction. However, the use of this kind of natural data was ruled to be impractical for the present study. The objectives of this study make it important to obtain multiple instances of the same speech act being performed in the same context, to enable valid comparisons between groups of subjects; and this is not feasible in natural interaction. As Fraser, Rintell and Walters (1980: 81) put it, in natural discourse

the likelihood is very, very small that any practicable number of observations will provide enough examples of the same speech act with the contextual variables sufficiently controlled to permit satisfactory speculation on their significance. ${ }^{4}$

In the case of learner subjects, the difficulties in obtaining satisfactory natural data are compounded. Trosborg points out that a reliance on authentic data from learners "is hardly possible, as foreign language learners seldom have the opportunity of operating in a real L2 environment" (Trosborg 1995: 141).

A very common method of eliciting speech act performance in empirical studies, most notably used in the CCSARP project (see 1.6.2.2), is the use of discourse completion tasks (DCTs), in which the subject writes an utterance in a space provided in response to a written cue (cf. Kasper and Dahl 1991; Aston 1995). The written DCT method has certain practical advantages: it allows contextual variables to be well- controlled and at the same time enables data to be elicited from a large number of subjects in a short time (cf. Rintell \& Mitchell 1989; Wolfson et al $1989)^{5}$. However, the DCT method was considered inappropriate for the present study. The main reason was that, as frequently been pointed out (e.g. Rose 1994; 
Aston 1995), the absence of an interlocutor makes the production of speech acts in DCTs highly unlike that of real conversation. As Aston (1995: 63) argues, the fact that utterances are

joint productions, of which the form, placement and sequential implications are negotiated by participants, whose verbal and non-verbal reactions (or their absence) combine to shape the utterance as it is progressively produced...

makes it impossible for discourse completion tasks to capture crucial discourse features of authentic speech acts.

Furthermore, Rose (1994) suggests that DCTs may be particularly inappropriate for use with subjects from non-Western cultures. Rose (1994) claims that while Western cultures tend to use 'speaker-based' speech act strategies, where the onus is on the speaker to convey the meaning clearly, some non-Western cultures including Asian ones (notably Japanese) may prefer 'hearer-based' strategies, where the hearer has the active role of intuiting the speaker's meaning. This means that in DCTs, where there is no interlocutor, subjects from hearer-based cultures may not be able to select their preferred speech act strategies (for example, they may not be able to make requests by means of hints, as there is no addressee to intuit their meaning). For this reason, too, in this study of speech act performance in Indonesian it was considered prudent not to elicit speech acts by means of a DCT. 6

Interactive role play, the elicitation method chosen in the present study, has a number of advantages. Like the DCT, it enables multiple instances of the same speech act to be gathered with the situational and social context effectively controlled, which allows valid comparisons between groups (cf. Fraser, Rintell \& Walters 1980). At the same time, it preserves important features of natural discourse. It allows speech acts to be produced within complete interactions, which have an opening and a closing phase (cf. Scarcella \& Brunak 1981: 60), and within which the construction of speech acts may be jointly negotiated by the interlocutors. This is likely to make speech acts elicited in roleplays more representative of natural discourse than the "decontextualised written segments" (Wolfson et al 1989: 182) elicited by discourse completion tasks. Moreover, there is some empirical evidence that oral roleplay may be able to reveal selection preferences in speech act strategies which go untapped by DCTs. Zhang finds that while Chinese learners of English in DCTs make relatively direct requests (Zhang 
1995a), in oral role plays they use less direct requesting strategies (Zhang 1995b), managing to elicit offers from the interlocutor by means of hints instead.

The validity of oral role play data can be enhanced if - as in the present study - a method of 'role enactment' rather than 'role play' is used. ${ }^{7}$ In role enactment, subjects are required to be themselves in various situations, rather than being required to pretend that they are other people. This enables subjects to identify as closely as possible with their roles, and thus is likely to produce more natural conversational behaviour (cf. Kasper \& Dahl 1991: 245; Aston 1995: 64). As Trosborg suggests, "if the subjects can identify with their roles and otherwise accept the roles they have been given, the outcome comes as near as possible to naturally occuring speech" (Trosborg 1995: 144). Rintell and Mitchell (1989: 251), similarly, claim that role plays where the subjects play themselves are thought to be a good indication of subjects' natural way of speaking.

Still, as a method of data collection, the role play method is obviously not ideal. A key limitation is the fact that even if role enactment is used, role plays are artificial. Subjects are interacting not because they have a genuine communicative purpose but because they are told to. And, as Edmondson (1981) acknowledges in relation to his own choice of the role play method, "what one does when asked to behave in a certain way may be different from what one would in fact do if actually in a certain situation" (Edmondson 1981: 79, original emphasis). So, while the blend of naturalness and control offered by oral role play make it the best method for present objectives, it should be borne in mind that the findings it produces may differ from those of natural data. 8

One last point about choice of method is worth noting. It has been convincingly argued (e.g. by Olshtain and Blum-Kulka 1985; Wolfson 1986; Wolfson et al 1989) that the ideal method of carrying out pragmatic research is with a combination of natural and elicited data. Wolfson (1986: 697) recommends an iterative process, in which ethnographic data provides the insights required to design more sensitive elicitation instruments, and the data from these elicitation instruments in turn provides the impetus for more focused and systematic ethnographic research, which is used to design better elicitation instruments still, and so on. To some extent, this insight about the potential of natural data to inform the process of data elicitation has been applied in designing the present study. During two separate one-month trips to Indonesia in the year prior to data collection (1993), one spent travelling throughout Java and one spent studying in Central Java; this researcher noted situations in which requests were made in everyday 
interaction (both situations in which the researcher was a participant and ones in which he was an observer), and the resulting list of situations was used as an initial basis for selection of the roleplay situations included in this study (outlined in the following section).

\subsection{The roleplay situations}

Request situations were selected on the primary criterion of frequency and usefulness for learners of the type investigated in the study ${ }^{9}$; namely, Australian university students of Indonesian. The most common purposes of this group for going to Indonesia (as confirmed through social conversations and informal interviews with many students and with teachers of Indonesian at two Australian universities) are to travel, or to study, or both. Therefore, situations were selected which had relevance to everyday life as a student or a traveller in Indonesia.

The social variables most commonly thought to influence linguistic choices in request performance; namely, relative power, size of social distance, and size of imposition (cf. Brown \& Levinson 1978, 1987) were applied as a secondary criterion. Thus, in selecting roleplay situations from among the authentic situations noted during the two field trips mentioned above, care was taken to include situations which represented a variety of permutations of these variables, as far as was feasible; and in order to permit somewhat wider and more systematic variation of these factors, several situations not observed during field trips were added to the list. These extra situations were devised in consultation with native speaker informants, who judged whether the request situation was a frequently occuring one in Indonesia.

The final list of role play situations comprised twenty seven request situations. Two of the situations involved two requests ${ }^{10}$. The total number of requests thus elicited from subjects was approximately 290 requests by learners and approximately 260 requests by $B I$ native speakers (for a complete list of role play situations see Appendix A). 


\subsection{Assessment of the role play situations according to social variables}

In order to investigate contextual variation in use of various request features, each role play situation was analysed for the value of certain social variables. The variables assessed were i) status of the requester relative to the addressee, ii) size of imposition involved in the request, and iii) how comfortable the requester feels making the request.

The variable of status was chosen for examination as it is a manifestation of power, which is considered a major factor in linguistic politeness (see 1.4.2). The relevance of power (or 'dominance') for linguistic politeness is confirmed by the CCSARP project, where this factor was found to be important in influencing a request's level of indirectness (Blum-Kulka \& House 1989: 144-45). As Goody (1978: 11) observes, while power is the more general factor, status tends to be the obvious cue to power which is presented in interaction. Therefore values of status are likely to be more transparent than values of power and hence more validly assessable by informants. In addition, the element of status is generally thought to be of great importance for social interaction in Indonesia specifically (cf.Geertz 1976; Draine \& Hall 1990; Mulder 1989; Reeve 1995; Quinn 1996b), which makes this factor a likely candidate to help determine linguistic choices in speech acts in Bahasa Indonesia.

The size of imposition on the hearer was selected as a variable to be assessed as this factor, too, is thought to have a major influence on linguistic politeness (see 1.4.2). Some empirical evidence exists for this; for example, in the CCSARP project, two components of imposition, namely the speaker's right to demand compliance and the hearer's obligation to comply, were found to correlate with level of directness of request strategy across cultures (Blum-Kulka \& House 1989: 144- 145).

The factor of social distance between interlocutors is also likely to be important (see 1.4.2), however, it was not deemed necessary to have the values of this variable in each situation systematically assessed by informants, as values of social distance (unlike those of status and imposition) tend to be transparent (for example, social distance can be assumed to be large in situations when the interlocutor is a stranger, small when the interlocutor is a classmate, and very small when the interlocutor is a friend). 
The factor of how comfortable the speaker feels making the request was assessed because this factor seems intuitively likely to provide a useful overall indication of a speaker's perception of the size of threat to face. Therefore, if the factors of status, imposition, and social distance do not in fact adequately capture subjects' perceptions of threat to face in a given situation, the comfort of the speaker in making the request may serve to indicate that perceptions of threat to face in that situation are lower or higher than suggested by the other factors above.

The values of the three variables above in the roleplay situations were assessed as follows. Fifteen BI native speakers of Indonesian and twenty Australian learners of Indonesian (gathered from the same university population as the role play subjects) were given a questionnaire, in which they asked to read a description of all the request situations in the present study. For each situation, they awarded a value from 1 to 5 for each of the three variables of status, imposition, and speaker's comfort (see Appendix F for the elicitation instrument). Mean values were then calculated, which were used as a basis to attribute a raw score for the value of each variable in each situation. For example, a raw score of 3.47 for speaker's status signifies that in that situation, on a five-point scale, with lowest possible value of 1.00 and highest of 5.00; respondents awarded a mean value of 3.47 for speaker's status relative to that of the hearer. On the basis of these raw scores, situations were also ranked for each variable. For example, a ranking of $=6$ for speaker's status signifies that in this situation, the mean value awarded for speaker's status is equal 6th highest of the 26 situations assessed (see Appendix $C$ for a tabular summary of mean values and rankings of each situation).

\subsection{Judgments of appropriacy and pragmatic effect}

The appropriacy and/ or the pragmatic effect of strategy choices and modification choices by learners and BI NS subjects in this study were determined through a process of discussion with BI native speaker informants. In any instance in the data when a subject's choice of strategy or modification was of questionable appropriacy, or the pragmatic effect of the choice was not entirely clear, at least two $\mathrm{BI}$ native speaker informants were shown a written version of the relevant extract of the data (with precise specification of the situation in which it occured), and were asked non-directively to comment on it. If necessary, the informants were then asked further questions which directed their attention specifically to the appropriacy 
or pragmatic effect of the feature in question, in order to obtain the relevant judgements.

\subsection{Procedure for conducting role play sessions}

Role play sessions were conducted in groups of four, consisting of two subjects and two BI native-speaking partners. Each role play subject interacted with two BI native speaker partners, performing half his or her role plays with one partner and half with the other. This was to help minimise the influence of the dynamics between a subject and a particular interlocutor on the subject's speech act performance. In addition, all data elicitation sessions were organised in such a way that one of the role play partners was male and the other was female, to help minimise unintended effects of the gender of the interlocutor.

It was established in two trial data elicitation sessions that it was impractical to require each subject to perform every request situation, as it would have made the elicitation session extremely long. Therefore each subject performed half the request situations (14 or 15). Each subject also performed a number of non- request situations (4 or 5). These 'distractor situations' (cf. Olshtain \& Cohen 1983: 31) were to help conceal from subjects the fact that the focus of the study was the speech act of requesting, and hence, to help elicit more natural requesting behaviour (see Appendix A for a list of the non-request situations).

All role plays were performed in the researcher's office. Furniture was rearranged between role plays to help simulate the setting of each situation, and props were provided when appropriate. These measures were taken to make the role play situation resemble the real life parallel situation more closely, so that participants would be likely to interact in a more natural way.

Subjects and partners were instructed to imagine that they were in Indonesia for all situations. They performed their role in each situation on the basis of a written cue (see Appendices D and E for cues to all situations). The cues were worded in such a way that subjects were not explicitly told to make a request; instead, the need to make a request was evident from the description of the situation. Written cues for all Indonesian participants (BI NS subjects and role play partners) were in Bahasa Indonesia. The written cues for Australian learner subjects were written in English, with an Indonesian version underneath. 
The role play participants were given as much time as they wanted to read the written cue for the relevant situation before each role play began. All role plays were audio-recorded. ${ }^{11}$ After all role play sessions had been conducted, the data were transcribed by the researcher.

\subsection{Method of data analysis}

Lastly, the method of data analysis used in the present study should be commented upon. This study involves relatively fine analysis of a small number of tokens of requests by learners and $\mathrm{L} 2$ native speakers in each situation, including analysis of interactional features involving conversational management. This kind of close contrastive analysis yields rich data which can be highly suggestive of a great many pragmatic features and processes, and so is particularly valuable as a basis for hypothesis generation, and can also help to confirm or to challenge a variety of findings from other studies. However, as House (1996: 235) points out, data of this kind cannot readily be subjected to rigorous methods of quantitative analysis involving statistical comparisons. And in the present study, while quantitative comparisons between aspects of the data from the two groups are made when practical, statistical comparisons are deemed to be of very limited value and so are not undertaken. 


\subsection{Notes to Chapter 2}

1 The slightly older age of the BI NS group reflects the fact that a great many of the Indonesians studying in Australia are there for postgraduate rather than undergraduate study.

2 Most of the BI NS subjects were bilingual in Bahasa Indonesia and a regional language (cf. Introduction), the most common regional language being Javanese or Sundanese; others spoke Bahasa Indonesia only. The possibility of selecting BI NS subjects from one region only, to minimise the likely influence of variation in regional language and culture on their Bahasa Indonesia, was considered. However, it is difficult in practical terms to find a sample of Indonesian speakers with a culturally uniform background, and this difficulty reflects the artificiality of doing so; including speakers of diverse linguistic and cultural backgrounds more accurately reflects the realities of use of Bahasa Indonesia as the unifying national language of diverse cultures.

${ }^{3}$ It should be acknowledged that these data on requesting in English from previous studies do not constitute an ideal data set, as they are not obtained under the same experimental conditions as the other two sets (cf. Selinker 1972: 214). Also, using data by native speakers of varieties of English other than Australian as a basis for conclusions about the likely role of the $\mathrm{L} 1$ in this study is potentially problematic, as there is some evidence (Michaelis 1992; cited in Kasper 1992: 224) that native speakers of different varieties of English may show differences in their pattern of selection of request strategies. However, any possible decrease in validity of comparisons in the present study due to lack of precisely parallel native English data is outweighed by the fact that the use of existing L1 English data allowed a great deal more data on requests by both BI native speakers and learners of Indonesian - for which no published data are available - to be collected and analysed.

4 Natural data have been used in relatively few studies of pragmatic production (cf.Kasper \& Dahl 1991; Rose 1994). For an account of problems with using natural data for pragmatic research see Rintell and Mitchell (1989: 250) and Beebe and T. Takahashi (1989: 120).

5 For advantages of the DCT method, see Wolfson et al (1989: 183-184), and Hill et al (1986: $353)$.

6 For disadvantages of the DCT method, see Rintell and Mitchell (1989), Trosborg (1995: 14243), and Hinkel (1997). 
7 This distinction between role enactment on the one hand and role play on the other is made by McDonough (1981: 80-81).

8 Some empirical evidence suggests that there may in fact be important differences between the way speech acts are performed in role plays and in natural speech. Dahl (undated; cited by Kasper \& Dahl 1991: 243-244) found that role plays elicited shorter realisations of speech acts, which were performed over fewer turns, and used more direct strategies, than authentic discourse. These aspects of speech act length and directness of strategy are important for conveying politeness, so if the findings of Dahl's study are applicable to role play data generally (which Dahl expresses some doubt about), then this is a significant limitation of the role play method for investigating pragmatic performance (for criticisms of the role play method of data elicitation, see Aston 1993: 229, 1995: 63-64).

${ }^{9}$ Using frequency and usefulness in everyday life as the primary criterion for selecting request situations means that none entail a very large imposition upon the hearer, so that none are highly threatening to the hearer's face. While requiring subjects to perform highly face-threatening requests does have certain advantages (e.g. that such situations are likely to reveal learners' pragmatic difficulties very starkly), it also has potential disadvantages. One is that it requires subjects to perform requests which in real life they would very likely choose not to perform at all (which seems likely with certain requests in Trosborg's (1995) study: see e.g. Trosborg 1995: 231), and House's (1996) study: see e.g. House 1996: 231). This means that subjects may have to distance themselves considerably from the role in order to carry out the request. Another disadvantage in the case of subjects of relatively low proficiency - such as those in the present study - is that these subjects are likely to find performing role plays with a native speaker partner very difficult, so that making them perform requests which they would feel uncomfortable about making even in their first language would probably make the experience of data elicitation a highly unpleasant one for them.

10 With hindsight, it may have been more consistent with the approach taken elsewhere in this study to analyse only the first request in each of these two pairs as a request proper, and to analyse the second as a 'follow-up' request (see 4.1.9) instead, for the reason that the request speech event is already in progress when the second request is made.

11 Ideally, role plays would have been video- as well as audio-recorded, to allow a more complete representation of the way that participants interacted. However, the logistical problems presented by video-recording were considerable. 


\section{CHAPTER 3. REQUESTS: AN INTRODUCTION}

This chapter provides a background to the following chapters, in which the request data are described and discussed. Firstly the notion of a 'request' is clarified, and the descriptive framework used to analyse the request data in this study is outlined. Then the various request strategies used by subjects in this study are briefly introduced, and decisions regarding their classification are explained.

\subsection{The speech act of requesting}

While Austin in his early taxonomy of speech acts does not mention the act of requesting explicitly; it clearly falls into his proposed category of "Exercitive" speech acts; that is, speech acts which entail "the exercising of powers or influence" (Austin 1955/1976: 151). Similarly, Searle classifies requesting as a Directive speech act; that is, one whose illocutionary purpose is to get the Hearer to do something (Searle 1971/1990: 359). Searle describes a request as follows: an act which counts as an attempt to get $\mathrm{H}$ to do an act which $\mathrm{S}$ wants $\mathrm{H}$ to do, and which $\mathrm{S}$ believes that $\mathrm{H}$ is able to do; and which it is not obvious that $\mathrm{H}$ will do in the normal course of events or of H's own accord (Searle 1969: 66). ${ }^{1}$ This notion of an "act" which $\mathrm{S}$ attempts to elicit from $\mathrm{H}$ may include the purely verbal acts of giving information, or granting permission.

From the formulation offered by Searle (1969), above, a certain coercive element to requests can be inferred. Brown and Levinson $(1978,1987)$ highlight this coercive element explicitly by classifying a request as an intrinsically face-threatening act whose face-threatening nature creates a need for politeness in performance of the speech act (see 1.4.2). Leech (1983), similarly, conceives of a request as a "competitive" speech act; that is, one whose illocutionary goal competes with the social goal of establishing and maintaining comity, and hence, as an act which by its nature creates discord. Leech (1983) suggests that politeness is required when performing a request in order to mitigate the intrinsic "discourtesy" of the illocutionary goal (Leech 1983: 105-106). 


\subsection{The components of a request}

While no empirical data is available on how requests are performed in Bahasa Indonesia specifically, the extensive work which has been carried out on description of requests in other languages, particularly English (see 1.6.2.2), has enabled taxonomies of request strategies to be developed (e.g. by Ervin -Tripp 1976; Fraser 1978; CCSARP 1989; Trosborg 1995). A useful descriptive framework of the components of a request was also developed for the CCSARP project (see 1.6.2.2) ${ }^{2}$, and this framework is used in the present study. It enables a request to be analysed into several key components. This framework is outlined below with reference to an example BI NS request from the present data (explanatory comments are based closely on those of Blum-Kulka, House and Kasper (1989) and CCSARP (1989), except where otherwise stated).

[a passenger in a city bus to the conductor]

Mas, $\quad$ saya mau ke Jalan Kartini tapi saya nggak tahu harus

'Brother', I want to go to Kartini Street but I don't know where I

turun di mana.

Tolong Mas dikasihtahu ya kalau ada stop

should get off.

Please 'brother' (I) be told yes when we get

bus yang terdekat dengan Jalan Kartini. ${ }^{3}$

to the stop closest to Kartini Street.

A request has an optional Alerter component (Mas "Brother"). As Sifianou (1992: 181) observes, Alerter elements

are used to attract the addressee's attention, literally or figuratively, before the actual request is launched. When used metaphorically they imply the speaker's concern for a pleasant, harmonious encounter. ${ }^{3}$

A request also has an obligatory component: the head act. This is the main element; the request 'proper', which can realise the request independently of other elements (dikasihtahu kalau ada stop yang terdekat dengan Jalan Kartini "(I) be told when we get to the stop closest to Kartini Street"). 
A request has optional internal modifiers, which are part of the head act component (tolong "please", Mas "brother", and ya "yes"). The concept of an internal modifier is discussed in detail later (see 5.1).

A request also has optional external modifiers. These are moves additional to the head act, which indirectly modify its effect (Saya mau ke Jalan Kartini tapi saya nggak tahu harus turun di mana "I want to go to Kartini Street but I don't know where I should get off"). These moves can occur before or after the head act (see 6.1.2 for further discussion of the notion of an external modifier).

\subsection{Request strategies}

The Head Act of a request may vary in strategy type. Request strategies have different levels of directness; that is, they differ in the length of the inferential pathway which the hearer must follow in order to attribute requestive intent to the utterance (Blum-Kulka et al 1989). The degree of indirectness of a request is related to its politeness, although the two dimensions do not have a simple parallel correspondence (cf. Blum-Kulka 1987), and the relation between the two dimensions may be culture- and language- specific (cf. Wierzbicka 1991).

In the CCSARP scale of request strategies three levels of directness are identified: direct, conventionally indirect $(\mathrm{CI})$, and non-conventionally indirect (non-CI) (Blum-Kulka et al 1989). At each of these levels, sub-strategies are proposed ${ }^{4}$, yielding a taxonomy of nine request sub-strategies, which was used as a basis for analysis of the CCSARP requesting data. While this taxonomy has been criticised in some respects (see for example van Mulken (1996)), it provides a suitable framework to analyse request strategies in the present study, and has been used with only minor adaptations. 5

The classificatory framework of request types used by subjects in this study is presented in Table 1 below. The utterances used to illustrate each type are (unless otherwise stated) taken from the BI native-speaker data in the present study) ${ }^{6}$ 
Table 1: Request strategies used by subjects (in order of directness)

\begin{tabular}{|l|l|}
\hline \multirow{4}{*}{ A. DIRECT } & i) Imperative \\
\cline { 2 - 2 } & ii) Explicit performative \\
\cline { 2 - 2 } & iii) Hedged performative \\
\hline & iv) Goal statement \\
\cline { 2 - 2 } B. CONVENTIONALLY Want statement \\
\hline INDIRECT (CI) & $\begin{array}{l}\text { vi) Query preparatory: ability or } \\
\text { permission }\end{array}$ \\
\cline { 2 - 2 } & vii) Query preparatory: availability \\
\hline C. NON-CONVENTIONALLY & viii) Question hint \\
INDIRECT (NON-CI) & ix) Statement hint \\
\cline { 2 - 2 } &
\end{tabular}

\subsubsection{Direct sub-strategies}

Table 1 above shows that five sub-strategies used by subjects in this study can be regarded as direct request types. ${ }^{7}$

i) The imperative is the most direct sub-strategy of all. It derives its requestive force from the grammatical mood itself. ${ }^{8}$ An example of an imperative request is: Tolong cucikan pakaian saya yang kotor "Please wash my dirty clothes."

Included within this sub-strategy of imperative is a request type which may be regarded as an elided imperative. ${ }^{9}$ This form consists of the name of the object requested. An example is this request by a diner in a restaurant for a menu: Menu makanannya itu. "The menu".

ii) The second most direct sub-strategy is the explicit performative request. In this type of request the speaker names the illocutionary intent explicitly, with a relevant illocutionary verb. The illocutionary verb may be either minta or mohon.. The first of these verbs, minta, is the very common, usual Indonesian equivalent to the English verbs "ask for" or "request". The second of these verbs, mohon, is also commonly equated with English "ask for" or "request", but differs from minta in that it conveys greater formality, and also suggests that the requestee is in a position 
of authority with respect to the requester (somewhat akin to the English verb "beseech"). Examples of explicit performative requests are these:

1 (a diner to a waiter in a restaurant)

Sava minta nasi goreng saja.

I ask for just fried rice.

2 (a university student asking a lecturer for an extension on an essay deadline)

......saya mohon untuk bisa menyelesaikan esai saya itu pada hari Senin depan...

...... ask to be able to finish my essay next Monday...

In explicit performative requests the actor need not be explicitly mentioned, 10 as demonstrated in the following example:

3 (a customer to the ticket seller in a cinema)

Minta karcis satu Mbak.

(I) ask for one ticket 'sister.'

Explicit performative requests such as those above convey quite a polite effect, as Quinn (1996a: 61) observes. He states that the phrase Saya minta is more like the English phrase "Please give me" than simply "Give me" in its effect; and in fact, this Indonesian request form probably conveys more politeness than either of those proposed English equivalents. The gloss provided by Sneddon (1996: 331), for the request Minta air (literally: “Ask for water"); namely "Can I please have some water?" provides a fairly accurate notion of the degree of politeness conveyed.

iii) In the direct sub-strategy of 'hedged performative', the performative verb is modified by a modal verb, such as mau "want/ would like" or bisa "can". This modal verb creates a hedge on the illocutionary force of the performative verb which makes the request less direct than the explicit performative strategy. ${ }^{11}$ Examples of the hedged performative strategy are as follows:

4 (a prospective student to an official in the immigration office)

Saya mau minta formulir ...untuk mengajukan studi di Australi.

I want to ask for the forms... to study in Australia. 
5 (a customer to a clerk in the post office)

Bisa minta amplop dan perangko untuk dikirim ke Australi?

Can (I) ask for envelopes and stamps to send to Australia?

iv) In the fourth direct sub-strategy, the Goal statement, the speaker states the desired state of affairs, or goal, of the request. In this way the requestive force of the utterance is derivable from the semantic meaning of the utterance itself. ${ }^{12}$ Examples of Goal statements are as follows.

6 (asking to try on shoes in a store)

Coba yang sepatu ini.

(I) try these shoes.

7 (a student asking a classmate to look on at their book)

Ikut baca sama-sama, ya.

(We) read together, yes.

This strategy of Goal statement conveys a certain optimism that $\mathrm{H}$ will comply with the request, and in this way conveys a degree of positive politeness (see 1.4.2). ${ }^{13}$

v) In a Want statement, the speaker states his or her desire for the goal of the request to be realised, using a relevant modal verb. The verb used is typically mau "want". Examples of Want statements are as follows:

8 (asking to listen to a cassette in a music store)

Saya mau mencoba kaset Iwan Fals yang terbaru.

I want to try the latest cassette by Iwan Fals.

9 (asking for a magazine at a street stall)

Saya mau majalah Tempo Pak.

I want Tempo magazine 'father'.

The force of Want statements of the type above is quite direct and assertive, and for that reason, this sub-strategy is classified as direct rather than conventionally indirect. ${ }^{14}$ At the same time, these requests are considered by informants to be quite 
polite; more so than the English request form "I want...", and roughly equivalent in effect to the English form "I'd like...".15

Want statement requests can also be made using a modal verb other than mau "want"; namely, the modal verb ingin "want/ wish" (or pingin, a Javanese variant of ingin ). An example is as follows:

10 (asking a clothes store manager to exchange a shirt bought yesterday)

... kalau boleh saya ingin menukarkan.

... if (I) may I want to exchange (it).

However, Want statements with ingin are considered by BI native-speaking informants to be less idiomatic (i.e. conventionalised) as requests than Want statements with mau, and hence, to be a less appropriate means of making requests.

\subsubsection{Conventionally indirect (CI) sub-strategies}

Table 1 above shows that two sub-strategies (vi and vii) used by subjects can be regarded as conventionally indirect.

vi) In query preparatory (QP) requests, the speaker asks about a condition necessary for the request to be fulfilled. In the sub-strategy of query preparatory modal request, the speaker uses a modal verb to ask about hearer's ability, or speaker's permission.

Queries about the hearer's ability are made from the perspective of the hearer, using the modal verb bisa "can". 16 An example is this:

11 (asking a stranger to move over in a crowded eating stall)

Bisa bergeser sedikit, Mas?

Can (you) move over a little, 'brother'?

Queries about speaker's permission are made from the perspective of the speaker, and use either the modal verb bisa "can" or boleh "may/ allowed to". An example of a permission request with each of these modal verbs is below: 
12 (a new hotel guest asks to borrow a pen from a hotel receptionist to fill in the registration form)

Bisa pinjem bolpoinnya?

Can (I) borrow a pen?

13 ("hotel guest" situation above)

Boleh saya pinjem pena?

May I borrow a pen?

Requests for permission using the modal verb boleh "may/ be allowed" (as in [13]) are slightly more deferential in effect, other things being equal, than those using bisa "can" (as in [12]). Although both forms can legitimately be regarded as questions about the hearer's permission ${ }^{17}$, the selection of boleh "may/ be allowed" seems to convey this sense more overtly, and hence, place the speaker more clearly in a subordinate position to the hearer.

vii) Another query preparatory sub-strategy is one in which the speaker questions the condition that goods are available, using the verb ada "there is/ there are" or the verb punya "have". Examples of query preparatory availability requests are these:

14 (asking a waiter for a menu)

Ada daftar menu nggak?

Is there a menu (or) not?

15 (asking a stranger for a light for a cigarette)

Punya api Mbak?

(Do you) have a light 'sister' ?

While this request type has been classified here as conventionally indirect, it is on the "fuzzy" boundary (cf. Aijmer 1996: 196-197) between conventionalised and non-conventionalised speech acts, and could legitimately be classified as a non-CI request (or hint) instead. ${ }^{18} \mathrm{An}$ argument for regarding this type of request as a hint is that it often functions as a pre-request (cf. Levinson 1983; Schegloff 1995) rather than a request proper - and pre-requests, as Aijmer (1996: 137) observes, are usually not regarded as conventionalised request forms. The potential prerequestive function of availability questions is illustrated in [16] below: 
16 (at a magazine stall)

Customer: Ada majalah Gatra?

Seller: $\quad$ Ada.

Customer: $\quad$ Satu, Pak.

Seller: (gives a magazine to the customer)

Customer: Do you have (lit: "is there") Gatra magazine?

Seller: Yes.

Customer: One, 'father'.

Seller: $\quad$ (gives a magazine to the customer)

[fabricated]

In [16], the customer's question about the availability of the magazine is interpreted not as a request, but as an information question, and thus functions as the first move in a pre-sequence of question and answer. After this pre-sequence the customer makes a request for the magazine: Satu, Pak "One, 'father'," which meets with compliance by the seller, in the form of supply of the magazine.

However, as Aijmer (1996: 137) points out, ${ }^{19}$ pre-request forms are so commonly used that they do in fact become conventionalised - and this occurs with the Indonesian forms at issue here. This is illustrated in the dialogue below:

17 (at a magazine stall)

Customer: Ada majalah Gatra, Pak?

Seller: $\quad A d a$. Ini (gives the customer a magazine)

Customer: Do you have (lit: “is there") Gatra magazine, 'father'?

Seller. $\quad$ Yes. Here (gives customer a magazine)

[fabricated]

In [17] above, the customer's question about availability of the magazine is met with compliance by the seller. In this way the utterance achieves the status of a request proper.

Moreover, in some contexts, the only plausible interpretation for such question forms is that of a request proper. This is demonstrated by the unlikelihood of the (fabricated) dialogue below: 
(asking to borrow a pen in class)

Student 1: Ada bolpoin, Mas?

Student 2: ? Ada.

Student 1: ?Bisa pinjem ?

Student 2: ?Bisa (hands over a pen)

Student 1: Do you have (literally: "is there") a pen, 'brother'?

Student 2: ?Yes.

Student 1: $\quad$ ?Can (I) borrow (it)?

Student 2: $\quad$ ?Yes (hands over a pen)

In this situation in [18] there is no other plausible interpretion for the first student's question about the availability of a pen other than as a request to borrow one (we are assuming that Student 1 in his or her question is referring to a spare, or second, pen and that this is mutual knowledge). Therefore, dialogue [18], in which this question achieves the status of a mere pre-request, seems unnatural. A much more likely development of the discourse would be that of [19] below, in which the same question achieves the status of a request proper:

19 (same "pen" situation as above)

Student 1: Ada bolpoin, Mas?

Student 2: $\quad$ Ada. Ini (hands over a pen)

Student 1: Do you have (lit is there) a pen,'brother'?

Student 2: $\quad$ Yes. Here (hands over a pen)

[fabricated]

Therefore, in this specific situation, the question form used by the requester (Ada? "Do you have?") can be said to be fully conventionalised as a request. 20

Considering the above, the most theoretically valid approach to classification would seem to be to regard 'availability' requests as conventionally indirect in some contexts (i.e. those in which they can plausibly function only as a request), but as hints in other contexts (i.e. those where they could plausibly have functioned as a genuine question). ${ }^{21}$ However, for descriptive coherence, it is desirable to classify this request type consistently as either $\mathrm{CI}$ or non-CI. And due to the nature of the situations selected for the present study, this request type is common enough to 
merit recognition as a strategy of its own. Therefore, rather than being grouped together with other question hints, this type of request has been classified as a separate conventional strategy.

\subsubsection{Non-conventionally indirect requests (hints)}

Table 1 above shows that two sub-strategies (xiii) and (ix) used by subjects may be classified as non-conventionally indirect requests, or hints.

Hints are indirect question forms which are not conventionalised in the language, ${ }^{22}$ and hence require more inferencing activity for the hearer to derive the speaker's requestive intent. Hints may vary on two dimensions (Weizman 1989, 1993). The first is illocutionary transparency: how directly the utterance conveys requestive force. The other is propositional transparency: how explicitly the utterance conveys what it is that the hearer is requested to do. 23

In the CCSARP taxonomy of request strategies (cf. Blum-Kulka et al 1989; CCSARP 1989), hints are sub-classified as "strong" or "mild". This distinction between strong and mild hints appears to rest on the dimension of propositional transparency. For example, if someone were trying to lift a heavy piece of furniture, and said to the person watching: "I could do with some help here", this would be classified as a mild hint, because it contains no explicit reference to H's intended action. However, the utterance "I could do with some help lifting this desk" would be a strong hint, because the explicit reference to lifting the desk makes it clear precisely what action of $\mathrm{H}$ is requested.

In the present study, hints are classified as questions or statements rather than as strong and mild, for two reasons. The first is theoretical. Weizman (1989: 86-87) suggests that hints consisting of questions have greater illocutionary transparency than statement hints; that is, they convey the force of a request more directly, because the speaker by asking a question demands a response from the hearer, and so cannot so readily deny having tried to involve the hearer. The question/ statement distinction therefore is consistent with the rest of this request taxonomy, which is based on the primary criterion of directness. ${ }^{24}$ The second reason is practical. The particular nature of the hints used by subjects in this study makes the question/statement distinction an important and a descriptively useful one (as will become clear in later chapters). 
xiii) A question hint is an interrogative utterance which functions as a request, but which is not conventionalised as a request form (unlike interrogative forms such as Bisa saya? "Can I?" or Boleh saya? "May I?" which are so conventionalised). As question hints do not convey requestive force by virtue of their formal properties, their requestive force is heavily dependent on context. Examples of question hints are these:

20 (asking a friend from college, who is getting on his or her motorcycle at the shops, for a lift back to college)

Mau pulang?

Are you going home?

21 (asking an official in the immigration office for the forms to apply to study in Australia)

Formulir apa aja yang diperluin Bu?

What forms do I need 'mother'?

In [20] above, highly context-specific features (e.g. that the interlocutors live together at college, and that the requester is on foot) allow the owner of the motorcycle to infer from the question Mau pulang? "Are you going home?" that the speaker wants a lift back to college. In [21] above, similarly, context-specific features (e.g. the knowledge - shared and known to be shared - of the interlocutors that in order to apply for a visa the student needs actual forms and not merely information about them, and that these forms can be obtained from the immigration office), allows the official to infer that the student wants to be given the forms in question.

ix) A statement hint is a declarative utterance which functions as a request, but which is not conventionalised as a request form (unlike e.g. the Want statement Saya mau "I want", which is so conventionalised); and secondly, does not allow requestive force to be directly derived from its semantic meaning (unlike e.g. the Goal statement Coba sepatu ini "(I) try these shoes," where the force of a request to try on the shoes is so derivable). As a result, statement hints, like question hints, are heavily dependent on context for their requestive force. Examples of statement hints are these: 
22 (asking a classmate to let you look on at their book in class)

Saya ketinggalan bukunya.

I've left my book behind.

23 (asking a bus conductor to tell you when you reach your stop)

Saya mau ke Jalan Kartini tapi saya nggak pasti ini mau turun di mana ...

I want to go.to Kartini Street but I'm not sure where to get off...

In [22] above, highly context-specific features (e.g. that the requestee has a textbook open in front of him or her, and that the interlocutors are sitting close enough to read it together) allow the hearer to infer from this statement that the speaker wants to look on at his or her book. In [23] above, too, context-specific features (e.g. the knowledge - shared and known to be shared - of the interlocutors that bus passengers sometimes ask the conductor to tell them when they reach a given stop, and that conductors regularly comply with this request) allows the conductor to infer that the passenger wants to be told when the stop is reached.

\subsection{Request perspective}

The second dimension on which the head act of a request may vary, after directness, is perspective (Blum-Kulka et al 1989). Perspective refers to the matter of whose role is focused on in the request. Every request has one of these perspectives: speaker, hearer, inclusive (speaker and hearer), or impersonal (neither speaker or hearer). These four perspectives are illustrated below.

\section{Speaker perspective}

Bisa saya pinjam bolpoinnya, ya?

Can I borrow a pen, yes?

In [24], the speaker focuses on his or her own role (saya "I") in bringing about the desired state of affairs.

\section{$25 \quad$ Hearer perspective}

Bisa geser sedikit?

Can (you) move over a little? 
In [25], the speaker focuses on the role of the hearer in bringing about the desired state of affairs, by specifying that the hearer is to perform an action.

26 Inclusive perspective

Bisa kita berhenti ndak membeli rokok...?

Can we stop (or) not to buy cigarettes...?

In [26], the speaker focuses on both his or her own role and that of the hearer, by presenting the requisite action as one to be performed jointly by the interlocutors (kita "we).

27 Impersonal perspective

(asking a store manager to exchange a shirt bought yesterday)

Bisa diganti nggak Pak?

Can (it) be exchanged (or) not 'father' ?

In [27] the speaker focuses on neither his or her own role nor that of the hearer, focusing instead on the desired state of affairs itself (the shirt being exchanged).

All, or most, of these request perspectives are frequently available to a speaker in a single situation. However, (as Blum-Kulka et al (1989) observe), not all perspectives will necessarily be available for the same request strategy. For example, if a diner in a restaurant asks the waiter to bring a drink, and uses an imperative strategy, only two perspectives are available: hearer perspective or impersonal perspective, as in [28] and [29] below, respectively:

28 Tolong bawain sebotol bir

Please (you) bring me a bottle of beer [ = hearer perspective]

29 Tolong dibawain sebotol bir

Please (I) be brought a bottle of beer. [= impersonal perspective]

However, if the diner selects a different request strategy, then another perspective may become available too. For example, an explicit performative strategy will allow speaker perspective: 
$\underline{I}$ ask for a bottle of beer.

The dimension of perspective is related to politeness. Brown and Levinson (1978, 1987) suggest that impersonal perspective in a request is negatively polite, and this appears to be true in Indonesian. An imperative request with impersonal perspective (as in [29]) has a milder, more polite effect than one with hearer perspective (as in [28]) because in the former case the speaker conveys a desire to be indirect and to avoid naming the hearer explicitly (cf. Johns 1977: 276; Verhaar 1984: 56; D.P.\&K 1993: 287). Blum-Kulka et al (1989) in fact suggest that selecting any perspective other than hearer perspective may make a request form less coercive, and hence function to convey politeness. 25

\subsection{Asking vs requesting}

One important decision in classifying and analysing the request data needs to be explained: the fact that requests for information are, largely, analysed separately from other requests. This is because of problems presented by one obvious strategy for requests of this type: the 'direct question', which is not a request, strictly speaking. Examples of direct questions in asking for information are these:

31 (asking where the post office is)

Di mana kantor pos?

Where is the post office?

32 (asking a stranger if the train that just pulled in goes to Bandung) Apa kereta ini yang ke Bandung Mas, ya?

Is this train the one to Bandung 'brother', yes?

33 (asking a coach conductor during a long journey how much longer until the coach arrives at Denpasar)

Berapa jam sih ke Denpasar?

How many hours to Denpasar? 
This notion of a 'direct question' is difficult to define rigorously. Edmondson (1981) defines a direct question (which he calls a "Question") as a query-locution used to perform a request for information with "a minimum of indirectness" (Edmondson 1981: 195). As he acknowledges, this qualifying clause is rather unsatisfactory; however, a sufficiently clear intuitive notion of what is meant by a direct question can be gained by contrasting such a question with other interrogative request forms, as below.

[asking a stranger in the street the way to the post office]

"Where's the post office?"

"Can I ask where the post office is?"

"Can you/will you tell me where the post office is?"

"Do you know where the post office is?"

"Is the post office far from here?"
[= direct question]

[= hedged performative request]

[=query preparatory request] [=query preparatory request ] [=question hint]

Considerable theoretical support exists for this decision to distinguish direct questions from requests. Edmondson (1981: 194-196) believes that these questions cannot readily be brought within a coherent model of requests in discourse because they behave differently from other requests. For example, although one can typically give verbal assent to a request before complying with the request, this is not possible with direct questions, as demonstrated in [34] below:

A: Where's the post office?

B: ? Yes. It's about 100 metres straight ahead.

[fabricated]

Leech (1983: 275) points out another way in which questions do not behave as requests. The answer "no" in response to a request constitutes a refusal to comply. However, the answer "no" in response to a yes/no question cannot be interpreted in this way; instead, it constitutes cooperative behaviour. Because of facts like this 
about the usage of questions, Leech (1983) argues, the view that questions are requests to tell (cf. Gordon \& Lakoff $1971: 66$ ) is a mistaken one. ${ }^{26}$

The most compelling reason for regarding the direct question as a non-request in the present study is purely practical: that it cannot be placed satisfactorily within the taxonomy of request strategies outlined above. Although it is an interrogative construction, it is an even more direct way of asking for information than an imperative construction (compare, for example, "Where's the post office?"and "Tell me where the post office is"). For this reason, requests for information are analysed on a separate scale of directness from other requests (see 4.1.10). And while the term 'request' is generally used in this thesis to refer to all requests, including those for information, sometimes this special type of request is explicitly distinguished from others by use of the term 'Ask', and the situations in which this type of request occurs are referred to as 'Asking situations'.

\subsection{The notion of 'interactional value'}

The criterion for assigning the status of a request to utterances in the present study is, as a rule, that of interactional value (cf. Edmondson 1981): whether the utterance is assigned requestive function by the interlocutors, such that it functions as a request in the discourse. This criterion can be contrasted with the criterion of illocutionary purpose: whether the speaker intends the utterance as an attempt to get $\mathrm{H}$ to do the act.

The implications of using the criterion of interactional value can be understood by examining the two dialogues below:

35 (at a magazine stall)

Customer: Ada majalah Gatra?

Shopkeeper: Ada.

Customer: Satu, Pak.

Shopkeeper: Ini . (gives the customer a magazine)

Customer: Makasih . (hands over money) 
Customer: Do you have (lit: "is there") Gatra magazine?

Shopkeeper: Yes, we do.

Customer: One, 'father'.

Shopkeeper: Here. (gives the customer a magazine)

Customer: Thanks. (hands over money)

[fabricated]

36 (at a magazine stall)

Customer: Ada majalah Gatra?

Shopkeeper: Ini (gives the customer a magazine)

Customer: Makasih (hands over money)

Customer: Do you have (lit: is there) Gatra magazine?

Shopkeeper: Here (gives the customer a magazine)

Customer: Thanks. (hands over money)

[fabricated]

In [35], the customer's question Ada majalah Gatra? "Do you have Gatra magazine?" does not achieve the value of a request. It achieves the value of a prerequest only. The customer may have intended it to be a request (that is, to elicit compliance from the shopkeeper, in the form of provision of a magazine). Alternatively, the customer may have intended it to be a pre-request (that is, to elicit information only, about the availability of the goods). As Edmondson (1981) observes, speakers' intentions in discourse are for practical purposes unknowable. What matters for present purposes is that this utterance is interpreted as a prerequest by the shopkeeper and the customer cooperates in this interpretation, by initiating a following request sequence with Satu, Pak "One, 'father". It is this second utterance by the customer which functions as a request, and which would be assigned request status in the present study.

In [36] above, the customer makes exactly the same initial move as the customer in [35]. Again, this question may or may not have been intended by the speaker as a request. However, this time it does function as a request: it is interpreted as one by the shopkeeper, who responds by giving the customer the magazine, and the customer cooperates with this interpretation by taking the magazine and paying for it (instead of renegotiating the value of the utterance by, for example, declining to 
take the magazine and asking its price instead). So in [36] this question by the customer would be assigned request status.

One exception is made to this criterion of interactional value for identifying requests in the data. Utterances which elicit offers by $\mathrm{H}$ to perform an act are interpreted as requests (hints), even though they do not have that interactional value. This is illustrated in the dialogue below:

37 (asking a fellow college resident for a lift home from the shops on his or her motorbike)
A: Hey! Mau pulang?
B: Iya. Mau ikut?
A: $\quad$ Iya.

(A gets on B's motorbike and they ride back to college together)
A: Hey! Are you going home?
B: Yeah. Want a lift?
A: Yeah.
(A gets on B's motorbike and they ride back to college together) [fabricated]

In [37] above, the underlined utterance by A, Mau pulang? "Are you going home?" does not, strictly speaking, function as a request in the discourse, but as a prerequest. It does not elicit verbal assent (e.g. Boleh "(Yes, you) can"), or actual compliance (e.g. starting to take A home) or refusal (e.g. Maaf, tidak bisa "Sorry, (I) can't"): all of which responses would give it the interactional value of a request (cf. Edmondson 1981). The utterance which does count as the attempt to get B to do the desired act, strictly speaking, is A's next utterance instead: Iya "Yeah" (to which B responds with compliance).

An important consideration here is that of 'preference organisation.' As frequently observed (e.g. by Levinson 1983; Brown \& Levinson 1987; Schegloff 1995), an offer is a preferred response to a pre-request. It is preferred because it eliminates the need for an explicit request to be made in a following sequence. In this way, A's question in [37], Mau pulang? "Are you going home?" can be regarded as oriented towards the preferred sequence of offer-acceptance; and therefore, as an utterance which is structurally designed to elicit an offer of a lift. 27 
Another relevant consideration here is our intuitive notions of requests. While utterances like Mau pulang? "Are you going home?" in the "lift" situation in [37] intuitively seem like requests of a hinting type, utterances like the following one by the same speaker in that dialogue, Iya "Yeah", are too far removed from the usual, common-sense notion of a request to be of interest in this study (as Edmondson (1981) points out, utterances of this type are not requests in everyday terms; they are acceptances of an offer). Therefore the criterion of interactional value, while applied generally, is discarded in the specific case of utterances which elicit offers. 


\subsection{Notes to Chapter 3}

1 Other writers conceive of a request in more narrow terms than Searle (1969) above. Fraser (1978: 6) restricts the notion of a request to a directive speech act which, in its attempt to get the hearer to do something, appeals to the hearer's sense of mutual cooperation. This criterion distinguishes a request from, for example, an order or a command; both of which appeal to the hearer's lack of status instead. Aijmer (1996: 134) also narrows the notion of a request in a way that Searle (1969) does not by claiming that "requestive" speech acts should be distinguished from "advisories" (such as offers), on the grounds that the speaker in requestives does not believe that the postulated action is good for the hearer. By this criterion, at least one of the 'request' situations in the present study (buying a magazine at a street stall from the owner) does not entail a request, as $\mathrm{S}$ is likely to regard H's action (that of supplying the magazine) as good for $\mathrm{H}$ as well as for him or herself.

2 The classification system for requests used in the CCSARP project is in turn based on earlier work on classifying request strategies and components; most obviously that of House and Kasper (1981), also that of Edmondson (1981), Ervin-Tripp (1976) and Fraser (1978), and originally that of Searle (1975).

${ }^{3}$ Sifianou (1982: 181) refers to these devices as Attention-getters rather than Alerters.

4 These proposed request sub-strategies are largely derived from those proposed by House and Kasper (1981).

5 Some preliminary work on classification of Indonesian request strategies, specifically, has been carried out. Sarumpaet (1977: 144-165) presents a list of eight Indonesian request strategies (in what he suggests as descending order of politeness), and Sneddon (1996: 324-332) offers a grammatical description of various Indonesian request types. However, while both of these studies yield a number of valuable insights for interpreting the present data, neither is suitable as a basis for a taxonomy of the request types that subjects used in this study, as the disparity between the descriptive categories offered and the request types in the data is too great.

6 Pauses and hesitations are omitted and conventional punctuation used in the requests provided as examples in this introductory chapter, to make the essential structure of utterances as clear as possible. 
7 The decision whether to classify sub-strategies as direct in the present study is to some extent intuitive, based on a perception of which sub-strategies convey requestive intent with substantially more directness than the archetypal conventionally indirect sub-strategy: the query preparatory (e.g. Boleh saya "May I" or Bisa Anda "Can you"). A more rigorous criterion for classification would be to restrict the notion of a direct request to one which conveys requestive force as part of its 'literal force' (cf. Levinson 1983); that is, by purely syntactic means (by grammatical mood or an explicit performative verb). By this criterion, all request sub-strategies other than imperatives and performatives would be regarded as indirect (a position taken by Levinson (1983)). However, in empirical studies of requesting, the category of direct requests is regularly broadened to encompass other sub-strategies as well on apparently intuitive grounds (e.g. in the CCSARP study (BlumKulka et al 1989), Trosborg (1995), and Aijmer (1996)). This results in some inconsistency between studies about precisely which sub-strategies are classified as direct, and means that the distinction between direct and indirect requests is a somewhat fuzzy one.

8 cf. the name of 'mood derivable' given to this sub-strategy in the CCSARP project (CCSARP 1989).

9 Whether this type of request form is truly an elided form of a full imperative request, such that Menu makanannya itu "The menu" is an elided form of (say) Bawakan menu makanannya itu "Bring the menu", is arguable. Both Ervin-Tripp (1976: 30) and Trosborg (1995: 204) classify ,English requests of this type as elided imperatives. However, as Merritt points out, "a serious problem with the notion of ellipsis ... is deciding what has been ellipsed or deleted, or if there is in fact a 'full form' at all" (Merritt 1976: 326). Regarding the issue of whether there is a full form for these requests, Aijmer (1996) appears to be ambivalent. She classifies certain request forms of this kind (e.g. "Extension 258 please", and "The department of mathematics, please") as elided imperatives (Aijmer 1996: 133), but implicitly rejects the notion of ellipsis in classifying others (e.g. "The next slide, please" by a speaker giving a slide presentation, which she classifies as the strategy of "Naming the object requested" instead (Aijmer 1996: 133). And even assuming that these request forms in the data are an elided version of a longer request form, we cannot be sure what that full form is. It could plausibly be a request type other than imperative altogether, for example, an explicit performative (cf. Minta daftar makanannya itu "(I) ask for the menu").

10 It is interesting to note that Sneddon (1996: 331) appears to regard explicit performative requests without mention of the actor (e.g Minta air, literally "Ask for water", as a request to a waiter for water) as being in imperative mood. However, this interpretation is not found elsewhere in the literature and is expressly contradicted by at least one grammarian (Yohanni Johns, personal communication). 
11 As van Mulken (1996: 692) points out, this assumption that the hedged performative request is a different sub-strategy to the explicit performative request is questionable. She observes that the modal verb in a so-called hedged performative could alternatively be classified as an internal modifer instead. By this analysis, the requests Saya minta amplop... "I ask for envelopes..." and Say a mau minta amplop... "I want to ask for envelopes..." would be two realisations of the same performative request strategy, the second containing a downgrading modifer (the modal verb mau "want") and the first not. This observation of van Mulken (1996) raises an important question about the theoretical validity of the distinction in the CCSARP framework (and that of the present study) between indirectness on the one hand, and mitigation on the other. Fraser (1978: 15), for instance, appears to conflate these two notions, asserting that one obvious means for mitigation is indirectness.

12 cf. the CCSARP direct sub-strategy of 'locution-derivable' requests (CCSARP 1989) from which the notion of a Goal statement used in this study is derived.

13 While BI native speaker informants consider that Goal statements in the data do convey an effect of positive politeness (i.e. friendliness), it is worth noting that conveying optimism about the outcome of a request may alternatively convey negative politeness. Brown and Levinson $(1978,1987)$ point out that speaker's optimism may also function to convey to $\mathrm{H}$ that the imposition involved in the request is small, which minimises the threat to H's negative face.

14 This classification of Want statements as direct in Bahasa Indonesia seems to gain support from Kaswanti Purwo (1990). He explicitly contrasts the effect of the Want statement, Saya mau bicara dengan Pak Harahap "I want to talk with Mr Harahap", with the effect of the three forms classified in the present study as conventionally indirect: Boleh bicara dengan Pak Harahap? "May (I) talk with Mr Harahap?"; Bisa bicara dengan Pak Harahap? “Can (I) talk with Mr Harahap?"; and Pak Harahap ada? "Is Mr Harahap there?." Kaswanti Purwo claims that the Want statement above conveys an authoritative attitude on the part of the speaker which the other three forms do not convey (Kaswanti Purwo 1990: 176-177). Nevertheless, there is inconsistency in the literature on whether Want statements are classified as direct or conventionally indirect. While the CCSARP study (cf. Blum-Kulka et al 1989, CCSARP 1989) classifies them as direct (across languages, including English), both Trosborg (1995) and Aijmer (1996) call Want statements in English conventionally indirect. 
15 One likely reason that the Indonesian request formula Saya mau "I want" is more polite than English "I want" is that English speakers when requesting can select the more polite conditional form "I'd like" in preference to "I want", and (as Blum-Kulka (1987) observes) routinely do so. As a result, the request form "I want" is marked in English for lack of politeness. However, in Indonesian (which does not encode conditionality in verbs), there is no equivalent 'softened' form of Want statement which can be selected in preference to Saya mau "I want", and so this form is not marked as a less polite choice.

16 Questions asking about hearer's ability with the modal verb dapat, which also means "can" (but which, unlike bisa, is restricted to formal register), do not appear to be conventionalised in BI as a formula for making requests. Thus, informants do not consider requests such as * Dapat saya duduk di sini? "Can I sit here?" to be acceptable. This seems roughly analogous to the way in which English requests using "be able" rather than "can" have not become conventionalised, such that the request form "Am I able to sit here?" rather than "Can I sit here?" is of doubtful appropriacy in English.

17 This claim is supported by van der Wijst (1995: 481-482, 487table), Trosborg (1995: 199200), and Aijmer (1996: 15), all of whom classify both "can I?" and "may I?" as questions about hearer's permission. These writers make the same distinction as in the present study between these two forms on the one hand and the form "can you?" on the other, regarding the latter as a question about hearer's ability.

18 Ervin-Tripp (1976) and Trosborg (1995), for example, are both equivocal on the question of whether to regard questions about availability as conventional requests. Ervin-Tripp (1976: 40) claims on the one hand that these request forms tend to be selected when there is a real possibility that the request may not be fulfilled (implying that such forms genuinely, not just conventionally, question a condition). On the other hand, she emphasises that some questions of this type (e.g. "Is Sybil there?" as a request to speak to Sybil on the phone) must be excluded from this claim, as they have become conventionalised to the extent that they are no longer off-record and are obvious requests. Similarly, Trosborg (1995) classifies questions about availability in her study as hints, but acknowledges that in service encounters concerning availability of goods in stock, requests of this kind have become conventionalised in English and so function as transparent request forms.

19 Aijmer (1996) cites Tsui (1994: 111) as support for this observation. 
20 A similar example is that of Brown and Levinson (1978: 116-117), who classify the question about availability "Got any spare cash?," when asking for money in the street, as a conventionally indirect request rather than as a hint.

21 Brown and Levinson (1987) observe in this regard that whether a request is on- or off-record depends on context. They point out that sometimes "[utterances] constructed like hints are actually, in the context, on record", because a requestive interpretation is the only acceptable interpretation (Brown and Levinson 1987: 212).

22 Leech (1983: 97), however, uses the notion of a hint more broadly. He regards all indirect request forms (including highly conventionalised ones such as "Will you answer the phone?" or "Can you answer the phone?") as hinting strategies.

23 Fraser (1978: 9) draws the same distinction between the two dimensions of illocutionary and propositional explicitness, with regard to requests generally rather than to hints specifically.

24 It is not the case that the CCSARP researchers chose between sub-classifying hints by propositional opacity and by illocutionary opacity and opted for the former approach; rather, it is on the basis of data from the CCSARP study itself that Weizman (1989) was able to identify these two separate dimensions for hints. And this analytical insight yields, as Blum-Kulka et al observe, "a substantially refined categorisation for Hints from the one originally suggested by the CCSARP coding scheme" (Blum-Kulka et al 1989: 24).

25 However, it is important to bear in mind that the specific meanings conveyed by perspective (as with directness) can be culture and language-specific. For example, in Polish, an impersonal request construction may be regarded as less polite than a hearer-oriented one, as it conveys a sense of distance between hearer and speaker, which can convey coldness (Wierzbicka 1991).

26 Further support for a distinction between a question and a request is provided by Goody (1978: 23) and by Searle (1976/1990: 360, 360ff), both of whom argue that the two speech acts are distinct. At the same time, both writers observe that the two speech acts are closely related. Goody (1978) points out that questions, like requests, have command characteristics, as they compel the hearer to reply; Searle (1976/1990) states that questions, like requests, are directives, as they are attempts by the speaker to get the hearer to do something (namely, to answer). Wierzbicka's (1987: 66-68) semantic description of the two English speech act verbs: "ask" in the sense of asking a question, and "ask" in the sense of asking someone to do something, is particularly enlightening on the relationship between questions and requests. 
27 Schegloff (1995) emphasises that this notion of conversational preference is not a psychological notion: the terms "preferred" and "dispreferred" do not refer to the motives or desires of the participants, but rather, to "a structural relationship of sequence parts" (Schegloff 1995: 59). Nevertheless, Brown and Levinson (1987) explain this preference for offers over requests in terms which are in part psychological; namely, in terms of face-considerations. They observe that "there is less face risk in A's inducing B to make an offer than in A making a request of $B$, because $B$ may refuse the request, but not withdraw the offer" (Brown \& Levinson 1987: 39). 


\section{CHAPTER 4. REOUESTS: THE HEAD ACT}

This chapter examines how learners and BI NSs perform the most important component of the request: the head act. In the first part of the chapter (Results) request head acts in the data are described; in the second part of the chapter (Discussion) the most important findings are selected and discussed.

In extracts from the data below, $\mathrm{L}$ denotes learner subject, $\mathrm{BI}$ NS denotes BI native speaker subject, and $\mathrm{P}$ denotes (BI native-speaking) partner.

\subsection{Results}

\subsubsection{Choice of request head act strategy: BI native speakers}

BI native speaker subjects use a range of request strategies in these situations: direct sub-strategies, conventionally indirect sub-strategies, and hints (see Table 2 below).

\subsubsection{Direct requests by BI native speakers}

Direct requests comprise a very large proportion $(42.7 \%$ or $91 / 213)$ of BI NS requests. In particular, BI NSs make frequent use of the most direct sub-strategy of all: the imperative. Imperatives account for $17.4 \%$ (or 37/213) of requests by BI NS subjects (see Table 2). Approximately half of NS BI imperative requests are full imperatives (19/37) and half are elided imperatives (18/37) .

No other single direct sub-strategy is used by BI NSs with comparable frequency to the imperative. However, together, other direct sub-strategies account for a sizeable proportion ( $25.4 \%$ or $54 / 213$ ) of total BI NS requests.

The most frequently used of these is the hedged performative, which accounts for $10.3 \%$ (or 22/213) of BI NS requests. All of the hedged performative requests by BI NSs employ the performative verb minta "ask for" (see 3.3.1). 
Table 2: Proportion of different request strategies used by BI native speaker subjects

\begin{tabular}{|l|l|cc|}
\hline Strategy type & & $\mathrm{n}$ & $\%$ \\
\hline \multirow{4}{*}{ DIRECT } & Imperative & 37 & 17.4 \\
\cline { 2 - 4 } & $\begin{array}{l}\text { Performative } \\
\text { or Goal } \\
\text { statement }\end{array}$ & 39 & 18.3 \\
\cline { 2 - 4 } & Want statement & 15 & \\
\hline \multirow{4}{*}{$\begin{array}{l}\text { CONVENT- } \\
\text { IONALLY } \\
\text { INDIRECT }\end{array}$} & $\begin{array}{l}\text { Query } \\
\text { preparatory: } \\
\text { modal }\end{array}$ & $\begin{array}{l}\text { Query } \\
\text { preparatory: } \\
\text { availability: }\end{array}$ & 10 \\
\hline \multirow{2}{*}{$\begin{array}{l}\text { NON- } \\
\text { CONVENT- } \\
\text { IONALLY }\end{array}$} & Hint: Question & 10 & 46.5 \\
\hline & $\begin{array}{l}\text { Total No of } \\
\text { request head } \\
\text { acts }\end{array}$ & 3 \\
\hline
\end{tabular}

Occasionally BI NSs make requests using Want statements. This sub-strategy accounts for 6.3.\% (15/237) of requests by BI NSs (see Table 2). These Want statements nearly always employ the modal verb mau "want", but in a couple of instances use ingin "want/wish" or pingin (a Javanese variant of ingin : see 3.3.1)

Two other direct sub-strategies occasionally used by BI NSs are Goal statement ( $4.7 \%$ or $10 / 213$ of requests), and explicit performative $(3.3 \%$ or $7 / 213$ of requests). Almost all explicit performative requests by BI NSs use the verb minta "ask for"; one, used in asking a university lecturer for an essay extension, uses the more deferential verb mohon, below: 
38 NS: ... jadi saya mohon untuk bisa menyelesaikan esai saya itu pada

NS: $\quad$ hari Senin depan (.) kalau bisa itu.

NS: $\quad$... so $\underline{\text { I ask }}$ to be able to finish my essay next Monday (.) if (I)

NS: can.

\subsubsection{Conventionally indirect (CI) requests by BI native speakers}

Conventionally indirect $(\mathrm{CI})$ requests comprise the largest category of request head acts by BI NS subjects (see Table 2 above). Over half $(51.1 \%$ or 109/213) of requests by $\mathrm{BI}$ NSs are conventionally indirect.

The vast majority of these CI requests are query preparatory modal requests; that is, ones which question the condition of either ability or permission, with the modal verb bisa "can" or boleh "may/ be allowed" (see 3.3.2). This QP modal substrategy alone accounts for nearly half ( $46.5 \%$ or $99 / 213)$ of the requests made by BI NSs (see Table 2).

In these QP modal requests, BI NS subjects show a clear preference for the modal verb bisa "can" over boleh "may/ be allowed". In those QP modal requests where the speaker has a choice between bisa "can" or boleh "may/ be allowed," BI NS subjects select bisa "can" almost five times as frequently as they do boleh "may/ be allowed" (74 instances of bisa compared with only 15 instances of boleh ).

A small proportion of CI requests by BI NSs employ the other query preparatory sub-strategy: that of questioning the availability of the desired item. This substrategy accounts for $4.7 \%$ (or 10/213) of requests by BI NS subjects (see Table 2). The majority of these use the verb ada? "is there/ are there?"; several others use the verb punya? "have?" instead (see 3.3.2). 


\subsubsection{Non-conventionally indirect requests (hints) by BI native speakers}

BI NSs use considerably fewer non-conventionally indirect (Non-CI) requests, or hints, than either of the other two categories of requests above (see Table 2). Hints comprise only $6.1 \%$ (or 13/213) of the total requests by BI NSs.

When BI NSs do use hints they are generally in the form of questions. Most of these question hints are potential pre-requests, checks on information which function as requests because they succeed in eliciting an offer from the interlocutor. Examples are [39] and [40] below (the hint is underlined in each example):

39 (asking a friend for a lift back to college on their motor-scooter)

NS: Mau pulang?

P: $\quad Y a($.$) mau pulang?$

NS: $\quad Y a$

P: Sama-sama deh?

NS: Are you going home?

P: Yeah (.) are you going home?

NS: Yeah

P: (We'll go) together huh?

40 (asking a friend to pass some magazines across, while watching TV together at his or her house)

NS: Itu majalah-majalah baru bukan itu.

P: Mau pinjem?

NS: Those magazines are new aren't they.

P: Want to borrow them?

Statement hints are only used very occasionally by BI NS subjects. They account for only $1.4 \%$ (or $3 / 213$ ) of total requests by BI NSs (see Table 2). All these statement hints are potential grounding moves (supportive reasons for making the 
request), consisting of the information that the speaker does not have the desired item. An example is this:

41 (asking a hotel receptionist for a pen to fill in the registration form)

NS: $O$ maaf saya tidak membawa bolpoin.

NS: Oh sorry I didn't bring a pen.

\subsubsection{BI native speakers' choice of strategy: Summary}

As evident from Table 2 above, most requests by BI native speaker subjects are conventionally indirect. One CI sub-strategy in particular, the QP modal request, is easily the most frequent single request sub-strategy for BI NSs. Direct requests also account for a large proportion of BI NSs' requests. While no single direct substrategy is nearly as common as the QP modal request, the most direct of all, the imperative, is frequently used; and several other direct sub-strategies are also used regularly. Non-CI requests, or hints (in contrast with both $\mathrm{CI}$ and direct requests) are only very infrequently used by BI NS subjects.

\subsubsection{Choice of request head act strategy: Learners}

\subsubsection{Direct requests by learners}

While learners use somewhat fewer direct requests than BI NSs, this strategy comprises a large proportion $(32.9 \%$ or $78 / 237)$ of learner requests as well. However, learners use the various direct sub-strategies in very different proportions to BI NSs (see Table 3 below). Imperatives, the favoured direct substrategy of BI NSs are used only occasionally by learners (in 5.5\% or 13/237 of their requests). Elided imperatives, in particular, are almost never used by learners ( $1.3 \%$ or $3 / 237$ requests). The sub-strategies of explicit performative, hedged performative, and Goal statement are virtually never used by learners. Together, these three sub-strategies account for only $1.7 \%$ (or 4/237) of learner requests.

On the other hand, Want statements are used very frequently by learners, much more so than by BI NSs (see Table 3). This sub-strategy alone accounts for the vast majority (78.2\%) of direct requests by learners, and for a substantial proportion $(25.7 \%$ or $61 / 237)$ of learner requests overall. 
Table 3: Proportion of different request strategies used by learner and BI native speaker subjects

\begin{tabular}{|c|c|c|c|c|c|}
\hline & & \multicolumn{2}{|c|}{ Learners } & \multicolumn{2}{|c|}{ BI NSs } \\
\hline & & & $\%$ & $\mathrm{n}$ & $\%$ \\
\hline \multirow{3}{*}{ DIRECT } & Imperative & 13 & 5.5 & 37 & 17.4 \\
\hline & $\begin{array}{l}\text { Performative } \\
\text { or Goal } \\
\text { statement }\end{array}$ & 4 & 1.7 & 39 & 18.3 \\
\hline & Want statement & 61 & 25.7 & 15 & 7.0 \\
\hline \multirow{2}{*}{$\begin{array}{l}\text { CONVENT- } \\
\text { IONALLY } \\
\text { INDIRECT }\end{array}$} & $\begin{array}{l}\text { Query } \\
\text { preparatory: } \\
\text { Permission }\end{array}$ & 98 & 41.4 & 99 & 46.5 \\
\hline & $\begin{array}{l}\text { Query } \\
\text { preparatory: } \\
\text { Availability: }\end{array}$ & 23 & 9.7 & 10 & 4.7 \\
\hline \multirow{2}{*}{$\begin{array}{l}\text { NON- } \\
\text { CONVENT- } \\
\text { IONALLY } \\
\text { INDIRECT }\end{array}$} & Hint: Question & 16 & 6.8 & 10 & 4.7 \\
\hline & Hint: Statement & 22 & 9.3 & 3 & 1.4 \\
\hline & $\begin{array}{l}\text { Total No of } \\
\text { request head acts }\end{array}$ & \multicolumn{2}{|c|}{237} & \multicolumn{2}{|c|}{213} \\
\hline
\end{tabular}

Learners in general select the same modal verbs in Want statements as BI NSs subjects. Like BI NSs, they use the modal verb mau "want" in the majority of Want statements, and occasionally use ingin "want/wish" instead. However, on several occasions, learners select a modal verb which BI NSs subjects never use in Want statements: perlu "need" or harus "must/should". In each instance, this choice of modal verb is judged inappropriate by informants. Examples are these:

42 (asking a waiter for a menu)

L: $\quad$... saya perlu daftar makanan.

L: $\quad$... Ineed a menu. 
(ordering a drink from a waiter in a restaurant)

L: $\quad$ Saya harus membeli sebotol bir juga (.) sekarang

L: I I should/must buy a bottle of beer too (.) now

In [42] above, the use of perlu "need" creates an unidiomatic effect (and prompted one informant to ask, "needs it for what?"). In [43] above, the use of harus "should/must" is clearly inappropriate, as it suggests an obligation to carry out the act which does not in fact exist. ${ }^{1}$

Certain discourse features especially seem to elicit Want statements from learners. Learners tend to resort to Want statements when a complication develops during the request speech event, and order must be restored by conveying the illocutionary force, or the nature of the request goal, very clearly. An example is [44] below:

44 (asking a friend from college for a lift home on their motor scooter)

L: (calls out to attract attention) Hey kok (.) NAME pulang ke

L: asrama?

(.)

P: Uh ya (.) mau ke mana?

L: $\quad \mathrm{Ke} /$ (.) ya terima kasih (.) saya mau ikut.

P: $\quad$ Oh baiklah ya (.) sama-sama

L: (calls out to attract attention) Hey 'kok' (.) are you going

L: home to college?

(.)

P: Uh yeah (.) where are you going?

$\mathrm{K}$ : $\quad \mathrm{To} /($.$) yeah thank you (.) I want to come too.$

P: Oh all right yeah (.) (We'll go) together

In [44] the learner starts to respond to the interlocutor's question Mau ke mana? "Where are you going?" with information about her destination (Ke ... "To ..."), but then seems to decide in mid-utterance that the question was an offer of a lift, and so thanks the interlocutor instead. But she still appears to be uncertain whether she has in fact been offered a lift, and so she follows her thanks with a Want 
statement, as if to make her intentions quite clear: Saya mau ikut "I want to come too".

Another example of a learner using a Want statement to restore order to the discourse is [45] below:

45 (buying a magazine from a street stall)

L: $\quad$ Apa ada (.) majalah (.) Tempo? (.) di sini?

P: $\quad$ Majalah Tempo ya (.) ada (.) mau edisi yang keberapa.

L: Berapa uang?

P: $\quad$ O (.) harganya? (.) harganya 3000 rupiah.

L: $\quad A a h$.

P: $\quad$ Iya

L: $\quad$ Saya mau.

P: $\quad$ Ah ya (.) silakan (gives her the magazine)

L: $\quad$ Is there (.) Tempo magazine? (.) here?

$\mathrm{P}$ : Tempo magazine yes (.) there is (.) what number issue do

P: you want?

L: How much money?

P: $\quad$ Oh (.) the price? (.) the price is 3000 rupiahs.

L: Aah.

P: Yeah.

L: $\quad$ I want (it).

P: $\quad$ Ah yeah (.) here (gives her the magazine)

In [45] above, a misunderstanding develops because the learner does not understand the seller's question Edisi keberapa? "What number issue?" (literally: "the 'how many-th' issue?"). The learner apparently thinks that the seller may mean "How much money?", and checks that interpretation with the seller, by asking Berapa uang? "How much money?". The seller in turn misinterprets that question as one about the price. He tells her the price, and the interaction appears to stall at that point. To restore coherence to the speech event, the learner then makes an unambiguous request for a magazine, with a Want statement: Saya mau "I want (it)". 
In what appears to be a related phenomenon, learners also tend to use Want statements after making a check on availability which does not achieve request status. An example is [46] below:

46 (asking to buy a magazine from a street stall)

L: $\quad$ Saya mau membeli majalah Tempo yang terbaru (.)

L: $\quad$ sudah ada?

P: $\quad$ Ada

L: Berapa harganya.

P: $\quad$ Ini (shows the price on the cover)

L: $\quad$ Okay saya mau membeli.

L: I want to buy the latest Tempo magazine (.) do you have

L: $\quad$ it?

P: $\quad$ Yes

L: $\quad$ How much is it.

P: $\quad$ Here (shows the price on the cover)

L: $\quad$ Okay I want to buy it.

A similar example is [47] below:

47 (ordering a meal in a restaurant)

L: $\quad$ Ada nasi goreng di sini?

P: $\quad$ Ada

L: $\quad$ Saya mau makan sepiring nasi goreng.

L: Do you have (lit: "is there") fried rice here?

P: Yes.

L: $\quad$ I want to eat a plate of fried rice.

This use of a Want statement to make a request proper after a pre-request is related to its use in [44] and [45] earlier. In each case a potential request has been made, but it has not been interpreted as a request, and the speaker now wants to make it clear that a request is intended. 
BI NS subjects, by contrast, do not use Want statements for this function. In the "magazine" and "restaurant" situations in [46] and [47] above, for example, BI NSs who made the same kind of check on availability then proceeded carry out the request proper not with Want statements, but with other sub-strategies (elided imperatives, explicit performatives, or Goal statements). An example is this:

48

(ordering a meal in a restaurant)

NS: Ada nasi goreng?

P: $\quad A d a$

NS: $\quad$ Satu Mbak.

NS: Do you have (lit: "is there" fried rice?

P: Yes.



The way learners prefer to use Want statements for this particular function of restoring clarity to discourse contributes to the much higher overall use of Want statements by this group than by BI NSs. However, learners also use Want statements in instances where their requestive intention is not problematic. An example is this:

49 (ordering a meal in a restaurant)

P: $\quad$ Mau pesan apa?

L: $\quad$ Sava mau nasi putih dan cap cay?

P: What do you want to order?

L: I I want boiled rice and 'cap cay'?

A more native-like way to make the request in [49] above would be an elided imperative, Nasi putih dan cap-cay. "Boiled rice and 'cap-cay." The 'want' element has already been explicitly supplied by the waiter in the previous turn, with the question Mau pesan apa? "What do you want to order?," so that the learner's repetition of this element in the request creates a rather overexplicit effect. Learners, then, appear to favour Want statements both when the development of the discourse requires the requestive intent to be made particularly clear and when it does not. 
Another distinctly non-native trait of a number of learners' Want statements is the inclusion of a main verb after the modal verb when requesting goods. For example, several learners do this in ordering a meal, as in [47] earlier, and in [50] and [51] below:

L: Saya mau makan (.) gado-gado?

L: I want to eat (.) 'gado-gado'?

51 L: $\quad$ Saya mau membeli nasi goreng dan dua piring nasi

L: putih.

L: I want to buy a fried rice and two plates of boiled rice.

This feature, too, creates an effect of overexplicitness. The Want statements in [50] and [51] above would sound considerably more idiomatic if the verbs makan "eat" and membeli "buy" respectively were omitted from the utterance. 2

\subsubsection{Conventionally indirect (CI) requests by learners}

Learners, like BI NS subjects, use more CI requests than any other category of request (see Table 3 above). More than half of the requests by learners, too, are conventionally indirect $(51.1 \%$ or $121 / 237)$.

The vast majority of CI requests by learners are query preparatory modal requests, with bisa "can" or boleh "may/ be allowed." Learners use this request type almost as frequently as BI NSs do (41.4\% of learner requests: see Table 3 ).

In a striking contrast to BI NSs, learners show a strong preference for the modal verb boleh "may/ be allowed" over bisa "can" when using this sub-strategy. In those QP modal requests where a speaker can choose between the two modal verbs, learners select boleh "may/be allowed" more than twice as frequently as bisa "can" (60 instances of boleh compared with only 26 instances of bisa). In fact, even when bisa "can" must be chosen, because the focus of the request is on the hearer, learners sometimes select boleh "may/ be allowed". An example is this: 
52 (asking a stranger to make room for you to sit down in a crowded eating stall)

L: $\quad$... boleh Anda bergeser sedikit?

L: $\quad$... may you move a little?

Learners use boleh in a large proportion (40\% or 5/12) of their QP modal requests where it is not acceptable because of hearer-perspective, like [52] above.

Another notable tendency of learners in using this QP modal strategy is to transfer the common English request formula "Can I have ?" into Indonesian. This request formula is not conventionalised in Indonesian. One may conventionally ask if one can (or may) borrow something (Bisa/boleh saya meminjam ...?) or if one can (or may) get something (Bisa/boleh saya mendapat(kan)...?), for example, but the two verbs which equate most closely to "have" (mempunyai or its less formal variant punya; and $a d a$, are not used in this way. An example of this kind of inappropriate request form by a learner is as follows:

53 (asking an official for forms for a visa extension)
L: $\quad$ * Boleh saya punya formulir untuk memperpanjang visa
L: saya?

L: $\quad$ May I 'have' the forms to extend my visa?

The pragmatic effect of [53] is roughly that of the English question "May I possess the forms to extend my visa? Because the verb punya "have" is not conventionally used in QP modal requests, forms like [53] run the risk of not being understood as requests at all. One informant remarked on [53] that it sounds as if the learner is enquiring whether it is within the regulations for her to have the forms, rather than asking to be given them. An acceptable alternative in [53] would have been for the learner to ask Boleh saya mendapat(kan) formulir untuk memperpanjang visa saya? "Can I get/obtain the forms to extend my visa?"

One more example of this type of request by a learner, using a different verb, is [54] below: 
(asking to borrow a pen from a classmate)
L: $\quad$ * Bolehkah saya ada sebuah bolpoin?
L: $\quad$ May-INT I 'have' a pen?

The effect of [54], too, is highly unidiomatic, because of the choice of verb. An acceptable alternative would have been for the learner to ask for a pen with Boleh(kah) saya pinjam...? "May I borrow ...?".

As well as producing this unacceptable "have" permission request in a number of instances, learners produce another unacceptable form in several instances, apparently in order to avoid literal transfer of the "have" form. In this second form, the main verb is omitted from the permission request. An example is this:

55 (asking a waiter for a menu)
$\mathrm{L}: \quad$ *Boleh saya (.) um (.) uh (.) daftar makanan?
L: $\quad$ May I (.) um (.) uh (.) the menu?

In [55], the pauses and hesitations ("um", "uh") after the first part of the request (Boleh saya "May I") suggest that the speaker has realised at this point that the verb "have" is unacceptable, and is attempting to find a strategy to solve this problem; her eventual solution being to leave out the verb altogether. So in one way or another, negative transfer of the common English request formula "Can I have?" seems to be a significant problem for these learners in using their main L2 request sub-strategy. ${ }^{3}$

Learners use the other query preparatory sub-strategy, that of asking about the availability of a desired item, slightly more frequently than BI NSs (9.7\% or 23/237 of requests: see Table 3 above). Generally, learners perform these requests using the same verb as BI NSs: ada? "is there/ are there? or punya? "have"? (see 3.3.2). However, in a number of instances learners select an unidiomatic verb form for this type of request. This form is mempunyai, the formal variant of punya "have." As Quinn (1996a:151, 1996d:137) observes, this formal variant is somewhat narrower in semantic scope than punya, tending towards the meaning "possess". Query preparatory requests using this verb are considerably less conventionalised than those using punya or $a d a$. Examples by learners are as follows: 
56 (asking a stranger for a light for a cigarette)
L: Apa Saudara mempunyai korek api?
L: Do you have a match?

A BI native speaker would be much more likely to use punya in [56] above (e.g. Punya api? “(Do you) have a match?”).

57 (buying a magazine at a street stall)
L: $\quad$ Saya mau membeli majalah Tempo yang terbaru (.)
L: apakah Pak mempunyai?
L: I want to buy the latest Tempo magazine (.) do you have
L: $\quad$ (it)?

A BI native speaker would be more likely to use ada in [57] above (e.g. Saya mau Tempo yang terbaru. Ada? "I want the latest Tempo. Do you have it? (lit: "is there?").

The learner requests in [56] and [57] above are distinctly non-native in their effect. In fact, although these forms using mempunyai "have" have been classified as conventionally indirect along with the other QP availability request forms using punya "have" and ada "there is/ there are", this is largely a matter of descriptive convenience. The choice of this verb form mempunyai makes the requestive force considerably less transparent, so that the pragmatic effect becomes closer to that of a non-conventionally indirect request: a question hint.

\subsubsection{Non-conventionally indirect requests (hints): Learners}

Learners use hints considerably more often than BI NS subjects do (see Table 3 above). Hints comprise a substantial minority $(16.0 \%$ or $38 / 237)$ of learner requests. Statement hints, particularly, are used much more frequently by learners than by BI NSs, accounting for almost $10 \%$ of learner requests.

Nearly all the learners' statement hints are potential grounding moves, consisting of the information that the learner does not have something, or does not know something, or cannot do something. Examples are these: 
58 (asking a hotel receptionist for a pen to fill in the registration form)

L: ... saya tidak ada pena?

L: ... I don't have a pen?

59 (asking a bus conductor to tell you when you get to the stop nearest to Kartini Street)

L: ... saya (.) uh (.) tidak tahu di mana (.) uh (.) Jalan Kartini

L: ... I (.) uh (.) don't know where (.) uh (.) Kartini Street is

60 (asking a lecturer for an extension on an essay deadline)

L: $\quad$... saya tidak bisa (.) menyelesaika/ menyelesaikan (.) uh

L: $\quad$ (.) esu (.) esai (.) esai

P: $\quad H m ~ h m$

L: esaimu?

L: $\quad$.. I can't (.) fini/ finish (.) uh (.) you/ (.) your (.) your

P: $\quad \mathrm{Hm} \mathrm{hm}$

L: $\quad$ your essay?

Learners also use quite a high proportion of question hints, slightly more than BI NSs ( $6.8 \%$ or $16 / 237$ of requests: see Table 3 above). However, while some of these question hints are similar in kind to BI NS question hints, and apparently strategically motivated, at least half of the learners' question hints seem intended as conventionally indirect requests, not as hints. For example, $6 / 16$ of question hints by learners consist of the same incorrect request form, exemplified below:

61 (asking a bus conductor to let you know when the bus gets to the stop closest to Kartini Street)

L: $\quad$ *... apa Anda memberitahu saya ... ketika kami (.) uh (.) datang

$\mathrm{L}: \quad k e($.$) stop bis yang terbaik?$

L: $\quad$... do you tell me ... when we (.) uh (.) come to (.) the best bus

L: $\quad$ stop? 
Requests like [61] above query the condition of whether the hearer performs the desired act. This strategy is not conventionalised as a means of requesting in Indonesian. However, it is likely that learners in producing requests like [61] above are trying to formulate a QP modal request, such as Apa Anda bisa memberitahu saya... "Can you tell me...?", and inadvertently leave out the modal verb, thus creating an idiosyncratic pragmalinguistic form, meaning "Do you...?".

Another example of a question hint by a learner which is apparently intended as conventionally indirect is this one:

62 (asking a fellow college resident for a lift home from the shops on his or her motor scooter)

L: $\quad$... uh saya (.) mau (.) ikut (.) um (.) dengan (.) kamu (.)

L: $\quad$ apakah itu (1.0) baik? ata-a-u-u

P: $\quad$ Ya (.) bisa ...

L: $\quad$.. uh I (.) want (.) to come (.) um (.) with (.) you (.) is that

L: (1.0) good? o-o-r

P: $\quad$ Yes (.) you can ...

The speaker in [62] apparently tries to transfer the conventional English request formula "Is that all right?". 4 He gets as far as "Is that" (Apakah itu) and then pauses for a long time, as if realising the problem that there is no exact Indonesian semantic equivalent of "all right," and eventually adds "good" (baik). However, asking if a proposed action by the speaker is all right, or good, is not a conventionalised means of requesting in Indonesian, so the learner's request in this case functions as a highly unusual hint.

\subsubsection{Learners' choice of request strategy: Summary}

As evident from Table 3 above, learners show important similarities and differences with BI NSs in their choice of head act. Like BI NSs, they use conventionally indirect requests more frequently than either direct requests or hints, and select query preparatory modal requests as their main type of CI request. However, learners generally use a different modal verb from BI NSs to realise this substrategy, using boleh "may/ be allowed to" rather than bisa "can". Both groups 
also use direct requests frequently. However, learners' choice of direct substrategies is very different from BI native speakers: they use almost all types of direct requests much less frequently than BI NSs, and use Want statements much more frequently than BI NSs. Learners also use Non-CI requests (hints) considerably more often than BI NSs do, particularly statement hints.

\subsubsection{Situational variation in selection of request strategy}

Another important aspect of subjects' choice of request strategy is how they vary their choice according to situation. In the following section, learners and BI NSs are compared in this regard (see Appendix B for a table of the proportion of subjects who use each sub-strategy in each situation).

Situational variation is examined with regard to several request types: imperatives (as the main direct sub-strategy of BI NSs), Want statements (as the main direct sub-strategy of learners), query preparatory modal requests (as the main CI substrategy of both groups), and hints.

Mean values and rankings of speaker's status relative to hearer, size of imposition, and degree of speaker's comfort in various situations, referred to below, are based on assessments by BI native speaker and learner informants (see 2.5). A tabular summary of values and rankings of these three variables in each situation is provided in Appendix C.

\subsubsection{Situational variation in selection of imperatives: BI native speakers}

There are three situations where BI NSs show a notable tendency to select imperatives: asking the bus conductor to tell them when they reach their stop (5/9 subjects), asking a taxi driver to stop for a minute so they can buy cigarettes (5/9 subjects), and asking a hotel servant to have their dirty clothes washed (3/9 subjects). No single factor clearly explains the selection of imperative strategy in all three situations; however, certain factors seem to influence the choice of imperative in certain of them. 
In the "hotel servant" situation above, the speaker's perceived high status relative to the hearer seem likely to have influenced imperative selection, as speaker's status in this situation ranks very high: 1 st out of the 26 situations, with a mean value of 3.80. The status of the speaker seems intuitively likely to influence choice of imperative, as imperative is a strategy generally thought to have command characteristics. And it seems significant that in the "bus conductor" situation, too, the requester's status in relation to the hearer ranks high (equal 6th out of the 26th situations, with a mean value of 3.47), suggesting that high status of speaker is indeed an important influence on imperative choice.

In the "taxi driver" situation, too, the speaker's status is perceived of as higher than the hearer's (ranked 11th of the 26th situations, with a mean value of 3.33), but the status difference between the interlocutors is less salient than in two situations above. An additional factor probably influences choice of imperative in this "taxi driver" situation; namely, the factor of urgency, which may override social factors. Brown and Levinson $(1978,1987)$ observe that the imperative is used when a message has to be conveyed very quickly and clearly, so that the need for efficiency takes priority over face considerations. Speakers asking the taxi driver to stop for a minute during a trip through the city are likely to regard this request as urgent in that sense, because stopping is frequently difficult and dangerous in crowded Indonesian city streets, making clear communication between speaker and hearer very important.

One other possible determinant of imperative choice is worth considering: the notion of a 'standard situation' (cf. House 1989). House (1989) has found that imperatives are used relatively frequently in English and German to make requests in standard situations: those situations where the speaker has a strong right to ask, the hearer has a high obligation to comply, and there is little difficulty involved in performing the act. In such situations, both speaker and hearer 'know where they stand', and so the act of requesting is seen as inherently easy. However, the situations where NS BIs favour imperatives are not uniformly "standard" in this sense. Most notably, in asking a bus conductor to tell them when they reach their stop, the size of the imposition on the hearer is perceived as large (ranked 1st out of the 26 situations; with a score of 3.67). As imposition is largely a composite of those factors (rights, obligations, and difficulty) which determine the 'standardness' of a situation; 5 the speaker in this "bus conductor" situation does not appear to have (e.g) a strong right to ask, and the hearer (e.g.) a strong 
obligation to comply. Similarly, in asking the taxi driver to stop for a minute, the speaker is perceived as relatively uncomfortable about making the request (degree of comfort ranks equal 20th out of the 26 situations). In standard situations, however, the act of requesting is seen as inherently easy, so that the speaker would not be expected to feel uncomfortable about making the request.

In only one other situation is an imperative request used by more than one NS BI subject: asking a friend to pass across some magazines while watching TV together ( $2 / 9$ subjects). ${ }^{6}$ A likely factor in imperative selection in this situation is the very small social distance between speaker and hearer, combined with the fact that the interlocutors are the same in status (speaker's status relative to hearer is assessed as precisely equal). This close and equal relationship between speaker and hearer is likely to be decisive in making the imperative an appropriate choice of strategy.

In summary, no single factor or combination of factors is identified which consistently determines use of the imperative by BI NSs subjects. However, in certain situations, factors can be identified (such as speaker's high status relative to hearer, perceived urgency of the request, and close social distance betwen speaker and hearer) which appear to seem to influence imperative selection.

\subsubsection{Situational variation in selection of imperatives: Learners}

Learners show striking similarities to BI NSs in their selection of imperatives according to situation. Most obviously, the one situation in which learners use imperatives very frequently (5/10 subjects) is one in which BI NSs, too, strongly favoured imperatives: asking a taxi driver to stop for a minute so they can buy cigarettes. This suggests that learners may be sensitive to the factor of urgency in the same way as BI NSs: learners, too, appear to assess efficiency and clarity as of paramount importance in this situation and to select imperatives for that reason. Additionally, learners in this situation perceive their status as high in relation to hearer (ranked equal 5th out of 26 situations), and this is likely to be another factor influencing their willingness (as with that of BI NSs) to make imperative requests here.

In two other situations, more than one learner subject (2/10) makes an imperative request. One of these situations, asking a hotel servant to have their clothes washed, is one where BI native speakers used imperatives frequently as well. 
Learners, like BI NSs, perceive their status in relation to the hearer as very high in this "hotel servant" situation (ranked 1st out of the 26 situations by learners). This strongly suggests that learners in this situation, like BI NSs, are influenced largely by the factor of status in their selection of imperatives .

The other situation in which more than one learner (2/10) makes an imperative request is ordering a drink from a waiter (a situation in which a BI native speaker subject (1/9), too, uses an imperative request). In this situation, as well, learners regard their status in relation to the hearer as very high (ranked equal 3rd out of 26 situations, with a raw score of 3.80), suggesting again that the factor of high speaker's status is important. Learners also feel very comfortable making this "drink" request compared to other requests (speaker's comfort is ranked 1st out of the 26 situations), and this factor of degree of comfort may combine with the factor of high speaker status to encourage learners to use imperatives in this situation.

The only other situation in which a learner uses an imperative request is, again, one in which BI NSs (2/9) used this sub-strategy: asking a friend to pass across some magazines while watching TV together. This suggests that learners, too, may be responsive to the factor of very close social distance in this situation. Moreover, learners (like BI NSs) assess speaker's status in this situation as precisely equal to hearer's (a score of 3.00). So learners, too, appear to be influenced by the existence of a close and equal relationship in their selection of an imperative strategy.

In one striking difference from BI NSs, learners use no imperatives at all in asking a bus conductor to tell them when they reach the right stop. One reason could be that learners assess their status relative to the hearer as less high than BI NSs do in this situation (learners rank their status as 13 th out of 26 situations, while BI NSs ranked theirs as equal 6th). It may also be significant that learners appear to feel less comfortable than BI NSs about making this request (learners rank comfort in this situation as 19th out of the 26 situations; while BI NSs rank comfort as 10th). In any case, it appears that this situation is perceived as particularly appropriate for use of the imperative by BI NSs, but not by learners.

To sum up, learners show close similarities to BI NSs in the way they select imperatives according to the situation. In particular, they appear sensitive in the same way to the social variables of status and of social distance, as well as to the factor of perceived urgency. However, in one situation in which BI NSs strikingly 
favour imperatives (the "bus conductor" situation), learners did not use imperatives at all; a difference which may be partly due to different perceptions of the situation by the two groups.

\subsubsection{Situational variation in selection of Want statements: BI native speakers}

For NS BI subjects, the situational setting seems the most important factor in determing whether subjects use Want statements. Subjects show a clear tendency to use this strategy most frequently in transactional service encounters. The only two situations where this strategy is used with notable frequency are service encounters: buying stamps and envelopes in the post office (4/8 subjects), and asking an official in the immigration office for forms to apply for a visa ( $3 / 9$ subjects). Moreover, almost all the other situations where Want statements are used by BI NSs are service encounters (e.g. buying a cinema ticket, ordering a drink, asking to try on shoes, and asking to exchange a shirt).

It appears from respondents' assessment of situations that NS BIs tend to feel comfortable in service encounters about making the request. For example, in the "post office" situation above, they feel extremely comfortable (comfort is ranked 1 st out of the 26 situations). Therefore this factor of speaker's comfort in its own right might be thought decisive in eliciting the strategy of Want statement. However, it is interesting that in the other service encounter where NS BIs notably select Want statements, the "immigration official" situation, NS BIs do not seem to feel especially comfortable about making the request (comfort is ranked equal 11th out of the 26 situations; with a score of 3.20 ).

The size of imposition, too, is not consistent in service encounters where BI NSs use Want statements. While in some the imposition is regarded as small, in others it is assessed as large (for example, in exchanging a shirt in a store, imposition is ranked as 2 nd biggest out of the 26th situations). So it appears to be the service encounter setting itself, rather than the value of the social variables in that setting, which tends to influence the selection of Want statements by BI NSs.

At the same time, it is important to note that BI NSs do not consistently select Want statements in service encounters. They use no Want statements at all, for example, in buying a magazine from a street stall (and only use them very 
occasionally in others: see Appendix A). So, while the existence of a service encounter setting is important for selection of this sub-strategy, it seems to have a rather erratic effect.

\subsubsection{Situational variation in selection of Want statements: Learners}

Learners, like BI NSs, appear to be primarily influenced by the existence of a service relationship in their selection of Want statements. All the situations in which learners use Want statements most frequently are service encounters: buying a cinema ticket ( $8 / 10$ subjects), ordering a meal in a restaurant ( $7 / 10$ subjects, changing a large note in a bank (7/10 subjects), buying a magazine at a roadside stall ( $5 / 10$ subjects), asking to try a cassette in a store ( $5 / 10$ subjects). Almost all the other situations in which learners use Want statements are service encounters as well (see Appendix A).

Some of the service encounters in which learners use Want statements are ones in which BI NSs use them too (e.g. buying stamps and envelopes in a post office); however, others are situations where BI NSs do not use them (e.g. buying a cinema ticket). So, while learners and BI NSs seem to be influenced by the same broad situational feature (the presence of a service relationship) in selecting this sub-strategy, more fine-grained similarities in situational variation by the two groups are not apparent from the data.

While learners use Want statements very frequently in service encounters, they, too, do so inconsistently. For example, while a clear majority of learners (7/10) used a Want statement to order a meal in a restaurant, only one learner $(1 / 10)$ uses a Want statement to order a drink in a restaurant. So for learners, too, the presence of a service relationship appears to correlate somewhat erratically with the use of Want statements.

An additional factor that may be relevant in the case of learners but not BI NSs is that learners sometimes favour Want statements in situations where the propositional content of the request goal is is difficult to convey. In three situations where learners used Want statements very frequently, they had to supply hard-toexpress information or a large amount of information: in changing a large note in a bank they had to use a lot of high numbers in talking about denominations of notes 
(which several learners stumbled over or got wrong); in the cinema, they had to describe a very specific seat position, the middle-front row (which led to misunderstanding in several instances) and in the post office, they had to include several items of information: number of envelopes, number of stamps, and destination of letter. So the tendency for learners sometimes to resort to Want statements for their explicitness and clarity (see 4.1.2.1) may also help to determine in which situations learners use this strategy.

To sum up, both groups seem also to be influenced by the presence of a transactional, service relationship in selecting Want statements. However, the specific situations in which learners and BI NSs use Want statements are sometimes different. Moreover, both learners and BI NSs show somewhat erratic variation by situation in selection of this strategy. It is possible that learners may be influenced by an additional factor in selecting Want statements: the issue of how linguistically difficult the request goal is to convey.

\subsubsection{Situational variation in selection of $Q P$ modal requests: $B I$ native speakers}

BI NSs show a clear tendency to use this sub-strategy most frequently in situations where the value of the factors examined (status, imposition, and degree of comfort) point to a relatively face-threatening act. This is evident from examining the ten situations in which this strategy is used very frequently (by $5 / 9$ or more subjects).

In most of these ten situations, the values of variables strongly indicate a facethreatening act. For example, in the situation in which this sub-strategy is used most frequently of all (9/9 subjects): asking a stranger to move over in a crowded eating stall; speaker's status is assessed as very low (24th out of the 26 situations; with a value of 2.53), the imposition as high (equal 2nd out of the 26 situations; with a value of 3.60), and the degree of speaker's comfort as very low (25th out of 26; with a value of 2.20). These features of low speaker status, high imposition, and low degree of comfort are also strikingly present in, for example: asking to look on at a classmate's textbook (where 6/9 subjects used this strategy), asking a lecturer for an essay extension (6/9 subjects), and asking a lecturer for last week's handout (5/9 subjects). 
Only two of the ten situations where this sub-strategy is most frequently used do not clearly fit the pattern described above. These are the only two service encounters in this group of situations: asking to listen to a cassette in a store, and asking to try on shoes in a store. In both these situations the speaker's status is regarded as relatively high, and in one, the "cassette" situation, the speaker is regarded as relatively comfortable about making the request. However, this strategy of QP modal request is not used frequently in any other situations where values for the three factors above indicate a relatively low threat to hearer's face.

Another striking feature about this sub-strategy is that although BI NSs use it most frequently in relatively face-threatening situations, they use it to some degree in almost every situation (in all but two of the 26 situations). This makes the QP modal strategy the archetypal request strategy for BI NSs, in that it is selected across a broad range of situation types.

\subsubsection{Situational variation in selection of $Q P$ modal requests: Learners}

Learners, like BI NSs, tend to use QP modal requests most frequently in situations where the values of social variables (status, imposition, and degree of comfort) indicate a relatively high threat to face. This is evident from examining the six situations in which this sub-strategy is used very frequently (by $6 / 10$ or more) of learner subjects. In five of these situations the factors of low speaker status, high imposition, and low degree of speaker's comfort are present; strongly so in several instances (such as in asking a stranger to move over in a crowded eating stall (7/10 subjects) and in asking to exchange a shirt in a store (7/10 subjects). In only one of these six situations where QP modal requests are most frequently used is the threat to hearer's face apparently perceived as low: asking to try on shoes in a shoe store (7/10 learners).

Even more clearly than for BI NSs, this strategy appears to be the archetypal request strategy for learners. Like BI NSs, they use it in almost all situations $(25 / 26)$, and unlike BI NSs, they use it with fairly high frequency in many situations where threat to face is perceived as low, including routine service encounters (such as in asking for a menu, where 4/10 of learners use it; and in ordering a drink (4/10 learners)). In fact, the most striking feature of learners' 
selection of this sub-strategy is their readiness to use it across a wide range of situations.

To sum up, learners and BI NSs show two important similarities in their selection of this sub-strategy. Firstly, both groups (particularly BI NSs) tend to use it more frequently in situations where the threat to hearer's face is apparently perceived as relatively large. Secondly, despite the tendency above, both groups use it as their archetypal request type, by selecting it across a broad range of situations.

\subsubsection{Situational variation in selection of non-conventionally indirect requests (hints): BI native speakers}

BI NSs do not appear to display a coherent pattern of situational variation in their selection of hints. This is evident from an examination of the three situations in which hints are used most frequently by BI NSs: asking a hotel servant to have their clothes washed ( $3 / 9$ subjects), asking a friend for a lift home from the shops (2/9), and asking an official for forms for a visa application (2/9).

The "hotel servant" situation and the "lift home" situation above, in particular, are assessed quite differently. In the "hotel servant" situation, the speaker's status in relation to the hearer is assessed as very high (ranked 1st out of the 26 situations), and the speaker's comfort in making the request as high also (ranked equal 3rd out of the 26 situations). In the "lift home" situation, however, the speaker's status is assessed as only moderate and the speaker's comfort as fairly low (18th out of the 26 situations, with a score of 2.87).

One factor, however, does seem to be shared by all three situations above: the perceived imposition upon the hearer is at least moderately high. This is also true of almost all (6/7) of the other situations in which a hint is used by a BI NS subject: in these situations, too, imposition is consistently assessed as moderately high or higher (while the value of speaker's status and speaker's comfort once again, varies widely). This indicates a possible tendency for BI NSs to select hints in situations of relatively large imposition on the hearer.

On the whole, variation in use of this highly indirect strategy appears to be erratic; and is not linked with a perceived large threat to hearer's face, as predicted by Brown and Levinson $(1978,1987) .{ }^{7}$ The only observable pattern of variation is a 
possible tendency by BI NSs to use hints in situations when the imposition on the hearer is relatively large.

\subsubsection{Situational variation in selection of non-conventionally indirect requests (hints): Learners}

Learners, like BI NSs, do not display a coherent pattern of situational variation in their selection of hints. This is demonstrated by comparing the two situations in which learners use hints most frequently: asking a hotel receptionist to borrow a pen to fill in the hotel registration form (7/10 learners) and asking a university lecturer for an extension on an essay deadline ((6/10 learners).

These two situations are assessed quite differently in terms of social variables. In the "hotel receptionist" situation, the threat to face is apparently perceived as small. The speaker's status is high (equal 3rd out of 26 situations, with a value of 3.80) the imposition is the smallest of any situation (a value of 1.45), and the speaker's degree of comfort in making the request is very high (ranked equal 1st out of the 26 situations, with a value of 4.65). By contrast, in the "essay extension" situation, the threat to face seems relatively large: speaker's status is the lowest of any situation (a value of 1.45), imposition is the highest of any situation (a value of 4.50 ), and the speaker is the least comfortable of any situation (a value of 1.60). Nevertheless, in both these situations, learners show a striking tendency to select hints.

All the other situations in which learners use hints with notable frequency ( $3 / 10$ or 4/10 subjects) are situations which are perceived as relatively face-threatening (such as asking a lecturer for a copy of last week's handout, asking a stranger to move over to make room in a crowded eating stall, and asking a friend for a lift home from the shops). This suggests at first glance that learners might indeed select hints on the basis of the social variables examined here. However, the striking anomaly observed above makes one suspect that factors other than social variables play a role in selection of hints, and indeed, several such factors are probably influential.

One likely factor is the wording of written cues for subjects. In certain situations where learners used hints frequently, instructions to subjects were phrased in the form of a potential hint statement, which may have influenced learners' choice of 
this strategy (see 4.2.7). For example, in the anomalous "hotel receptionist" situation above, learners were told in their cue instructions:

... Resepsionis akan memberi Anda selembar formulir untuk diisi. (Anda tidak mempunyai pulpen).

... The hotel receptionist will give you a check-in form to fill out. (You do not have a pen).

and all the hints by learners in this situation were statements consisting of the information that they did not have a pen, variously worded (e.g. Saya tidak punya pena "I don't have a pen", Saya tidak ada pena "I don't have a pen", Tidak ada pena "There's no pen").

Another factor is the use of hint-like utterances without strategic intent. Learners may sometimes state their problem as an intended preliminary move to a more direct request, and have this preliminary utterance taken up as a hint (discussed in more detail in 4.2.7). A final factor is that the learners' hints in some situations may be meant as conventionally indirect requests, but be unintentionally phrased as hints due to linguistic errors (see 4.1.2.3).

In summary, use of hints is marked by somewhat erratic situational variation by both groups. For BI NSs, no coherent pattern of situational variation emerges. For learners, while hints are (generally speaking) used most frequently in relatively face-threatening situations, factors other than social variables are likely to be influential, such that many of their 'hints' may not be motivated by faceconsiderations at all.

\subsubsection{Situational variation in selection of request strategy: Summary}

Learners and BI NSs show close similarities in their variation in choice of strategy by situation. In the use of imperatives, they appear to be similarly sensitive to speaker's status; as well as to social distance in one situation, and to urgency in another. However, the two groups show a marked difference in use of imperatives with regard to one situation (asking a bus conductor to tell them when they reach their stop), which seems only partly explicable by different perceptions of the situation by the two groups. 
In the use of query preparatory modal requests, an important similarity is evident between groups: an apparent absence of factors in these situations which mitigate strongly against selection of the strategy. In other words, both groups use this strategy across situations as the archetypal requesting strategy. Moreover, in selection of this sub-strategy, both groups show a similar sensitivity to the size of threat to hearer's face.

Two other request types, Want statements and hints, reveal no clear pattern of variation by situation for either group. With Want statements, a certain similarity can be detected between the two groups, both groups selecting Want statements most often in service encounter settings. However, no social variables are found to consistently influence the selection of either Want statements or hints by either group.

In conclusion, for the strategies where a coherent pattern of situational variation could be observed for either group, learners and NSs showed marked similarities in variation in selection of the strategy. For certain other strategies, neither group showed a clear pattern of variation in selection according to situation.

\subsubsection{Appropriacy of learners' choice of strategy}

The choice of request strategy by learner subjects in this study is nearly always acceptable for the situation (in the judgement of BI native speaker informants: see 2.6). Several factors enable learners to consistently make an acceptable strategy choice. The most obvious (from the analysis above) is a certain ability of learners to make native-like adjustments to situation. For example, with regard to imperatives, learners display considerable sensitivity to factors conducive to their selection; with regard to Want statements, too, learners are sensitive to the presence of a service relationship between interlocutors, and nearly always eschew this strategy in situations where its acceptability is considered doubtful by informants (for example in asking a lecturer for an essay extension, and in asking a stranger to move over to make room in a crowded eating stall).

However, learners are also greatly aided by another factor in making acceptable strategy choices: the archetypal nature of their main request sub-strategy (QP modal request); that is, the fact that it has very wide acceptability across situations. This 
makes it easy for learners to make an acceptable choice of strategy, because selecting their favoured sub-strategy in any of these situations results in an acceptable choice.

The final factor enabling learners to make acceptable choices consistently is the wide range of acceptable variation of strategy choice in these situations generally. This is demonstrated by certain BI NS choices which are judged as acceptable by native speaker informants. For example, in asking hotel servant to have their clothes washed, BI NS subjects selected the full range of strategies, from very direct (imperatives), through conventionally indirect (query modal requests), to very indirect (hints), and all these requests were judged acceptable. Another example is that in asking a university lecturer for last week's handout, one BI NS subject selects an imperative. This is an apparently risky choice of strategy for this 'sensitive' situation (where speaker's status relative to hearer's is assessed as low, and speaker's comfort is assessed very low); however, informants judged this request form to be adequately polite in the context. On the whole, then, while learners do often appear to adjust to the situation in native-like ways, their ability to make acceptable strategy choices consistently is greatly facilitated by other factors as well.

\subsubsection{Discourse considerations in strategy selection}

Sometimes, despite the ability of learners to adjust to contextual variables in selecting a request strategy, they do select a strategy which is inappropriate to the context. However, this is very rarely because the strategy selected is inherently inappropriate to the situation; rather, it is almost always because the learner's request head act is poorly aligned to the ongoing discourse, as constructed jointly by the interlocutors.

In the most obvious cases, the request by the learner becomes superfluous because of the development of the discourse, such that any choice of head act strategy is inappropriate at that point. This occurs in a number of instances; an example is below: 
63 (asking a conductor to tell you when the bus gets to the stop nearest Kartini Street)

L: $\quad$ Maaf Sus? (.) saya (.) uh (.) tidak tahu di mana (.) uh (.)

L: Jalan Kartini

P: $\quad$ Uh (.) ya ya saya akan (.) menunjukkannya (.) pada

P: $\quad$ Anda (.) silakan duduk dahulu.

L: $\quad A h$ (.) terima kasih (.) er (.) uh (.) apa Anda

L: $\quad$ memberitahu saya di mana (.) ketika kami (.) uh(.)

L: $\quad$ datang ke (.) stop bis yang terbaik?

P: $\quad Y a($.$) ya pasti (.) silakan duduk dahulu.$

L: $\quad$ Excuse me 'sister'? (.) I (.) uh (.) I don't know where (.)

L: $\quad$ uh (.) Kartini Street is

P: Uh, yes yes I'll (.) point it out (.) to you (.) please sit down

$\mathrm{P}$ : in the meantime.

L: $\quad$ Ah (.) thank you (.) er (.) uh (.) do you tell me where (.)

L: when we (.) uh (.) come to (.) the best bus stop?

P: $\quad$ Yes (.) yes certainly (.) please sit down in the meantime.

In [63] above, the learner's first turn, Saya tidak tahu di mana... "I don't know where ...", is interpreted as a request, by virtue of the partner's response, in which she assures the learner that she will show her where Kartini Street is. But the learner seems to disregard this contribution of the partner to the discourse, by following it with a request for the partner to do more or less what she has just promised to do: tell the learner when they get to the best stop (Apa Anda memberitahu saya...? "Do you tell me...?"). The lack of alignment to the partner's previous turn makes this request an inappropriate one; it would have been more appropriate for the learner not to make it, thus allowing her first utterance, Saya tidak tahu di mana... "I don't know where...", to achieve the status of a statement hint.

Below is another example of a learner request which is poorly aligned to the interlocutor's contribution: 
64 (asking an official in the immigration office for forms for a visa extension)

L: $\quad$ Uh (.) saya mau (.) memperpanjang (.) visa?

L: $\quad$ uh saya harus (.) membawa (.) mengambil (.) formulir?

P: $\quad$ He eh

L: Yang I seperlunya?

P: $\quad$ Uh (.) ini ada beberapa/ (starts to give her the forms)

L: Dimana.

(.)

P: $\quad$ Di sini kebetulan ada

L: $\quad$ Uh (.) I want (.) to extend (.) a visa?

L: $\quad$ uh I have to (.) bring (.) take (.) the forms?

P: $\quad$ [Uh huh

L: $\quad$ which] are needed?

P: $\quad$ Uh (.) here are several/ (starts to give her the forms)

L: Where.

(.)

P: They happen to be here.

In [64] the learner tells the official that she needs the forms to extend her visa, and the official interprets this as a request for the forms, by starting to give them to the learner, while telling her what they are. However, the learner interrupts the official at this point to ask where the forms are (Di mana "Where"), compelling the official to break off his utterance and respond to the question. This question hint by the learner is superfluous at that point in the conversation, because the official has already made it clear that he has the forms and is willing to give them to the learner; and because of the interruption it entails it creates a rather rude effect.

To sum up, learners sometimes display a lack of orientation to the interlocutor's contribution to the discourse which results in request head acts which are inappropriate to the context. Usually this only creates lack of discourse cohesion, but occasionally it causes impoliteness. 


\subsubsection{Choice of request perspective by subjects}

Learner and BI NS subjects are compared for their choice of perspective in two request sub-strategies: the QP modal, as the main request type for both groups; and the imperative, as a request type which offers an important choice of perspective to speakers.

\subsubsection{Choice of perspective for $Q P$ modal requests: $B I$ native speakers}

The majority (75.0\% or 72/96) of QP modal requests by BI NSs have speaker perspective (see Table 4 below). An example is this:

65 (asking to change large notes for smaller ones in a bank)

NS ... bisa saya tukar dengan uang yang kecilan.

NS: $\quad .$. can I change [this] for small money.

A small proportion of QP modal requests by BI NSs (13.5\% or 13/96) have impersonal perspective (see Table 4). This perspective is achieved by using a passive construction ${ }^{8}$, to indicate only indirectly that it is the hearer who is expected to perform the action. An example is this:

66 (asking to exchange a shirt in a clothes store)

NS: $\quad$... bisa diganti nggak Pak.

NS: $\quad .$. can [it] be exchanged or not 'father'.

Another small proportion of QP modal requests by BI NSs (10.4\% or 10/96) have hearer perspective (see Table 4). An example is this:

67 (asking a stranger to move over to make room in a crowded eating stall)

NS: Bisa geser sedikit Pak?

NS: Can _you) move a little 'father' ?

Virtually no BI NS requests have inclusive perspective (see Table 4). Utterance [68] below is the only instance of such a QP modal request by a BI NS subject. 
68 (asking a taxi driver to stop for a minute to buy cigarettes)

NS: $\quad$... kita bisa berhenti ndak membeli rokok ...

NS: ... can we stop or not to buy cigarettes ...

The virtual absence of requests with inclusive perspective is probably due to the nature of the particular situations in this study: in only one roleplay situation, the "taxi driver" situation in [68] above, could the action (in this case, stopping to buy cigarettes) be construed as performable by both speaker and hearer.

Table 4: Proportion of query preparatory modal requests with each perspective

\begin{tabular}{|l|cc|cc|}
\hline Type of perspective & \multicolumn{2}{|c|}{ Learners } & \multicolumn{2}{|c|}{ BI NSs } \\
\hline Speaker & 81 & 82.7 & 72 & 75.0 \\
\hline Hearer & 12 & 12.2 & 10 & 10.4 \\
\hline Inclusive & 3 & 3.1 & 1 & $\mathrm{n} / \mathrm{a}$ \\
\hline Impersonal & 2 & 2.0 & 13 & 13.5 \\
\hline Total No of QP modal requests & \multicolumn{2}{|c|}{98} & \multicolumn{3}{|c|}{$96^{*}$} \\
\hline
\end{tabular}

* three QP modal requests by BI native speakers which had ambiguous perspective were omitted from this table

\subsubsection{Choice of perspective for QP modal requests: Learners}

Learners, like BI NSs, use speaker perspective in the majority of QP modal requests, selecting this perspective in an even greater proportion of instances than BI NS ( $82.7 \%$ or $81 / 98$; see Table 4 above). Learners also choose hearer perspective approximately as often as BI NSs do (12.2\% or $12 / 98$ of instances). Learners, like BI NSs, also use inclusive perspective very rarely (3.1\% or $3 / 96$ of instances: in the same "taxi driver" situation as BI NSs). However, in a notable difference from BI NSs, learners also use impersonal perspective very rarely ( $2.0 \%$ or $2 / 98$ of instances), while this perspective was a relatively common variant for BI NS subjects. 


\subsubsection{Choice of perspective for imperatives: BI native speakers}

In making (full) imperative requests BI NSs use two perspectives in roughly equal proportions. The first is hearer perspective, which accounts for almost half (47.4\% or 9/19) of imperatives (see Table 5 below). An example is this:

69 (asking a hotel servant to have your clothes washed)

NS: Tolong cucikan pakaian saya yang kotor

NS: $\quad$ Please (you) wash my dirty clothes

The other perspective regularly used by BI NSs is impersonal perspective. This perspective is used in over half $(52.6 \%$ or $10 / 19)$ of imperatives by this group (see Table 5 below). An example is this:

70 (asking a bus conductor to tell you when you reach your stop)

NS: Tolong Mas nanti dikasihtahu ya kalau ada stop bus

NS: yang terdekat dengan Jalan Kartini.

NS: Please 'brother' (I) be told yes when there's a bus stop

NS: closest to Kartini Street.

As mentioned earlier (3.4), this choice of impersonal perspective on imperatives is considered to makes the request less forceful, and hence, more polite; because of the suggestion that the request is directed at a third person instead of the hearer.

\subsubsection{Choice of perspective for imperatives: Learners}

Learners, in an important difference in choice of perspective from BI NSs, never use impersonal perspective on imperatives (see Table 5 below). Instead, they always use hearer perspective (100\% or $10 / 10$ of instances). 
Table 5: Proportion of (full) imperative requests with each perspective

\begin{tabular}{|l|cc|cc|}
\hline Type of perspective & \multicolumn{2}{|c|}{ Learners } & \multicolumn{2}{c|}{ BI NSs } \\
\hline Hearer & 10 & 100 & 9 & 47.4 \\
\hline Impersonal & 0 & 0 & 10 & 52.6 \\
\hline $\begin{array}{l}\text { Total No of full imperative } \\
\text { requests }\end{array}$ & \multicolumn{1}{|c|}{10} & & 19 \\
\hline
\end{tabular}

To sum up, in both sub-strategies examined, the same important difference can be seen: learners use impersonal perspective less frequently than BI NSs. In the case of imperatives, in particular, the difference is very striking.

\subsubsection{Other aspects of head act realisation by learners}

Certain other points about learners' performance of request head acts are worth noting. They are discussed briefly below.

\subsubsection{Phrasing of the request goal by learners}

A very obvious feature is that learners have a great deal of difficulty expressing the goal of requests appropriately. One aspect of this inappropriacy is the matter of register; the learners almost invariably use formal register in expressing their requests, regardless of situation. Another aspect is that lexical and grammatical errors by learners routinely result in highly unidiomatic phrasing of the request goal. Examples of unidiomatic phrasing due to lexico-grammatical error are [71] and [72] below:

71 (asking a friend from college for a lift back home on their motor scooter)

L: $\quad$ Uh (.) apakah/(.) uh apakah (.) ada (.) kursi di (.) uh (.)

L: $\quad$ dalam (.) se/ motor sepeda (1.0) NAME?

$\mathrm{L}: \quad \mathrm{Uh}($.$) is/ (.) uh is (.) is there (.) a seat in (.) uh (.) inside$

$\mathrm{L}$ : $\quad$ your $(1.0) \mathrm{mo} /$ 'cycle motor'? 
72 (asking to try on shoes in a store)
L: $\quad$... bolehkah saya memakai sepatu itu sebentar?
L: $\quad$... may I wear those shoes for a minute?

Sometimes learners seem to know that the phrasing is unidiomatic, and to feel frustrated at being driven to clumsy paraphrase in expressing their request goal. This is suggested by the speakers' hesitations and sighs in [73] and [74] below:

73 (buying a cinema ticket for a seat in the middle- front row)

L: $\quad$ Bolehkah saya menduduki (.) uh (.) (sighs) kursi um (.)

$\mathrm{L}: \quad$ di tengah-(.) depan?

L: $\quad$ May I occupy uh (.) (sighs) a chair um (.) in the middle- (.)

L: front?

74 (asking a stranger for a light)

L: $\quad$ Boleh saya (.) um (1.0) (sighs) bolehkah saya (1.0) $u$-u-

L: $\quad m-m$ (.) menggunakan (.) uh korek api Anda?

L: $\quad$ May I (.) um (1.0) (sighs) may I (1.0) u-u-u-m (.) use (.)

$\mathrm{L}$ : uh your matches?

In addition, learners quite frequently confuse a word which is crucial to expression of the request goal with a different word, resulting in a bizarre-sounding request. Examples are [75] and [76] below:

75 (asking a stranger in a park for a light)

L: $\quad$... bisa saya menunjang korek api Anda?

L: ... can I support your matches? [cf.meminjam "borrow"]

76 (asking to look on at a university classmate's textbook during class)

L: $\quad$...uh (.) apa saya (.) uh (.) mengenai (.) textbook (.)

L: Saudara? 


\section{L: $\quad$... uh (.) do I (.) uh (.) about (.) your (.) textbook? \\ [cf. memakai: "use"]}

\subsubsection{Negotiation of the request goal}

In many cases where the learners' requests are expressed poorly, the hearer manages to deduce the intended nature of the request from the situation. However, in cases when the hearer cannot understand from an initial request what it is that the learner wants, the learners have a lot of difficulty in clarifying the nature of the request goal through interaction with the hearer. Outcomes of such negotiation sessions include: partial misunderstandings persisting between learner and requestee until the end, the requestee abandoning his or her effort to understand exactly what the learner wants and just giving them something that they hope will satisfy them; and, occasionally, communication breaking down completely so that the roleplay has to be abandoned. Such negotiation sessions tend to be very long; a relatively short example of the first of these outcomes only (a persistent misunderstanding) is provided in [77] below:

77 (buying a cinema ticket for the middle- front row)

$1 \quad$ L: $\quad$ Um (.) saya mau (.) um (.) sebuah karcis untuk

2 L: film "Four Seasons".

$3 \quad$ P: Ya hanya satu? satu [karcis?

4 L: Dua]

$5 \quad$ L: $\quad$ dua (.) dan saya mau (.) um (.) tempat duduk di

$6 \quad$ L: $\quad$ bagail bagian (.) um (.) tengah-depan

7 L: bioskop (.) kalau bisa.

8 P: Di tengah atau di depan.

9 L: Ditengah

10 P: Ditengah [( )

11 L: dan didepan]

(.)

12 P: Oh(.) di tengah dan di depan.

13 L: $Y a$.

14 P: Duduknya nggak sama-sama. 
15 L: Maaf?

16 P: Duduknya dengan temannya nggak sama-sama .

$17 \mathrm{~L} \quad O-o-o-h-h$ (sounds very disappointed)

$18 \quad$ P: $\quad$ Kalau mau (.) di tengah.

19 L: Ya?

20 P: Bisa (.) ada dua karcis ( ) di tengah

(.)

21 L: $\quad$ Okelah saya harus (.) um (.) mempunyai (.)

22 L: membeli karcis itu.

23 P: Ya ini dua (gives the tickets)

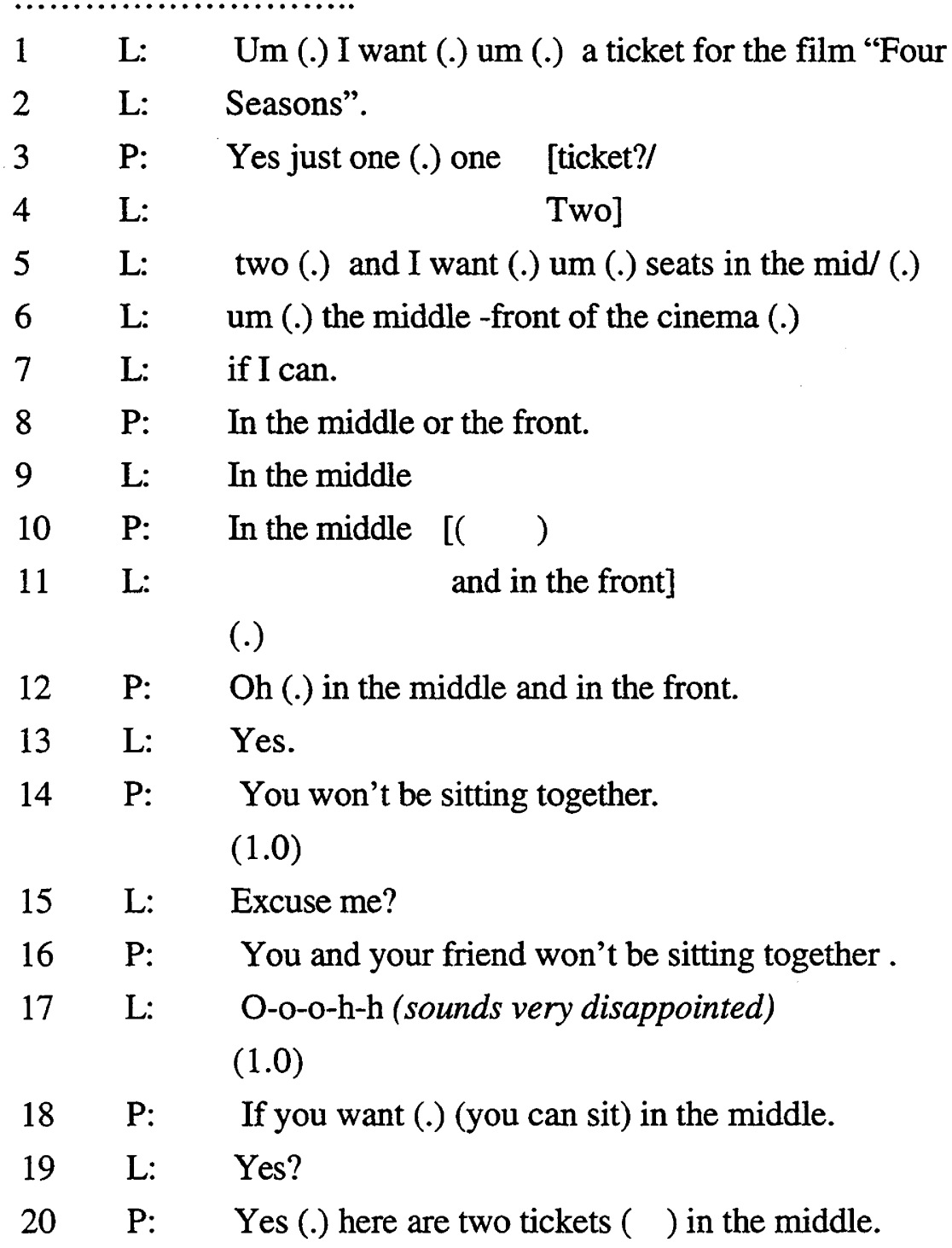




\section{(.)}

$21 \quad$ L: $\quad$ Okay then I'll have to (.) um (.) have (.) buy those

22 L: tickets.

23 P: Yes here are two (gives the tickets)

In excerpt [77] above, the ticket seller does not understand the learner's initial request for seats in the middle- front (line 5-7). The learner attempts to explain what he means (line 9 and 11), but the seller apparently takes him to mean that he wants one ticket in the middle and the other in the front, and asks for confirmation of this interpretation, asking Duduknya nggak sama-sama "You won't be sitting together" (line 14). The learner thinks that he is being told that he and his friend will not be able to sit together, and reacts with disappointment (line 17). At this point the seller appears confused, but eventually suggests that the learner and his friend sit together in the middle (line 18). The learner accepts this proposal (line 21-22). So at the end of this excerpt the learner and the seller have managed to reach some kind of agreement, and carry out the transaction. However, a misunderstanding still persists. The learner thinks that he and his friend have to sit in the middle because there were not two seats together in the middle- front, while the ticket seller never realised that the learner wanted seats in the middle- front.

\subsubsection{Realisation of head act formulas by learners}

As well as frequent difficulty in expressing the goal of the request, learners sometimes have difficulty expressing the request formula itself appropriately. This was implicit from certain examples earlier (e.g. [56], [57], and [61]). Below are further examples, in which the learner's expression of the request formula results in impoliteness.

78 (asking a stranger to move over to make room in a crowded eating stall)

L: Apakah Pak mau bergeser sedikit?

$\mathrm{L}$ : Do you want to move over a little?

In [78] above the learner apparently intends a conventionally indirect request of the query preparatory type. However, she chooses an inappropriate modal verb mau "want", resulting in a non-conventional request type which questions the hearer's 
desire to perform the action. This request is insufficently polite for the situation, as asking if the hearer wants to perform an action which is costly to the hearer "aggravates rather than mitigates the illocutionary force" of the request (Faerch \& Kasper 1989: 229). ${ }^{9}$ Another impolite realisation of a request formula by a learner is [79] below:

79 (asking a bus conductor to tell you when you get to the stop closest to Kartini Street)

$\mathrm{L}: \quad$...um (.) uh (.) saya ingin (.) uh (.) uh kamu untuk

L: $\quad$ memberitahukan saya ketika (.) um (.) sampai pada

L: perhentian bis (.) yang terbaik.

L: $\quad$...um (.) uh (.) I want (.) uh (.) uh you to tell me when (.)

L: $\quad$ um (.) we arrive at the best (.) bus stop.

The learner's request in [79] creates a distinctly rude impression. Unlike in the other Want statements in the data, the learner does not say that he wants goods ("I want $X$ "), or that he wants to do something ("I want to..."), but instead spells out that he wants the hearer to do something ("I want you to......"). This makes the Want statement considerably more coercive; 10 excessively so for this situation, where the speaker is asking a favour.

\subsubsection{Inappropriate pronoun selection by learners}

A striking feature of learner requests in the data is their tendency to select an inappropriate second person pronoun. ${ }^{11}$ This feature compounds the rude effect created by the learner's request in the "bus conductor" situation in [79] above. The learner uses the pronoun kamu "you" in addressing the bus conductor, while this pronoun is used only to address people with whom the speaker is close, or feels superior to, or children (cf. Sneddon 1996). When used to an adult stranger, as to the bus conductor here, kamu conveys disrespect (an acceptable alternative would have been, for example, the pronoun substitutes Mas or Saudara meaning "brother" and "sibling" respectively; or the pronoun Anda "you").

The learners use this intimate pronoun kamu in a number of requests when addressing hearers to whom it is highly inappropriate (such as university lecturers, 
to whom it would be insulting, due to their high status in these situations). Learners also use another pronoun, Anda "you", inappropriately in many instances. This pronoun Anda "you" conveys equality and at the same time a certain social distance (cf. Sneddon 1996), so it is not appropriately used to address either people of higher status (to whom the pronoun substitute of Bapak or Ibu, literally "father" and "mother" respectively, would be appropriate); or friends (to whom the intimate pronoun kamu "you", or a given name as a pronoun substitute might be appropriate). However, the learners often use this pronoun Anda "you" when making requests to both people in positions of authority (such as lecturers, a police officer, and a government official) and to friends. 12

\subsubsection{Intonation on head acts by learners}

Another striking feature of learners' realisation of requests is that they very often use rising intonation, sometimes very strongly rising; on declarative and on imperative head acts. This feature can be observed in the case of statement hints in [58] and [60] earlier. Examples of the same phenomenon in Want statements and imperatives are as follows:

\section{A. Want statements}

80 (ordering a meal in a restaurant)
L: $\quad$ Saya mau gado-gado?
L: I want a 'gado-gado'?

81 (buying stamps and envelopes in a post office)
L: $\quad$ Saya mau membeli(.)kan (.) uh (.) perangko-perangko
L: $\quad$ dan dua amplop?(.) untuk (.) uh surat-surat?ke
L: Australia?
L: I want to buy (.) uh (.) stamps and two envelopes? (.) for
L: $\quad$ (.) uh letters? to Australia? 


\section{B. Imperatives}

82 (asking a taxi driver to stop for a minute so you can buy cigarettes)
L: Hentilah sebentar?
L: $\quad$ Stop for a minute?

83 (asking a hotel servant to have your clothes washed)
L: $\quad$ Tolong mencuci pakaian itu?
L: $\quad$ Please wash those clothes?

Sometimes the learners use this rising intonation not only on the end of the request but periodically throughout the request, on individual elements of the head act as well (as in [81] above). The rising intonation in examples such as those above creates an interrogative tone which is at odds with the non-interrogative forms in which it occurs, and which creates an incongruous and highly non-native effect.

To sum up, learners show distinctly non-native performance with regard to realisation of request head acts. They have difficulty expressing simple request goals in acceptably idiomatic language. In addition, when they do not express the goal of a request clearly enough to be understood, they have trouble clarifying the nature of the request by negotiation with the interlocutor. Lastly, they frequently create a highly non-native effect by their rising intonation on several sub-strategies.

\subsubsection{Follow-up 'requests'}

The primary focus of this study is the main request that the speaker makes in each situation (this comprises all the data examined above, and all the data in later chapters). However, sometimes after making the main request, a subject will make another request-like utterance in a following turn. These utterances are not always requests, strictly speaking. Often they are part of a 'repair sequence' (cf. Schegloff, Jefferson \& Sacks 1977; Schegloff 1995) which clarifies or modifies the goal of the request. For example, the request goal may be specified in more detail (e.g. after a beer has been ordered, the information may be added in a following turn that the beer is to be a large one); or an additional component may be added to the 
request goal ( e.g. after a dish has been ordered, a second dish may be added to the order in a following turn).

The occurence of these follow-up requests is highly irregular, both in their frequency and in their nature, so that systematic comparisons between those of learners and those of BI NSs are not practicable. For that reason these utterances are not systematically examined. Nevertheless, the most striking differences between those of learners and those of BI NSs are well-worth examining, because these differences reinforce and add to the picture of overall requesting performance.

When learners are asked to provide more information about the item(s) they want, they usually respond in an essentially native-like way, by giving a simple specification of the required item. An example of this type of utterance by a BI NS and by a learner are as follows:

\section{BI native-speaker example}

84 (asking to listen to a cassette in a store)

NS: $\quad$ Uh (.) kaset Iwan Fals yang baru (.) tolong

NS: dipasangkan.

P: Yang mana?

NS: Yangterbaru.

NS: Uh (.) the new (or "a new") Iwan Fals cassette (.) please

NS: put it on.

P: Which one?

NS: The latest.

\section{Learner example}

85 (buying stamps and envelopes in the post office)

L: $\quad$... saya mau (.) membeli (.) dua amplop dan perangko

L: $\quad$ untuk mengirim surat kepada Australia.

P: $\quad$ Ekpres atau biasa?

L: $\quad U m($.$) biasa.$ 
L: $\quad$ I want (.) to buy (.) two envelopes and stamps to send a

L: $\quad$ letter to Australia.

P: $\quad$ Express or normal?

L: $\quad$ Um (.) normal.

However, even in this type of highly controlled follow-up request in which the learner simply provides an elicited piece of information, learners often produce a distinctly non-native effect by using a Want statement strategy. Examples are [86] and [87] below:

86 (asking to try a cassette in a store)

L: $\quad$ Saya (.) saya mau (.) uh (.) mendengar (.) uh (.) kaset (.)

L: Iwan Fals.

P: $\quad$ O iya (.) kita punya kaset Iwan Fals yang banyak (.)

P: Anda mau mencoba yang mana?

L: $\quad$ O saya mau (.) uh (.) ter/ uh (.) terlalu (.) yang baru.

P: $\quad O($.$) yang terbaru ...$

L: I (.) I want (.) uh (.) to hear (.) uh (.) an Iwan Fals (.)

L: cassette.

P: $\quad$ Oh yes (.) we have a lot of Iwan Fals cassettes (.) which

P: one do you want to listen to?

L: Oh I want (.) uh (.) the/ uh (.) the latest (.) one.

P: $\quad$ Oh (.) the latest ...

87 (ordering a drink in a restaurant)

L: $\quad$ Saya (.) saya harus (.) uh (.) membeli (.) sebotol bir juga

L: (.) sekarang.

P: $\quad$ Merek apa (1.0) uh (.) bir jenis apa (1.0) [yang

L: $\quad$ O-o ]

L: $\quad$ o-o ya um (.) sava mau (.) minum bir (.)( ) Amerika. 
L: $\quad$ I (.) I must (.) uh (.) buy (.) a bottle of beer too (.) now.

P: What brand (1.0) uh (.) what type of beer (1.0) [do

L: $\quad$ O-o]

L: o-h-h ya um (.) I want (.) to drink (.)( ) American

L: $\quad$ beer.

In sequences of this type, learners' use of a Want statement creates a rather incongruous effect, by the impression it gives that the learner is making a request proper, rather than answering a question. In [86] and [87] above, this effect is reinforced by the fact that learners also used this Want statement strategy for the main request in the previous turn. Therefore learners sound as if they are recycling the opening request sequence, even though by this later stage of the interaction their requestive intent has become obvious.

In situations where the subject initiates the sequence containing the follow-up 'request', the difference between learner and BI NS behaviour is also evident. The BI NS subjects in these instances almost always use brief, elided request forms: sometimes elided imperatives, and very often Goal statements. Importantly, they never use their usual strategy for making initial requests: the query preparatory modal form with Bisa? "Can?" or Boleh? "May?". This creates a contrast between their main requests and their follow-up 'requests' which emphasises that the two types of utterance occur at different points in the discourse and have a different function. Here are several examples of typical follow-up requests by NS BI subjects:

88 (asking to change large notes for smaller ones in a bank)

NS: Bisa saya tukar begini (.) uang seribu ini jadi lima

NS: ratusan

P: $\quad Y a($.$) oke$

NS: Ditukar dua aja va?

P: $\quad$ Okay

NS: Can I change like this (.) these one thousands for five

NS: hundreds.

P: $\quad$ Yes (.) okay.

NS: I change (lit: "be changed") just two yes?

P: Okay 
In [88] above, while the BI NS subject used a QP modal form for the main request, for the extra request in which she specifies how many notes to change, she switches to a strategy of Goal statement instead. A similar example is [89] below:

89 (buying a magazine at a street stall)

NS: Tempo yang baru udah datang belum?

P: $\quad$ Ooo ini baru saja ( ) ini Bu (gives her magazine)

NS: O iya deh (.) lihat dulu ya?(.) ['ntar ya?

$\mathrm{P}$ :

Iya iya]

NS: Has the new Tempo come in yet or not?

$\mathrm{P}$ : Ooh this just ( ) here 'mother ' (gives her magazine)

NS: Oh yeah (.)(I) look first yes? (.) [just a second yes?

P:

Yeah yeah]

In [89] above, the BI NS subject switches from the question hint sub-strategy she used in her main request, to a Goal statement, for her extra request to have a look at the magazine before buying it. One more example is provided below:

90 (asking to try shoes in a store)

NS: Bisa coba sepatu itu Mas yang warnanya merah itu ...

P: $\quad O$ bisa (.) ini ini (gives her the shoes)

NS: $\quad A h$ (tries them on) ........... oh ini (.) nggak cukup ini

NS: Mas kurang besar(.) [coba

P: $\quad(1)]$

NS: $\quad$ deh nomornya di atasnya satu? (.) 38 ya Mas ya?

P: O iya (.) sebentar ya

NS: Can I try those shoes 'brother' the red ones ...

$\mathrm{P}$ : Oh yes (.) here here (gives her the shoes)

NS: Aah (tries them on) ............ oh this (.) this isn't big

NS: enough 'brother' it's too small (.) [(I) try

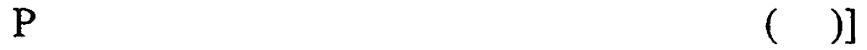

NS: the size above? (.) 38 yes 'brother 'yes?

P: $\quad$ Oh yeah (.) just a minute yes. 
In [90], after using a QP modal request in asking to try on the first pair of shoes, when a second request (to try on a pair of a different size) develops naturally out of the interaction, the speaker switches to a Goal statement (Coba deh ...? "I try ...?") instead.

Learners, on the other hand, perform these follow-up 'requests' using the same sub-strategies as they use for main requests. They frequently use Want statements and query preparatory modal forms, and occasionally use full imperatives, but use few elided imperatives, and use no Goal statements at all. This makes learners appear unresponsive to development of the discourse; to the fact that their followup 'requests' occur in quite different contexts to initial requests. It also creates a rather mechanical effect, reinforced by the fact that they often select the same strategy twice in the same dialogue (first for the main request and then for a followup request), so that they appear to be repeating a formula. Here are characteristic examples of learner follow-up requests, made in similar contexts to those of BI NSs above:

91 (asking to try on shoes in a store)

L: $\quad$ Boleh saya mencoba sepasang sepatu itu yang (.) putih?

P: $\quad$.......ah ini mungkin (gives her a pair of shoes) (customer tries the shoes on, asks the price, and is told it)

L: $\quad O$ (.) 50.000 terlalu mahal saya kira (.) um (.) boleh saya

$\mathrm{L}$ : mencoba (.) yang lain? (.) yang murah?

L: $\quad$ May I try a pair of those (.) white shoes?

P: $\quad$......ah these maybe (gives her a pair of shoes)

...... (customer tries them on, asks the price, and is told it)

L: $\quad$ Oh (.) 50,000 is too expensive I think (.) um (.) may I

L: $\quad$ try (.) some other ones? (.) cheap ones?

In [91] above, the learner makes an initial request to try the shoes with a QP modal form: Boleh saya mencoba... ? "May I try...?", and later in the interaction when she wants to try a cheaper pair, she uses the same sub-strategy with the same wording. Another example is below: 
92 (asking a taxi driver to stop for a minute so you can buy cigarettes)

L: $\quad$ Tolong hentilah sebentar? (.) saya mau beli rokok?

(.)

P: Boleh.

L: $\quad Y a ?$ (.) tolong (.) hentilah di SANA sebentar?

L: $\quad$ Please stop-IMP for a minute? (.) I want to buy

L: cigarettes?

(.)

P: $\quad$ All right

L: Yes? (.) please (.) stop-IMP THERE for a minute?

The learner in [92] initially asks the driver to stop with a full imperative form. Then, in order to add a little more information by saying he wants the driver to stop "there", he repeats his initial request form word for word, adding the extra element "there" (di sana) . A more native-like way to make this follow-up 'request' would

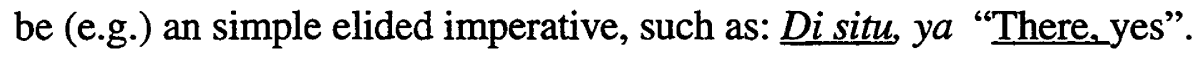

A further learner example is below:

93 (buying a cinema ticket)

L: $\quad$ Uh (.) saya (.) uh mau (.) uh (.) karcis (.) untuk duduk (.)

L: $\quad$ uh(.) di tengah (.) depan bioskop? ya?

P: $\quad$ He eh

L: $\quad$ Ada (.) ada ongkosnya

(.)

P: $\quad$ Uh (.) tiga ribu lima ratus.

L: $\quad$ Oke (.) uh (.) saya mau (.) uh (.) satu (.) satu karcis (.) ya? 
L: Uh (.) I (.) uh want (.) uh (.) a ticket (or "tickets") (.) to

$\mathrm{L}$ : $\quad$ sit (.) uh (.) in the middle (.) front of the cinema? yes?

P: Uh huh/

$\mathrm{L}$ : What (.) what is the cost

(.)

P: $\quad$ Uh (.) three thousand five hundred.

L: $\quad$ Oke (.) uh (.) I want (.) uh (.) one (.) one ticket (.) yes?

In [93] above, after using a Want statement to ask for a seat in the middle front, the learner then wants to add information about the number of tickets. To do this, he repeats his original strategy of Want statement (instead of saying, for example, Satu, Pak "One, 'father"').

A neat contrast between learner and BI NS behaviour is provided by the following attempt by a subject from each group to renegotiate the goal of the same request. First, here is the learner example, in [94] below:

94 (asking to look on at a classmate's book in class)

L: $\quad$ Saya ketinggalan buku saya di rumah tadi pagi (.) boleh

L: $\quad$ saya (.) uh

(.)

P: $\quad$ Mau pinjam buku ini?

L: $\quad Y a /$ no saya (.) saya mau (.) juga menggunakan (.)

L: $\quad$ dengan kamu.

L: I left my book at home this morning (.) may I (.) uh (.)

P: $\quad$ You want to borrow this book?

L: $\quad$ Yes/ no I (.) I want (.) to use it too (.) with you.

The learner in [94] above hesitates in expressing the goal of his request, and the partner tries to anticipate what he wants, but guesses wrongly (Mau pinjam buku ini? "You want to borrow this book?") so that a follow-up 'request' becomes necessary. At this point the learner resorts to a Want statement (Saya mau juga menggunakan dengan kamu "I want to use it too with you"). Compare this to the behaviour of the NS BI subject in the same situation, in [95] below: 
95 (asking to look on at a classmate's book in class)

NS: Bisa ikutan (.) baca?

P: $\quad$ O silakan (.) ambil aja (.) pakai aja (moves the book to

$\mathrm{P:} \quad$ the speaker's side of the desk)

NS: $\quad O$ iya nggak sama-sama aja deh

NS: Can (I) read (.) together with you?

P: $\quad$ Oh go ahead (.) just take it (.) just use it (moves the book

$\mathrm{P}$ : $\quad$ to the speaker's side of the desk)

NS: Oh yeah no just together huh.

The BI NS subject in [95] above makes the initial request to look on at the book with a QP modal form, just as the learner did in [94]. However, when a problem arises concerning the nature of the goal, the BI native speaker deals with it quite differently from the learner. He makes a brief (elided) Goal statement (Sama-sama aja deh "Just together huh") to reiterate what he wants - a characteristically native strategy.

\subsubsection{Follow up 'requests': Summary}

Two important findings from the main request data are reinforced by this examination of follow-up requests. The first concerns choice of strategy. In followup requests, as in main requests, learners use Want statements more frequently than BI NSs do, and BI NSs use Goal statements and elided imperatives more frequently than learners. The second finding concerns discourse constraints on strategy choice. In follow-up requests (as in main requests) learners are sometimes unresponsive to development of the interaction. By performing follow-up 'requests' with the same strategy as the main request in a previous turn, instead of switching to a different strategy as BI NSs do; learners fail to mark the fact that the action is already underway at the time the follow-up request is made, which conveys insensitivity to this feature of the discourse. In addition, this repetition of the same request strategy within a speech event makes learners' requesting seem more mechanical and formulaic than that of BI NSs, conveying an impression of scant pragmalinguistic resources. 


\subsubsection{Asking}

This section examines findings on the small class of requests classified as Asks; namely, those requests made in the five situations where the goal is information.

\subsubsection{Choice of Asking strategy: BI native speakers}

When asking for information, BI NSs use a direct strategy in the vast majority $(80 \%$ or $36 / 45)$ of instances. In particular, BI NSs make very frequent use of the sub-strategy of direct questions (see Table 6 below). This sub-strategy alone accounts for a large majority (73\% or 33/45) of BI NSs head acts. Examples of direct questions by BI NSs are these:

96 (asking a stranger on a railway platform if the train that just came in goes to Bandung)

NS: Apa ini kereta yang mau ke Bandung?

NS: Is this the train that goes to Bandung?

97 (asking a police officer on duty at the station where to report your lost passport)

NS: $\quad$... saya kehilangan paspor Pak (.) ke mana ya harus

NS: melaporkannya?

NS: $\quad$... I've lost my passport 'father' (.) where yes should I

NS: report it?

No asking strategy other than direct questions is used with high frequency by BI NSs (see Table 6). Only in isolated instances do they use a different direct substrategy, either a hedged performative ( Saya mau tanya di mana ... "I want to ask where ..."), or a Want statement (such as Saya ingin tahu di mana...? "I want to know where...?"). 
Table 6: Proportion of different Asking strategies used by learner and BI native speaker subjects

\begin{tabular}{|c|c|c|c|c|c|}
\hline & & \multicolumn{2}{|c|}{ Learners } & \multicolumn{2}{|c|}{ BI NSs } \\
\hline & & $\mathrm{n}$ & $\%$ & $\mathrm{n}$ & $\%$ \\
\hline \multirow{3}{*}{ DIRECT } & Direct question & 34 & 68.0 & 33 & 73.3 \\
\hline & $\begin{array}{l}\text { Performative } \\
\text { (hedged) }\end{array}$ & - & - & 1 & 2.2 \\
\hline & Want statement & 5 & 10.0 & 2 & 4.4 \\
\hline \multirow{2}{*}{$\begin{array}{l}\text { CONVENT- } \\
\text { IONALLY } \\
\text { INDIRECT }\end{array}$} & $\begin{array}{l}\text { Query } \\
\text { preparatory: } \\
\text { Permission }\end{array}$ & 2 & 4.0 & 4 & 8.9 \\
\hline & $\begin{array}{l}\text { Query } \\
\text { preparatory: } \\
\text { Availability: }\end{array}$ & 3 & 6.0 & 1 & 2.2 \\
\hline \multirow[t]{2}{*}{$\begin{array}{l}\text { NON- } \\
\text { CONVENT } \\
\text { IONALLY } \\
\text { INDIRECT }\end{array}$} & Hint: Statement & 6 & 12.0 & 4 & 8.9 \\
\hline & $\begin{array}{l}\text { Total No of } \\
\text { Asking head acts }\end{array}$ & \multicolumn{2}{|c|}{50} & \multicolumn{2}{|c|}{45} \\
\hline
\end{tabular}

Occasionally BI NSs use a conventionally indirect request form to ask for information ( $11.1 \%$ or $5 / 45$ of instances). These forms are nearly all QP modal requests, all of which use the modal verb bisa "can". An example is [98] below:

98 (asking a stranger in the street the way to the post office)

NS: Bisa saya tolong dikasihtahu jalan ke kantor pos 'tuh

NS: lewat mana ya

NS: Can I please be told the way to the post office yes 
In one instance a BI NS subject uses a different CI strategy type: a query about availability of hearer's knowledge, illustrated in [99] below:

99 (asking a stranger on a railway platform if the train that just came in goes to your destination)

NS: Coba Anda tahu nggak ya ini kereta api yang baru

NS: $\quad$ nyampe ini ke mana.

NS: Please do you know or not yes where this train that just

NS: arrived goes to.

Non-conventional Asking forms, or hints, are used occasionally by BI NSs $(8.9 \%$ or 4/45 of instances: see Table 6). These hints all consist of a statement that the speaker does not know the desired information. An example is [100] below:

100 (asking the police officer on duty at the station where to report your lost passport)

NS: $\quad$... paspor saya hilang tapi saya nggak tahu kepada

NS: siapa saya harus melapor.

NS: $\quad$... my passport's lost but I don't know who I should

NS: report it to.

In summary, as evident from Table 6 above, BI NSs tend to ask for information with a direct sub-strategy, nearly always a direct question. Occasionally BI NSs make a $\mathrm{CI}$ request instead, usually a request for permission; or a Non-CI request, in the form of a hinting statement that the speaker does not know the desired information.

\subsubsection{Choice of Asking strategy: Learners}

Learners, like BI NSs, strongly favour a direct strategy to ask for information (78.0\% or $39 / 50$ of instances). They, too, show a strong preference for the substrategy of direct questions (see Table 6 above). This sub-strategy accounts for a clear majority of Asks by learners ( $68.0 \%$ or $34 / 50)$. Learners' only other type of 
direct Asking sub-strategy is the Want statement, which they use slightly more often than BI NSs (10.0\% or 5/50 of instances).

Learners occasionally ask for information with conventionally indirect requests (see Table 6 above). They use the same CI sub-strategies as BI NSs subjects: a QP modal request ( $4.0 \%$ or $2 / 50$ of instances), or a query about availability of hearer's knowledge $(6.0 \%$ or $3 / 50$ of instances).

Like BI NSs, learners occasionally use statement hints to ask for information (see Table 6). Several of these are of the same type that BI NSs use: statements that the speaker does not have the necessary information. Several others, used by learners when asking for directions, consist of the information that the speaker is seeking the place in question. An example is [101]:

101 (asking a stranger in the street for directions to the Language Centre)

L: $\quad$ Saya mencari Pusat Bahasa.

L: I'm looking for the Language Centre.

\subsubsection{Choice of Asking strategy: Summary}

Both groups tend to ask for information with a direct strategy, and in the great majority of cases this is a direct question. Both groups occasionally perform a CI request instead: either a QP modal request or a query about availability of hearer's knowledge. Both groups also occasionally use a statement hint, which contains the information either that the speaker does not know something or, in the case of learners, that the speaker is looking for a place.

\subsubsection{Situational variation in selection of Asking strategies}

Situational variation in use of the main Asking sub-strategy, the direct question, is examined below, with reference to those five situations in which the request goal is information (see Appendix B for a table of the proportion of subjects who use each strategy in each situation).

Mean values and rankings of speaker's status relative to hearer, size of imposition, and degree of speaker's comfort in various Asking situations, referred to below, 
are based on assessments by BI native speaker and learner informants (see 2.5). A tabular summary of values and rankings of these three variables in each situation is provided in Appendix C.

\subsection{Situational variation in selection of direct questions: BI native speakers}

BI NSs use direct questions to ask for information consistently across situations in this study. In all five Asking situations, this strategy is frequently selected.

A slight tendency can be observed for BI NSs to use direct questions more frequently when the request is less face-threatening. For example, in asking a coach conductor when the coach will arrive at Denpasar, direct questions are used more frequently ( $9 / 9$ subjects) than in any other Asking situation, and the threat to face in this situation is apparently perceived of as smaller than in any other (speaker's status being clearly highest, the imposition clearly smallest, and the speaker's comfort clearly the highest).

However, this trend is not clear- cut. For example, the Asking situation in which direct questions are used least often: asking a police officer at the station where to report a lost passport (4/9 subjects), is assessed as no more face-threatening in terms of social variables than other situations in which direct questions are used more frequently: asking a stranger in the street for directions (7/9 subjects to Post Office and 6/9 subjects to Language Centre); and asking a stranger on a train platform if a certain train goes to Bandung (7/9 subjects).

On the whole, direct questions appear to be used consistently by BI NSs across Asking situations. While the data suggest a tendency for BI NSs to use direct questions most when the threat to face is low, this trend does not emerge clearly. For one thing, the nature of the Asking situations in this study make such a trend hard to detect: none of these situations are assessed as highly threatening to hearer's face, so it is not clear whether BI NSs would eschew this highly direct sub-strategy in such situations. 


\subsection{Situational variation in selection of direct questions: Learners}

Learners use direct questions even more consistently than BI NSs across Asking situations. They use this sub-strategy very frequently in every situation, with only a small range of frequency between situations (from $6 / 10$ subjects to $8 / 10$ subjects).

A slight tendency can be observed for learners to use direct questions more when the situation is less face-threatening. Like BI NSs, learners use direct questions most frequently ( $8 / 10$ subjects) in asking the conductor when the coach will arrive in Denpasar - the situation which appears to be assessed by learners, too, as the least threatening to face (speaker's status being clearly the highest and imposition clearly the lowest, although degree of speaker's comfort is much the same as for most other Asking situations). And in the situation which learners assess as clearly the most face-threatening (by all three factors of status, imposition, and degree of comfort), asking a police officer at the station where to report a lost passport, learners use direct questions with the equal lowest frequency $(6 / 10)$.

However, as with BI NSs, this trend is not clear-cut. For example, learners use direct questions no more frequently (6/10 subjects) in asking for directions to the post office than they do in the "police officer" situation above, although the threat to face in the former situation appears to be regarded as considerably lower.

\subsection{Situational variation in use of direct questions: Summary}

Direct questions are used with striking consistency across Asking situations by both groups, particularly by learners. While a slight trend can be observed for both groups to use direct questions more frequently when the threat to face is smaller, this tendency does not emerge strongly. It appears that the direct question is the archetypal Asking strategy for both groups, and that no variables mitigate strongly against its use; however, it may also be that these five Asking situations are too uniform in social variables to elicit variety in strategy choice by situational factors. 
Regarding appropriacy of strategy selection, learners' choice of strategy, once again (as with other requests: see 4.1.5) is consistently judged by BI informants as acceptable for the situation. Once again, learners are aided both by the fact that a variety of strategies is considered acceptable in these situations, and especially, by the archetypal nature of their main sub-strategy (the direct question), which means that selecting this sub-strategy in any of the situations results in an acceptable choice by learners.

\subsubsection{Additional features of Asks by learners}

Some important features of learner requests observed earlier in this chapter can be observed in the case of Asks as well. One is that learners occasionally show insensitivity to discourse constraints in selecting an Asking strategy. An example is this:

102 (asking a stranger for directions in the street)
L: $\quad$ Uh (.) saya tersesat (.) um
P: $\quad$ Anda mau ke mana?
L: Di di mana (.) Pusat Bahasa?
L: Uh (.) I'm lost (.) um
P: Where are you going?
$\mathrm{L}: \quad \mathrm{Wh} /$ where (.) is the Language Centre?

In [102] above, the direct question by the learner is not appropriate to the context, because it is not aligned with the previous move by the interlocutor. The interlocutor has just asked the learner a question (Anda mau ke mana? "Where are you going?"), which makes an answer (such as Ke Pusat Bahasa "To the Language Centre") a more appropriate move for the learner at this point in the interaction.

Learners also show striking difficulty in phrasing direct questions (as with requests) in an acceptably idiomatic way. An example is [103] below: 
103 (asking a coach conductor during a long journey how long until the coach arrives at Denpasar)
L: $\quad$... uh (.) bagaimana sudah lama (.) uh (.) uh sampai (.)
L: $\quad u h($.$) tiba (.) di Denpasar?$
L: $\quad$... uh (.) in what way has it been long (.) uh (.) uh until
L: $\quad$ (.) we arrive (.) in Denpasar?

The learner in [103] above attempts to ask "How long...?", but uses a word for "how" (bagaimana) which is not used to ask about length of time. The appropriate phrase for the learner's question is Berapa lama...? (literally: "How much long...?).

\subsubsection{Request head act findings: Summary}

A number of points emerge from this examination of request head acts by learners and BI NS subjects. In choice of head act strategy, the two groups exhibit important similarities and differences. Learners, like BI NSs, use mostly CI requests, in the form of the same sub-strategy: QP modal requests. However, the two groups generally select a different modal verb to realise this sub-strategy. Both groups use direct requests frequently. However, learners use a certain direct substrategy (Want statements) a lot more frequently than BI NSs, and another one (imperatives) a lot less frequently, as well as virtually never using several other direct sub-strategies which BI NSs sometimes use. Learners also use considerably more hints than BI NSs, especially statement hints.

Concerning situational variation in choice of strategy, learners show close similarities to BI NSs in their sensitivity to social variables, particularly in their use of the imperative and QP modal sub-strategies; and consistently manage to choose a strategy that is acceptable for the situation (aided by certain factors discussed above).

However, learners do not manage so successfully to choose an appropriate strategy when their ability to do so depends on responsiveness to development of the discourse; specifically, on successful orientation to the interlocutor's previous contribution. In these cases, learners sometimes choose a strategy which (although 
inherently acceptable in terms of social variables) is not appropriate at that particular point, given the development of the interaction.

With regard to other main dimension of head act, choice of perspective, learners show similarities with BI NSs as well as one major difference. In QP modal requests they favour the same perspective as BI NSs (speaker perspective). However, they use impersonal perspective less frequently than BI NSs for this sub-strategy, and in imperatives this contrast is more stark: learners never use impersonal perspective while BI NSs use it in a very high proportion of instances.

Learners have considerable difficulty in realising different head act types appropriately. They tend to express the goal of requests in highly unidiomatic and sometimes unclear ways. In addition, when they do not succeed initially in conveying the request goal clearly, they have trouble in clarifying the nature of the request goal in cooperation with the interlocutor. Moreover, they frequently use an inappropriate second person pronoun, and use markedly non-native intonation on a number of request types.

Follow-up 'requests' yield additional findings which confirm the picture provided by the main data. In follow-up requests, too, learners use Want strategies frequently while BI NSs prefer elided imperatives and Goal statements instead. In follow-up requests, too, learners display a lack of sensitivity to interactional constraints. They do this by performing these requests with the same sub-strategy they use for the main request, while BI NSs select different sub-strategies for the two utterances.

An examination of Asking head acts confirms certain of the findings above. Learners and BI NSs show a striking similarity in selection of strategies, both using direct questions as their main sub-strategy consistently across the range of Asking situations. However, learners sometimes select an Asking strategy that is inappropriate due to unresponsiveness to the discourse context; and in asking direct questions, as well, learners demonstrate difficulty in expressing themselves in acceptably idiomatic language. 


\subsection{Discussion}

\subsubsection{Introduction}

In this section, the most important findings from above are selected and discussed in some detail. Possible explanations for the findings are suggested, and implications of the data for how learners perform L2 requests - and L2 speech acts in general - are considered. Implications of the data for how learners develop the ability to make requests are also discussed, by comparing the performance of Low, Middle, and High learners (see 2.1.1). In addition, certain aspects of the BI native speaker data which are suggestive of how requests may be performed across languages are considered.

\subsubsection{Frequency of QP modal requests by learners}

This section discusses the finding that the learners in this study select the query preparatory modal sub-strategy as their main request type (see 4.1.2.2).

The factor of $\mathrm{L} 1$ transfer is likely to be an important cause for this finding. There is very strong evidence from empirical research that native speakers of Australian English (AE) strongly favour query preparatory requests, and in particular QP modal requests, over any other type of request strategy; and do so consistently, across a wide range of situations (Blum-Kulka \& House 1989; Blum-Kulka 1989, Tanaka 1986, 1988; X. Nguyen 1990; Wierzbicka 1991). This finding is also confirmed for native speakers of other varieties of English: British English (House and Kasper 1987; Trosborg 1995; Fukushima 1996) and Canadian English (BlumKulka 1983). Therefore it seems likely that the learners in the present study do not need to make significant adjustments from the directness level that they select when making requests in the native language; instead, they can 'fall back' on L1 pragmatic knowledge to a large extent in selecting this request type. ${ }^{13}$

However, L1 influence is unlikely to be the only factor causing these learners to select a QP modal strategy so frequently. Influence of instruction probably plays a large role as well. The main textbook of these learners (Johns (1977) ${ }^{14}$ devotes considerable attention from an early stage to QP modal request forms with boleh "may/ be allowed" (such as Boleh saya ...? "May I ...?" and Bolehkah saya ...? 
“May- INT I ...?"). These forms, called "modal questions", are explicitly modelled, and drilled extensively. Therefore, even though learners are given no explicit pragmatic information about these forms in their textbook (e.g. the information that they are frequently used to make requests), and given little or no communicative practice in using these questions to make requests, they receive enough exposure to this request form to know that it exists in the L2, and hence, that their L1 pragmatic knowledge about this type of request can be transferred to the L2.15

A final factor that probably contributes to learner's use of this strategy is its formal simplicity. This type of modal question is structurally simple, consisting minimally of Modal verb + Agent + Verb (e.g. Boleh + saya + pinjam, structurally parallel to May $+\mathrm{I}+$ borrow), so learners are unlikely to be discouraged by considerations of formal complexity in selecting this strategy. ${ }^{16}$

It is interesting to note that this request sub-strategy is selected consistently by learners at all levels of proficiency in the present study, including the Low group (two of the three Low subjects using it as their most common or equal most common request type). Trosborg (1995), similarly, remarks on the ability of her learner subjects from all three proficiency groupings to use this polite, conventionally indirect strategy type. The present study confirms and extends Trosborg's finding: it shows that when the same strategy exists in the L1, and the L2 pragmalinguistic form is formally simple, learners even well below the proficiency of Trosborg's lowest level learners are able consistently to select a polite, conventionally indirect strategy in the $\mathrm{L} 2$.

The fact that native speaker Indonesian subjects consistently select the QP modal strategy is of interest itself. The query preparatory request appears to be the main request sub-strategy of native speakers across a large number of languages (cf. Blum-Kulka 1989: 52; Kasper 1989: 47). However, the vast majority of languages for which the predominance of this request type has been established are Germanic or Romance languages, such as German, Danish, English, French (in the CCSARP project, cf. Blum-Kulka \& House 1989); or Spanish (le Pair 1996), or Dutch (van Mulken 1996); or at least languages of strongly Western-influenced cultures, such as Hebrew (Blum-Kulka \& House 1989). And in fact, the few studies on requests by native speakers of non-European languages do not seem to produce the same finding with the same consistency. While Fukushima (1996) confirms the finding for Japanese native speakers, Mandarin native speakers in one study (Lee-Wong 1994), 17 and Vietnamese native speakers (X. Nguyen 1990), 
clearly appear to favour direct requests instead. So the present finding that native speakers of Indonesian favour query preparatory requests over other types appears to confirm the likely importance of this strategy for requesting across languages.

However, this finding might well reflect the nature of the sample group of BI native speakers in this study. Wierzbicka (1991: 30-37) argues that the very strong preference of Australian English speakers for query preparatory requests is linked specifically to values that prevail in Australian culture: a strong egalitarian ethos and a strong concern with individual autonomy. This suggests that in Indonesian society, which is generally regarded as distinctly non- egalitarian and highly conscious of status differences (see 2.5), and as placing strong value on group membership, rather than individual autonomy (cf. Draine \& Hall 1990: 124; Reeve 1995: 8), this sub-strategy is unlikely to be the archetypal means of requesting. However, these BI NS subjects, who are studying at university in Australia, and hence are uniformly well-educated, middle-class, and familiar with Western culture, are likely to identify more with Western cultural values (such as egalitarianism) and less with 'traditional' Indonesian ones than the 'average' Indonesian. Thus, their preference for query preparatory requests might partly reflect the cultural ethos of a small 'elite' Indonesian sub-culture (see 7.6).

It is also possible that this finding is partly caused by the data elicitation method. An artificial egalitarianism may have prevailed to some extent in the role plays in this study. The fact that the partners with whom BI NS subjects interacted were not really (e.g.) shop assistants, or waiters, but were really well-educated middle class Indonesians, of the same social background as the BI NS subjects, might sometimes have influenced BI NS subjects to select a request type (such as query preparatory) which reflected this real-life equal relationship, rather than the imaginary, role play relationship in which the addressee was lower in status. 18

\subsubsection{Choice of modal verb by learners in QP modal requests}

This section discusses the finding that the learners in this study consistently choose a different modal verb from BI NSs in query preparatory requests for permission; namely, boleh "may/ be allowed" instead of bisa "can" (see 4.1.2.2).

Importantly, transfer of the English modal verb "may" - by which boleh is consistently glossed in the learners' main textbook (Johns 1977) - does not 
appear to motivate the learners' strong preference for boleh over bisa "can". Permission requests in English are made at least as frequently with the modal verb "can/ could" as they are with "may" (cf. Aijmer (1996: 161) for British English; Blum-Kulka (1989: 59ff) for Australian English). Moreover, as observed earlier, learners in the present study sometimes choose boleh even when the L1 equivalent "may" cannot be used in the parallel English request (e.g.*Boleh Anda...? "May you...?": see 4.1.2.2). This suggests that the learners are not transferring this feature from the L1. 19

An explanation suggested for a closely parallel finding in the CCSARP data may be relevant here. Faerch and Kasper (1989) found that Danish learners of German consistently chose the modal verb dürfen "may" when making query preparatory requests, while German native speakers preferred the modal verb können "can" instead. Faerch and Kasper (1989) suggest that the inherently unequal relationship between native and non-native speaker may have prompted those learners to select a more deferential modal verb. Similarly, learners in the present study may feel that their status as non-native speakers calls for more tentative verbal behaviour, and so choose to mark their request for negative politeness, by choosing the modal verb (boleh "may") which more strongly suggests that the hearer has power over the speaker.

While this factor above may well be influential, another factor is likely to have the decisive role; namely, the instruction received by these learners in the use of these two modal verbs. In the learners' main textbook (Johns 1977) the modal verb bisa "can" is used to refer to ability only; it is never presented or practiced in the context of asking for permission. Instead, the verb boleh "may/be allowed" is invariably used for the latter function. In fact, while it is never explicitly stated in this textbook that bisa "can" is not used to ask for permission, the two modal verbs are implicitly contrasted in model dialogues, in a way that seems intended to suggest that this is so. ${ }^{20}$ An example is the following excerpt from a dialogue between a schoolchild and his teacher:

Bu, bolehkah saya bertanya?

Ya, boleh.

Apa Ibu bisa berbicara bahasa Inggeris?

Ya, bisa. 
Miss, may I ask a question?

Yes, you may.

Can you speak English, Miss?

Yes, I can.

(Johns 1977: 31, emphasis added) :

So it appears that the learners have acquired this preference for boleh over bisa primarily by secondary teaching induction (see 1.6.3.4). The way that these two modal verbs are presented and practiced has probably caused learners to form the II -specific rule that bisa is not used to make requests. As a result, learners avoid transfer of the very common English request formula "Can $\mathrm{I}$ Can you ...?" to Indonesian, as they do not believe this formula to be acceptable in Indonesian.

It is interesting in this regard to compare the performance of the Low and the High group of learners. The Low group clearly prefer the BI native speaker choice of modal verb, bisa "can", using it in almost all (8/9 instances) of their QP requests for permission. By contrast, the High group chooses boleh "may/ be allowed" in almost all (8/9) instances (and the Middle group, too, strongly favours this modal verb). The fact that the High learners seem to avoid transferring the English request formula "Can I...?" into Indonesian while the Low learners transfer it successfully lends some support to Kasper's (1995a) claim (see 1.6.3.2) that advanced learners sometimes resist transfer of $\mathrm{L} 1$ pragmalinguistic forms that can be transferred, due to overcaution, while lower level learners may successfully transfer the same forms.

This proficiency difference in the use of bisa "can" to ask for permission is probably not because Low and High learners have different representations of knowledge about the transferability of this modal verb. As discussed earlier (1.6.3.2), linguistic proficiency appears to have little effect on learner's perceptions of pragmatic transferability. Instead, different degree of control over pragmatic knowledge (cf. Bialystok 1993) by Low and High learners is likely to be decisive. The High group is probably able to attend to their pragmatic knowledge about the likely non-transferability of "can", while the Low group, who have to invest a great deal of processing effort in order to participate in spoken discourse, are unable to think about whether this modal verb can be successfully transferred to the L2 or not. 


\subsubsection{Frequency of imperatives by learners}

This section discusses the finding that the learners in this study use few imperatives compared with BI native speakers (see 4.1.2.1).

An interesting diversity exists in previous findings about this most direct of all request types. In some studies learners underuse imperatives compared with L2 native speakers (for example, intermediate and advanced English learners of Hebrew: Blum-Kulka 1983; and intermediate Dutch learners of Spanish: le Pair 1996). In other studies, learners overuse imperatives (beginner English learners of Spanish: Koike 1989; and English "upper-division" undergraduate learners of French: Harlow 1990). Trosborg (1995) reports mixed findings: while two of her groups of Danish learners of English greatly underuse imperatives, the other group (the most advanced) uses them with very similar frequency to L2 native speakers.

The main explanation offered for the underuse of imperatives by learners in studies above (Blum-Kulka 1983; Trosborg 1995; le Pair 1996) is that the learners are 'playing it safe' with regard to pragmatic meaning. From fear of appearing impolite in a foreign language (it is suggested), learners avoid this extremely direct request sub-strategy and opt for what they perceive as safer strategies instead. While this factor may help to explain the underuse of imperatives by these Australian learners of Indonesian, it does not seem adequate by itself. These Australian learners do not show a general reluctance to express themselves directly in Indonesian, as they use another direct sub-strategy (Want statements) much more frequently than BI NSs. So they do not consistently 'play it safe' with regard to politeness.

Influence from the L1 may well be another partial explanation. It is well-established that English native speakers use (full) imperatives only infrequently to make requests. Studies on Australian English (AE) specifically observe this: Wierzbicka (1991: 36) observes a "strong reluctance" in AE to use flat imperatives when requesting, and in the CCSARP project, native $\mathrm{AE}$ speakers displayed reluctance to use direct sub-strategies (including imperatives), instead showing a consistent preference for CI requests across situations (Blum-Kulka \& House 1989). This finding is confirmed for British English as well (Brown \& Levinson 1987: 248; Sifianou 1992). Therefore, if Australian learners fall back on L1 pragmatic knowledge about the imperative sub-strategy they are likely to use this request type less frequently than Indonesian native speakers. 
However, transfer from English does not seem sufficient explanation for the underuse of imperatives by these Australian learners, either. This is in view of the fact that the learners who overused imperatives in the studies cited above (Harlow 1990 and Koike 1989) were also native speakers of English. An important additional factor is likely to be the formal complexity of this request type in Indonesian.

There are complex rules in Indonesian for whether to retain or to drop verbal prefixes on full imperative constructions. If the verb is intransitive, the verbal prefix is retained (e.g. Tolong berhenti. "Please stop.", not *Tolong Ø-henti .). If the verb is transitive and it is directed to a specific object, the verbal prefix is deleted (e.g. Tolong Ø-bawakan sebotol bir. "Please bring a bottle of beer.", not *Tolong membawakan ...). However, if the verb is transitive and it is not directed to a specific object, the verbal prefix is retained (e.g. Tolong membaca. "Please read.", not *Tolong $\emptyset$-baca. ) (Johns 1977: 115). Therefore, even if these learners begin to plan a request with an imperative strategy, they are likely to realise that they have uncertain knowledge of the rules for forming the imperative, or that they lack the automatic control over these rules needed to apply them in real time; and so choose another type of request instead.

These Australian learners, then, may well be 'playing it safe' not with regard to politeness but with regard to formal accuracy, by opting for strategies that they can realise with grammatical correctness. The great emphasis placed on formal accuracy in the Indonesian course that these learners follow, reflected in the central importance given to a structurally-based textbook (Johns 1977), is likely to encourage them to believe that formal accuracy is of primary importance in conversation, even when performing face-threatening speech acts (where interpersonal meaning is actually more important). The method of data elicitation used in this study, too, may well contribute to a primary concern for formal correctness. The learners knew that their role play conversations were being audiorecorded, and so were likely to feel that their linguistic competence was under closer scrutiny than it is in real life.

It is interesting to note the heavy emphasis given to imperatives in the learners' main textbook. In this textbook (Johns 1977) the imperative mood is evidently regarded as a major component of grammar, as imperative constructions using different verb types are modelled and drilled extensively, from the earliest to the 
later chapters. In fact these learners are exposed to and produce many more imperative request forms than $\mathrm{QP}$ modal request forms. It seems likely that learners would infer from this heavy teaching emphasis on the imperative that this substrategy is used very frequently in Indonesian to make requests. This supports the contention that if these learners rarely use the imperative, it may be largely because of the formal difficulties it presents.

Another factor may be that imperative requests by learners have a different pragmatic effect to many of those by BI NSs. This is because learners, unlike BI NSs, never use impersonal perspective to mitigate the coerciveness of this request type. As a result, learners might (quite correctly) assess imperative forms as more coercive than BI NSs, and hence, as appropriate in more restricted contexts. The importance of this factor is suggested by the fact that in the "bus conductor" situation where BI NSs use imperatives very frequently and learners never do (see 4.1.4.2), all but one of the BI NS imperatives are softened by impersonal perspective. It is possible that if the learners had this mitigating device in their repertoire, they would assess imperatives more frequently as being appropriate.

While no clear proficiency differences can be observed in the use of full imperatives, proficiency-related findings on use of elided imperatives specifically are worth mentioning. The only few instances of elided imperatives by these learners are produced by the two High learners. This sub-strategy does not demand high linguistic proficiency; on the contrary, it is formally very simple (e.g. Satu nasi goreng "One fried rice"). It seems that the extreme brevity and elliptical nature of this strategy might discourage lower level learners, in particular, from using it. They would be likely to doubt that they were using enough words to communicate their message successfully (see 1.6.3.3); while the higher proficiency learners may well have more confidence in their ability to communicate effectively with this very short form. Thus, it is likely that acquisition of this request type will follow a 'Ushaped' developmental curve (cf. Strauss 1982; Kellerman 1983). We know from previous research (Ellis 1992) that elided imperatives are used by beginning learners, who simply state the desired object (e.g. "Pencil") when requesting, because they lack the linguistic ability to elaborate. The present data suggest that this feature may disappear from interlanguage at a somewhat higher level of proficiency (the present Low and Middle groups), and then, at a higher level still (the present High group), once again start to emerge. 


\subsubsection{Frequency of Want statements by learners}

This section discusses the finding that the learners in this study use Want statements much more frequently than BI NSs do (see 4.1.2.1).

The same finding has been made about L2 learners in a number of studies. Statements of personal desire, and/ or statements of need, appear to be quite consistently used by learners more than by $\mathrm{L} 2$ native speakers (for example Trosborg 1995; Koike 1989; Rintell 1981; Scarcella and Brunak 1981).21

Koike (1989) suggests that the overuse of Want statements by learners reflects a general tendency of learners to opt for less polite forms that are most efficiently and easily expressed, due to a strong concern with clarity (see 1.6.3.3). This claim that learners may select Want statements mainly for their clarity is supported by a piece of retrospective data from a Hebrew learner of English (Cohen \& Olshtain 1993: 40). This learner planned to make a polite hint to her teacher for a lift home from class: "Do you have any room in the car?"; but decided that the meaning might not be clear, and opted for a Want statement ("I want to drive with you"), instead, so that the teacher would understood her better. Learners in the present study, too, could well be partly motivated by a concern for clarity in their selection of Want statements. As observed earlier, they sometimes seem to select this strategy in order to clear up a potential misunderstanding (see 4.1.2.1); or to express a request goal which is difficult to convey (see 4.1.4.4).

However, a number of factors are likely to contribute to this feature of learner requests in the present study. Another is that Want statements are used frequently to make requests in the learners' main textbook (Johns 1977). An example is this model dialogue, in a restaurant: 


$\begin{array}{ll}\text { Pelayan: } & \text { "Tuan dan Nyonya Harun mau makan apa? Ada soto, } \\ & \text { sate dan bakmi goreng." } \\ \text { Nyonya H: } & \text { "Saya mau bakmi goreng." } \\ \text { Tuan H: } & \text { "Saya mau sate." } \\ \text { Pelayan: } & \text { "Sate ayam, sate kambing, atau sate daging, Tuan?" } \\ \text { Tuan H: } & \text { "Saya mau sate ayam." } \\ \text { Pelayan: } & \text { "... Tuan dan Nyonya mau minum apa?" } \\ \text { Nyonya H: } & \text { "Saya mau teh." } \\ \text { Tuan H: } & \text { "Saya mau kopi" }\end{array}$

Waiter: "What do you want to eat, Mr and Mrs Harun? We have soup, sate, and fried noodles."

Mrs H: "I want fried noodles."

Mr H: "I want sate."

Waiter: "Chicken, goat, or beef sate, Sir?"

Mr H: "I want chicken sate."

Waiter: “... What do Sir and Madam want to drink?"

Mrs H: "I want tea."

Mr H: "I want coffee."

(Johns 1977: 94, emphasis added)

In the model dialogue above, Want requests are used more often than would be natural in real life discourse. Learners may well infer from this kind of deviant input (cf. Kasper 1982) that Want statement requests are the norm in the above "restaurant" situation. Furthermore, they may generalise from this $\mathbb{L}$ knowledge to other contexts, to form the knowledge that Want statements are normative in other service encounters, too (such as in shops, banks, and post offices) - service encounters being the situations in which these learners use Want statements with conspicuous frequency.

Another possible factor is stereotyping of the L2 culture by learners. Australian learners tend to be told that Indonesian society is highly status conscious, and so they are likely to presume that Indonesians will make direct requests to addressees 
of low status. However, this attempt to "converge psychologically" with L2 native speakers may result in learners "overshooting the mark" (Beebe \& T. Takahashi 1989: 119) — and ending up sometimes making requests to low status addressees which are more direct than those of BI NSs (who often opt for CI requests when learners use Want statements). A similar explanation is proposed by Blum-Kulka (1991) for her finding that advanced learners of Hebrew use more direct request strategies than L2 native speakers in certain situations. She surmises that the learners in her study were stereotyping the presumed Israeli ethos of directness.

Another possible factor contributing to the heavy use of Want statements by learners in the present study is influence from the wording of cue card instructions given to subjects (see Appendix D). Instructions to roleplay subjects were often phrased as potential Want statements (e.g. "You are sitting in a cheap restaurant ... and you want a menu....") and although BI NSs subjects had identically worded cue instructions, it is possible that the learners were more heavily influenced than the L2 native speakers by the language of the cues they had read shortly before. ${ }^{22}$ However, no clear evidence exists for a 'cue card effect' on learners' responses in the present study: in some situations where the instructions contain a potential Want statement no learners select Want statements, and in some situations where the instructions do not contain a potential Want statement, learners use Want statements frequently.

A clear proficiency difference can be observed in the selection of Want statements in the present data. The Low group are conspicuous for their heavy use of Want statements, being the three most frequent users in the entire sample group, while the High group do not use this request type at all. This is consistent with previous findings. Scarcella and Brunak (1981) and Trosborg (1995) both report a clear trend for lower proficiency subjects to use statements of personal desire or need a lot more frequently than higher proficiency subjects. While the proficiency levels of learners are not uniform in the three studies, the direction of apparent development is the same: in each case lower level learners overuse Want statements while higher level ones do not. This suggests that learners may use this request type with diminishing frequency as they become more proficient in the L2.

One learner in the Low group (Low -2) in this study shows a particularly strong preference for Want statements, making most of his requests (8/13) by means of this sub-strategy. By contrast, he uses the QP modal request type (the most common sub-strategy of learners) on only one occasion. This suggests the 
possibility of a 'pre-modal' stage of request strategy development whereby learners at an even lower level of proficiency than the Low Group in the present study might use Want statements in preference to QP modal requests. This is consistent with Scarcella and Brunak's (1981) impression of the Want statement sub-strategy. They compare learners' Want statements with children's simple "need" statements in early L1 acquisition, and suggest that this strategy may be one of the first directive types to emerge in second language acquisition.

\subsubsection{Range of direct sub-strategies by learners}

This section discusses the finding that the learners in this study use a narrower range of direct sub-strategies than BI native speaker subjects, virtually never producing performatives, hedged performatives, or Goal statements (see 4.1.2.1).

This finding can best be attributed to the factor of pragmalinguistic knowledge. The learners are likely to lack native-like representations of knowledge of the formulas used for these three Indonesian request types and of their frequency in the L2. This is only to be expected, considering the following points. Firstly, the learners are not exposed to or given practice in any of these three request types as part of their formal instruction (none of these request types occur in their textbooks). Secondly, the learners have had little or no authentic exposure to L2 requesting in naturalistic settings, which would allow them to gain the requisite knowledge in that way. Lastly, these three sub-strategies (unlike the other request strategies that learners use in the data) do not have a L1 pragmalinguistic equivalent which is used with comparable frequency.

This lack of a readily available English equivalent is clearest in regard to Goal statements (cf.*"I borrow a pen"). While the explicit performative and hedged performative strategy do have possible English realisations (e.g. "I'm asking you to move over" and "I'd like to ask for a lift", respectively), these request types are not frequently used in English. In requests by Australian English speakers, neither X. Nguyen (1990) or Tanaka $(1986,1988)$ find any instances of either of these substrategies, while in British English requests, Aijmer (1996: 150table) and Trosborg (1995: 225table) find no instances of either, and House and Kasper (1987:12581260 tables) find very few. This suggests that to a large extent learners are unable to gain the requisite pragmatic knowledge from the $\mathrm{L} 1$, leaving no source from which 
learners can gain the knowledge required to integrate these request sub-strategies into their L2 repertoire.

This absence of certain BI NS request strategies from the learner repertoire can be regarded as part of the broader trend for these learners to have a smaller repertoire of linguistic resources at their disposal than BI NSs to realise requests (seen also in their internal and external modification: cf. Chapters 5 and 6). This feature of a smaller range of linguistic resources has been observed frequently in studies of learner requesting and speech act performance in general (see 1.6.3.3).

One contrasting finding about learners' range of request strategies is worth mentioning. House and Kasper (1987) find that Danish and German learners of English actually used a greater range of direct sub-strategies than L2 native speakers. Instead of concentrating on a single level of directness (conventional indirectness), as English native subjects did, these learners used a variety of direct sub-strategies (although often at small frequencies). Trosborg (1995), however, who did not find this kind of "overvariety" in her own study of Danish learners of English, argues that House and Kasper's (1987) finding may be attributable to the CCSARP method of data elicitation. She points out that as subjects in the CCSARP were presented with a written questionnaire containing a list of five different request situations, they are likely to feel that they are expected to vary their responses in the different situations (and as it was a written questionnaire, subjects were able to visually compare their choices of strategy across situations). Native speaker subjects, however, are unlikely to be affected by this elicitation method in the same way; they will have a strong intuitive knowledge of what strategy is appropriate and therefore will feel more secure about maintaining the same directness level across request situations (Trosborg 1995: 292-93).

\subsubsection{Frequency of statement hints by learners}

This section discusses the finding that the learners in this study use statement hints much more frequently than BI NS subjects (see 4.1.2.3).

Trosborg's (1995) interpretation of hints by learners in her study is very helpful in understanding the present finding. Trosborg (1995) suggests that some of the hints produced by her Danish learners of English should not be regarded as hints proper, for the reason that they were probably not uttered with strategic intent; that is, with 
the intention of "blurring the illocutionary force" (Trosborg 1995: 229). ${ }^{23}$ An example of such a 'hint' from her data is below:

(asking to be released from a baby-sitting arrangement).

Learner: $\quad$ Eh it's about tonight - my boyfriend called me this morning

NS: $\quad$ Ehem

Learner: $\quad$ and eh asked me if I want to go with him to a concert.

NS: Oh yes.

Learner: This night.

NS: This night, and you were going to babysit this night, weren't you?

(Trosborg 1995: 229, emphasis added)

Trosborg (1995) suggests that in instances like the one above, learners get no further than making a preliminary to a request because they are doubtful about how to phrase the actual request. The addressee, however, interprets the preliminary move as a hint, eliminating the need for the learner to make a 'real' request at all. Trosborg (1995) compares this phenomenon to $\mathrm{L} 1$ requests by children, who just state a problem (e.g. "Mummy, I'm cold"), and leave it to the addressee to solve it. One reason Trosborg (1995) suspects this phenomenon of 'hints' to be at work in her study is that her three groups of learners use hints in inverse proportion to the linguistic proficiency of the group. The greater number of hints by lower level learners is probably because these learners have greater difficulty in phrasing requests appropriately, and thus, more often leave it to the interlocutor to anticipate their need.

It seems highly likely that the Australian learners in the present study, too, are often performing 'hints' rather than hints. They tend to formulate preliminary moves slowly and haltingly. This gives the interloctor ample time to realise what the learner wants, so that he or she can cut in and pre-empt a more explicit request by the learner - whether to save the learner the trouble of formulating a request, or to save time, or from impatience. And as most of the learners in the present study are of lower proficiency even than Trosborg's (1995) lowest proficiency group, they are likely to pause more often, and hesitate longer, and thus to have their requests pre-empted more often. It is also suggestive that (although Low and Middle learners use statement hints with similar frequency) the High learners in the 
present study use no statement hints at all. This has parallels with Trosborg's proficiency finding (above), and strengthens the claim that statement hints in the present data are sometimes due to difficulty in phrasing requests.

An example of an utterance by a learner in the present study which is apparently intended as a preliminary move but which is interpreted as a statement hint is [63], reproduced below:

104 (asking a conductor to tell you when the bus gets to the stop nearest Kartini Street)

L: $\quad$... saya (.) uh (.) tidak tahu di mana (.) uh (.) Jalan

L: $\quad \underline{\text { Kartini }}$

P: $\quad$ Uh (.) ya ya saya akan (.) menunjukkannya (.) pada

P: $\quad$ Anda (.) silakan duduk dahulu.

L: $\quad$ Ah (.) terima kasih (.) er (.) uh (.) apa Anda

L: $\quad$ memberitahu saya di mana (.) ketika kami (.) uh (.)

L: $\quad$ datang $k e($.$) stop bis yang terbaik?$

P: $\quad Y a$ (.) ya pasti (.) silakan duduk dahulu.

L: $\quad$... I (.) uh (.) don't know where (.) uh (.) Kartini

L: $\quad \underline{\text { Street is }}$

P: $\quad$ Uh, yes yes I'll (.) point it out (.) to you (.) please sit down

$\mathrm{P:} \quad$ in the meantime.

L: $\quad$ Ah (.) thank you (.) er (.) uh (.) do you tell me where (.)

L: $\quad$ when we (.) uh (.) come to (.) the best bus stop?

P: $\quad$ Yes (.) yes certainly (.) please sit down in the meantime.

In [104] above, the utterance Saya tidak tahu di mana Jalan Kartini "I don't know where Kartini Street is" was probably not intended as a hint. Evidence for this is that when the partner interprets it as a hint (by undertaking to show her where Kartini Street is), the learner reasserts the preliminary status of the move, by making a more explicit request in her following turn.

Learners' use of hinting statements to deal with linguistic difficulties in formulating requests may sometimes be a conscious (or potentially conscious) 'communication strategy' (cf. Faerch \& Kasper 1983). Evidence for this is supplied by a chance piece of retrospective data from one learner in the Middle group. She used a statement hint when asking for a pen from a hotel receptionist: Saya tidak punya 
pulpen "I don't have a pen", and then, when the roleplay was finished, remarked with a laugh "I don't know how to say "Can I have ...?" in Indonesian, so I just say that I don't have it instead." So one learner, at least, clearly intends the interlocutor to anticipate her need and thus save her the trouble of formulating a more direct request. 24

A contributing factor to the high frequency of statement hints (or 'hints') by learners may be that BI native roleplay partners are more 'indulgent' of learner than of BI NS subjects; that is, more willing to 'take the hint'. This is illustrated by a comparison of [105] and [106] below:

[105] (asking a university lecturer for an extension on an essay deadline)

L: $\quad$ Saya (.) tidak dapat menyelesaikan esai saya (.) um pada hari Jumat

L: saya kira

P: $\quad O($.$) ya (.) tidak apa-apa (.) kalau gitu (.) kapan mau diserahkan?$

L: $\quad$ I (.) can't finish my essay (.) um on Friday I think.

P: $\quad$ Oh (.) yes (.) it doesn't matter (.) in that case (.) when do you

P: $\quad$ want to hand it in?

In [105] above, the learner's initial move (Saya tidak dapat menyelesaikan esai saya ... "I can't finish my essay...") is met with an offer of an extension, so that it functions as a statement hint. Compare this with the reception of a very similar move by a BI NS subject, below:

106 ("essay extension" situation above)

NS: Itu esai saya tentang Kebudayaan Jawa? (.) kayaknya

NS: $\quad$ nggak bisa (.) di(.)kumpulin pada hari Jumat deh

P: $\quad$ Terus? (.) mau Andanya? (.) mau Anda?

NS: $\quad$ Paling tidak hari Senin apa hari Selasa (.) ...

NS: That essay of mine on Javanese Culture? (.) it looks like I

NS: can't (.) hand it in on Friday

P: $\quad$ And? (.) what is it you want? (.) what do you want?

NS: At least (until) Monday or Tuesday (.) ... 
In [106] above, the partner seems to deliberately resist a hint interpretation for the initial move by the BI NS subject, 24 by urging him to make his illocutionary purpose clearer (Terus? Mau Andanya? Mau Anda? "And? What is it you want? What do you want?").25

Other factors are also likely to contribute to this feature of learner behaviour. Some learner statement hints, at least, are likely to be hints proper (rather than 'hints'), and $\mathrm{L} 1$ influence could well have a role in causing learners to select this request type. Native speakers of Australian English have been found to use a large proportion of hints when requesting, compared with native speakers of other languages in the CCSARP study (Blum-Kulka and House 1989), and, in fact, to show a distinct preference for precisely this type of hint: a statement consisting of a potential grounding move (Weizman 1989). Native speakers of British English, too, have also been found to use hints in a substantial proportion (22.8\%) of requests which involve a large imposition (Trosborg 1995: 225table). This suggests that the learners in the present study may tend to select statement hints partly because they are relatively common in the $\mathrm{L} 1$.

It is also possible that learners tend to select hinting statements partly under influence of the wording of cue instructions. Instructions for some of the roleplay situations were phrased as potential statement hints, including certain situations where learners frequently used this sub-strategy (see 4.1.4.8). Although the cues used by BI NS subjects were identically phrased, it is possible that learners were more influenced than BI NSs by the language of the cues they had seen shortly before performing the roleplay. However (as with Want statements), there is no clear evidence for such a 'cue card effect': learners sometimes use statement hints quite frequently when the cues are not phrased as potential hint statements, and vice versa.

\subsubsection{Variation in selection of request strategy by learners}

This section discusses the finding that the learners in this study vary their selection of head act strategy according to the situation, and tend to do so appropriately (see 4.1.4; see also 4.1.10.4). 
The ability of L2 learners to vary request strategy according to situation is wellattested. Blum-Kulka (1991) notes that CCSARP learners of Hebrew varied their choice of request strategy from situation to situation, irrespective of proficiency level (from lower-intermediate to advanced) and irrespective of mother tongue. Sometimes learners even display greater sensitivity to certain contextual factors in selecting a strategy than L2 native speakers do (House \& Kasper 1987: 1269 for requests; Beebe \& T. Takahashi (1989: 120) for disagreeing and giving embarrassing information).

Blum-Kulka (1991) concludes that learners' sensitivity to contextual constraints is part of the 'general pragmatic knowledge base' (see 1.6.3.1) that all speakers have. This claim allows us to interpret the inability of beginner learners to vary their request strategies by situation (cf. Scarcella \& Brunak 1981) as being due to simple linguistic limitations. Even beginner learners, we may assume, are likely to know that it is appropriate to vary strategy type by situation, but may lack the necessary linguistic resources to do so.

Learners in the present study not only vary their choice of request strategies by situation, but often do so in very similar ways to BI NSs (see 4.1.4; see also 4.1.10.4). This success in adjusting to situation in native-like ways seems largely attributable to transfer of $\mathrm{L} 1$ knowledge about the appropriacy or non-appropriacy of given request types in given contexts. The learners' tendency to use QP modal requests across a wide range of situation types seems attributable to use of L1 pragmatic knowledge, the tendency to use a QP modal sub-strategy as the 'archetypal' request form across situations being a striking feature of requests by native $\mathrm{AE}$ speakers as well (see 4.2.2). Similarly, the learners' tendency to use Want statements mainly in service encounters, and to eschew this sub-strategy in 'sensitive' situations where the threat to face is assessed as relatively high (see 4.1.4.4; see also 4.1.5) seems attributable to L1 pragmatic knowledge.

At least one element of these learners' ability to vary request strategies appropriately by situation: their native-like sensitivity to the factor of urgency in selecting imperatives, could be due either to transfer of L1 knowledge or to reliance on universal knowledge (Brown \& Levinson (1978: 100-102) suggesting that urgency is a universal factor in imperative selection). Moreover, in the light of CCSARP research in which the use of both direct and $\mathrm{CI}$ request strategies followed a similar trend in variation according to situation by native speakers across all languages 
examined (Blum-Kulka \& House 1989), it appears that a considerable amount of knowledge about situational variation in strategy choice may be universal. So, while it appears that L1 transfer played a major role in enabling appropriate variation in L2 strategy choice by these learners, application of universal pragmatic knowledge may have been important as well.

At least some of the sucessful learner variation by situation appears to require L2specific pragmatic knowledge. For example, learners use full imperatives appropriately in situations where this strategy would be of doubtful acceptability in $\mathrm{AE}$ (e.g. asking a hotel servant to have your clothes washed, and ordering a drink in a restaurant); and hence does not seem explicable by $\mathrm{L} 1$ transfer. There are at least two possible sources of this L2-specific pragmatic knowledge by learners about the use of full imperatives to lower status hearers in service roles. One is successful generalisation by learners from L2 cultural knowledge. Australian learners might infer from their knowledge of the highly status-conscious nature of Indonesian society (see 4.1.4.4) that highly direct imperative requests to addressees of this type are likely to be acceptable in the L2 (an example of 'successful stereotyping' of the L2 culture).

Another possible source of the requisite knowledge is successful generalisation from rules of use implicit in teaching materials. In the learners' main textbook (Johns 1977), imperative forms (when used within an identifiable context) are invariably used to address a child, by a speaker who is clearly dominant and of higher status: for example, by a teacher to address a school pupil, or mother to child, or older sister to younger sister. Learners may form initial representations of knowledge about when imperatives are used from these contexts, and then generalise from this $\mathrm{IL}$ knowledge to form further representations of knowledge; namely, that this sub-strategy can also be used to address adults of relatively low status in service roles.

One of the few studies to draw explicit conclusions about the nativeness or nonnativeness of learner situational variation is that of Trosborg (1995). Trosborg's conclusions about the success of her Danish learners in this regard are somewhat different from those in the present study. She concludes that while the learners did show some adjustment to the parameters studied (dominance and social distance), their ways of adjusting were not in agreement with those preferred by NSs, and that these deviations showed a lack of awareness of target norms (Trosborg 1995: 279). However, on examination, her findings do not seem entirely to warrant her 
harsh conclusions. While each of the three groups of learners in her study uses $a$ certain strategy type to $a$ certain type of interlocutor more than NSs do, these single group differences appear as relatively minor discrepancies in a general pattern of conformity with NS ways of adjustment. Only one difference in situational variation between the learners in general (as opposed to a single learner group) seems to be observed; namely, that learners seem less sensitive than NSs to variations in social distance in selecting the strategy of hints (Trosborg 1995: 276279). Moreover, this difference is understandable; given the serious doubts Trosborg has about whether some learner hints in her data are strategically motivated at all (cf. Trosborg 1995: 228-230), it would be surprising if their selection varied with native-like sensitivity by social parameters.

As regards developmental aspects, Trosborg (1995) concludes that appropriate adjustments to sociopragmatic constraints by learners "occur late in pragmatic development", and claims that this is so because such adjustments require both sociopragmatic and pragmalinguistic competence (Trosborg 1995: 429). At this point she is using the notion of "adjustments" broadly, and speaking on the basis of all her findings, not only those on variation in strategy choice. However, insofar as her conclusion pertains to request strategy variation specifically, two comments seem appropriate. Firstly, a distinction should be drawn between ability to make adjustments that are in line with L1 pragmatic knowledge and those that are not. There is no strong reason to assume that the ability to make the former kind of adjustment should be acquired late. ${ }^{26}$ Secondly, with regard to L2-specific adjustments in strategy choice, Trosborg's (1995) conclusions about 'lateness' of acquisition - based on her comparison of three groups of learners at different levels of proficiency - seems to imply that at a high level of proficiency, learners may finally learn to make such adjustments. However, it is doubtful that an increase in linguistic proficiency alone can result in the acquisition of L2-specific sociopragmatic knowledge. As S. Takahashi (1996) claims (see 1.6.4), learners are more likely to acquire this kind of knowledge through familiarity with context; that is, through actual exposure to the L2 culture.

\subsubsection{Frequency of impersonal perspective by learners}

This section discusses the finding that the learners in this study never use impersonal perspective on imperative requests (see 4.1.7.4). 
A major factor explaining this feature is likely to be the formal complexity entailed in this construction. Practice items in the learners' textbook appear to be linguistically demanding: they consist of changing active, 'conventional' imperatives 27 such as Cucilah tanganmu sebelum makan! "Wash-lah your hands before eating!" to an impersonal form, Tanganmu dicuci sebelum makan, va! "Your hands (to be) washed before eating, yes!" (Johns 1977: 276). This kind of transformation appears to be complex. It involves placement of the imperative verb in sentence-internal position, which requires more processing effort than placing it in initial position (cf. Clahsen 1984);28 as well as passivisation of the verb ${ }^{29}$ and the addition of a new lexical modifier in final position ( $y a$ "yes").

A complementary factor is the limited attention given to this pragmalinguistic form in the learners' teaching materials. Learners are given very limited active practice in this impersonal construction, compared with the amount of practice of the 'conventional' imperative, in their main textbook (Johns 1977). Even with more formal practice, however, it is arguable whether they would be able to acquire active mastery over this construction at their level of lingustic proficiency.

An additional problem for these learners may be the lack of a formal equivalent to this impersonal construction in the L1. English does not offer a choice of perspective in imperatives (only hearer perspective is possible, as in "(You) wash your hands"), so Australian learners cannot transfer L1 pragmalinguistic knowledge of this feature to the L2.

Impersonal perspective may be difficult for L2 learners for other reasons as well. Trosborg (1995) finds that even advanced Danish learners of English underuse this perspective in making complaints in the L2, even though it is the favoured perspective in their L1, and does not appear to entail complex pragmalinguistic structures, simply requiring the speaker to assert an undesirable state of affairs (e.g. to say "My rash is worse" to a doctor who prescribed the wrong treatment for a rash: cf. Trosborg 1995: 326; 355). ${ }^{30}$ These Danish learners apparently underuse impersonal perspective due to $\mathbb{I}$-specific socio-pragmatic knowledge: they do not perceive the same need as L2 native speakers to mitigate the force of this highly face-threatening speech act in the L2 (Trosborg 1995).

However, L2 learners do not consistently find impersonal perspective difficult to acquire on speech acts. Blum-Kulka \& Levenston (1987) found that intermediate 
(and advanced) learners of Hebrew overused impersonal perspective on conventionally indirect requests, in the form of a relatively simple infinitive construction (which they further simplified by ignoring lexical constraints on its use). So, while L2 learners do increase their range of perspectives on speech acts with increasing proficiency (cf. Ellis 1992), and while it appears that impersonal perspective may often be difficult for learners for various reasons, it seems doubtful whether this perspective or any other is inherently early- or late-acquired.

\subsubsection{Performance in discourse-related aspects of requesting by learners 31}

This section discusses the finding that the learners in this study have evident difficulty in aspects of requesting which are closely linked to conversational management; specifically, that they sometimes select a head act strategy which is poorly aligned to a previous move by the interlocutor (see 4.1.6), tend to select the same head act formula repeatedly through a request speech event, regardless of the point in the interaction at which it occurs (see 4.1.9); and have difficulty clarifying the nature of the request goal through interaction with the interlocutor (see 4.1.8.2).

The first of these findings, the use of inappropriate request strategies when in a responding role, has been observed in other studies of more advanced learners (see 1.6.3.3). House (1996) provides a convincing explanation for this feature. She argues that learners perform requests much less appropriately when their request is made in a responding turn partly because they tend to "overrehearse" their requests. As they may not have firm knowledge of $\mathrm{L} 1$ pragmalinguistic routines, let alone have automatic control over them (cf. Bialystok 1993), they need to rehearse these routines internally more than native speakers do before producing them, and during this rehearsing process they often neglect to attend to upcoming input from the interlocutor (House 1996: 248).

The second finding, that learners repeat the same request formula within a speech event, has a very close parallel in a finding by Trosborg (1995). Her upperintermediate and advanced learners of English tended to use the same head act strategy in repeated turns when making the same request more than once within a conversation, creating a 'mechanical' effect compared with L2 native speakers, who varied their request strategies through the dialogue. 
In the present study, a likely partial explanation for this feature is influence of instruction. In the learners' main textbook (Johns 1977), whenever a dialogue contains more than one request, the same request form is used each time (as with Want statements in the "restaurant" dialogue examined earlier: see 4.2.5).32 Learners could infer from this deviant input that unvarying repetition of the same request strategy is the norm in $\mathrm{BI}$ discourse.

An important explanation for all the discourse-related difficulties of these Australian learners can be found in an observation by House (1996). She points out that when participating in discourse under real time constraints, the processing capacity of learners' cognitive systems is likely to be overloaded. Learners simply cannot process input quickly enough, and select from their own knowledge quickly enough, to interpret interlocutors' contributions and respond to them appropriately "in the fast give-and-take of ongoing spontaneous talk" (House 1996: 248). 33

Another important reason for these discourse-related features of learners' requests in the present study is the relatively small amount of attention paid to discourse competence (see 1.2) in traditional FL teaching, of the type received by these learners. In traditional teacher-fronted classroom instruction, learners engage in a very limited range of types of interactions, and perform only a narrow range of discourse functions (cf. Kramsch 1981; Trosborg 1995: 133; House 1996). However, as House (1996) points out, learners require experience in a wide variety of conversational contexts in order to learn how to manage interaction in the L2. And as these learners have few opportunities to participate in authentic L2 discourse outside the classroom, as well, it is not surprising if their ability to construct discourse jointly with an interlocutor is underdeveloped.

Proficiency differences in the present data are highly suggestive about learners' development of the ability to handle discourse-related aspects of requesting. The Low group perform considerably more poorly than other learners in all of these discourse-related aspects. In fact, the three Low learners produce a large proportion of the striking discourse-related inappropriacies of all three types. By contrast, in relation to two of these discourse-related aspects: making requests in a responding role, and varying strategy type within an interaction; the two High learners are noticably better than any other learners (for example, they quite often vary their strategy type). With regard to ability to negotiate the nature of the request goal when it is unclear to the addressee, the High group is hard to assess, because they 
consistently managed to convey request goals clearly in the first instance. However, even the Middle group performed strikingly better than the Low group in this respect (for example, the Low learners accounted for all instances of abandoned roleplays due to irretrievable communication breakdown).

On the whole, then, the data clearly suggest that L2 learners have much more serious discourse-related difficulties in requesting at lower-intermediate proficiency level (Low group) than at upper-intermediate level (High group). This finding is useful in two ways. Firstly, it lends support to House's (1996) contention that the discourse-related difficulties are largely due to processing limitations. The processing demands, and hence the likelihood of cognitive overload, will logically be much greater for lower proficiency than for higher proficiency learners.

Secondly, this finding helps to put findings from previous studies of more advanced learners (Edmondson et al 1984; Trosborg 1995; House 1996) in perspective. It enables us to see that while these more advanced learners, too, have requesting difficulties caused by poor discourse management, we may probably reject the notion that increased linguistic proficiency has failed to bring about a significant improvement in this aspect of their requesting. Instead, the present study suggests that the discourse-related performance of these subjects from previous studies is probably much better than it was at earlier stages of proficiency.

The present proficiency findings seem at first glance to contradict those of House (1996) in one important respect. These High learners of Indonesian are only at upper-intermediate proficiency level, but did not show obvious discourse-related weaknesses in their requesting; House's (1996) German learners of English were highly advanced, and yet their weaknesses in this respect were noticeable. However, this apparent contradiction seems explicable by the different tasks demanded of learners in the two studies.

The oral roleplays in House's (1996) study clearly demanded more challenging and complex interactional behaviour from subjects. House's (1996) request situations had an important built-in feature to guarantee interactional complexity: the addressees were instructed to initially resist the request, so that in all dialogues "a substantial amount of interactional work became necessary" (House 1996: 231).

Also the requests in House's study were by their nature highly sensitive, involving a large imposition. This made it likely that (unlike in the present data) a significant 
amount of preliminary small talk would typically take place while the requester found a suitable opportunity to broach the request; and an appropriate transition from this kind of small talk to a request utterance was an aspect that these highly advanced learners found difficult (House 1996: 243).

Therefore, it appears that the High group in the present study did not have their discourse-related weakness exposed, because they are able to cope well with the discourse demands of requesting in relatively simple interaction, where request speech events do not involve many turns by each speaker, and where contributions to discourse are relatively predictable and non-contentious. For the Low group (and to a large extent the Middle group), however, even these relatively undemanding exchanges reveal clear weaknesses in their interactive requesting competence.

\subsubsection{Intonation on requests by learners}

This section discusses the finding that the learners in this study frequently create a highly non-native effect by using rising intonation at the end of Want statements, hint statements, and imperatives, as well as sometimes on individual elements within these request types (see 4.2.11).

A very similar finding have been noted previously. In the Bochum project, German learners of English used rising intonation at the end of declaratives, producing a "contradictory communicative effect", as a general pragmatic feature of their speech (Edmondson et al 1984: 21). Furthermore, these German subjects, too, sometimes used this type of rising intonation on individual linguistic elements within utterances (Kasper 1982).

Kasper (1982: 105) suggests that these German learners' use of non-native rising intonation is due to influence from the specific properties of classroom discourse. She claims that the learners are influenced by the initiation- response - feedback sequences which are characteristic of the classsroom. Within these sequences, when learners perform responses which have non-interrogative function, they often appeal for feedback from the teacher at the same time on whether their response is corrrect, by means of interrogative intonation, which conveys the message "Is that right?". This factor is likely to be important in the present study as well. As these Australian learners, too, received instruction in which this traditional pattern of discourse would account for a large part of classroom interaction, it is likely that 
they may appeal for feedback on the formal correctness or appropriacy of their requests by means of interrogative intonation.

Another factor may play a role in the case of Want statements and imperatives. Learners may use rising intonation on these direct request forms as a politeness strategy. They may have doubts about whether these direct requests are sufficiently polite, and so try to make them sound less coercive by using rising intonation to create an effect of tentativeness and uncertainty. So the function of this intonation pattern in some cases may not be an appeal for feedback on correctness ("Is that right?") but an appeal for the hearer's cooperation ("Is that all right with you?").

Another plausible motivation for rising intonation suggests itself in the case of statement hints. As noted previously (3.3.3), statement hints are highly opaque in their illocutionary force because they do not demand a response from the addressee. By using interrogative intonation on this type of request form, however, learners may be able to convey that a response is expected to the statement and, hence, that a request has been made. Given that learners probably use statement hints sometimes because of linguistic difficulties (see 4.2.7), this strategy may allow learners to 'have their cake and eat it too', by avoiding the need to phrase an explicit request, but at the same time conveying requestive force with some degree of explicitness.

An initially attractive explanation for rising intonation on L2 requests by these Australian learners is the factor of $\mathrm{L} 1$ transfer. The use of a rising intonational contour sometimes on declarative utterances is a distinctive feature of Australian English (cf. Bryant 1980; Horvath 1985). However, the intonation contour of these requests by learners is different from that on declaratives in Australian English. The intonation of these learners' requests (as far as the sometimes imperfect quality of the audio-recordings allows one to discern) consistently follows the typical contour for a question in English; that is, it rises gradually over the whole utterance, or when it occurs on individual segments, over the whole segment. Australian High Rising Tone, by contrast, consists of a sharp rise on the final syllable only. ${ }^{34}$ Therefore, it appears unlikely that this feature of learners' requests is strongly influenced by intonation characteristics of the $\mathrm{L} 1$. 


\subsubsection{Frequency of direct questions by learners}

This section discusses the finding that the learners in this study use direct questions as their main Asking strategy (see 4.1.10.2).

Learners do not appear to be relying on L1 pragmatic knowledge in selecting this strategy to ask for information. Evidence consistently shows English native speakers to favour query preparatory forms, not direct questions, in asking for information. In a study by Blum-Kulka $(1982,1983)$, Canadian English subjects used no direct questions at all to ask directions from a stranger in the street; instead, QP modal forms were invariably used (Blum-Kulka 1982: 46). In a study by Cook (1985), British English speakers routinely selected query preparatory strategies (e.g. "Could you tell me ...?") or question hints (e.g. "Have you got the time?") to ask for information in common situations, and Aijmer (1996: 180), too, finds that query preparatory forms ("Can you?" and "Could you?") are routinely used in asking for information by British English speakers.

In selecting direct questions to ask for information in Indonesian, these learners are likely to be influenced by formal instruction. In their main textbook (Johns 1977), structures containing indirect questions (such as equivalents to "Can you tell me if...?" or "Do you know where...?") are not presented or practiced at all. On the other hand, direct questions are given very heavy emphasis. Simple interrogative forms are modelled and drilled extensively, from a very early stage (from Chapter 2 ), and occur very frequently in illustrative dialogues throughout the textbook. The learners are likely to infer that the direct question is the most appropriate strategy in these specific instances, and then to generalise from this $\mathbb{L}$ knowledge to conclude that it is the most appropriate strategy in these role play situations, too. Another likely result of this intensive instruction in direct questions is that learners are likely to develop sound formal mastery over direct questions, in the sense of highly automatized knowledge of these forms (cf. Bialystok 1991, 1993). This, too, is likely to influence them to select these forms in speech.

The element of formal simplicity of direct questions is also likely to influence the learners' selection of this strategy. The main request strategy of these learners the query preparatory modal request - involves considerably more formal complexity in asking for information than in other requests. This is because it requires a question to be embedded inside the modal request (e.g. Bisa saya 
diberitahu di mana kantor pos? "Can I be told where the post office is?"). So even if these learners start planning their Asks by analogy with English conventionally indirect forms, they are likely to perceive linguistic difficulties and choose to reformulate with a direct question instead.

The importance of formal simplicity in the selection of direct questions by learners seems borne out by Harlow's (1990) research. In this study, "upper-level" English learners of French mostly used direct questions in asking for information, and this seems to be partly because the conventionally indirect forms favoured by L2 native subjects demanded linguistic resources the learners lacked. For example, the expression $m$ 'indiquer "show me" which was routinely used by the L2 native speakers to make conventionally indirect requests for directions (cf. "Could you show me the way?") seemed unknown to the learners who, apparently, would ask a direct question (Ou est...? "Where is...?") in this situation instead.

The finding that BI NSs themselves use direct questions as their main Asking strategy is itself interesting. Blum-Kulka, Danet and Gherson (1985) find that despite a general ethos of directness in Israeli speech act behavour, native speakers of Hebrew opt for conventionally indirect strategies when asking for information. Moreover, these authors imply (Blum-Kulka et al 1985: 130) that the use of indirect strategies in asking for information is to be expected, as this act by its nature consists of two elements: a genuine question about an unknown fact and a request to be told that fact. 35

Accepting that point of view for a moment, the prefacing moves that BI NS subjects frequently use before direct questions (see 6.1.3.3.1) can perhaps be seen as a means of fulfilling this norm. This is illustrated in [107] below:

107 (asking a stranger for directions to the post office)

NS: Bisa nanya ini Bu?

P: $\quad H m \quad[m m$

NS: $\quad$ uh] (.) kantor pos utama di mana ya?

NS: $\quad$ Can (I) ask this 'mother'?

P: $\quad \mathrm{Mm} \quad[\mathrm{hm}$

NS: $\quad$ uh] (.) where's the main post office yes? 
In [107] above, the request element of the Ask could be said to be located in the prefacing move (Bisa nanya ini...? "Can I ask this...?"), and the question element to be located in the head act itself (Di mana kantor pos utama...? "Where's the main post office...?"). However, this analysis seems to beg the question of why speakers should choose to make a request - rather than simply ask a question in the first place, particularly in a society where an ethos of directness prevails. And indeed, Blum-Kulka et al (1985) acknowledge that factors such as the particular information asked about in their study (about a puppy for sale, including delicate information such as whether it was "house-clean"), as well as the channel used (telephone rather than face-to-face), may have prompted their subjects to opt for indirect Asking strategies. Also, it seems important (although not mentioned by Blum-Kulka et al 1985) that all Hebrew native subjects in an earlier study by Blum-Kulka used a direct question to ask for information (asking for directions in the street from a stranger: Blum-Kulka 1983: 50). This suggests that direct questions, rather than $\mathrm{CI}$ requests, may indeed be the norm in asking for information in Hebrew.

To sum up, this finding that BI NS subjects favour direct questions in asking for information challenges the notion that the $\mathrm{CI}$ request is an inherently natural means of asking for information, and provides evidence that it is not the archetypal strategy used for this speech act across languages.

\subsection{Request head acts: Summary and conclusion}

Learners and BI NS subjects show important similarities in the request head act, as well as a number of differences (see 4.1.11 for a detailed summary of findings). The two groups favour the same main request type (QP modal), and the same main Asking sub-strategy (direct question) and vary their choice of strategy by situation in similar ways.

However, with respect to direct requests, the two groups strongly favour different sub-strategies, and learners use a narrower range of sub-strategies. With regard to hints, learners use this request type a lot more frequently than BI NSs. Learners also select a different modal verb to realise their main request type from that chosen by BI NSs, and differ in choice of perspective on requests (by underusing impersonal perspective). 
Learners also exhibit $\mathbb{L}$ - specific features in their realisation of the various request types (for example their intonation on certain sub-strategies), as well as showing distinctly non-native performance in discourse-related aspects of requesting.

A number of conclusions can be drawn with regard to the findings above. Most obviously, the claim is confirmed that a pluricausal explanation of ILP phenomena tends to be the most convincing (cf. Kasper 1992; S. Takahashi 1996). More than one causal factor clearly seems to contribute to most of these features of learner head acts.

With regard to native- like features of head acts by these learners, the importance of positive transfer from the $\mathrm{L} 1$ is evident (for example, in learners' consistent selection of a QP modal strategy, and in other aspects of their native-like variation of strategy by situation). Instruction also appears to play a major positive role in accounting for native-like request features, by providing these learners with the requisite $I L$ knowledge (e.g. for the use of direct questions as the main Asking strategy).

For some native-like features (such as the learners' choice of their main requesting and Asking forms), the factor of formal simplicity of pragmatic structures also seems to play an important role - larger than tends to be emphasised in ILP studies.

With regard to non -native features of head acts by these learners, a major causal factor appears to be the negative influence of formal instruction. This may take the form of influence from teaching materials (e.g. in the avoidance of bisa "can" to make requests, and the overuse of Want statements in service encounters), or influence from classroom-specific discourse norms (as with the use of rising intonation on non-interrogative forms). The omission of certain native-like request features from teaching materials is also important. It creates a lack of awareness of these features (such as explicit performative, hedged performative, and Goal statement forms) which causes learners to underuse them.

For non-native features, the factor of formal complexity also appears to play an important role, by constraining learners in their selection of certain pragmatic structures (such as imperatives, especially impersonal ones; and indirect questions). 
The performance of request head acts by these learners has implications for Bialystok's (1993) contention that development of control over attention to pragmatic knowledge is the vital thing for adult L2 learners (see 1.6.4). The highly non-native performance of these learners in discourse-related aspects of requesting appears to support her claim. This non-native feature seems largely due to learners' inability to select the requisite pragmatic knowledge, due to processing overload caused by the cognitive demands of face-to-face interaction. However, certain findings (such as the absence of several direct sub-strategies from the learners' repertoire) also suggest that acquisition of new pragmatic knowledge is also a significant task for adult L2 learners.

At the same time, this study illustrates the difficulty of verifying or falsifying Bialystok's (1993) claims on the basis of performance data alone. For example, while we may assume that learners underuse impersonal perspective on imperative requests partly because of the formal complexity entailed in this pragmatic structure, we cannot be certain whether this formal complexity prevents learners from forming representations of knowledge of the structure, or if it only makes it hard for them to acquire sufficiently automatic control over their knowledge to access it in conversation.

Proficiency differences in head act findings have implications for development in acquisition of various features. The data appear to confirm an earlier claim that lower level learners use Want statements more frequently than higher level learners, and that this request type may be one of the earliest that learners acquire. The data also suggest that acquisition of the sub-strategy of elided imperatives may follow a U-shaped curve of development, with learners using it at beginner levels, avoiding it at intermediate proficiency, and then using it again at higher levels. In addition, this study complements earlier findings that advanced learners perform poorly in discourse-related aspects of requesting by suggesting that, nevertheless, competence in this aspect of requesting improves a great deal with increased linguistic proficiency.

Lastly, the request head acts of BI native speakers themselves have important implications for the way requests are performed across languages. Their preference for query preparatory modal requests supports the contention that this sub-strategy is an important means of making requests cross-linguistically, and their striking preference for direct questions over other Asking strategies casts doubt on a claim 
that $\mathrm{CI}$ requests, rather than direct questions, may be the inherently natural means of asking for information. 


\subsection{Notes to Chapter 4}

${ }^{1}$ Although these requests using harus "should/must" are not strictly speaking Want statements, being statements of obligation rather than of desire, they are so few in number that they are included in the category of Want statement for descriptive convenience.

2 However, the resulting Want statements (e.g. Saya mau nasi goreng... "I want fried rice...") would still be less conventional than requests based on a different request sub-strategy altogether, such as an elided imperative: Satu nasi goreng.... "One fried rice..." (I owe this observation to Emmy Oey, personal communication).

3 cf. the frequently reported finding (e.g. Scarcella and Brunak 1981; Eisenstein and Bodman 1986, 1993; House 1996) that even advanced L2 learners have difficulty in performing speech act routines appropriately.

4 The behaviour of this learner subject in another situation confirms the impression that he is trying to transfer the English request form "Is that all right?". In asking to exchange a shirt in a store, he begins by telling the manager that he wants to get a shirt of a different colour, and asks Apakah itu (.) uh (.) cocok/ "Is that(.) uh (.) suitable/" - again demonstrating apparent difficulty in finding a suitable Indonesian equivalent for "all right". He then stops abruptly and reformulates his request (using an entirely different strategy).

5 S. Takahashi (1996) provides an operational definition of "Imposition" entailed in the request, as consisting of a) the Legitimacy of the request (consisting in turn of speaker's right to ask and hearer's obligation to comply), and b) the Cost to the hearer (consisting in turn of hearer's ability and hearer's willingness to comply).

${ }^{6}$ In the four other situations where this full imperative strategy is used by BI NSs, it is selected by one (1/9) subject only (see Appendix B).

${ }^{7}$ In fact, there is empirical evidence that hints may not be the most polite request strategy (as claimed by Brown and Levinson $(1978,1987)$ after all. Blum-Kulka (1987) finds that native speakers of both English and Hebrew perceive CI requests to be more polite than hints, and Gunarwan (1993) finds Indonesian native speakers, specifically, to do so as well. This is likely to be because conventional indirectness strikes an optimal balance between indirectness and illocutionary clarity (Blum-Kulka 1987). In the light of findings such as those of Blum-Kulka 
(1987) above, Brown and Levinson (1987: 21) themselves concede that off-record strategies may not after all be the least face-threatening means to perform an FTA.

8 There is disagreement over whether the di-construction in Indonesian, called a passive in the present study, is in fact a passive. Most grammarians of Indonesian regard it as a passive (e.g. McCune 1979, 1989; Chung 1989; Cartier 1989; D.P \& B. 1993; Sneddon 1996). However, other grammarians hedge on this question (Dreyfuss (1978: 1), for example, referring to the $d i$-form as "the so-called passive"), and one at least - Verhaar $(1984,1989)$ - explicitly states that some diconstructions are not passive (including di- imperatives, which he classifies as ergative: Verhaar 1984: 56). This disagreement is reflected in Indonesian language textbooks, some of which refer to $d i$-forms as passives and others of which refer to them as "object- focus" constructions instead.

${ }^{9}$ Faerch and Kasper (1989) found Danish learners to use the same request type inappropriately to make requests in German.

10 Aijmer (1996) in her taxonomy of request strategies in English distinguishes explicitly between two Want statement strategies: those of the type "I want X", on the one hand; and those of the type "I want YOU...", on the other. The latter type, she claims, leaves the hearer little choice whether to comply with the request (Aijmer 1996: 139), and is essentially the same strategy as an imperative (Aijmer 1996: 197ff).

11 Two additional features of learners' second person pronoun selection in these data are also worth noting. Firstly, the learners sometimes switch between an intimate and a formal pronoun within the one request utterance (a finding made also by Faerch and Kasper 1989 for Danish learners of German). Secondly, the learners frequently use the abbreviated forms of Bapak "father" and Ibu "mother", namely Pak and $B u$ respectively; as pronoun substitutes (as in * $\underline{P a k}$ bisa bergeser sedikit? “ Can you move a little?"). However, these abbreviated forms Pak and Bu are generally restricted to use as vocatives (cf. Sneddon 1996; D.P. \& K. (1993).

12 Indonesian has a wide variety of second person pronouns and second person pronoun substitutes. Quinn, for example, suggests that it has "around a dozen that are in common use, and probably more than fifty altogether" (Quinn 1996b: 345). The choice of an appropriate second person pronoun is a delicate and difficult one even for native speakers, who tend to deal with the problem by avoiding the use of second person pronouns (cf. Sneddon 1996; Quinn 1996b: 347), for example by use of ellipsis. This is evident in the present study. BI native speaker subjects, for example, elide the second person pronoun in almost every QP modal request with hearer focus (saying e.g. "Bisa bergeser sedikit? "Can (you) move over a little?"). Learners, by contrast, never 
elide the second person pronoun in their requests, despite the difficulty they have in selecting an acceptable one.

13 Similarly, Blum-Kulka (1983) and Trosborg (1995) both contend that L1 transfer is a major cause for the consistent selection of a QP modal request strategy by their learner subjects (English learners of Hebrew and Danish learners of English respectively).

14 This textbook, Langkah Baru Book 1, is the sole text used by these learners in their first year of university study. It is structurally-based, and covers almost the whole grammatical system of Bahasa Indonesia.

15 Kasper (1992) points out the likelihood of this type of interaction between transfer and instruction. Firstly instruction influences learners' perceptions of what can and cannot be transferred to the $\mathrm{L} 2$, and then on the basis of these perceptions, learners selectively transfer pragmatic knowledge from the L1.

16 One more elaborate permutation of the QP modal request, however, does pose structural problems for learners. This is the variant which places an optional interrogative particle before the modal verb. An example is this:

$\begin{array}{cccccc}\text { 1a } & \text { Apa(kah) } & \text { boleh } & \text { saya } & \text { duduk } & \text { di sini? } \\ & \text { INT. } & \text { may } & \text { I } & \text { sit } & \text { here? }\end{array}$

"May I sit here? "

When attempting to use the form above, learners sometimes make a grammatical error, producing the form below:

$\begin{array}{lllll}\text { 1b } & \text { * } \underline{\text { Apa }(\mathrm{kah})} & \text { saya } & \text { duduk } & \text { di sini? } \\ & \underline{\mathrm{INT}} & \mathrm{I} & \text { sit } & \text { here? } \\ \text { *“Do I sit here? “ } & & & \end{array}$

In requests of the type in [1b] above the modal verb appears to be accidentally omitted, suggesting that learners find it more difficult to place the modal verb in medial position than in initial position. This is consistent with Clahsen's (1984: 222) claim that permutations which move constitutents into first or final position are easier than ones which move them into sentenceinternal positions. 
17 Zhang (1995a), however, finds the query preparatory sub-strategy to be the most common request type by speakers of Mandarin.

18 cf. Aston (1995), who observes that role play participants are likely to be influenced by their real-life relationship (as opposed to their imaginary role play relationship) in the way they interact with each other.

19 It is possible, however, that the learners tend to equate bisa "can" with English "can", and boleh "may/ be allowed" with English "could". Therefore, in instances when they would tend to choose "could" over "can" in English, in order to increase the level of deference conveyed; they may tend to choose boleh over bisa in Indonesian in an attempt to convey the same pragmatic effect.

20 This is likely to reflect a belief by the textbook writer that the use of bisa "can" to ask for permission is non-standard usage, in the same way that some Australian native speakers (usually older, well-educated ones, with strong feelings about correct English) feel that only "may," and not "can," can legitimately be used to ask for permission.

21 But see le Pair (1996) for contrasting findings.

22 Beebe and T. Takahashi (1989) observe a general tendency for ESL learners to rely on the wording of written or spoken cues in their responses.

23 The motivation of learners in producing hint-like requests may often be difficult to interpret. Le Pair (1996), while finding that Dutch learners of Spanish used more hints than L2 native speakers, suspects that many of these learner hints were not motivated by strategic lack of transparency. He claims that the vagueness of these hints suggests that the learners may simply not have understood the situation (i.e. the task) properly.

24 The learner's strategy in this instance appears to be one of 'functional reduction' (see Faerch and Kasper 1983 for a classification of problem-solving communication strategies into three broad types: achievement, functional reduction, and formal reduction).

25 This may be one factor contributing to a proportion of hinting requests by BI NS subjects which is, perhaps, surprisingly low. This writer has on occasion observed Indonesians (from Java) to employ hints, both in Bahasa Indonesia and in English, to make requests which (it intuitively seemed) would tend to be made more directly in native English. Margaret DuFon (personal 
communication), similarly, has observed a tendency for Indonesians (from Java) to interpret 'innocent' remarks made in Bahasa Indonesia as requests. Moreover, it has been asserted by anthropologists (Geertz 1976: 242-43; Mulder 1989: 51) that an ethos of indirectness exists in Javanese culture, and that requests are often made by means of hints by speakers of Javanese, to save the face of the parties concerned. All this suggests that Indonesians - particularly ones with a Javanese background (as with almost all these BI NS subjects) - are likely to use hints frequently when requesting. It may be that the request situations in the present study are not 'sensitive' enough to reveal this tendency. In more highly face-threatening situations, the proportion of hints by BI NSs might have been considerably higher. Or, it may be that the data elicitation method discouraged a hinting strategy. Despite precautions taken to conceal the exact focus of the study (see 2.7), subjects might have felt obliged to make a 'real' request, to meet the expectations of the researcher.

26 As Blum-Kulka says, L2 learners' pragmatic performance "seems to approximate native usage where the rules [that govern speech act performance and interpretation] are cross-culturally shared and to deviate from native usage where the rules are language- and culture-specific" (Blum-Kulka 1983: 47-48).

27 The verb in this type of imperative construction (e.g. Cuci tanganmu... "Wash your hands...") is conventionally regarded as active (cf. Sneddon 1996: 326). However, it is regarded by Verhaar $(1984,1989)$ as ergative - and on its way to becoming active, due to the sharply decreased use of an oblique agent (olehmu "by you") with this construction (Verhaar 1989: 244).

28 Clahsen (1984) claims that constituents are less perceptually salient when placed in sentenceinternal position than when placed in initial or final position, and that the former kind of permutation is therefore more difficult for learners to carry out.

29 See footnote 8 above for discusssion of whether use of this 'di-' construction genuinely entails passivisation of the verb.

30 This strategy of stating the undesirable state of affairs is a common means of conveying impersonal perspective on complaints in Trosborg's data (cf. Trosborg 1995: 354-355). The present claim that this strategy is relatively simple linguistically seems supported by the fact that Trosborg's lowest level learners used this perspective more frequently than higher level learners (cf. Trosborg 1995: 356table). 
31 The term "discourse-related" is used narrowly here to refer to those aspects of requesting which involve joint construction of interactional structures by interlocutors, and hence are closely tied to conversational management (see 1.2.4).

32 This is presumably done for the pedagogical purpose of giving learners maximum exposure to the single target structure (see 7.4).

33 See also House's account elsewhere (House 1993: 175-178) of learners' “operational difficulties" in encoding utterances during conversation.

34 See Bryant (1980: Appendix A) for an acoustic description of the difference between English questioning intonation and High Rising Tone.

35 This belief seems to be based on the assertion of theoreticians such as Gordon and Lakoff (1971: 64) that the logical form of a question is "A requests B to tell A something", rather than "A asks B something." 


\section{CHAPTER 5. REOUESTS: INTERNAL MODIFICATION}

This chapter examines how learners and BI NSs internally modify their requests. In the first part of the chapter (Results) the use of internal modifiers in the data is described, and in the second part (Discussion) the most important findings are selected and discussed.

\subsection{Introduction}

The notion of an 'internal modifier' (IM) was developed for the CCSARP project. In that study, IMs on requests are defined as "elements within the request proper (linked to the Head Act), the presence of which is not essential for the utterance to be potentially understood as a request" (Blum-Kulka et al 1989: 19).

Internal modifiers in the CCSARP project are classified as either Upgraders or Downgraders. ${ }^{1}$ Upgraders aggravate, or intensify, the impositive force of the request; for example, the word "bloody", in "Clean up that bloody mess" (no upgrading modifiers occur in the present data, and so this type need not concern us any further). Downgraders mitigate; or 'soften' the impositive force of the request (Blum-Kulka et al 1989: 19; CCSARP 1989: 281, 283). ${ }^{2}$

It is not entirely obvious what criteria were used in the CCSARP project to decide which optional elements within the head act to regard as downgrading internal modifiers. Some negatively polite elements (see 1.4.2) are counted as IMs. An example is the Understater, in which the speaker "underrepresents the state of affairs denoted in the proposition", as in: "Could you tidy up a bit?" (CCSARP 1989: 283). Some positively polite elements (see 1.4.2) are also counted as IMs. An example is the Cajoler, which functions to "increase, establish, or restore harmony between the interlocutors"; that is, to promote good feelings between S and H (e.g. "You know, I'd really like you to present your paper next week") (CCSARP 1989: 284). At the same time, it does not appear that all negatively or positively polite elements within the head act are regarded in the CCSARP as IMs. An apparent absence is terms of address. These can have positive politeness function, by conveying familiarity, and hence, the existence of close relationship with the hearer (as with terms like "darling", "love", or "pal"). They can also have negative politeness function by conveying respect, and hence, deference towards 
the hearer (e.g. "Sir", or "Madam") (cf. Brown \& Levinson 1978, 1987). However, terms of address do not seem to be included within any of the subcategories of internal modifiers in the CCSARP project. $^{3}$

It is important to note that the classification of modifier types in the CCSARP project was not intended to be definitive. It is emphasised that the various subcategories proposed for that study "should be supplemented, refined, conflated, or left out according to the structure of the language(s) and culture(s) under study and the research goal pursued" (CCSARP 1989: 274-75). With this in mind, the CCSARP notion of an internal modifier will be adapted to suit the nature of the present data, to refer to any feature linked to the request head act, the presence of which is not essential for the utterance to be potentially understood as a request, and whose primary function is to convey information about the relationship between speaker and hearer. ${ }^{4}$

\subsection{Results}

As Faerch and Kasper (1989: 222) point out, the use of modifiers can be validly examined only if strategy type is held constant as an independent variable. And the most obvious criterion for selecting the strategy, as they observe, is frequency. Thus, the most common request type of both groups - the QP modal request - is the main focus of this study of $\mathrm{IM}$. Internal modification of imperative requests will additionally be examined, because learner modification of this sub-strategy yields important additional findings. The most frequent Asking strategy of both groups, the direct question, is also examined for internal modification.

\subsubsection{Internal modification of query preparatory modal requests}

To further increase validity of findings, internal modification of QP modal requests is examined only in those situations in which this request type is used with reasonable frequency by both groups (cf. Faerch \& Kasper 1989: 223). Those situations in which either group uses few QP modal requests (defined as $<30 \%$ of head acts) were discarded from this analysis. This leaves data from eleven request situations, which contain the majority of QP modal requests made in this study by both learners and BI NSs (61/98 of those by learners and $65 / 99$ of those by BI NSs). 


\subsubsection{Internal modification of $Q P$ modal requests: $B I$ native speakers}

BI native speaker subjects use internal modification on roughly two thirds of their QP modal requests (66.7\% or 44/65: see Table 7 below). Despite this high frequency of internal modification, BI NSs use quite a narrow range of internal modifiers (see Table 8 below).

Table 7: Proportion of query preparatory modal requests by BI native speaker subjects which are internally modified*

\begin{tabular}{|l|cc|}
\hline & $\mathrm{n}$ & $\%$ \\
\hline head acts with one internal modifier & 31 & 47.7 \\
\hline head acts with $>1$ internal modifier & 13 & 20.0 \\
\hline $\begin{array}{l}\text { Total No of internally modified head } \\
\text { acts }\end{array}$ & 44 & 67.7 \\
\hline Total No of head acts & & 65 \\
\hline
\end{tabular}

* data are based on eleven situations in which QP modal requests are used relatively frequently (30\% or more of subjects) by both groups

The most common IM used by BI NSs is the Negator ${ }^{5}$, consisting of the word $n g g a k$, or occasionally ndak (both of which are informal equivalents of "no/not"). 6 This modifier is used in over a third (35.4\% or 23/65) of QP modal requests by BI NSs (see Table 8). Examples are these:

108 (asking to exchange a shirt in a store)

NS: ... bisa nggak saya tukar sama warna lain?

NS: ... can (or) not I exchange it for another colour?

109 (asking a taxi driver to stop for a minute)

NS: $\quad$... kita bisa berhenti ndak beli rokok di satu tempat

NS: itu ...

NS: $\quad .$. can we stop (or) not to buy cigarettes somewhere ... 
110 (asking a stranger for a light)

NS: $\quad$.. boleh pinjemin koreknya nggak

NS: $\quad$... may (I) borrow a match (or) not

111 (asking a friend from college for a lift home)

NS: ... bisa ikut nggak

NS: $\quad$... can (I) come too (or) not

The negating element can occur in medial position (as in [108] and [109] above) or in final position (as in [110] and [111] above). In either case the effect is essentially the same: to convey a certain degree of pessimism about the likelihood of the request being granted, by explicitly raising the possibility of non-fulfilment of the necessary condition (namely, the hearer's ability or willingness). This strategy of 'polite pessimism' (cf. Brown \& Levinson 1978, 1987) makes it easier for the hearer to refuse the request, by offering him or her a 'way out', and in this way functions to reduce the coerciveness of the utterance. ${ }^{7}$

Table 8: Proportion of QP modal requests by learner and BI native speaker subjects which contain each type of internal modifier*

\begin{tabular}{|c|c|c|c|c|}
\hline \multirow[t]{2}{*}{ Type of internal modifier } & \multicolumn{2}{|c|}{ Learners } & \multicolumn{2}{|c|}{ BI NSs } \\
\hline & $\mathrm{n}$ & $\%$ & $\bar{n}$ & $\%$ \\
\hline $\begin{array}{l}\text { Negator } \\
\text { (nggak or ndak "no/ } \\
\text { not") }\end{array}$ & - & -- & 23 & 35.4 \\
\hline $\begin{array}{l}\text { Kinship term of address } \\
\text { (Pak "father" etc ) }\end{array}$ & - & - & 13 & 20.0 \\
\hline $\begin{array}{l}\text { Appealer } \\
\text { (ya "yes") }\end{array}$ & 1 & 1.6 & 6 & 9.2 \\
\hline $\begin{array}{l}\text { Understater } \\
\text { (e.g. sedikit "a little" }\end{array}$ & 3 & 4.9 & 9 & 13.8 \\
\hline Other & - & - & 6 & 9.2 \\
\hline $\begin{array}{l}\text { Total No of QP modal } \\
\text { requests }\end{array}$ & & & & \\
\hline
\end{tabular}

* data are based on eleven situations in which QP modal requests are used relatively frequently ( $30 \%$ or more of subjects) by both groups 
Another internal modifier used quite frequently on QP modal requests by BI NSs is a ficticious kinship term of address (henceforth kinship TOA). This modifier is used in $20.0 \%$ (or 13/65) of head acts (see Table 8 above). Examples are below:

\section{2 (asking a taxi driver to stop)}

NS: ... bisa berhenti sebentar $\underline{P a k}$...

NS: ... can (we/I) stop for a minute 'father'...

113 (asking a store manager to exchange a shirt)

NS: ... bisa diganti nggak $\underline{B u}$

NS: $\quad$... can it be changed or not 'mother'

114 (asking a stranger to move over in a crowded eating stall)

NS: $\quad$... bisa geser sedikit Mas

NS: ... can (you) move a little 'brother'

115 (asking to try a cassette in a store)

NS: $\quad$... bisa saya coba $\underline{\text { Mbak }}$

NS: $\quad$... can I try (it) 'sister'

While Bahasa Indonesia has a wide variety of kinship terms of address, the choice of which varies widely from one region to another (cf. Jenson 1988; D.P. \& K. 1993), all the kinship TOAs used as internal modifiers by BI NSs in the present data consist of one of the four terms illustrated above. These are the very widely used terms Pak "father" or Bu "mother", or the distinctly Javanese terms Mas "brother" or Mbak "sister".

The precise pragmatic effect created by the addition of a kinship TOA to the head act is difficult to ascertain. For one thing, the interpersonal meaning conveyed by a given kinship TOA is highly dependent on the context; for another, the interpersonal meaning carried by the kinship TOA may be complex. For example, on the one hand, all Indonesian kinship TOAs convey some degree of intimacy, as they metaphorically include the addressee within the family of the speaker (cf. Badudu 1986: 66; Jenson 1988: 127; Quinn 1996b: 345). In this way, they can be regarded as having a positive politeness function: of expressing good feelings towards the addressee. On the other hand, certain kinship TOAs at least - notably $\mathrm{Pak}$ "father" and $\mathrm{Bu}$ "mother" above - clearly convey respect for the addressee; 
in the sense of acknowledging his or her status, whether by virtue of position or of age (cf. Johns 1977; Sneddon 1996; Quinn 1996b). And use of a deferential term of address, Brown and Levinson $(1978,1987)$ observe, conveys negative politeness. So these kinship terms $P a k$ "father" and $B u$ "mother" have connotations of respect and intimacy, and so, it seems, may convey politeness in more than one way.

To complicate matters further, the kinship TOAs Mas "brother" and Mbak "sister", above, may convey either of two subtly different messages when used by the same speaker to the same addressee. The message may be a positive one, of solidarity (or equality) with the addressee. However, it may be a neutral message instead, "with no implications of equality but also with no show of repsect (sic) or disrespect" (Jenson 1988: 131). Jenson suggests that using kinship TOAs with the latter meaning amounts to "ignoring the issue" of speaker's relation to the hearer (Jenson 1988: 131). This seems somewhat akin to Ide's (1989) notion of 'Discernment' politeness (see 1.4.3), whereby the linguistic feature is not used with strategic intent at all, but as a virtually automatic adjustment to the social context.

Therefore, while the optional kinship TOA element in requests in Indonesian makes them more polite, exactly how it makes them more polite will be difficult to say until considerably more research has been carried out into the pragmatics of the Indonesian address system (for a tentative description of the pragmatic effect of each kinship TOA used in the present study, see Table 9 below). 
Table 9: Description of kinship terms of address* used by learner and BI native speaker subjects $^{8}$

\begin{tabular}{|l|l|l|l|}
\hline Term & meaning & common addressee & $\begin{array}{l}\text { main pragmatic effect } \\
\text { conveyed }\end{array}$ \\
\hline (Ba)pak & father & $\begin{array}{l}\text { adult male of fairly mature } \\
\text { years and/ or higher rank }\end{array}$ & respect \\
\hline (I)bu & mother & $\begin{array}{l}\text { adult female of fairly mature } \\
\text { years and/ or higher rank }\end{array}$ & respect \\
\hline \multirow{2}{*}{ Mas } & older & $\begin{array}{l}\text { i) male of roughly equal age } \\
\text { and rank }\end{array}$ & $\begin{array}{l}\text { solidarity/ equality (or } \\
\text { neutrality**) }\end{array}$ \\
\cline { 3 - 5 } & (Jv) & $\begin{array}{l}\text { ii) male of roughly equal age } \\
\text { with lower rank*** }\end{array}$ & respect \\
\hline Mbak & $\begin{array}{l}\text { older } \\
\text { sister } \\
\text { (Jv) }\end{array}$ & $\begin{array}{l}\text { i) female of roughly equal } \\
\text { age and rank }\end{array}$ & $\begin{array}{l}\text { solidarity/ equality (or } \\
\text { neutrality) }\end{array}$ \\
\cline { 2 - 4 } & $\begin{array}{l}\text { ii) lower ranking female of } \\
\text { roughly equal age }\end{array}$ & respect \\
\hline $\begin{array}{l}\text { Dik } \\
\text { short for adik }\end{array}$ & $\begin{array}{l}\text { younger } \\
\text { sibling }\end{array}$ & $\begin{array}{l}\text { younger male or } \\
\text { rank }\end{array}$ & $\begin{array}{l}\text { familiarity (or } \\
\text { neutrality) }\end{array}$ \\
\hline $\begin{array}{l}\text { Bang (short for } \\
\text { abang) }\end{array}$ & $\begin{array}{l}\text { older } \\
\text { brother (Jkt) }\end{array}$ & $\begin{array}{l}\text { male of roughly equal age } \\
\text { with lower rank**** }\end{array}$ & $\begin{array}{l}\text { familiarity (or } \\
\text { neutrality) }\end{array}$ \\
\hline $\begin{array}{l}\text { Sus (short for } \\
\text { Zuster) }\end{array}$ & $\begin{array}{l}\text { sister } \\
\text { (Dutch) }\end{array}$ & $\begin{array}{l}\text { female of roughly equal age } \\
\text { and rank***** }\end{array}$ & $\begin{array}{l}\text { solidarity/ equality (or } \\
\text { neutrality) }\end{array}$ \\
\hline
\end{tabular}

Key: $\quad \mathrm{Jv}=$ Javanese; $\mathrm{Jkt}=$ Jakartan dialect

* the term "kinship terms of address" is used here to refer to kinship terms used with vocative function, not as pronoun substitutes (following Kaswanti Purwo 1984: 26-27, who distinguishes kata sapa "terms of address" from penunjuk persona kedua "second person indicators").

** 'neutrality' refers to the pragmatic effect noted by Jenson (1988), discussed above.

*** Jenson (1988: 131 table) suggests that Mas is also used respectfully to older males of lower rank; however, informants felt that to significantly older males (e.g. from a young adult to a middle-aged one), this term would be insufficiently respectful.

**** Jenson (1988: 131table) suggests that Bang is also used to address males of equal rank; however, informants felt that this usage would be insufficiently respectful (unless used by one low-ranking person to another (e.g. two rickshaw drivers).

$* * * * *$ Draine and Hall (1990: 88$)$ state that $S u s$ is used to address females of lower position specifically; however, informants disagreed with this assertion.

Another modifier used on a number of QP modal requests by BI NSs is the Understater (cf. CCSARP 1989). This element minimises the extent of the favour being asked in order to make it seem less of an imposition on the hearer. It is used on $13.8 \%$ (or $9 / 65$ ) of head acts (see Table 8 above). Examples are these: 
116 (asking a lecturer for an extension on an essay deadline)

NS: ... apa saya bisa mengumpulkannya agak mundur

NS: sedikit Pak

NS: ... can I hand it in somewhat later a little 'father'

117 (asking a stranger to move over in a crowded eating stall)

NS: $\quad$... bisa geser sedikit?

NS: $\quad \ldots$ can (you) move a little?

Most of the Understaters used by BI NSs were of the identical type, illustrated in [117]: the use of sedikit "a little" in asking a stranger to move over in a crowded eating stall. The inclusion of this modifier was probably influenced by the written description of this situation (which specified that if the stranger moved sedikit "a little" there would be room to sit down), so the relatively high frequency of Understaters in the data may be misleading.

The only other internal modifier used in any number on QP modal requests by BI NSs is an Appealer (cf. Blum-Kulka et al 1989): the element ya "yes". BI NSs use this modifier $y a$ "yes" in $9.2 \%$ (or 6/65) of their modal requests. An example is this:

118 (asking a hotel receptionist for a pen to fill in the registration form)

NS: ... bisa pinjam bolpoin $\underline{\text { } a \text { ? }}$

NS: $\quad .$. can (I) borrow a pen yes?

This element ya "yes" parallels the nggak "no" modifier (above) in structure, and to some extent in function. It makes the force of the request softer by drawing the addressee into agreement with the speaker (cf. Johns 1977: 276; Sneddon 1996: $328)$.

Only a small proportion $(9.2 \%$ or $6 / 65)$ of head acts by BI NSs are internally modified by an element other than those above (see Table 8). One such element (used in two instances) is a conditional clause. This functions to make the request seem somewhat hypothetical, and hence to reduce the impositive force, as in [119] below: 
119 (asking a lecturer for an extension on an essay deadline)

NS: $\quad$... kalau seandainya saya minta diperpanjang sampai

NS: hari (.) Sabtu bisa.

NS: $\quad$... if supposing I ask (for it) to be extended until (.)

NS: Saturday can it.

Another element used by BI NSs occasionally (in two instances) is the Downtoner. This device modulates the force of the request by "signalling the possibility of noncompliance" (Blum-Kulka \& Olshtain 1984: 204). An example is [120] below:

120 (asking a university lecturer for a copy of last week's handout)

NS: $\quad$... barangkali (.) Ibu bisa memberikan latihan itu (.)

NS: sekarang?

NS: $\quad$... perhaps (.) can you give (me) that exercise (.) now?

BI native subjects often exploit their relatively narrow repertoire of internal modifiers by combining different types. In a sizeable proportion (20.0\% or $13 / 65)$ of QP modal requests by BI NSs, more than one type of internal modifier is used on the one head act (see Table 7). This creates an effect of greater effort by the speaker to make the request acceptable to the hearer. Recurring combinations of IMs are exemplified below:

121 (borrowing a pen from a classmate in class)

NS: ... boleh nggak pinjem bolpoin ya?

NS: ... may (I) (or) not borrow a pen yes?

This request type in [121] above combines an expression of polite pessimism about H's willingness with an appeal for H's cooperation.

122 (asking a stranger to move over in a crowded eating stall)

NS: $\quad$... bisa geser sedikit Mbak?

NS: $\quad .$. can (you) move a little 'sister'? 
In [122] above, the speaker minimises the size of the imposition on the addressee as well as overtly expressing a relationship between them (with a kinship TOA).

123 (asking for a cinema ticket in a middle front seat)

NS: $\quad$... bisa nggak dapat ruang bagian tengah Pak

NS: $\quad .$. can (I) (or) not get a place in the middle ' father'.

The request in [123] above combines an expression of polite pessimism about the likelihood of compliance with an overt marker of respect for the addressee. Occasionally BI NSs use more than two internal modifiers on a QP modal request. An example is [124] below:

124 (asking a lecturer for an extension on an essay deadline)

NS: $\quad$... kira-kira bisa nggak kalau saya minta (.)

NS: $\quad$ diperpanjang (.) sampai hari Senin minggu depan.

NS: $\quad$... do you think it can or not if I ask (.) (for it) to be

NS: $\quad$ extended (.) until Monday next week.

In [124] above, the speaker uses a Consultative device ( kira-kira "do you think"), in an attempt to involve the hearer directly and to win her cooperation (cf. BlumKulka \& Olshtain 1984: 204), while also suggesting that the request is hypothetical (kalau "if"), and expressing some pessimism about the likelihood of $\mathrm{H}$ agreeing (nggak “(or) not”).

While the precise effect achieved by these various combinations differs, all the examples of compound IM above convey the effect of considerable work by the speaker to make the request a polite one.

\subsubsection{Internal modification of QP modal requests: Learners}

Internal modification by learner subjects provides a very different picture: Learners rarely use internal modifiers on QP modal requests: only $6.6 \%$ (or 4/61) of head acts have an internal modifier (see Table 10 below). 
The two internal modifiers used most frequently by BI NS subjects: the Negator nggak/ndak "no", and the kinship TOA, are never used by learner subjects. The next most frequent two IMs used by BI NS subjects, the Understater and the Appealer ya "yes", together account for all of the few learner internal modifiers (see Table 8 above).

Of the Understaters used by learners, all instances (3/3) are of the identical type: the addition of the element sedikit "a little" in asking a person to move over "a little" in a crowded eating stall. As discussed earlier, the inclusion of this element in requests in this specific situation is probably due to the wording of written instructions, which means that nearly all (3/4) of the few IMs that learners use are of doubtful validity.

Unlike BI NSs, learners never use more than one internal modifier in a request (see Table 10 below). So in no cases do learners convey the impression of considerable effort to make a request polite by means of internal modifiers.

Table 10: Proportion of query preparatory modal requests by learner and BI native speaker subjects which are internally modified*

\begin{tabular}{|c|c|c|c|c|}
\hline & \multicolumn{2}{|c|}{ Learners } & \multicolumn{2}{|c|}{ BI NSs } \\
\hline & $\mathbf{n}$ & $\%$ & $n$ & $\%$ \\
\hline $\begin{array}{l}\text { head acts with one internal } \\
\text { modifier }\end{array}$ & 4 & 6.6 & 31 & 47.7 \\
\hline $\begin{array}{l}\text { head acts with }>1 \text { internal } \\
\text { modifier }\end{array}$ & - & - & 13 & 20.0 \\
\hline $\begin{array}{l}\text { Total internally modified head } \\
\text { acts }\end{array}$ & 4 & 6.6 & 44 & 67.7 \\
\hline Total No of head acts & & & & \\
\hline
\end{tabular}

* data are based on eleven situations in which QP modal requests are used relatively frequently ( $30 \%$ or more of subjects) by both groups

It is interesting to note that elsewhere in the data ${ }^{9}$, in an apparent attempt to enhance their scant resources for internal modification, learners on several occasions use incorrect IMs. An example is the following attempt by a learner to say "please". 
(asking a waiter for a menu)

L: Bolehkah saya melihat daftar makanan *silakan?

L: $\quad$ May I see the menu 'please'?

The politeness marker silakan "please" is inappropriate in [125], as this marker is used only in asking someone to do something for their own benefit (as in Silakan $d u d u k$ ("Please have a seat"). It is not used when asking for an action to be performed which is costly to the hearer (cf. Sneddon 1996: 329). Another unsuccessful attempt to say "please" by a learner is in [126] below:

126 (ordering a drink from a waiter in a restaurant)

L $\quad$... bisa saya (.) biru? (1.0) bir? (.) * lah?

L: $\quad$... can I (.) blue? (1.0) beer? (.) 'please'?

The learner's request in [116] is hard to understand, as she omitted a main verb, and asked for "blue" the first time, instead of "beer". When the waiter does not respond to the request, she adds the marker -lah (sometimes translated as "please": see 5.2.2.2) to her utterance, as if in an effort to persuade him to cooperate. However, this element -lah as a marker on requests is restricted to use with imperative forms - as in the (fabricated) example below:

\section{Bawakanlah sebotol bir.}

Bring-'lah' a bottle of beer.

Indonesian does have politeness markers which are commonly translated as "please" and which can be used in QP modal requests. One such marker is tolong, literally "help" (see 5.2.2.1). This marker is used by BI NSs on several QP modal requests elsewhere in the data, as in [128] below:

128 (asking the conductor to tell you when the bus gets to the right stop for Kartini Street)

NS: ... kalau sampai di Jalan Kartini tolong bisa beritahu

NS: saya?

NS: $\quad .$. when we get to Kartini Street please can (you) tell

NS: me? 
Learners, however, never use this appropriate equivalent of "please", namely tolong, in their QP modal requests.

To sum up, while BI NSs have quite a small range of internal modifiers on QP modal requests, they use an internal modifier on most requests and often use more than one. Learners, however, almost never modify this request type internally, and do not use the most common BI NS internal modifiers at all.

\subsubsection{Situational variation in use of IMs on QP modal requests}

Learners use so few internal modifiers on QP modal requests that systematic examination of situational variation is not possible. However, it can readily be seen that they consistently use no or almost no internal modification in all types of situations in the data.

Regarding BI NS subjects, there is little clear variation in selection of individual IMs according to situational variables. The only apparent tendency is for BI NSs to vary their selection of kinship TOAs by size of social distance; specifically, to eschew this modifier when social distance is small (they do not use it in the few situations where the addressee is a classmate or a friend). However, other trends which might perhaps be expected are not found. For example, the learners do not select kinship TOAs more frequently when the addressee is perceived to be high in status, nor do they use the 'politely pessimistic' Negator more frequently when the imposition is perceived to be large.

A weak trend can be observed for BI NSs to use more internal modification overall as the overall size of threat to face increases (suggested by values of speaker's status, size of imposition, and speaker's comfort together: see Appendix C for rankings and values of social variables in each situation). While BI NSs sometimes use an internal modifier in situations where these values indicate a relatively low threat to face; they more frequently use an IM - or more than one - in those situations where the threat to face is relatively high. The most striking example is the situation of asking a lecturer for an extension on an essay - in which the threat to face is perceived of as large (speaker's status being assessed as very low, imposition as large and speaker's comfort in making the request as very low). Example QP modal requests in this situation by BI NS subjects are as follows: 
129 NS: ... apakah saya bisa mengumpulkannya (.) agak

NS: mundur sedikit $\underline{\text { Pak. }}$.

NS: $\quad .$. can I hand it in (.) somewhat later a little

NS: 'father.'

130 NS: ... kira-kira bisa nggak kalau saya minta (.)

NS: diperpanjang (.) sampai hari Senin minggu depan.

NS: $\quad \ldots$ do you think it can (or) not if I ask (.) (for it) to be

NS: extended (.) until Monday next week.

The compound internal modifiers in [129] and [130] above create an effect of considerable effort by the BI NS subjects to reduce the threat to face entailed in this 'sensitive' request.

Learners, like BI NSs, perceive the threat to face in this "lecturer" situation above as large (see Appendix $\mathrm{C}$ for values and rankings of social variables in each situation). However, they invariably use bare head acts to make their request in this situation. Here is a typical example:

131 L: $\quad$.. boleh saya menyerahkannya (.) hari Senin minggu

L: depan?

L: ... may I hand it in (.) on Monday next week?

The learner in [131] above, unlike the BI NSs in [129] and [130], does not mitigate this request by the addition of internal modifiers to the head act. And because both groups perceive this request as a sensitive one, this difference in modification behaviour is striking.

\subsubsection{Internal modification of $Q P$ modal requests: Summary}

The differences in learner and BI NS behaviour with respect to internal modification of their main request type outweigh any similarities. Internal 
modification is a very prominent feature of BI NS requests. They use an IM on most requests, and often use more than one. In relatively face-threatening situations particularly, internal modification tends to be an important feature of their requests. Learners, by contrast, almost never use internal modifiers on their requests, and never use the main BI NS types of internal modifier.

\subsubsection{Internal modification of (full) imperatives}

Internal modification of one more request sub-strategy, (full) imperatives, will also examined, because the findings reveals an important aspect of learner behaviour not evident from the examination of QP modal requests above. However, it should be borne in mind that comparisons between the two groups with respect to this substrategy are of limited validity, for the reason that only a small number of imperatives are used (particularly by learners), and to some extent they are used in different situations by the two groups.

\subsubsection{Internal modification of (full) imperative requests: BI native speakers}

BI native speakers use internal modification on imperative requests very consistently; in fact almost all $(89.5 \%$ or $17 / 19)$ of BI NS imperative requests are internally modified (see Table 11 below).

Table 11: Proportion of (full) imperative requests by learner and BI native speaker subjects which are internally modified

\begin{tabular}{|l|cc|cc|}
\hline & \multicolumn{1}{|c|}{ Learners } & \multicolumn{2}{c|}{ BI native speakers } \\
\hline & $\mathrm{n}$ & $\mathrm{n}$ & 31.6 \\
\hline $\begin{array}{l}\text { head acts with one internal } \\
\text { modifier }\end{array}$ & 7 & 70 & 6 & 57.9 \\
\hline $\begin{array}{l}\text { head acts with > 1 internal } \\
\text { modifier }\end{array}$ & 2 & 20 & 11 & 89.5 \\
\hline $\begin{array}{l}\text { total head acts with internal } \\
\text { modification }\end{array}$ & 9 & 90 & 17 & 19 \\
\hline $\begin{array}{l}\text { Total No of (full) imperative } \\
\text { requests }\end{array}$ & 10 & & & \\
\hline
\end{tabular}


By far the most frequent modifier used by BI NSs on imperatives is the politeness marker tolong, which literally means "help", but when used to modify requests can be translated as "please" (cf. Sneddon 1996: 329). This modifier tolong is used by BI NSs on a large majority (83.3\% or 16/19) of their imperative requests (see Table 12 below). Examples of BI NS imperatives modified with tolong are [132] and [133]:

132 (asking for a cinema ticket in the middle front row)

NS: $\quad$... tolong cari yang ini Mas (.) bagian tengah- depan.

NS: $\quad \ldots$ please look for this brother (.) the middle front.

133 (asking a taxi driver to stop for a minute)

NS: $\quad$...tolong berhenti sebentar (.) saya ada perlu untuk beli

NS: rokok

NS: $\quad$... please stop for a minute (.) I need to buy cigarettes

Use of this modifier tolong in examples like those above softens the force of the imperative request considerably. It tends to convey the impression that the speaker is asking a favour of the hearer. ${ }^{10}$

Table 12: Proportion of (full) imperative requests by learner and BI native speaker subjects whch contain each type of internal modifier

\begin{tabular}{|l|cc|cc|}
\hline & \multicolumn{2}{|c|}{ Learners } & \multicolumn{2}{|c|}{ BI NSs } \\
\hline Type of internal modifier & $\mathrm{n}$ & 70 & -- & \\
\hline $\begin{array}{l}\text {-lah } \\
\text { "please" (?) }\end{array}$ & 7 & 20 & 16 & 84.2 \\
\hline $\begin{array}{l}\text { tolong } \\
\text { "please" }\end{array}$ & 2 & 20 & 8 & 42.1 \\
\hline $\begin{array}{l}\text { ya } \\
\text { "yes" }\end{array}$ & 2 & & & 31.6 \\
\hline $\begin{array}{l}\text { kinship TOA } \\
\text { e.g. Pak "father" }\end{array}$ & -- & -- & 6 & 21.1 \\
\hline Other & -- & -- & 4 & \\
\hline
\end{tabular}


Another modifier frequently used on imperatives by BI NSs is the Appealer ya "yes". Almost half ( $42.1 \%$ or $8 / 19)$ of imperatives by BI NSs are modified with this ya element (see Table 12). An example is [134] below:

134 (ordering a drink in a restaurant)

NS: $\quad$... tolong bawain sebotol bir ya?

NS: $\quad \ldots$ please bring a bottle of beer yes?

This element ya "yes" has a distinct softening effect on imperatives. As Sneddon observes, it helps the speaker to avoid the appearance of a firm order by "drawing the listener into agreement" (Sneddon 1996: 328).

The other IM used quite frequently by BI NSs on imperatives is a kinship term of address. This modifier is used in almost one third (31.6\% or 6/19) of instances (see Table 11). The kinship terms selected are esentially the same ones as used in QP modal requests (with a single instance of an different kinship term, Bang "older brother", to a bus conductor). The addition of these kinship TOAs to imperative requests (as with QP modal requests) makes the request more polite, although, once again, the precise pragmatic effect is difficult to identify.

BI native subjects only occasionally use an internal modifier other than the three above (see Table 12). In two instances they use a politeness marker coba, literally "try" (cf. [139] and [140] below); 11 in two other instances they use a modal particle (deh).

Most imperative requests $(57.9 \%$ or $11 / 19)$ by BI NSs contain more than one type of internal modifier (see Table 11 above). This sometimes produces the effect of highly routinised modification. For example, of the five imperatives used by BI NSs in asking a bus conductor to tell them when they get to their stop, all have the same essential modification pattern of Politeness Marker + Appealer. This is best appreciated by comparing these five BI NS forms, below:

\section{Tolong nanti dikasih tahu va ...?}

Please later (I) be told yes...?

136 Tolong Mas nanti dikasih tahu ya ...?

Please brother later (I) be told yes...? 
Tolong ya saya diberi tahu....?

Please yes I be told ...?

138 Tolong kasih tahu saya... Bang ya?

Please tell me ... brother yes?

139

... coba dikasih tahu $\underline{\text { a }}$ ?

... please (I) be told yes?

Modification of imperatives by BI NSs can be highly compounded. A particularly elaborate example is below:

140 (asking a taxi driver to stop for a minute so you can buy cigarettes)

NS: $\quad \cdots \underline{\text { coba }}$ tolong berhenti sebentar $\underline{\text { Pak }}$ ya?

NS: $\quad .$. please please stop for a minute 'father' yes?

In [140] the speaker uses two different politeness markers, as well as a respectful term of address, and an Appealer; the combined effect of which is to greatly soften the effect of the command.

To sum up, imperative requests by BI NSs are nearly always mitigated by internal modifiers, and often these elements are used in combination, with a particularly powerful mitigating effect.

\subsubsection{Internal modification of (full) imperative requests: Learners}

Like BI NSs, learners internally modify nearly all their imperative requests. They use IM on 90\% (or 9/10) of imperatives (see Table 11). However, learners do not use the same modifiers as BI NSs. Most importantly, learners' most commonly used modifier is one which BI NSs never use: an imperative marker -lah. This modifier is used on a majority (70\% or 7/10) of imperatives by learners (see Table 12). Examples are these:

141 (asking a hotel servant to have your clothes washed)

L: $\quad$... cucilah pakaian kotor saya.

L: $\quad$... wash_lah' my dirty clothes 
142 (asking a taxi driver to stop for a minute so you can buy cigarettes)

L: $\quad$.. berhentilah sebentar ...

L: $\quad$... stop-'lah' for a minute...

This enclitic -lah, as Sneddon observes, "rarely occurs in imperative constructions in everyday speech" (Sneddon 1996: 328). Learners can be assumed to use it for its intended politeness value; they are taught (Johns 1977: 23) that it equates with "please" on imperative requests and that it makes such requests less abrupt. However, it is actually of doubtful effectiveness in softening requests such as [141] and [142] above. In the first place, there is considerable disagreement in the literature over whether this feature conveys politeness on imperatives at all, or simply marks imperative mood. ${ }^{12}$ Moreover, even if this feature does affect the politeness of an imperative, it may not always be in the way learners intend: Mintz (1994) claims that the pragmatic effect of -lah is highly context-sensitive, and that while it may sometimes "take the edge off" an imperative, it may sometimes aggravate the force instead, by conveying an emphatic, "somewhat condemnatory" tone (for example, in Apa lagi yang ditunggu? Pergilah. Orang lain sudah ada di sana. "Why are you still waiting? Go-lah. The others are already there.") (Mintz 1994: 237). ${ }^{13}$ On the whole, judging from the response of BI native speaker informants to learner imperative requests such as [141] and [142] above (e.g. "When I hear someone say something like that I know straight away it's a foreigner", and "It just sounds funny"), it seems safe to say that this modifier does not successfully convey the pragmatic force that learners intended.

Apart from this main modifier -lah, learners also sometimes use one of the two main BI NS choices of modifier: tolong "please" (in 20\% or 2/10 of head acts), or the Appealer $y a$ "yes" (in $30 \%$ or $3 / 10$ of head acts). However, unlike BI NSs, learners only occasionally use compound IM on an imperative (in 20\% or $2 / 10$ of head acts: see Table 11 above). And when they do, this compound contains the rather problematic element -lah as one of the two modifiers, so the effect is not one of highly modified requestive force, as probably intended. The learner imperatives with compound IM are below:

143 (asking a taxi driver to stop for a minute so you can buy cigarettes)
L: $\quad$ Tolong hentilah ...
L: $\quad$ Please stop-lah $\ldots$ 
144 (ordering a drink in a restaurant)

L: Bawalah saya sebotol bir juga ya?

L: Bring-lah me a bottle of beer too yes?

In the two examples above, any mitigation of the forcefulness of the imperative can be said to be due to the native-like modifier alone (i.e. to tolong "please" in [143] and to $y a$ "yes" in [144], rather than to the combination.

On the whole, while learners consistently use $\mathrm{IM}$ on their imperative requests, they rarely select an effective modifier, and rarely use more than one modifier.

\subsubsection{Situational variation in internal modification of imperative requests}

Detailed investigation of situational variation in modification of this sub-strategy is not practicable. Apart from the small number of imperative requests used by subjects (by learners especially), the fact that this sub-strategy is used only in a small number of situations, which are fairly uniform in values of social variables, leaves little scope for discernable variation by social factors within these situations.

An examination of when subjects use most, and least, modification shows no clear pattern of situational variation. For example, learners use both their most heavily modified imperative (one with two modifiers) and their least modified imperative (which contains no modifiers) in the same situation: ordering a drink from a waiter. Similarly, BI NSs use both their most heavily modified imperative (which contains four modifiers) and their two least modified imperatives (which contain no modifiers) in the same situation: asking a taxi driver to stop. Therefore, it seems that both groups regularly use IM on imperative requests, but show no tendency to use it particularly heavily, or to eschew it, in certain situations.

\subsubsection{Internal modification of imperatives: Summary}

Both learners and BI NSs use internal modification on almost all imperative requests. However, the two groups achieve quite different effects through use of internal modifiers. BI native speakers primarily use a politeness marker with a 
strong mitigating effect (tolong "please") and frequently combine it with other effective modifiers as well, sometimes achieving a routinised effect of quite elaborate modification. Learners, on the other hand, tend to use a modifier of dubious effectiveness (the enlitic-lah). While they sometimes use a more effective modifier instead, or as well, they produce no compound modification of comparable effect to that of BI NSs. Regarding situational variation, learners and BI NSs both include IM on imperatives consistently, showing no clear tendency to select it most frequently in certain contexts.

\subsubsection{Internal modification of direct questions}

Internal modification of the main sub-strategy used in Asking situations, the direct question, will also be examined. In this case of this sub-strategy, modification in all Asking situations can validly be examined, because both groups use direct questions frequently in all five.

\subsubsection{Internal modification of direct questions: BI native speakers}

BI native speakers modify direct questions internally in a large majority of instances ( $72.7 \%$ or $24 / 33$ of head acts: see Table 13 below).

Table 13: Proportion of direct questions by learner and BI native speaker subjects which are internally modified

\begin{tabular}{|l|cc|cc|}
\hline & \multicolumn{1}{|c|}{ Learners } & \multicolumn{2}{c|}{ BI NSs } \\
\hline & $\mathrm{n}$ & 2.9 & 13 & 39.4 \\
\hline $\begin{array}{l}\text { head acts with one } \\
\text { internal modifier }\end{array}$ & 1 & - & 11 & 33.3 \\
\hline $\begin{array}{l}\text { head acts with }>1 \\
\text { internal modifier* }\end{array}$ & -- & 2.9 & 24 & 72.7 \\
\hline $\begin{array}{l}\text { Total head acts with internal } \\
\text { modification }\end{array}$ & 1 & & & 33 \\
\hline Total No of direct questions & & 34 & & \multicolumn{2}{c|}{} \\
\hline
\end{tabular}

* This category refers to more than one type of internal modifier. So instances where only the Appealer ya is used, but it is used twice, are not included in this category. 
By far the most common modifier is the Appealer ya "yes". This modifier occurs on most direct questions by BI NSs (63.6\% or 21/33: see Table 14 below). An example is this:

145 (asking a stranger on the railway platform if the train that has just arrived is the one to Bandung)

NS: ... ini (.) kereta api yang baru saja datang ini apakah kereta yang ke

NS: Bandung ya?

NS: $\quad$... this (.) this train that just came is it the one to

NS: Bandung yes?

This modifier ya "yes" on direct questions as in [145] above has a similar effect to when it is used in requests proper: it appeals to the cooperation of the hearer and so makes the question seem less coercive.

Table 14: Proportion of direct questions by learner and BI native speaker subjects which contain each type of internal modifier

\begin{tabular}{|l|cc|cc|}
\hline & \multicolumn{2}{|c|}{ Learners } & \multicolumn{2}{c|}{ BI NSs } \\
\hline Type of internal modifier & $\mathrm{n}$ & $\mathrm{n}$ & $\%$ \\
\hline $\begin{array}{l}\text { Appealer } \\
\text { (ya "yes") }\end{array}$ & 1 & 2.9 & 21 & 33.3 \\
\hline $\begin{array}{l}\text { kinship TOA } \\
\text { (e.g. Pak "father") }\end{array}$ & - & - & 11 & 9.1 \\
\hline Hedge & - & - & 3 & \\
\hline
\end{tabular}

Kinship TOAs are also used by BI NSs as internal modifiers in a large proportion of direct questions ( $33.3 \%$ or 11/33: see Table 14). The addition of these relationship-markers to direct questions, as to other requests, adds an element of politeness to the head act. 
Hedges on the force of the question are occasionally used by BI NS subjects to soften the effect (in $9.1 \%$ or $3 / 33$ of instances: see Table 14). These Hedges in each case consist of the word kira-kira, to mean either "do you think?" or "roughly/ approximately". Examples are below:

146 (asking a police officer at the station where to report a lost passport)

NS: ... kira-kira di mana ya saya bisa ngelaporkannya.

NS: $\quad$... where yes do you think I can report it.

147 (asking the conductor during a long coach journey how long until the coach arrives)

NS: $\quad$... kira-kira berapa lama lagi sampenya sih Pak

NS: $\quad \cdots$ roughly how much longer till we get there 'father'

In [146] the element kira-kira conveys the impression that the hearer is not necessarily expected to know the information asked for, while in [147] this element suggests that the hearer is not expected to know the information with precision; in both cases, this Hedge on interrogative force makes the question seem less demanding.

A large proportion (33.3\% or 11/33) of direct questions by BI NSs have compound internal modification (see Table 13 above). Generally this consists of the Appealer combined with a kinship TOA. This combination of an appeal to the hearer's cooperation and overt marking of a relationship with the hearer creates an effect of considerable effort to make the question acceptable to the hearer. This is particularly so when the Appealer is used repeatedly as in examples [148] and [149] below:

148 (asking a coach conductor during a long journey how long until the coach arrives)

NS: Masih lama ya sampai Denpasar ya Mas ya.

NS: Is it still long yes to Denpasar yes 'brother' yes.

149 (asking a stranger in the street for directions to the Language Centre)

NS ...uh(.) ke (.) kalau mau ke Pusat Bahasa itu (.) lewat

NS: jalan mana ya Mbak ya 
NS: $\quad$... uh (.) to (.) to get to the Language Centre (.) which

NS: way is it yes 'sister' yes

\subsubsection{Internal modification of direct questions: Learners}

Learners demonstrate strikingly different behaviour from BI NSs with respect to direct questions. They almost never use internal modifiers at all: only one direct question by a learner (1/34 or $2.9 \%$ ) contains internal modification (the Appealer ya "yes"). So direct questions by learners almost never obtain the mitigated effect that questions by BI native speakers do. Examples of typical learner direct questions are these:

150 (asking a stranger in the street for directions to the Language Centre)
L: ... di mana Pusat Bahasa?
L: $\quad$... where's the Language Centre?

151 (asking the conductor during a long coach journey how long until the coach arrives)

L: $\quad$... berapa lama (.) sebelum (.) bus ini (.) tiba di

L: Denpasar?

L: $\quad$... how long (.) before (.) this bus (.) arrives in Denpasar?

152 (asking a police officer at the station where to report a lost passport)

L: $\quad$... paspor saya hilang di mana (.) uh (.) pergi saya untuk

L: $\quad$ (.) melaporkannya.

L: $\quad$... my passport's lost where (.) uh (.) do I go to (.) report

L: it.

These questions above convey the impression that no particular effort is being made by the speaker through linguistic choices to make the question acceptable to the hearer. 


\subsubsection{Situational variation in use of IM on direct questions}

Learners (as evident from the above) consistently use no or almost no IM on direct questions across Asking situations. By contrast, an examination of situational variation by BI NSs shows a pattern of highly consistent use: at least half the direct questions by BI NSs in every Asking situation are internally modified.

\subsubsection{Internal modification of direct questions: Summary}

BI native speaker subjects internally modify most of their direct questions, generally with the Appealer ya "yes". This modifier itself is used on most direct questions by BI NSs, sometimes more than once in the same head act. BI NSs also use other modifiers: kinship TOAs frequently, and Hedges occasionally. Moreover, BI NSs use internal modification consistently across Asking situations. Learners, on the other hand, almost never use internal modifiers on direct questions. They do so in only one instance (in which the Appealer ya "yes" is used).

\subsubsection{Appropriacy of internal modification by learners}

Looked at overall, the strong and consistent preference by learners for zero modification on both QP modal requests and direct questions is strikingly nonnative. This does not mean, however, that it produces non-native or unacceptable pragmatic behavour in the individual instances in which it occurs. There do not appear to be any situations in this study where it is considered obligatory to use internal modification (either in general, or of a particular kind) - illustrated by the fact that even in situations where BI NSs use IM frequently on their requests, it will regularly happen that one or more BI NS subjects use no IM at all, and informants will consider this to be within the range of acceptable requesting behaviour. And even in the few situations where all BI NSs internally modify their requests, the 'bare' head acts produced by learners are still an acceptable alternative. However, the apparent lack of IM resources by learners on these strategies greatly limits their options for making requests. BI NSs have the choice of whether to internally modify their requests, and very often choose to do so; learners, however, appear to lack the resources to modify at all. By and large, they seem restricted to one part of the BI NS repertoire of $\mathbb{M}$ behaviour: the option of zero modification. 
Only one aspect of learners' internal modification regularly results in instances of distinctly non-native behaviour: their use of the -lah marker on imperatives. Even in these cases, it is not clear that the pragmatic effect is actually impolite: informants tend to judge these learner imperatives as strange rather than rude. However, learners who use this marker -lah can be considered as failing in their intention to actually mark these requests for politeness, and to that extent, their intended pragmatic force is likely to be misconstrued by the hearer. So, in that sense, this feature does appear to result in 'pragmatic failure' (cf. Thomas 1983).

\subsubsection{Internal modification overall: Summary}

Learners generally use much less internal modification than BI NSs. On both the main request sub-strategy (QP modal) and the main Asking strategy (direct question) it is the norm for BI NS subjects, but the rare exception for learners. Only on imperatives do learners use IM with comparable frequency to BI NSs. And even on this request type, learners use much less compound internal modification than BI NSs do.

Learners also show striking differences in type of internal modifiers. In QP modal requests, the main BI NS modifiers (Negator and kinship TOA) are not used by learners at all; and in imperatives, learners favour a modifier which is never used by BI NSs (-lah).

Regarding appropriacy of performance, learners' lack of IM does not tend to result in non-native request realisations, as zero $\mathbf{I M}$ is consistently an acceptable option. However, this lack of IM gives a strong impression of limited resources; a lack of linguistic means to modify requests internally even if desired. And in the one substrategy (imperative) where learners do have an internal modifier as a regular element of their repertoire, their use of this modifier is of doubtful appropriacy, and does not create the desired pragmatic effect. 


\subsection{Discussion}

In this section, the most important findings about the use of $\mathrm{IM}$ on requests by learners are selected and discussed in some detail.

\subsubsection{Frequency of internal modification by learners}

This section discusses the finding that learners use much less internal modification on requests than BI NSs; in particular, the fact that they use almost no internal modifiers on their main request type: QP modal requests (see 5.2.1.2).

It seems clear that L1 influence cannot account for this finding. Studies consistently show that native AE speakers use downgrading frequently in query preparatory requests. In the CCSARP project (cf. Blum-Kulka 1991) native AE speakers frequently used the politeness marker "please", and also showed a strong tendency to use more than one downgrader, on this strategy (for example "I was wondering if you could possibly... "). Tanaka $(1986,1988)$, similarly, finds very consistent use of compound downgrading on this strategy by AE native speakers (especially with the syntactic modifier "can" --> "could", and the lexical and phrasal downgraders "I was wondering", “"please”, and “do you think...?"). X. Nguyen (1990) also finds consistent use of downgraders by AE native speakers on this request strategy, such as conditional "could" and "I was wondering".

Evidence from British English (BE) confirms this finding. House and Kasper (1987) found that BE native speakers in their requests - which were overwhelmingly of the QP modal type - regularly used the modifiers "please" (very frequently), "do you think", and "perhaps/ possibly" (quite frequently), and, in certain situations, "I was wondering" (quite frequently). Aijmer (1996), too, finds BE native speakers to use the modifiers "could" and "please" very commonly, often combined, on their QP modal requests.

One cause for these learners' absence of internal modifiers in Indonesian might be that internal modification of speech acts is inherently difficult for learners. Adding lexical or phrasal internal modifiers to a bare head act, as Trosborg (1995) implies, is likely to increase the complexity of the pragmalinguistic structure (Trosborg 1995: 428-429). This means that extra processing effort will be required to add 
internal modifiers, so that these Australian learners - who are likely to lack automatic control over even 'bare' (i.e. unmodified) pragmalinguistic routines and have to invest considerable effort in producing them - may not be able to add modifiers easily. ${ }^{14}$ This argument that internal modification is inherently difficult seems supported by the fact that L2 learners tend to use less downgrading on requests than L2 native speakers. Examples are Danish learners of both German and English (Kasper 1981, cited in House \& Kasper 1987: 1253); Danish learners of English (Trosborg 1995); German learners of English, in the Bochum project (Kasper 1982: 107-108) and in the CCSARP project (House \& Kasper 1987: 1284-85); US English learners of French (Harlow 1990); and Spanish learners of English (Rintell 1981). 15

While a small number of studies find learners to use much IM or even more IM than native speakers, it seems significant in the light of the above argument about processing complexity that all these appear to be studies in which subjects produce written requests (mixed nationality learners of Hebrew: Blum-Kulka \& Levenston 1987, and Danish learners of English: House \& Kasper 1987; Faerch \& Kasper 1989). The processing task is much reduced for learners by allowing them to write their requests, as they have time to think, and so learners may manage under these conditions to use complex structures, which they have not mastered well enough to draw on in spoken discourse.

The claim by Trosborg (1995) about the key role of processing complexity in explaining lack of internal modifiers is important, and probably plays a part in the present findings. However, other factors seem decisive in the case of these Australian learners. Importantly, almost none of the common English internal modifiers of QP modal requests are readily transferable to the $\mathrm{L} 2$ by these subjects. Either there is no BI formal and functional equivalent, or, if there is a BI equivalent, the learners are unlikely to know that it can be used with the same function in $\mathrm{BI}$ as in English.

The very common English politeness marker "please" on QP modal requests does have a close equivalent in BI. Of the several Indonesian words sometimes translated as "please", the marker tolong can be used in requests of this type as a close functional equivalent of the English marker "please" (see 5.2.1.2). However, these learners are unlikely to know that tolong is used in this way. It is taught to them as a marker of imperatives only (Johns 1977: 235), and the learners are not told that it means "please". Instead, the construction of Tolong + Imperative is 
glossed as "Would you mind -ing?" (Johns 1977: 234). Therefore the learners are unlikely to know that this marker can be used to mitigate QP modal requests, and would not perceive it as equivalent to "please" in such contexts.

There is no L2 formal equivalent of the very common English syntactic modifer "can" --> "could", as there is no syntactic means in BI of encoding conditionality in the modal verb. In addition, the BI formal equivalent of the English downgrader "I wonder/I was wondering" (namely, Saya ingin tahu "I want/ wanted to know") does not conventionally function as a downgrader of requests.

The English consultative device "do you think...?" on QP modal requests has a close formal and functional equivalent in the L2; namely, kira-kira (see 5.2.1.1). However, this BI form kira-kira lacks transparent equivalency. Its primary meaning is "approximately", and this is the only meaning of it that these learners are likely to know, so that they would not equate it readily with the English counterpart. In fact, of the common English downgraders on QP modal requests, it seems that only the Hedging device "possibly/ perhaps" has a BI formal equivalent (barangkali or mungkin ) which can be used with the same function as in English (see [120] above) and whose equivalency might be readily perceived by these learners.

A complementary obstacle faced by these learners in using internal modifiers is that they are not likely to know the most common modifiers used by BI NSs, either through L1 pragmatic knowledge or as a result of instruction. The most frequently used BI NS internal modifier, the Negator, has no formal and functional English equivalent. ${ }^{16}$ The English formal equivalent, the tag "or not?", is not conventionally used with downgrading function on English QP modal requests; instead if used on this request type it tends to produce an effect of slight asperity or impatience. Moreover, the learners' main textbook (Johns 1977) contain no instances of requests modified with a Negator.

Another internal modifier frequently used by BI NS subjects, the kinship term of address, does have a formal and functional equivalent in English. The terms "Sir" and "Madam" can be regarded as roughly parallel forms to the respectful BI kinship terms (Ba)pak "father" and (I)bu "mother". However, as Quinn (1996c: 78, 130131) points out, these English terms of address differ importantly from their Indonesian counterparts in frequency of use: while the two BI kinship terms are very common, the terms "Sir" and "Madam" (in Australia at least) are now rarely heard. Therefore these learners would be unlikely to use these L2 kinship TOAs to 
modify their $\mathrm{L} 2$ requests on the basis of $\mathrm{L} 1$ pragmatic knowledge. Furthermore the learners' teaching materials contain no instances of request head acts modified by kinship TOAs. While the use of this feature in other contexts, such as on Alerters and on expressions of thanks, is illustrated in dialogues in the learners' main textbook (Johns 1977), learners would not necessarily infer from these examples of usage that this feature is used to modify request head acts.

The internal modifier used very frequently by BI NS subjects on direct questions and to a lesser extent on QP modal requests, the Appealer ya "yes", has no formal and functional equivalent in English (cf. *"Where's the railway station, yes?"). While this modifier is presented and practiced in the learners' main textbook (Johns 1977), this is always as a modifier of passive imperatives, and learners might well find it difficult to generalise from this very specific context to form the IL knowledge that this feature is used to modify questions as well.

Clearly, then, there are several reasons why it is difficult for these learners to use internal modifiers on their $\mathrm{BI}$ requests. However, the arguments above contain the implicit assumption that the learners want to use internal modifiers, and this assumption itself warrants brief discussion.

Firstly, assuming for the moment that these learners are planning their BI requests by analogy with English request forms - which routinely contain internal modifiers - it is important to note that the learners might not be aware that English QP modal requests do contain internal modifiers. Faerch and Kasper (1989) argue that internal modifiers, unlike supportive moves, are largely unconsciously used. As they put it:

[F]rom a psycholinguistic point of view one can assume that native speakers use them with little conscious attention, precisely because they are void routines ... that do not contribute to the propositional development of the discourse (Faerch and Kasper 1989: 243).

Therefore, it is plausible that these Australian learners plan their $\mathrm{L} 2$ requests on the basis of an equivalent L1 utterance, but 'ignore' the internal modifiers in the underlying $\mathrm{L} 1$ utterance during this process of verbal planning because they do not notice them. ${ }^{17}$ 
Secondly, due to the type of L2 instruction these Australian learners have received, they are likely to be unaware that internal modification is desirable on requests in BI. Kasper (1982) makes this point with reference to German learners of English in the Bochum project, whose speech acts were similarly unmarked for modality. The expression of propositional meaning was given paramount importance in the FL instruction these German learners received (for example, through a strong focus on understanding and producing argumentative and expository texts), while by contrast, little attention was devoted to contexts where the expression of interpersonal meaning was crucial; for example, where face-threatening speech acts were performed. This meant that the learners were likely to generalise about the importance of the referential function to other contexts as well, and hence, to assume that propositional meaning is always what matters in the L2, even when performing acts such as requests (Kasper 1982). These Australian learners, too, have received traditional FL instruction which pays little regard to interpersonal functions of language (mastery of grammar was emphasised in the first year and study of expository and literary texts in later years), and therefore are likely to generalise about the importance of propositional meaning in the same way. ${ }^{18}$

\subsubsection{Frequency of the modifier -lah by learners}

This section discusses the finding that the learners regularly include this internal modifier on their imperative requests (see 5.2.2.2).

The regular use of this internal modifier by learners is largely explicable by influence of instruction. In the learners' main textbook, imperative constructions with the modifier -lah are presented and practiced extensively in drills, at various stages of the course (Johns 1977: Chapters 2, 3, 8, and 12). Given the restricted currency that this marker -lah on imperatives has in BI native speech (cf. Sneddon 1996), it seems clear that many of the imperatives with -lah that learners are presented with and required to produce in class constitute non-native use of language. Therefore learners' use of this marker -lah illustrates 'primary teaching induction' from this deviant input (see 1.6.3.4).

L1 transfer may also play a contributory role in the consistent selection of -lah on imperatives by these learners. They can be expected to equate -lah with English "please", as it is consistently translated as "please" in their main textbook (Johns 
1977). And native English speakers appear to use "please" frequently on imperatives, in particular (House 1989: 105; Aijmer 1996: 166). Therefore, these learners may perceive imperatives in the L 2 as a highly appropriate environment for a marker which equates to "please" partly due to L1 influence.

The fact that the learners tend to select this non-native modifier -lah instead of the BI NS modifier, tolong, as a downgrader of imperatives, merits brief discussion. One factor is probably amount of formal instruction. While the feature tolong, too, is presented and practiced in the learners' main textbook (Johns 1977), the learners receive approximately four times as much exposure to and practice of -lah on imperatives as they do of tolong - which is only presented and practiced in one chapter (in Chapter 12).

Learners may also be discouraged from using tolong "please" by a perceived grammatical restriction on its use. The learners' main textbook (Johns 1977: 235) clearly implies that tolong may be used only with transitive verbs (a restriction apparently disregarded by BI native speaker subjects in this study). ${ }^{19}$ While half of the imperatives $(5 / 10)$ used by learners in this study are transitive verbs, where tolong could be used, learners are likely to find it simpler not to use tolong on imperatives at all, rather than having to worry about whether they are using it on the right kind of verb. 20

The psycholinguistic factor of processing complexity, as well, probably helps to account for learners' preference for -lah over tolong. Clahsen (1984: 222) argues that the separation of a particle from the verb requires processing effort because it entails producing a surface structure which cannot be mapped directly onto the deep structure. Thus, the enclitic -lah (as in Bawakanlah... "Bring-lah...") should be easier to add to an imperative than the free element tolong (as in Tolong bawakan... "Please bring..."). Use of the particle -lah is also likely to require less "psycholinguistic preplanning capacity" (cf. Faerch \& Kasper 1989: 233-34) than the use of tolong. The particle -lah can be added to an imperative verb as an 'afterthought', while the element tolong, which must precede the verb, has to be incorporated into earlier stages of verbal planning.

The fact that the use of the marker -lah is taught much earlier than tolong in the learners' main textbook (Johns 1977) may also be influential in making the learners favour the former over the latter. The use of -lah on imperatives is practiced from when these learners are near-beginners (in Chapter 2), and only some months later 
is tolong introduced as an alternative marker (in Chapter 14). As Kasper observes, this kind of grading of two features can allow the early-taught feature to become "a stable and well-automatized element of the learners' IL system" before the later feature is introduced, making it harder for learners to learn to use the second one instead (Kasper 1982: 104).

The regular use by these learners of the modifier -lah on imperatives gives an insight into their non-use of internal modifiers on QP modal requests and direct questions. The intensive instruction learners receive in this imperative modifier -lah is in striking contrast to the virtual absence of instruction in internal modifiers for the other sub-strategies. This seems to support the claim above that lack of instruction was a major factor preventing them from using internal modifiers on those request types.

\subsection{Internal modification of requests: Summary and conclusion}

Learners' behaviour with respect to internal modification of requests is highly nonnative. Most importantly, learners use almost no internal modification on the main request strategy (QP modal requests) or on the main Asking strategy (direct questions), while BI native speakers use it consistently on both. Only on imperative requests do learners use IM with comparable frequency to BI NSs, and on this request type, learners' choice of IM (the enclitic-lah) is distinctly non-native (see 5.2.5 for a detailed summary of internal modification findings).

The factor of negative transfer from the $\mathrm{L} 1$ does not seem to be an important causal factor for the non-native features above. Rather, two specific psycholinguistic factors are likely to be of major importance: the additional processing effort required to add internal modifiers to an $\mathrm{L} 2$ request, and the largely unconscious nature of IM use, which may make learners unaware of internal modifiers on L1 requests.

Lack of knowledge of the internal modifiers used in the L2 also appears to be an important causal factor. This is partly due to lack of equivalence between L1 and L2 internal modifiers. Knowledge of certain BI modifiers cannot be gained from English, while knowledge of certain English modifiers cannot be transferred to BI. This suggests that Australian learners of BI may have a significant amount of L2- 
specific pragmatic knowledge to acquire in order to use internal modification on their requests.

Another important factor causing non-native modification by these learners is the nature of the formal instruction they receive. The teaching materials used by these learners omit common L2 modifiers or present them in such a way that generalisation to quite different contexts is required for learners to use them in their own requests. Moreover, the learners form IL-specific knowledge on the basis of deviant input in the materials which causes them to use one modifier which L2 native speakers do not use. 


\subsection{Notes to Chapter 5}

1 This distinction between Downgraders and Upgraders is made by House and Kasper (1981).

2 The notion of a Downgrader is based on earlier work on the mitigation of speech acts (including that of Lakoff 1973; Brown \& Levinson 1978; and Fraser 1978). The CCSARP classification of Downgrader types is based on earlier classifications of such devices; for example, those of House and Kasper (1981) and of Edmondson (1981).

${ }^{3}$ It is possible that no terms of address occured within head acts in the CCSARP request data, and that these elements were not classified as internal modifiers for that reason. However, one example utterance in the CCSARP coding manual, "Clean up the kitchen, dear ..." (CCSARP 1989: 285, emphasis added) seems to suggest that terms of address did occur in the data.

${ }^{4}$ One feature with potential internal modifying function is not examined; namely, hesitation phenomena (e.g. pauses, filled pauses ("um", "uh", etc) and false starts). 'Hesitators' of this type may be used deliberately when performing face-threatening acts such as requests, in order to show that the speaker has qualms about performing the act, and in this way reduce the threat to the hearer's face (House \& Kasper 1981: 168). In the present study BI native subjects appear sometimes to use this feature; their requests in relatively face-threatening situations (such as asking a lecturer for an extension) are noticeably marked by hesitations. The learner subjects, too, probably use 'hesitators', particularly to compensate for their lack of other internal modifiers. However, it is very hard to tell from textual data when hesitation phenomena are used with strategic intent; often they may be the result of operational difficulties in planning and executing utterances instead (which is especially likely in the case of learner subjects). Therefore, no attempt has been made to quantify 'hesitators' in this study.

5 This notion of a 'Negator' is derived from the CCSARP downgrading device called "Negation of a preparatory condition" (CCSARP 1989: 281).

6 Some notes on the Negator: i) Of these two elements ndak and nggak "no/not", the latter is distinctly Jakartan in flavour but is also used outside Jakarta, especially in large cities). ii) A more formal negating element, namely tidak "no/not", can be used with the same function in requests, as in Bisa saya duduk di sini atau tidak? "Can I sit here or not?"; however, no instances of this occur in the data. 
7 While most BI native informants agreed that this negating element in QP modal requests had the politeness function proposed above, this opinion was not unanimous. One informant felt that its function was to convey clarity rather than politeness. She suggested that the negating element in requests (e.g. Bisa duduk di sini nggak "Can (I) sit here (or) not?") functions to present two options to the hearer very explicitly, something like the effect of the English "or not" in the same context, but without the tone of slight impatience which the latter tends to convey.

8 The information in Table 9 was compiled from a variety of written sources (especially Jensen 1988, but also Johns 1977; Badudu 1986; Draine \& Hall 1990; White 1994; Sneddon 1996; Quinn 1996b, 1996d), supplemented by discussion with BI native speaker informants.

9 This refers to situations where QP modal requests were used only infrequently by one or both groups, so that systematic comparisons of learner and BI NS data were not undertaken (see 5.2.1).

10 John's (1977: 234) translation of the construction Tolong + Imperative as "Would you mind -ing?" is consistent with this claim.

11 Johns (1977: 237) claims that the politeness marker coba "please" is not used to ask someone to do something for one's own benefit, and Sneddon (1996), too, states that it is "not usually" used for such a purpose (Sneddon 1996: 329); if so, the requests by BI native speaker subjects in [125] and [126] above are somewhat unusual. However, both Wolff (1972: 44) and Kaswanti Purwo (1984: 198) suggest that coba, like tolong, can be used when asking for help.

12 Sneddon (1996: 328) claims that -lah probably does not function as a softener of imperatives for most Indonesians. Verhaar (1984: 53), similarly, appears to regard it as a purely grammatical marker. However, numerous other writers (e.g. Sarumpaet (1977: 145), Johns (1977: 23); D.P. \& K (1993: 248) claim that -lah functions to soften a command. Soebardi (1989) and Quinn (1996c) seem ambivalent on this question, claiming on the one hand that -lah can indeed make imperatives more polite, but suggesting on the other hand that its use is largely dictated by grammatical considerations, by observing that it occurs most frequently on those imperative constructions which are not otherwise marked for imperative mood (Soebardi 1989: 33,37,42; Quinn 1996c: 552).

13 Quinn (1996c: 552), too, claims that the addition of -lah to an imperative may potentially make the request more abrupt rather than less. 
14 cf. Trosborg's (1995: 430) contention that learners' ability to modify speech acts improves as their mastery over the head act itself increases (see 7.3).

15 This finding is not restricted to requests; Olshtain and Cohen (1983: 26), for example, find that learners of Hebrew add fewer Upgrading modifiers to their apologies than Hebrew native speakers.

16 This is not to say that English has no negating element which is used as a downgrader of QP modal requests. The negative element in (e.g.) "You couldn't lend me a pen, could you?" is used with downgrading function (cf. CCSARP 1989).

17 Kasper (1979: 275) suggests a similar explanation for the lack of modality markers in complaints by German learners of English.

18 See also an earlier study by Kasper (1979: 277), in which she claims that the FL instruction received by German learners of English at school - which was 'grammar-centred' at the beginning stage and 'content-centred' at the intermediate and advanced stage - is an important explanation for the lack of modality markers in those learners' L2 complaints.

19 This opinion of Johns (1977) is supported by other grammarians (e.g. Kaswanti Purwo (1984: 197ff) and Sneddon (1996: 329)). However, three BI native speaker subjects use tolong "please" on the intransitive verb berhenti "stop" when asking a taxi driver to stop (as in Tolong berhenti sebentar "Please stop for a minute").

20 Of the two instances where learner subjects do use tolong "please" to modify imperatives, they use it once on an intransitive verb (on berhenti "stop" in asking a taxi driver to stop) and once on a transitive verb. 


\section{CHAPTER 6. REQUESTS: EXTERNAL MODIFICATION AND ALERTERS}

This chapter investigates how learner and BI native speaker subjects externally modify their requests, and how they use Alerters on requests. The first part of the chapter (6.1) examines external modification by subjects. The second part (6.2) examines the relationship between the two types of modification, internal and external. The third part (6.3) examines the use of Alerters by subjects.

\subsection{External modification}

\subsubsection{Introduction}

This section examines the way in which subjects use external modifiers on requests. ${ }^{1}$ An external modifier is a move which is an adjunct to the head act, or main request. As such, it does not affect the head act directly, "but rather, the context in which it is embedded, and thus indirectly modifies illocutionary force..." (Blum-Kulka \& Olshtain 1984: 204). Thus, an external modifier can be regarded as a 'supportive move' (cf. House \& Kasper 1981; Edmondson 1981), and the terms 'external modifier' and 'supportive move'" will be used interchangeably in this thesis. ${ }^{2}$

The use of external modifiers will be examined with regard to the same request types as for internal modifiers: the QP modal request, the imperative, and the direct question.

\subsubsection{Results}

\subsubsection{External modification of query preparatory modal requests}

\subsection{QP modal requests: $B I$ native speakers}

BI native speakers use supportive moves on most of their QP modal requests (60.0\% or $39 / 65$ : see Table 15$)$. 
Easily their most common type of move is a Grounder, in which a speaker gives reasons, explanations, or justifications for his or her request (CCSARP 1989: 287). ${ }^{3}$ Slightly over half of QP modal requests by BI NSs are modified by this type of supportive move (see Table 16 below).

Grounders by BI NSs are sometimes relatively short and perfunctory, as in this example:

153 (asking a taxi driver to stop for a minute so you can buy cigarettes)

NS: ... bisa berhenti sebentar Pak (.) saya mau beli

NS: rokoknya

NS: $\quad$... can (we) stop for a minute 'father' (.) I want to buy

NS: $\quad$ cigarettes

At other times BI NS Grounders are quite lengthy and elaborate, as in [154] below:

154 (asking a lecturer in class for a copy of last week's handout)

NS: ... minggu lalu sava tidak bisa hadir di perkuliahan karena sakit (.)

NS: $\quad$ hh (.) saya tidak punya latihan yang diberikan (.) barangkali Ibu

NS: bisa memberikan latihan itu sekarang?

NS: $\quad$... last week I couldn't come to lectures because (I was)

NS: $\quad$ sick (.) uh (.) I don't have the exercise that was given out

NS: (.) can you perhaps give (me) that exercise now?

Providing grounds, or reasons, for a request helps to make the request more polite. It can convey positive politeness, by assuming the hearer's cooperation; that is, by conveying the belief that the hearer will want to help once he or she can see why it is necessary (Brown \& Levinson (1978: 133). It may also convey negative politeness, by showing the hearer that you would not impose on him or her without a good reason (Brown \& Levinson 1978: 175; cf. also House \& Kasper 1987: 1281-1282). 
Table 15: Proportion of $\mathrm{OP}$ modal requests by learner and BI native speaker subjects which are externally modified*

\begin{tabular}{|l|cc|cc|}
\hline & \multicolumn{2}{|c|}{ Learners } & \multicolumn{2}{c|}{ BI NSs } \\
\hline & $\mathrm{n}$ & $\%$ & $\mathrm{n}$ & 30.8 \\
\hline with 1 external modifier & 37 & 60.7 & 20 & 29.2 \\
\hline $\begin{array}{l}\text { with > 1 external } \\
\text { modifier** }\end{array}$ & 5 & 8.2 & 19 & 60.0 \\
\hline $\begin{array}{l}\text { Total head acts with external } \\
\text { modification }\end{array}$ & 42 & 68.9 & 39 & \\
\hline Total No of head acts & & 61 & & 65 \\
\hline
\end{tabular}

* data is from eleven situations where $\mathrm{QP}$ modal requests are used frequently (in at least $30 \%$ of head acts) by both groups

** this category refers to use of more than one type of supportive move (e.g. to Preface + Grounder), not to multiple use of the same type (for example, Grounder + Grounder). For one thing, it proved impracticable to distinguish with validity betweeen Grounding sequences consisting of one elaborate Grounder and those consisting of two or more separate Grounders, and so all Grounding sequences, regardless of length, are regarded as a single Grounder.

BI native speakers also use another type of supportive move quite frequently: the Preface. ${ }^{4}$ This type of move occurs in $20.0 \%$ (or 13/65) of requests (see Table 16 below). With a Preface, the speaker announces (with varying degrees of explicitness) that he or she is going to make a request, without revealing the nature of the request. Examples of BI NS Prefaces are these:

155 (asking a store manager to exchange a shirt bought yesterday)

NS: $\quad$ Begini Bu (.) kemarin saya ini (.) baru beli (.) uh (.) baju

NS: ini

P: $\quad M m ~ h m$

NS: $\quad$ tapi (.) ternyata (.) warnanya (.) saya kurang suka (.) Bu

NS: (.) bisa nggak saya tukar sama warna lain. 
NS: It's like this 'mother' (.) yesterday I (.) bought (.) uh (.)

NS: this shirt

P: $\quad \mathrm{Mmhm}$

NS: but (.) it turns out (.) I don't (.) like the colour (.) 'mother'

NS: (.) can (I) (or) not exchange it for another colour.

156 (asking for a copy of last week's handout)

NS: $\quad$ hh (.) ini begini ya kemar/(.) itu Bu um (.) minggu lalu

NS: itu saya tidak masuk itu Bu ya

P: $\quad Y a$

NS: $\quad$ soalnya saya waktu itu sakit

P: $\quad M m h m$

NS: jadinya saya sekarang ini saya tidak dapat (.) latihan

NS: itu (.) apa Ibu bisa kasih saya latihan-latihan itu

NS: $B u$ ?

NS: uh (.) this it's like this yes (.) yester/ (.) 'mother' um

NS: (.) last week I didn't come to class 'mother' yes

P: $\quad$ Ya

NS: the thing is I was sick at the time

P: $\quad$ Mmhm

NS: so now I haven't got (.) the handouts (.) can you give me

NS: those handouts 'mother'?

Prefacing moves by BI NSs typically consist of or contain the element begini "it's like this", as in [155] and [156] above. This element suggests that the speaker is about to explain a problem, for which he or she would like the hearer's help. A number of other Prefaces used by BI NSs suggest more explicitly that the speaker wants the help of the hearer, such as in [157] and [158] below: 
157 (asking a lecturer for an essay extension)

NS: $\quad$ uh (.)begini Pak (.) uh (.) sava punva masalah(.) [um

$\mathrm{P}$ : $\mathrm{hm}]$

P: $\quad m m$

NS: $\quad$ kelihatannya (.) saya tidak bisa mengumpulkan (.) uh

NS: (.) paper mengenai Kebudayaan Jawa (.) besok Jumat (.)

NS: $\quad$ uh (.) saya akan pulang kampung (.) Ibu saya sedang

NS: $\quad$ sakit (.) kalau (.) misalnya (.) Bapak tidak keberatan (.)

NS: apakah saya bisa mengumpulkannya (.) agak mundur

NS: sedikit Pak

NS: uh (.) it's like this 'father' (.) uh (.) I have a problem (.)

NS: [um

P: $\quad h m] \mathrm{mm}$

NS: it looks like (.) I can't hand in (.) uh (.) the essay on

NS: Javanese Culture (.) on Friday tomorrow (.) uh (.) I'm

NS: going back to my village (.) my mother's sick (.) if (.) for

NS: example (.) you don't mind (.) can I hand it in (.) a

NS: little later 'father'

158 (asking a lecturer for an essay extension)

NS: $\quad$ Maaf menggangu $B u($.$) uh(.) saya mau minta tolong$

NS: $\quad \underline{B u}$

P: Uh huh

NS: $\quad$ Uh (.) saya nggak bisa menyelesaikan es/(.) esai yang

NS: Ibu tugaskan kepada kami (.) hari Jumat ini (.) apakah

NS: Ibu (.) bisa (.) menerima esai saya pada hari Senin Bu? 
NS: Sorry to bother you 'mother' (.) uh (.) I want to ask for

NS: your help 'mother'

P: Uh huh

NS: uh (.) I can't finish the es/ (.) essay you set for us (.) this

NS: Friday (.) can you(.) accept my essay on Monday

NS: 'mother'?

All the Prefacing moves above can be regarded as conveying politeness in two ways. Firstly, they are a means of asking the hearer to be in agreement with the following speech act; they appeal to the cooperation of the addressee. ${ }^{5}$ Secondly, they signal that the speaker is about to take a fairly lengthy turn at speech, during which he or she will give an account of a problem of some kind. ${ }^{6}$ This kind of discourse-organising device makes it easier for the addressee to process the message, and hence it is hearer-supportive; it shows consideration for the addressee.

Table 16: Proportion of OP modal requests by learner and BI native speaker subjects which contain each type of external modifier

\begin{tabular}{|l|cc|cc|}
\hline & \multicolumn{2}{|c|}{ Learners } & \multicolumn{2}{c|}{ BI NSs } \\
\hline Type of external modifier & $\mathrm{n}$ & $\%$ & $\mathrm{n}$ & $\%$ \\
\hline Grounder & 40 & 65.6 & 34 & 52.3 \\
\hline Check & 3 & 4.9 & 8 & 12.3 \\
\hline Preface & 2 & 3.3 & 13 & 20.0 \\
\hline Imposition minimiser & 2 & 3.3 & 3 & 3.1 \\
\hline Disarmer & 1 & 1.6 & 2 & \\
\hline
\end{tabular}

Occasionally BI NSs modify their requests by preceding the head act with a Check on the availability of the hearer to comply with the request. These Check supportive moves are typical pre-requests. BI NSs use Checks on a relatively small number (12.3\% or $8 / 65$ ) of QP modal requests (see Table 16 above). An example is this: 
159 (asking a fellow-college resident for a lift home)

NS: $\quad$... mau ke mana NAME

P: $\quad$ Mau pulang

NS: Bisa ikut nggak

NS: $\quad \ldots$ where are you going NAME

P: Home

NS: Can (I) come (or) not.

Like Prefaces, this kind of Check supportive move in [159] functions to prepare the hearer for the ensuing request.

BI native speakers only occasionally use a type of supportive move other than those mentioned above. In a few instances they use an Imposition Minimiser: a move which reduces the size of the perceived imposition upon the hearer entailed in the request (see Table 16 above). An example is below:

160 (asking a store manager to exchange a shirt bought yesterday)

NS: ... ini kemejanya masih dibungkus (.) belum saya buka

NS: (.) apa bisa saya menukarkan ...?

NS: $\quad \ldots$ this shirt is still wrapped (.) I haven't opened it yet (.)

NS: can I exchange it ...?

In [160], the speaker attempts to make her request to exchange the shirt seem less of an imposition on the store manager, by pointing out that the shirt is still wrapped and unopened.

In a couple of instances BI NSs mitigate the force of the request through a Disarmer, a move in which "the speaker tries to remove any possible objection the hearer might raise upon being confronted with the request" (CCSARP 1989: 287). An example is [161] below:

161 (asking a university lecturer for an essay extension]

NS: $\quad$ Maaf menggangu $B u($.$) uh(.) saya mau minta tolong$

NS: $\quad B u$ 
NS: Sorry to bother you 'mother' (.) uh (.) I want to ask for

NS: your help 'mother'

In [161] above, one possible objection of the lecturer to the student making her request; namely, that the student's intrusion is a nuisance, is anticipated and effectively pre-empted by the apology for disturbing the lecturer.

BI native speaker subjects often combine different types of supportive moves to produce quite complex external modification. Almost a third $(29.2 \%$ or $19 / 65)$ of their QP modal requests are supported by more than one type of supportive move (see Table 15 above), the most frequent combination of supportive moves being Preface + Grounder. And occasionally, BI NSs use quite elaborate combinations of supportive moves, as in [157] and [158] above. One of those examples is reproduced below:

162 (asking a lecturer for an essay extension)

NS: $\quad$ uh (.) begini Pak (.) uh (.) saya punya masalah

NS: [ = PREFACE] (.) [um

P: $\quad h \mathrm{~m}] \mathrm{mm}$

NS: $\quad k e l i h a t a n n y a($.$) saya tidak bisa mengumpulkan (.) uh$

NS: (.) paper mengenai Kebudayaan Jawa (.) besok Jumat

NS: (.) uh (.) saya akan pulang kampung (.) Ibu saya

NS: $\quad$ sedang sakit [= GROUNDER] (.) kalau (.) misalnya

NS: (.) Bapak tidak keberatan [= IMPOSITION

NS: MINIMISER] (.) apakah saya bisa

NS: $\quad$ mengumpulkannya (.) agak mundur sedikit

NS: $P a k$ 
NS: uh (.) it's like this 'father' (.) uh (.) I have a problem

NS: [= PREFACE] (.) [um

P: $\quad \mathrm{hm}] \mathrm{mm}$

NS: it looks like (.) I can't hand in (.) uh (.) the essay on

NS: Javanese Culture (.) on Friday tomorrow (.) uh (.) I'm

NS: going back to my village (.) my mother's sick

NS: [= GROUNDER] (.) if (.) for example (.) you don't mind

NS: $\quad[=$ IMPOSITION MINIMISER] (.) can I hand it in (.) a

NS: little later 'father'

The use in [162] above of a fairly elaborate Preface, combined with a detailed and lengthy Grounder, and followed by an Imposition Minimiser, greatly mitigates the effect of the request itself (Apakah saya bisa mengumpulkannya...? "Can I hand it in...?”).

On the whole, BI NS subjects rely heavily on supportive moves to mitigate their QP modal requests; especially Grounders, and often Prefaces in combination with Grounders. They sometimes use other kinds of supportive moves as well, and occasionally produce quite elaborate combinations consisting of several types of supportive move. Thefore, mitigation by use of external modifiers is an important feature of this request strategy by BI NSs.

\subsection{External modification of QP modal requests: Learners}

Learners modify even more of their QP modal requests with supportive moves than BI NSs subjects. Over two thirds $(68.9 \%$ or $42 / 61)$ of learners' requests are externally modified (see Table 15 above). Learners, like BI NSs, use Grounders as their most common type of supportive move. They use Grounders slightly more frequently than BI NS subjects, almost two-thirds (65.6\% or 40/61) of their QP modal requests being supported by this type of move (see Table 16 above).

Learners, like BI NS subjects, use very short Grounders on some requests and considerably longer ones on others. Many of these Grounders by learners are native-like both in length and in choice of information. Examples are [163] and [164] below: 
163 (asking a taxi driver to stop for a minute so you can buy cigarettes]

L: $\quad$... um (.) boleh (.) kita um (.) stop? untuk (.) satu menit

L: saya mau membeli rokok?

L: $\quad$.. um (.) may (.) we um (.) stop? for (.) one minute I want

L: $\quad$ to buy cigarettes?

164 (asking a lecturer in class for a copy of last week's handout)

L: $\quad$... minggu yang lalu saya tidak hadir karena sava sakit

L: $\quad$ (.) dan sava tidak (.) tidak diberi latihan

P: $\quad O$

L: $\quad$ uh (.) boleh saya (.) um (.) di/(.) diberi latihan?

L: $\quad$...last week I wasn't here because I was sick (.) and I

L: $\quad$ wasn't (.) wasn't given a handout

P: $\quad$ Oh

L: $\quad$ uh (.) may I (.) um (.) be giv/ (.) given a handout?

The Grounding material provided by learners in [163] and [164] above parallels that typically provided by BI NSs in the same two situations (as illustrated in [153] and [154] respectively). However, many other Grounders by learners create a nonnative effect, by the inclusion of information which seems redundant or overexplicit. On some occasions, this involves the use of a Grounder by a learner in situations where no BI NSs use one. This is exemplified in [165] below:

165 (asking a stranger in the park for a light)

L: $\quad$... bolehkah Anda (.) memberikan saya (.) korek api?

L: $\quad$ karena sava lupa korek api saya di rumah saya

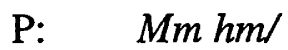

L dan saya mau merokok.

L: $\quad$... may you (.) give me (.) a match? because I forgot my

L: $\quad$ matches in my house

P: $\quad \mathrm{Mm} \mathrm{hm} /$

L: $\quad$ and I want to smoke. 
In the situation in [165] above, it is likely to be obvious to the hearer why the speaker wants a match. Not only is asking for a light for a cigarette a stereotyped request, but the speaker had a cigarette in her hand as she made the request. Therefore the information Saya mau merokok "I want to smoke," in particular, is likely to strike the hearer as redundant, and the effect is non-native.

On other occasions, this overexplicit effect involves the use of more Grounding information by a learner than BI NSs provide in the same situation. This may take the form of repeated information, as in [166] below:

166 (asking a taxi driver to stop so you can buy cigarettes)
L: $\quad$... saya mau membeli rokok (.) bisa (.) um (.) kita
L: $\quad$ berhenti untuk (.) di toko untuk saya (.) membeli rokok itu?
L: $\quad$... I want to buy cigarettes. (.) can (.) um (.) we stop at a
L: $\quad$ shop to (.) at a shop for me (.) to buy those cigarettes?

In [166], the first piece of Grounding information, Saya mau membeli rokok "I want to buy cigarettes" clearly conveys the speaker's reason for wanting to stop. This makes the second piece of Grounding information, untuk saya membeli rokok itu "for me to buy those cigarettes", seem redundant, so that the two Grounding segments together create an overexplicit effect. Another example of a learner request where the Grounding seems overexplicit is [167] below:

(asking a classmate to lend you a pen in class)

L: $\quad$ um (.) saya (.) tidak ada pena (.) uh (.) sava (.) lupa

L: pena (.) uh boleh saya (.) pinjam (.) pena Anda?

L: $\quad$ uh (.) I (.) don't have a pen (.) uh (.) I forgot (.) a pen (.)

L: $\quad$ uh may I (.) borrow (.) your pen?

In [167], the learner begins by grounding his request in a native-like way, with Saya tidak ada pena "I don't have a pen". Then he seems to feel the need to ground the request more fully, and after a pause, adds the information Saya lupa pena "I forgot a pen". Either the first or the second segment of the Grounder alone would have created an appropriate effect, but the addition of one to the other in this way creates an effect of redundant Grounding. A final example is [168] below: 
168 (asking a classmate to let you look on at their book in class)

L: $\quad$... uh (.) sava (.) saya ke(.) uh tinggalan (.) uh (.) buku (.)

L: $\quad$ buku sayauh (.) di rumah sava

P: $\quad M m ~ h m$

L: $\quad$ dan saya (.) saya (.) uh (1.0) (sighs) sava mau (.) uh (.)

L: membaca(.)uh(.)bukumu? [um

P: $\quad$ ( )]

L: $\quad$ boleh saya (.) boleh saya (.) um (.) membaca buku Ibu?

L: $\quad$...uh (.) I (.) I've le/ uh left (.) uh (.) my (.) my book

L: behind uh (.) in my house

P: $\quad \mathrm{Mm} \mathrm{hm}$

L: $\quad$ and I (.) I (.) uh (1.0) (sighs) I want (.) uh (.) to read (.)

L: $\quad$ uh (.) your book? [um

P: $\quad($ )]

L: $\quad$ may I (.) may I (.) um (.) read your book?

In [168], the learner begins by grounding his request in an appropriate way, by saying that he has left his book behind. However, instead of proceeding directly to a request for permission to look at the classmate's book, he first adds an extra piece of Grounding information: that he wants to look at the classmate's book. This piece of information is implicitly contained in the main request itself, as asking for permission to look at the book effectively conveys the information that the speaker wants to look at it; and so its explicit inclusion creates a non-native effect. It is interesting that the speaker in [168] seems to have a lot of difficulty expressing this additional piece of Grounding information (evident from repetitions, pauses, and sighs), but that he perseveres with it, as if he considers it to be an important component of the request.

This effect of overexplicitness in some Grounders by learners is compounded by other features. One is a tendency towards overexplicit phrasing. This is evident in [165] above, where in saying that she has forgotten her matches, the learner spells out that she has forgotten them "in my house" (di rumah saya). Similarly, in [168] above, the learner explains not only that he has left his book behind, but that he has left it behind "in my house" (di rumah saya). This tendency towards overexplicit phrasing, incidentally, is also apparent in request head acts (cf. [47] earlier, where a learner orders a meal with Saya mau makan sepiring nasi goreng "I want to eat 
a plate of fried rice" instead of the more native-like Saya mau nasi goreng "I want a fried rice").

Another feature contributing to the overexplicit effect of some Grounders by learners is the consistent use of explicit discourse linkers to clarify the logical relation between Grounder and head act. An example is [165] earlier, reproduced below:

169 (asking a stranger in the park for a light)

L: $\quad$... bolehkah Anda (.) memberikan saya (.) korek api?

L: $\quad$ karena saya lupa korek api saya...

L: $\quad$ May you (.) give me (.) a match? because I forgot my

L: $\quad$ matches ...

The learner in [169] conveys the fact that her forgetting her matches is the reason she wants a match by use of the explicit discourse linker karena "because". A more native-like effect would be achieved by eliding this element karena "because", so that the logical relationship is conveyed implicitly.

A similar effect is created on some Grounders by the repeated, overt use of the first person pronoun saya "I/my", both in subject position and possessive position; a feature which BI NSs tend to avoid, commonly by means of ellipsis. This learner feature is marked in two of the examples above. In [169], a learner says Saya lupa korek api saya di rumah saya dan saya mau merokok "I forgot my matches in my house and I want to smoke". In [168], another learner says Saya ketinggalan buku saya di rumah saya dan saya mau membaca bukumu. "I left my book behind in my house and I want to read your book". In instances such as these, the repeated, explicit mention of the first person element saya throughout the Grounder creates a distinctly non-native effect. Both the use of overexplicit discourse linkers, and the repeated, inclusion of the first person pronoun saya "I/my", convey an impression of a lack of shared knowledge between speaker and hearer, which in turn creates a sense of increased social distance between the interlocutors (cf. Edmondson et al 1984).

Regarding supportive moves other than Grounders, learners use exactly the same range as BI NSs do: Prefaces, Checks, Disarmers, and Imposition Minimisers (see Table 16 above). However, learners do not use any of these types of move 
frequently. Mostly notably, in contrast to BI NSs, they use Prefaces only very occasionally (on $3.3 \%$ or $2 / 61$ of head acts).

These non-Grounding supportive moves by learners are generally similar in content to BI NS moves of the same type. For example Checks by learners refer to the same conditions as Checks by BI NS subjects (in asking for a lift home, to whether the addressee is going home; and in asking to listen to a cassette in a store, to whether a cassette is in stock ). Only in one instance is a non-Grounding supportive move by a learner distinctly non-native: the Disarmer in [170] below:

170 (asking to exchange a shirt bought yesterday)

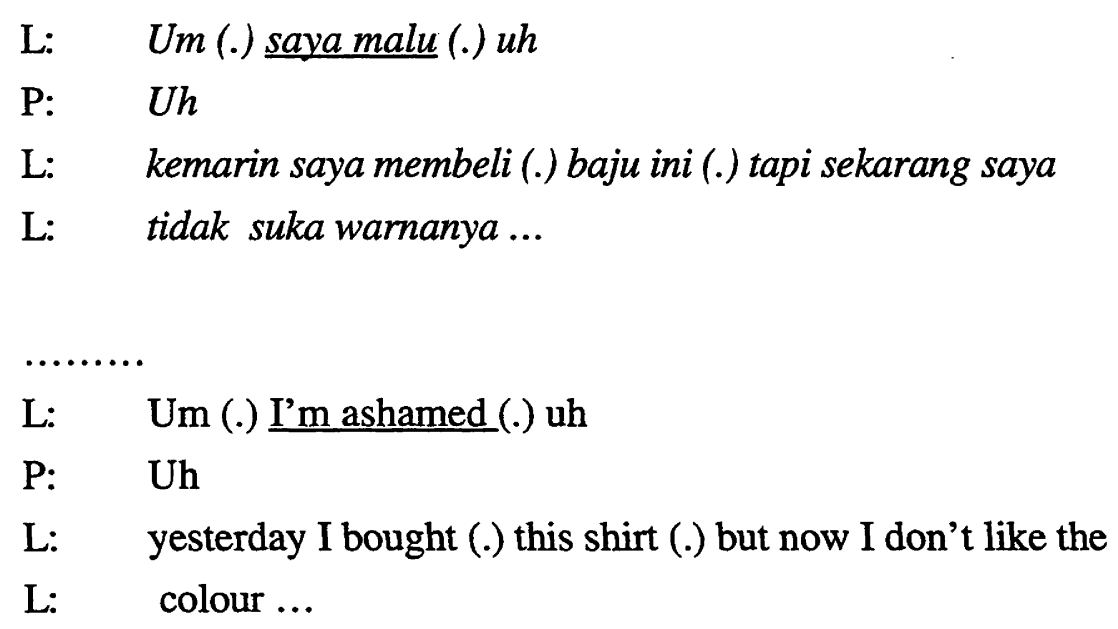

In [170] above, the learner's statement that he is is ashamed because he bought a shirt the colour of which he dislikes has an inappropriate effect. While the customer in this context might appropriately state, for example, that he has made a mistake (Saya keliru ), ${ }^{7}$ this forthright anouncement that he feels ashamed would be highly unusual and is likely to make the hearer uncomfortable.

Learners only occasionally use more than one type of supportive move on a request (in $8.2 \%$ or $5 / 61$ of instances: see Table 15 above). This is not surprising, given that learners almost never use Prefaces, so that the common BI NS combination of supportive moves, Preface + Grounder, is largely unavailable to them. However, occasionally learners do combine different types of supportive move, to achieve quite an elaborate mitigating effect. An example is [171] below: 
171 (asking the manager to exchange a shirt in a store)

L: $\quad$... saya (.) saya mempunyai masalah (.) yang kecil

L: $\quad$ [= PREFACE]

P: $\quad$ oya

L: $\quad$ um kemarin saya membeli (.) um baju ini (.) sebagai

L: hadiah untuk (.) suami saya [= GROUNDER] (.)

L: [tetapi

P: $\quad \mathrm{mm} \mathrm{hm]}$

L: $\quad$ um sebelum dia (.) um (.) membuka bungkusan ini

L: $\quad$ [= IMPOSITION MINIMISER] (.) saya ingat bahwa dia

L: tidak suka (.) um (.) warna itu [= GROUNDER] (.)

L: bolehkah saya (.) um (.) menukar (.) um (.) baju

L: itu?

L: $\quad$... I (.) I have a small (.) problem [= PREFACE]

P: $\quad$ Oh yes

L: um yesterday I bought (.) um this shirt (.) as a present

L: for (.) my husband (.) [= GROUNDER] [but

P: $\quad \mathrm{mm} \mathrm{hm]}$

L: $\quad$ um before he (.) um (.) opened this parcel

L: [= IMPOSITION MINIMISER] (.) I remembered that

L: he doesn't like (.) um (.) the colour [= GROUNDER] (.)

L: $\quad$ may I (.) um (.) exchange (.) um (.) the shirt?

\subsection{External modification of QP modal requests: Summary}

To sum up, learners show important similarities and differences with BI NSs in external modification of their main request type. Like BI NSs, they use supportive moves very frequently, and favour Grounders as their main type of supportive move. Many of the Grounders produced by learners are essentially native-like. Moreover, learners use several other types of supportive move (such as Checks and Imposition Minimisers) with similar frequency and in essentially similar ways to BI NSs. 
However, many of the Grounders produced by learners are distinctly non-native. They include content that seems redundant and which creates an effect of overexplicitness - an effect compounded by other features of learner Grounders as well. Another important difference in external modification by the two groups is that learners, unlike BI NSs, very rarely use Prefaces on their requests.

\subsection{Situational variation in use of external modifiers on $Q P$ modal requests}

Learners show clear similarities with BI NSs in the way they vary their decision whether to use external modifiers by situation. With regard to Grounders, both groups use this type of supportive move quite consistently across the 11 selected request situations. However, BI NSs show slightly more situational variation in use of Grounders than learners. They produce no Grounders at all in three situations (asking to try on shoes in a store, asking a stranger for a light, and asking a stranger to move over in a crowded eating stall), while learners use no Grounders in only one situation (asking to try on shoes in a store). So BI NSs seem slightly more selective in deciding whether to provide grounds for their requests.

As for situational variation in other types of supportive moves, the similarities are striking between the two groups. Both groups use Checks in the same two situations, and only those situations (asking to try a cassette in a store, and asking for a lift back to college). Similarly, both groups use Imposition Minimisers in the same one situation only (asking to exchange a shirt in a store). And learners use their only Prefaces in one of the five situations where BI NSs, too, use Prefaces (asking to exchange a shirt in a store).

It is interesting to note that the decision whether to use an external modifier in these situations sometimes seems to be affected not so much by social variables (such as relative status of interlocutors or size of imposition on the hearer) but by highly situation-specific features. For example, when asking a taxi driver to pull over for a minute to buy cigarettes, all learners and all BI NSs provide grounds for the request. Even though the speaker, in the role of paying customer, has the clear right to decide where the taxi will go and when it will stop; asking a taxi driver to stop before the previously stated destination is simply not appropriate unless a good 
reason is provided (the driver could think you intend to rob them, or at the very least get out without paying). Conversely, in asking to try on shoes in a store, no learners and no BI NSs provide grounds for this request, probably largely because the speaker's motives for wanting to try on shoes are self-evident, such that there are no grounds which are conventionally provided in this precise situation. Therefore it may be a similar responsiveness of the two groups to this kind of highly situation-specific feature which helps account for the similar choices of learners and BI NSs in deciding when to use different types of supportive moves.

On the whole, regarding situational variation in use of supportive moves, learners and BI NSs show strong similarities. They quite consistently select the same types of supportive moves for the same situations. This seems to reflect at least in part a similar response by the two groups to highly situation-specific features, rather than to social variables.

\subsubsection{External modification of imperatives: Learners and BI NSs}

Both learners and BI NSs use supportive moves quite frequently on imperative requests. These supportive moves are always Grounders, and they are used on a similar proportion of requests by the two groups ( $50.0 \%$ or $5 / 10$ for learners, and $57.9 \%$ or $11 / 19$ for BI NSs).

In the situations where both learners and BI NSs use imperatives, the two groups show strong similarities in whether they choose to use a Grounder. All learners and BI NSs use a Grounder when asking a taxi driver to stop for a minute to buy cigarettes, and no learners or BI NSs use a Grounder when asking a hotel servant to have their clothes washed, asking a friend to pass some magazines across, or ordering a drink from a waiter.

In the one situation above in which both learners and BI NSs use Grounders on imperatives (asking a taxi driver to stop), the Grounders produced by the two groups are very similar in length and choice of content (consisting invariably of a short statement that the speaker wants to buy cigarettes). 


\subsubsection{External modification of direct questions}

\subsection{Direct questions: BI native speakers}

In the five Asking situations, when BI NSs use direct questions, they usually modify them with a supportive move (in $60.6 \%$ or $20 / 33$ of instances: see Table 17 below).

Table 17: Proportion of direct questions by learners and BI NS subjects which are externally modified

\begin{tabular}{|l|lc|cc|}
\hline & \multicolumn{2}{|c|}{ Learners } & \multicolumn{2}{c|}{ BI NSs } \\
\hline & n & $\%$ & n & $\%$ \\
\hline with 1 external modifier & 11 & 32.4 & 19 & 57.6 \\
\hline with > 1 external modifier & -- & -- & 1 & 3.0 \\
\hline $\begin{array}{l}\text { Total No of direct questions } \\
\text { which are externally modified }\end{array}$ & 11 & 32.4 & 20 & \\
& & & & \\
\hline Total No of direct questions & \multicolumn{2}{|c|}{34} & & \multicolumn{2}{|c|}{33} \\
\hline
\end{tabular}

The vast majority of these supportive moves are Prefaces. BI NSs use Prefaces on more than half of their direct questions in these situations (see Table 18 below).

BI NS Prefaces to direct questions are of a distinct type, almost all (14/17) of them containing the key element tanya or nanya "ask". Examples are [172] to [175] below:

172 (asking the conductor during a long coach journey how long until the coach arrives)

NS: $\quad$... bisa numpang tanya (.) berapa lama (.) sampai ke

NS: Denpasar bus ini? 
NS: $\quad$... can I please ask (.) how long (.) until this bus arrives

NS: in Denpasar?

173 (asking a stranger in the street for directions to the Language Centre)

NS: Numpang tanya Mas? (.) [uh

P: $\quad Y a]$

NS: $\quad$ kalau mau ke Pusat Bahasa (.) itu di mana ya Mas ya.

NS: May I ask 'brother'?(.) [uh

P: $\quad$ Yes]

NS: if (I'm) going to the Language Centre (.) where is it yes

NS: 'brother' yes

174 (asking a stranger in the street for directions to the post office)

NS: Bisa nanya ini Bu?

P: $\quad M m[m m$

NS: $\quad u h]$

NS: $\quad$ kantor pos utama itu di mana ya?

NS: Can I ask this 'mother'?

P: $\quad \mathrm{Mm}[\mathrm{mm}$

NS: $\quad$ uh]

NS: where is the main post office yes?

175 (asking a police officer at the station where to report a lost passport)]

NS: $\quad$... saya mau tanya (.) uh (.) di mana tempat untuk

NS: melapor ( $/($.$) paspor saya hilang?$

NS: $\quad$.. I want to ask (.) uh (.) where's the place to report

NS: $\quad(\quad) /($.$) my passport's lost?$ 
All these Prefacing moves above, whether requests for permission to ask a question (as in [172] to 174]) ${ }^{7}$ or statements that the speaker wishes to ask a question (as in [175]), function to convey tentativeness about imposing on the hearer, and hence, make the question less coercive.

The few other instances of Prefaces on direct questions by BI NSs (3/17) have the word ini "this" as the main element, followed by a kinship term of address. This type is illustrated in [176] below:

176 (asking a police officer at the station where to report a lost passport)

NS: $\quad$ uh (.) ini Pak (.) saya kehilangan (.) paspor (.) uh (.)

NS: kira-kira di mana ya bisa ngelaporkannya.

NS: uh (.) this 'father' (.) I've lost (.) my passport (.) uh (.)

NS: where do you think yes I can report it.

The effect of Prefaces like [176] above is similar to those with begini "it's like this" (see 6.1.3.1.1); namely, they signal to the hearer that the speaker is about to tell him or her about a problem, and seek to establish cooperation between the interlocutors.

Table 18: Proportion of direct questions by learner and BI native speaker subjects which contain each type of external modifier

\begin{tabular}{|l|cc|cc|}
\hline Type of external modifier & \multicolumn{2}{|c|}{ Learners } & \multicolumn{2}{c|}{ BI NSs } \\
\hline & $\mathrm{n}$ & $\%$ & $\mathrm{n}$ & $\%$ \\
\hline Grounder & 9 & 26.5 & 3 & 9.1 \\
\hline Preface & 1 & 2.9 & 17 & 51.5 \\
\hline Precommitment & 1 & 2.9 & -- & -- \\
\hline Disarmer & -- & -- & 1 & 3.0 \\
\hline
\end{tabular}


Apart from Prefaces, BI NSs do not use any kind of supportive move frequently on direct questions. They occasionally use Grounders (9.1\% or 3/33 of instances), and once use a Disarmer (see Table 18 above). So, as might be expected, BI NSs rarely use compound external modification. Only one such instance occurs, below:

177 (asking a police officer at the station where to report a lost passport)

NS: $\quad$ Ini Bu $[=$ PREFACE] (.) maafngganggu $B u$

NS: [= DISARMER] saya (.) kehilangan (.) paspor Bu ke

NS: mana ya harus melaporkannya.

NS: This 'mother' [= PREFACE] (.) sorry to bother (you)

NS: 'mother' [= DISARMER] I've (.) lost my passport 'mother'

NS: where yes should I report it.

On the whole, BI NSs' external modification of direct questions consists of frequent use of Prefaces of quite a formulaic nature, but little other external modification.

\subsection{External modification of direct questions: Learners}

Learners use external modifiers on direct questions considerably less frequently than BI NSs do: on less than a third $(32.4 \%$ or $11 / 34)$ of head acts (see Table 17 above). They also tend to use a different type of external modifier. Unlike BI NSs, they almost never use Prefaces. In fact in only one instance (1/34 or 2.9\%) does a learner modify a direct question with a Preface (quite a native-like one, containing the formulaic native speaker elementtanya "ask").

Instead of Prefaces on direct questions, learners nearly always use Grounders (see Table 18 above). Generally, these Grounders by learners are quite appropriate in content and phrasing. An example is the Grounder in [178] below, which is used with only minor variations by several learners in the same situation:

178 (asking the way to the Language Centre when lost in the street)

L: $\quad$... saya tersesat(.) di mana Pusat Bahasa?

L: $\quad$...I'm lost (.) where's the Language Centre? 
However, certain other Grounders on direct questions by learners create a rather inappropriate effect, by the inclusion of rather superfluous-seeming information. An example is below:

179 (asking directions to the Language Centre)

$\mathrm{L}: \quad$... saya tersesat (.) saya orang dari Australi (.) um (.) di

L: mana Pusat Bahasa?

L: $\quad$... I'm lost (.) I'm a person from Australia (.) um (.)

L: where is the Language Centre?

In [179], after telling the addressee (appropriately enough) that she is lost, the learner adds the information that she is from Australia, a piece of news which is likely to strike the addressee as superfluous in this context.

Another Grounding move by a learner creates a rather bizarre effect due to a vocabulary error:

180 L: $\quad$... saya baru saja (.) tiba di sini [dan

P: $\quad Y a]$

L: $\quad$ saya hilang (.) um (.) bagaimana saya (.) ke (.) Pusat

L: Bahasa.

L: $\quad$... I've just (.) arrived here [and

P: Yes]

L: I've disappeared (.) um (.) how do I (.) go to (.) the

L: $\quad$ Language Centre.

The learner in [180] above probably intends to say that he is lost (tersesat or tersasar ), not that he has disappeared (hilang). The only instance of a nongrounding supportive move by a learner also produces a rather inappropriate effect. This is an attempt to obtain a Precommitment from the hearer, illustrated in [181 below]: 
181 (asking a coach conducter during a long journey how much longer until the coach arrives)
L: $\quad$ Bolehkah Anda (.) um (.) menolong saya?
P: $\quad$ O ya (.) $\mathrm{mm} \mathrm{hm}$
L: $\quad$ um (.) berapa lama (.) sebelum bus ini (.) um (.) tiba di
L: Denpasar?
L: $\quad$ May you (.) um (.) help me?
P: $\quad$ Oh yes (.) $\mathrm{mm} \mathrm{hm}$
L: $\quad$ um (.) how long (.) before this bus (.) um (.) arrives in
L: Denpasar?

Quite apart from the unconventional phrasing of the supportive move in [181] above (Bolehkah Anda...? "May you...?"), the request to the conductor to help her (menolong) gives the effect of quite a strong appeal, which is disproportionate to the routine nature of what the learner is asking. The addressee would probably be led by this supportive move to expect a larger imposition than the one involved here.

To sum up, learners quite often support their direct questions with a Grounder, but rarely use any other type of external modifier. The supportive moves they do use on direct questions are often appropriate and effective, but sometimes, due to choice of either content or phrasing, they produce an inappropriate effect.

\subsection{Situational variation in use of external modifiers on direct questions}

With respect to the only type of supportive move that learners employ with any frequency, Grounders, learners show considerable variation by situation. They use Grounders in only two of the five Asking situations: those in which they ask for directions in the street (to the post office, and when looking for the Language Centre when lost). BI NSs, likewise, only use Grounders when asking directions in the street (when looking for the Language Centre when lost). Therefore the two groups make a clearly similar choice in when to include a Grounder on direct questions. 
As for Prefaces, the favoured supportive move of BI NSs, learners regularly do not use this type of move in Asking situations. By contrast, BI NSs consistently do use Prefaces in these Asking situations, including them on a fairly large proportion of direct questions in each situation. So, the two groups display different behaviour consistently across situations.

\subsection{External modification of direct questions: Summary}

The two groups externally modify their direct questions quite differently. Most importantly, learners almost never modify them with Prefacing moves, while BI NSs frequently do. This difference applies across Asking situations generally. Another difference is that learners use Grounders on direct questions considerably more often than BI NSs do. These Grounders are usually appropriate to the situation; however, occasionally they are not.

\subsubsection{External modification of requests overall: Summary}

Learners and BI NSs show some important similarities with respect to use of external modifiers. Both groups frequently externally modify their main request type, the QP modal request, and do so using the same main type of supportive move: the Grounder. In addition, learners and BI NSs show close similarities in their choice of whether or not to use Grounders according to the situation, in all sub-strategies examined.

However, learners also differ importantly from BI NSs in their use of external modifiers. Firstly, unlike BI NSs, learners rarely use any type of supportive move other than Grounders. Most notably they rarely use Prefaces, which makes their pattern of external modification of direct questions, especially, strikingly different from that of BI NSs. Secondly, their realisation of their main move, the Grounder, is often problematic. A number of distinctly IL-specific pragmatic features makes many of their Grounders seem verbose or overexplicit. 


\subsubsection{Discussion}

In this section the most important findings on use of external modifiers by subjects are selected and discussed in some detail.

\subsubsection{Frequency of external modifiers by learners}

This section discusses the finding that the learners in this study frequently use supportive moves - especially Grounders - on their main request type, the QP modal request (see 6.1.3.1.2).

Previous research shows quite a consistent trend for L2 learners to use external modifiers frequently on requests. While certain studies find learners to underuse supportive moves compared with L2 native speakers (Trosborg 1995; Fukushima 1996); more commonly, learners are found to use external modification either as much as L2 native speakers (e.g Kasper 1981 (cited in House \& Kasper 1987: 1253); Edmondson et al 1984), or strikingly more than L2 native speakers (e.g. Blum-Kulka \& Olshtain 1986; House \& Kasper 1987; Faerch \& Kasper 1989; Blum-Kulka 1991).

It is argued by Faerch and Kasper (1989) that learners tend to exercise a preference for external over internal modifiers because the former are more explicit in their politeness function; they are longer, and derive their politeness value directly from the propositional content and the illocutionary meaning of the move itself. As a result, learners (who tend to feel uncertain about their linguistic ability in the L2) feel more confident that their intended politeness message is conveyed successfully if they use external rather than internal modifiers. This is likely to be one reason why these Australian learners tend to use external modifiers rather than internal ones. However, it is doubtful that these Australian learners are simply exercising a preference for the former type. Rather, as argued earlier (see 5.3.1), they probably find it difficult to use internal modifiers on requests even if they want to. So an important question is: why are these learners - even the Low learners - able regularly to produce external modifiers? The answer seems to be that the obstacles to internal modifier use discussed above either do not apply to external modifiers or apply to a greatly reduced degree. 
One factor thought to cause lack of internal modification by these learners; namely, that the main English modifiers are not readily available in BI and vice-versa (see 5.3.1), does not apply to external modifiers. The learners' main type of supportive move in BI requests, the Grounder, is consistently found to be the main type used by English native speakers (e.g. House \& Kasper 1987; Faerch \& Kasper 1989; Trosborg 1995; Fukushima 1996). In fact Grounders are consistently used across languages as the main type of external modifier, by both learners and native speakers; and it may be that giving reasons to justify a request is inherently the "psychologically most plausible" means of supporting a request (House \& Kasper 1987: 1281). Therefore these learners are likely to know that $\mathrm{L} 2$ requests can be effectively supported by Grounders; either from L1 knowledge or as part of the 'general pragmatic knowledge-base' (cf. Blum-Kulka 1991) that all speakers are equipped with.

The factor of processing complexity, as well, may be a less formidable obstacle for learners in the case of external modifiers than internal. While the addition of lexical or phrasal internal modifiers will tend to result in more complex 'chunks' of language for learners to plan verbally, due to the addition of extra elements that have to be incorporated into the pragmalinguistic structure; it is likely that in general the addition of supportive moves will not result in more complex structures. This is because the chunks, or constituents, by which utterances are verbally planned are small: typically a noun or verb phrase or short clause (cf. Clark \& Clark 1977: 248, 260 ), and so, as supportive moves occur outside the head act, it seems likely that they will typically be planned in separate constituents to the head act. Naturally, use of supportive moves will still increase the processing effort in planning a request by creating additional chunks which have to be verbally planned. ${ }^{9}$ However, the use of supportive moves - unlike internal modifiers - should not increase the complexity of the formal operations involved in planning the head act constituents themselves.

Another factor that may work against use of internal modifiers by learners also seems not to apply to the case of external ones. The proposal that learners may 'omit' internal modifiers on requests without even realising it, due to a concentration on propositional meaning instead of modal meaning (see 5.3.1), does not seem relevant to supportive moves. Unlike internal modifiers, which are primarily modality markers which contribute minimal propositional meaning to the request (cf. Kasper 1982), supportive moves such as Grounders do carry explicit 
propositional meaning, which learners are likely to be conscious of and therefore concerned to convey.

\subsubsection{Frequency of Prefaces by learners}

This section discusses the fact that the learners in this study greatly underuse Prefacing supportive moves compared with BI NSs, concentrating on the finding that they virtually never use them on direct questions (6.1.3.3.2).

One important reason for the lack of Prefaces by learners is that transfer of English pragmatic knowledge about this type of move is likely to result in drastic underuse in these situations in BI. The English pragmalinguistic equivalents to the customary BI Asking Prefaces with tanya/nanya "ask"; such as "Could I ask a question?", or "Can I ask you something?", have very restricted currency in English as Prefaces to requests for information. 10 Schegloff calls them "pre-delicates" in such cases, because they are used mainly when the information requested is potentially sensitive, such as personal information from a stranger (Schegloff 1980: 132); or when asking a question constitutes a violation of conversational expectations because normal turn-taking rules have been suspended, such as the case of a question from an audience member during a lecture (Schegloff 1980: 144-145). Sifianou (1992: 183), similarly, observes that these questions are not commonly used to precede requests for information in English. Therefore, learners are likely to need L2-specific pragmatic knowledge to be able to include Prefaces on their direct questions in $\mathrm{BI}$ in these routine Asking situations.

A complementary factor is the lack of requisite L2 pragmatic information in the learners' teaching materials. In the learners' main textbook (Johns 1977), they are presented with a number of formal permutations on an appropriate Preface formula, below:

Apa boleh saya bertanya?

Apakah boleh saya bertanya?

Bolehkah saya bertanya?

Boleh saya bertanya?

(Johns 1977: 36) 
INT May I ask (a question)?

INT May I ask (a question)?

May-INT I ask (a question)?

May I ask (a question)?

However, the learners are informed only that "[T]he above examples are all questions, meaning 'May I ask a question?'” (Johns 1977: 36). They are not told that it may be desirable for reasons of politeness to use these forms to preface another question, and they are given no practice in using these forms with Prefacing function: that is, by following one of these questions with another question. In fact the practice activities provided are likely to obscure any possible Prefacing function; for example, a drill involving substitution of pronouns: Apakah boleh mereka bertanya? --> Apakah boleh Tom bertanya?... "May they ask a question?" --> "May Tom ask a question?"... (Johns 1977: 37).

One of the above questions is used as a Preface in a dialogue in the learners' main textbook on two occasions (Johns 1977: 31; 96). However, those are the only instances of contextualised use of these forms, and it would not be surprising if this minimal pragmatic information were insufficient to enable learners to infer that these forms (or very similar ones) are commonly used with Prefacing function in BI discourse.

\subsubsection{Learner-specific features of Grounders}

This section discusses the finding that the learners in these study often create a verbose or overexplicit effect in their Grounders, mainly by including redundant or apparently excessive information, and also by consistently using overt discourse linkers and the overt first person pronoun saya " $\mathrm{I}$ my" (see 6.1.3.1.2).

The primary finding to be discussed, the frequent use of excessive information in Grounders, is consistent with previous research. Verbosity appears to be a characteristic trait of $\mathrm{L} 2$ learners' speech act performance in general, and excessive Grounding of requests, specifically, has been frequently noted in ILP studies (see 1.6.3.3; see also 6.1.4.1). 
Several causes suggested for this feature in previous studies (see 1.6.3.3) are likely to be at work in the case of these Australian learners. They are likely add excessive information in Grounding moves from a concern to make themselves understood, due to lack of confidence in their linguistic ability (cf. Blum-Kulka \& Olshtain 1986; Faerch \& Kasper 1989). They may also do so to assert their linguistic competence; to show that they (unlike beginning learners) are able to produce lengthy utterances (cf. Faerch \& Kasper 1989). They may also add overdo these hearer-supportive moves to demonstrate an intention to be polite, due to a lack of confidence in their social ability in BI (cf. House \& Kasper 1987). In addition, these Australian learners might use excessive Grounding information partly as a form of compensation. They may feel the need to mitigate the potentially brusque effect achieved by their lack of internal modifiers on requests by putting extra effort into externally modifying the request instead. ${ }^{11}$

It is interesting to note that in studies of requests in oral discourse, unlike in written elicitation tasks, learners generally do not use excessive support on requests (cf. Edmondson \& House 1991: 279). For example, Danish learners of English in oral roleplays actually use less support on requests than NS subjects (Trosborg 1995), and German learners of English in oral roleplays in the Bochum study used a similar amount of support on requests to NS subjects (Edmondson \& House 1991: 279). 12

This contrast between findings from oral data and finding from CCSARP studies using written data (the DCT method) can be interpreted in different ways. On the one hand it may be argued (cf. House \& Kasper 1987) that written elicitation tasks simply allow learners to realise their natural need for lengthy supportive moves. In oral discourse, too, learners will experience the same need to justify their requests in a lengthy and explicit way, but may not be able to realise this need, due to "interactional, socio-dynamic, and processing constraints" (House \& Kasper 1987: 1285). 13

On the other hand, it is suggested by Trosborg (1995) that the CCSARP elicitation method creates this need for lengthy supportive moves. Observing, firstly, that in her oral data some learners show a tendency to give all their supportive reasons in their initial request turn, rather than holding some back to use in later turns as native speakers often do; and secondly, that in written discourse completion tasks subjects are forced to make their requests in a single turn only, Trosborg argues that as a 
combined result of these two factors the CCSARP learners may tend to cram every possible supportive reason for their request into the first - and only - turn available (Trosborg 1995: 301).

While the above proposal by Trosborg (1995) is interesting, there may a simpler way in which the CCSARP elicitation method encourages excessive Grounding by learners in requesting. The written cues for CCSARP items appear to contain a good deal of potential Grounding information. It is likely that foreign learners, who tend to rely on the language of written cues provided for tasks in formulating responses (cf. Beebe \& T. Takahashi 1989), and are also likely to have a more anxious, conscientious, 'test-taking' approach to the task than NS subjects, and so wish to show that they have not overlooked anything; tend simply to include more of this information in their response. ${ }^{14} \mathrm{~A}$ comparison of a response by a CCSARP learner with the matching written cue shows the plausibility of this explanation. The CCSARP cue is this:

\section{At a Union Meeting}

The meeting is over. Bob's bus has just left and the next one is not due for an hour. Bob knows that the couple next to him (who he knows by sight only) live in the same street as he does and that they have come by car.

Bob:

Woman: I'm sorry, but we're not going home straight away.

(reproduced in Trosborg 1995: 299)

A response to the cue above by a CCSARP German learner of English, which contains excessive Grounding described as "typical" (House \& Kasper 1987: 1283), is as follows:

Good evening. Perhaps you've already seen me once, we're living in the same street. You know, my bus has just left, and as I noticed that you have come by car I was going to ask you whether you could give me a lift. 
Each piece of information provided as support to the above learner request can be matched to a corresponding piece of information in the above cue ("my bus has just left" with Bob's bus has just left; "we're living in the same street" with the couple... live in the same street; "I noticed that you have come by car" with they have come by car; and "perhaps you've already seen me once" with who he knows by sight only.

It is likely that in the present study as well, the inclusion of potential Grounding information on the written cue cards plays a role in learners' excessive support on requests. The information conveyed in Grounders by both Australian learners and BI NS subjects tends to be that supplied in the written cue instructions for that item, and it seems likely that these learners were more influenced by this written information than the BI native subjects. A comparison of an 'over-supported' request by an Australian learner with the corresponding cue information demonstrates this. The written cue is as follows

You are walking in a park. You feel like a cigarette, but you do not have any matches. There is someone sitting smoking on a bench nearby. Approach them.

[Anda sedang berjalan-jalan di kebun raya. Anda ingin merokok, tetapi tidak mempunyai korek api. Ada seseorang yang duduk di bangku dekat Anda sementara merokok. Dekatilah dia.]

[emphasis added]

The learner's response to this item is below:

182 (asking a stranger in the park for a light)

L: $\quad$.. bolehkah Anda (.) memberikan saya (.) korek api?

L: $\quad$ karena saya lupa korek api saya di rumah saya

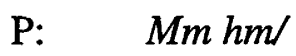

L dan saya mau merokok.

L: $\quad$ May you (.) give me (.) a match? because I forgot my

L: $\quad$ matches in my house

P: $\quad \mathrm{Mm} \mathrm{hm} /$

L: and I want to smoke. 
The two pieces of Grounding information in [182] can be matched to a corresponding piece of information in the above cue. The first piece, saya lupa korek api saya di rumah saya "I forgot my matches in my house", correlates with the cue card information Anda... tidak mempunyai korek api "you don't have any matches". The second piece, saya mau merokok "I want to smoke", correlates closely with the cue information Anda ingin merokok "You feel like a cigarette".

The fact that these Australian learners did not tend to oversupport requests as dramatically as learners in the CCSARP may be partly because this oral roleplay method did not permit for such a strong 'cue card effect' as in the CCSARP study. These Australian learners were not allowed to refer to the written cues while performing the roleplays; that is, while producing the requests; and also tended to be given less potential Grounding information on their written cues (see Appendix E) than CCSARP subjects were given in theirs. So, while oral roleplay studies such as the present study are likely to cut down on a 'cue card effect' in producing excessive support on requests, they may not satisfactorily eliminate it. There appears to be a strong need for natural requesting data by learners, to see if in the absence of any potential supportive information at all in written form, learners do in fact exhibit this feature. 15

In the present study, a proficiency effect on amount of Grounding on requests can be observed. This takes the form of a U-shaped distribution (see 4.2.4) whereby lowest level learners approximate L2 native behaviour, middle proficiency learners diverge from this behaviour, and learners at a high level, once again, approximate native speakers. From the Low group, two of the three learners (Low-1 and Low2) never use excessive supportive moves on any requests. They consistently provide the same amount of Grounding material as BI NS subjects, or on occasions even less. By contrast, the Middle group of learners shows a clear tendency to include excessive or redundant information in Grounders. However, at a higher level still, this feature is not found: neither High learner ever uses excessive grounding on a request.

This finding concurs with previous findings in an important respect. Blum-Kulka and Olshtain (1986) found that, while CCSARP learners of Hebrew in their study generally provided excessive support on requests, the lowest level subjects (lowintermediate proficiency) did not. They tended to eschew verbosity, presumably 
because their linguistic knowledge was very limited, and as a result provided much the same amount of support on requests as $L 2$ native-speakers.

However, Blum-Kulka and Olshtain's (1986) study also yields an interesting difference from the present findings: even advanced learners in that study were found to provide excessive support on requests. Only those learners who had lived in the target culture for some time (5-7 years) managed to approximate L2 natives in their amount of support on requests; advanced learners who had not lived in the target culture did not appear to become 'cured' of their verbosity simply by virtue of high linguistic proficiency. So the present finding that the two High Australian learners (upper-intermediate in proficiency) manage to approximate L2 native subjects in their amount of support on requests is perhaps surprising. A partial explanation may be that the present study (as suggested earlier) does not elicit oversupport on requests as readily as the CCSARP study. Therefore, perhaps only those Australian learners most prone to verbosity will over-support their requests, and this is likely to be the mid-intermediate Middle group, who will be less confident than High learners in their ability to express meaning clearly, and more anxious to mark themselves as distinct from beginning learners. In written DCT tasks, on the other hand, very strong and confident intuitions about L2 requesting norms - derivable only from a long stay in the target culture - may be needed to resist the 'cue card effect'.

Another proficiency-related aspect of the present data is worthy of mention. One of the three Low learners (Low-3) shows strikingly different behaviour to the other two Low learners with respect to length of supportive moves. He is perhaps the worst 'offender' of all learners in the study, frequently creating an inappropriate effect by his Grounding of requests.

This difference between the other two Low learners, and Low-3, seems to correlate with a clear difference in interactional style. Low- 1 and Low-2 are noticeably nervous and withdrawn during the roleplays compared with other subjects, and seem highly conscious of their linguistic shortcomings; they speak very softly, rarely initiate sequences, give brief or sometimes no responses to initiating moves by partners, rarely smile or laugh, and generally seem unhappy and ill-at-ease during interaction. They seem to opt for minimal involvement in order to minimise opportunities for interactional difficulties to arise. However, Low-3 gives a very different impression. Even though he has equally low linguistic ability, it does not seem to disconcert him. He speaks very loudly, often initiates sequences, responds 
at length to initiating moves by the partner, smiles and laughs a lot, and despite his very real communicative difficulties, generally gives an impression of being confident, relaxed and of enjoying himself.

Thus, it appears that due to his unusually high confidence and willingness to take risks in interaction, the subject Low-3 is embarking 'early' on verbose requestsupportive behaviour; that is, at a stage of linguistic proficiency when learners typically do not exhibit this feature. This seems analogous to the 'multidimensional' aspect of the model proposed for acquisition of grammar by learners (cf. Meisal, Clahsen \& Pienemann 1981), in which, although all learners move through the same sequence of ordered developmental stages, individual socialpsychological factors of this kind are crucial in determining how learners move through the stages; for example, how soon they enter a certain stage and how long they remain at it.

Regarding the other overexplicit features of learner Grounders in this study: overt use of discourse linkers and overt first person pronouns; similar findings have been made by other researchers. Overuse of explicit discourse linkers, instead of ellipsis, has been observed in speech acts, including requests, by German learners of English (Edmondson et al 1984). Drastic overuse of overt personal pronouns "you" and " $T$ " has been noted in requests and invitations by Arabic learners of English (Scarcella \& Brunak 1981), overuse of personal pronouns by Australian learners of Mandarin (Charters 1997), and overuse of the pronoun saya "I/my" by US English learners of Indonesian specifically (Margaret DuFon, personal communication).

Certain causes can be suggested for these features. The tendency of learners in general to 'play it safe' with regard to clarity is likely to be compounded by the emphasis in traditional FL teaching on expressing propositional meaning clearly; an emphasis which, as Kasper (1982) suggests, may lead learners to express such meanings too explicitly. And in the case of these Australian learners, the teaching materials themselves contain examples of unnaturally explicit speech act realisation. Their main textbook (Johns 1977) presents model dialogues containing elements likely to be elided in everyday speech, as illustrated in the excerpt below:

Ibu: $\quad$... Engkau mau memasak apa?

Minah: $\quad$ Saya mau memasak telur mata sapi.

(Johns. 1977: 122, emphasis added) 
Mother: What do you want to cook?

Minah: $\quad$ I want to cook fried eggs.

A more appropriate response to the question: Engkau mau memasak apa? "What do you want to cook?" would be Telur mata sapi "Fried eggs". The part of the response underlined above would normally be elided, by virtue of its status as understood information (cf. Sneddon 1996: 368-369). Through exposure to this kind of input, these Australian learners are likely to be deterred from eliding optional elements in their own speech acts, including requests.

Moreover, as Kasper (1982) points out, the classroom interaction patterns of traditional FL instruction necessitates the overt inclusion of elements which would be elided in normal speech. Learners are typically required to respond in complete sentences during drills, in order to practice target structures. For example, these Australian learners would be likely to be required to answer a question beginning Mengapa...? "Why...?" with a response beginning Karena ... "Because...", in class, and as a result, they would learn to include overt discourse linkers of this type (karena "because", sehingga "so" etc) in BI speech acts even when BI native speakers often would not.

\subsubsection{External modification: Summary and conclusion}

Learners and BI NSs show important basic similarities with respect to use of external modifiers. Both groups frequently externally modify their main request type (the QP modal request) and do so using the same main type of supportive move, the Grounder. However, learners also differ importantly from BI NSs in their use of external modifiers. They rarely use Prefaces, and their realisations of Grounders are often problematic; a number of distinctly $\mathbb{L}$-specific pragmatic features making them seem verbose or overexplicit (see 6.1.3.4 for a detailed summary of findings on external modification).

With regard to native-like behaviour by the learners, positive transfer from the L1 appears to play a strong causal role. However, universal pragmatic knowledge may play a decisive role instead. Our uncertainty about the respective importance of L1 knowledge or universal knowledge for selection of Grounders by learners demonstrates how little is known about what pragmatic knowledge is universal. 
The factor of formal simplicity also appears to have an important enabling role in native-like behaviour. The relatively small processing effort involved in producing external modifiers (unlike internal ones) is probably highly important, at least for learners with relatively low linguistic proficiency such as those in the present study.

One key non -native aspect of the learners' behaviour, their lack of polite Prefaces to direct questions, demonstrates the importance for learners of acquiring new L2 pragmatic information. This aspect of their behaviour demonstrates how, even when a feature has the same form and function in the L1 and L2, reliance on L1 pragmatic knowledge may result in non-native pragmatics when the distribution of the feature is different in the two languages.

This non-native aspect of learner behaviour also demonstrates the importance of active communicative practice and explicit pragmatic information for the teaching of pragmatic features which are not transferable from the L1. The fact that the considerable amount of instruction given to the learners about Prefaces on direct questions focused almost entirely on the formal properties of the relevant formulas, and that this instruction did not result in use of this feature by the learners, suggests that they needed instruction which gave them practice in and awareness of the function of this feature within discourse.

Other non-native aspects of the learners' behaviour, overuse of overt discourse linkers and of overt first person pronouns; demonstrate an important negative role for formal instruction. These findings show how a heavy emphasis in teaching materials on expressing propositional meaning, together with instances of actual deviant input, combined with classroom-specific interactional norms which encourage non-native response patterns to questions; may play an important role in producing non-native pragmatic performance.

Another non-native aspect of the learners' behaviour, their tendency to include excessive Grounding information, provides the basis for certain developmental claims. It seems that learners may follow a U-shaped curve of development related to proficiency with regard to this feature; at the same time, it appears that the path learners take through this curve of development may be strongly influenced by individual social-psychological factors. However, the present data also provide some evidence for the contention that this feature is partly an artefact of the 
elicitation method, and thus demonstrate a need for natural data to confirm or disconfirm this finding.

\subsection{Relationship between internal and external modification}

Two different types of modification of requests have been examined, internal (IM) and external (EM), and it is useful to try to discern what the relationship is between the two. As Faerch and Kasper (1989: 241) observe, different relationships are possible between these two types of modification: they may exist in a compensatory relationship, meaning that if one is used the other will not be used; or they may exist in a combinatory relationship, meaning that if one type is used the other will also be used. The three request types whose modification has been examined above (QP modals, imperatives, and direct questions) will be examined from the point of view of a possible relationship between the two types of modifier.

\subsubsection{Relationship between IM and EM of query preparatory modal requests}

For learners, the relationship between IM and EM cannot be systematically examined, for the reason that learners almost never use IM on this request strategy. For BI native speakers, who use both types of modification, there is no clear relationship between the two types. BI NS subjects show much the same propensity to use supportive moves on requests which are internally modified as on those which are not internally modified. When the request is internally modified, BI NSs use external modifiers in a large proportion of instances $(56.8 \%$ or $25 / 44)$. An example is below:

183 (asking a store manager to exchange a shirt bought yesterday]

NS: ... kayaknya (.) saya nggak suka deh warnanya

NS: [=SUPPORTTVE MOVE] (.) bisa diganti nggak Pak

NS: [= INTERNAL MODIFIERS] (.) sama warna lain

NS: $\quad .$. it seems (.) I don't like the colour

NS: [= SUPPORTIVE MOVE (.) can it be changed

NS: (or) not 'father' [=INTERNAL MODIFIERS] (.) for

NS: another colour 
When the request is not internally modified, BI NS subjects use supportive moves in a similar proportion $(66.7 \%$ or $14 / 21)$ of instances. An example from the same situation is [184] below:

184 (asking a store manager to exchange a shirt bought yesterday) NS ... tapi (.) ternyata (.) warnanya (.) saya kurang suka NS: [= SUPPORTIVE MOVE] (.) bisa saya tukar sama warna lain

NS: ... but (.) it turns out (.) I don't really like (.) the colour

NS: [= SUPPORTIVE MOVE] (.) can I change it for another

NS: colour

So, while for learners the relationship between IM and EM on QP modal requests cannot be systematically examined, for BI NSs the two types seem to be used independently of each other. They use both IM and EM frequently, but show no clear preference for using both types together, or for using one type alone.

\subsubsection{Relationship between IM and EM of imperatives}

Learners use internal modification consistently on full imperative requests, regardless of whether they use supportive moves or not. All their requests with supportive moves (5/5) are internally modified; and almost all those without supportive moves (4/5) are also internally modified. In this way, IM seems to be an almost invariable choice, unaffected by the presence or absence of supportive moves.

BI NS subjects use the two types of modifiers on imperatives in the same way as learners. They use IM consistently regardless of whether they use supportive moves. All their requests with supportive moves (11/11) are internally modified; and almost all those without supportive moves (6/8) are also internally modified. Thus, for both groups, the presence of supportive moves does not appear to affect whether IM is used. Internal modification seems a virtually obligatory feature, while EM is an optional one, apparently used partly in response to highly situationspecific features (see 6.1.3.1.4). 


\subsubsection{Relationship between IM and EM of direct questions}

For learners, the relationship between IM and EM once again cannot be systematically examined, as learners almost never use IM on direct questions. For BI native speakers, who use both types of modification, there is no clear relationship between the two types. In direct questions (as in QP modal requests), BI NS subjects show much the same propensity to use supportive moves on head acts which are internally modified as on those which are not. When the direct question is internally modified, BI NSs use supportive moves in a large proportion of instances $(50.0 \%$ or $11 / 24)$. When the direct question is not internally modified, BI NS subjects use supportive moves in a similar proportion $(66.7 \%$ or $6 / 9)$ of instances. Thus, while BI NSs use internal modifiers very frequently, and also use external modifiers frequently, they show no clear preference either for using both types together, or one type alone.

\subsubsection{Relationship between internal and external modification: Summary}

As far as systematic examination of a relationship is feasible, it seems that both groups tend to use the two types of modifier independently of whether the other type is used. On imperative requests, both learners and BI NSs use internal modification as a virtually obligatory choice, irrespective of whether a supportive move is used. On QP modal requests and direct questions, BI NSs use both types of modifier frequently, but show no clear preference for using one type in the presence or absence of the other type. Therefore, for both learners and BI NSs, no evidence exists for a compensatory or a combinatory relationship between the two types of modifier.

\subsection{Alerters on requests}

\subsubsection{Introduction}

One additional component of the request utterance remains to be examined: the Alerter. The Alerter component is perhaps the least important element of the request, and may be regarded in a sense as being outside the request itself (see 
3.2). For simplicity of description, findings about use of Alerters on all requesting strategies will be dealt with together, and summarised only relatively briefly.

\subsubsection{Results}

\subsubsection{Use of Alerters: BI native speakers}

BI NSs use an Alerter on a large majority of their requests (81.3\% or $104 / 128$ instances (see Table 19 below).

Table 19: Proportion of requests by learner and BI native speaker subjects which contain an Alerter*

\begin{tabular}{|l|lc|cc|}
\hline & \multicolumn{2}{|c|}{ Learners } & \multicolumn{2}{c|}{ BI NSs } \\
\hline & $\mathrm{n}$ & $\%$ & $\mathrm{n}$ & 81.3 \\
\hline requests with an Alerter & 128 & 85.9 & 104 & 18.8 \\
\hline $\begin{array}{l}\text { requests without an } \\
\text { Alerter }\end{array}$ & 21 & 14.1 & 24 & 128 \\
\hline Total No of requests & \multicolumn{2}{|c|}{149} & \multicolumn{2}{|c|}{} \\
\hline
\end{tabular}

* Use of Alerters is examined only in those (16) situations where the encounter begins with the request from the speaker; not in situations where participants have already begun interacting when the request is made (for example, when the subject asks a hotel receptionist for a pen, after already asking for a room for the night and being handed the registration form to fill in). This is because in the latter situations the interlocutors are already engaged in conversation at the time the request is made, so the context is a less natural one for the requester to preface the request by attracting the addressee's attention, even metaphorically. Nor is use of Alerters examined in the one situation where subjects are specifically instructed in cue cards to use an Alerter (in calling out to a friend in the street to ask for a lift back to college).

BI NSs used two Alerter formulas frequently. Both formulas contain a kinship term of address. This kinship TOA is almost always one of four kinship TOAs customarily used to modify head acts: (Ba)pak "father", (I)bu "mother", Mas "brother", or Mbak "sister". On two occasions only, a different kinship TOA is used as an Alerter (Bang "older brother" and Dik "younger sibling": see Table 9 for information about these kinship TOAs). 
The most frequently used Alerter formula by BI NSs consists of the greeting Selamat + [time of day] or the entreaty Maaf/ Permisi "Excuse me", modified by a kinship term of address. This type comprises $45.2 \%$ (or 47/104) of Alerters by BI NSs (see Table 20 below). Examples are these:

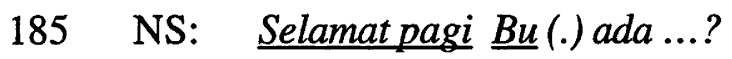

NS: Good morning 'mother' (.) do you have ...?

186 NS: MaafMbak(.) saya mau ...

NS: Excuse me 'sister'(.) I want ...

Table 20: Proportion of Alerters by learner and BI native speaker subjects which consist of each type of formula

\begin{tabular}{|l|cc|cc|}
\hline Type of Alerter formula & \multicolumn{2}{|c|}{ Learners } & \multicolumn{2}{c|}{ BI NSs } \\
\hline $\begin{array}{l}\text { bare kinship TOA } \\
\text { (e.g. Pak "father") }\end{array}$ & $\mathrm{n}$ & 4.7 & 40 & 38.5 \\
\hline $\begin{array}{l}\text { bare greeting/ excuse } \\
\text { formula } \\
\text { (e.g. Selamat pagi "Good } \\
\text { morning") }\end{array}$ & 80 & 62.5 & 17 & 16.3 \\
\hline $\begin{array}{l}\text { Greeting/ excuse formula } \\
\text { + kinship TOA } \\
\text { (e.g. Selamat pagi Pak } \\
\text { "Good morning 'father") }\end{array}$ & 42 & 32.8 & 47 & 45.2 \\
\hline
\end{tabular}

The other frequently used Alerter formula by BI NSs is a 'bare' kinship term of address. This type accounts for over a third (38.5\% or 40/104) of their Alerters (see Table 20 above). An example is this:

187 NS: $\underline{\text { Pak }}($.$) bisa saya ...?$

NS: 'Father' (.) can (I)...? 
This bare kinship TOA is quite often duplicated, for example:

NS: $\quad$ Mas Mas (.) bisa ....?

NS: 'Brother' 'brother' (.) can (I) ...?

Sometimes BI NSs use the Alerter formulas Selamat + [time of day] or Maaf I Permisi "Excuse me" as bare forms; that is, without a kinship term of address ( $16.3 \%$ or $17 / 104$ instances; see Table 20 ). However, the modified forms illustrated in [185] and [186] are much more frequently used.

It is interesting to note that when a BI NS speaker does not use an Alerter on a request, the speaker tends to include a kinship TOA in whatever other component comprises the first unit of that request (head act or supportive move). Examples are these:

189 NS: Uh (.) boleh saya mencoba sepatu ini Pak [= HEAD ACT]

NS: Uh (.) may I try these shoes 'father' [= HEAD ACT]

190 NS: Numpang tanya Mbak [= PREFACE] (.) di mana ya

NS: $\quad$ kantor pos it/(.) yang dekat

NS: May I ask a question 'sister' [=PREFACE] (.) where yes is the post

NS: office/ (.) the one near here

So, in one way or another, BI NSs consistently use a kinship TOA in the first component of their requests.

\subsubsection{Use of Alerters: Learners}

Learners, like BI NSs, use an Alerter on the vast majority of their requests (85.9\% or 128/149: see Table 19 above). They choose two main types of Alerter. The most common type is the 'bare' greeting Selamat + [time of day] or the 'bare' entreaty Maaf "Excuse me". This type comprises a clear majority of Alerters by learners (62.5\% or $80 / 128$ : see Table 20 above). It is illustrated below: 
191

$\begin{array}{ll}\text { L: } & \text { Selamat pagi (.) saya mau ... } \\ \text { L: } & \text { Good morning (.) I want ... }\end{array}$

192
L: $\quad$ Maaf? (.) boleh saya ...?
L: $\quad$ Excuse me? (.) may I ...?

The other main type of Alerter used by learners is considerably less frequent (32.8\% or 42/128 of instances). It consists of Selamat + [time of day] or Maaf "Excuse me", modified by a kinship TOA. In this type of Alerter, the kinship TOA used by learners is almost always $(B a) p a k$ "father" or $(I) b u$ "mother". In one instance a different kinship TOA is used: Sus "sister" (see Table 9 for information about this TOA).

Unlike BI NSs, learners only very occasionally use a 'bare' kinship TOA as an Alerter on requests (4.7\% or $6 / 128$ of instances). So, on the whole, it is clear that learners use kinship TOAs considerably less frequently than BI NSs in Alerters, just as they use them much less frequently as internal modifiers of the head act (see 5.2.1.2).

When learners use a different type of Alerter to those types mentioned above, the Alerter tends to be inappropriate. For example, learners occasionally use the formula Permisi dulu "Excuse me for now" as an Alerter although it is actually a formula for taking leave of someone. Also, learners on several occasions use an inappropriate occupational term of address in an Alerter. An examples is this.

193 (asking a taxi driver to stop for a minute to buy cigarettes)

L: $\quad$ Permisi $*$ Sopir ...

L: $\quad$ Excuse me Driver...

Occupational terms of address in Indonesian are preceded by a kinship term of address (cf. Jenson 1988). Therefore, while the driver can be appropriately

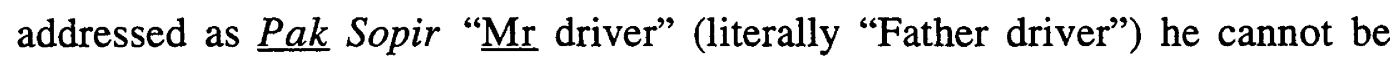
addressed as bare *Sopir "Driver", as in [193] above. Another inappropriate example is this: 
194 (asking a lecturer in class for a copy of last week's handout)
L: $\quad$ Maaf $*$ Guru...
L: $\quad$ Excuse me Teacher...

Occupational terms of address are only used for a restricted set of occupations in Indonesian, and university lecturer is not one of these. Therefore this term of address * Guru "Teacher" in [194] is inappropriate, and would be even if preceded by a kinship term of address (as in *Pak Guru "Mr Teacher"). Instead, the (male) lecturer in this situation should be addressed with a kinship term of address, (Ba)pak "father".

Also, in a couple of instances learners use rather excessive greetings as Alerters. An example is [195]:

195 (buying a ticket at the cinema)

L: $\quad$ Selamat pagi apa kabar(.) saya mau ...

L: $\quad$ Good morning how are you (.) I want ...

The rather effusive greeting to the ticket seller in [195] is somewhat inappropriate for this routine service encounter.

\subsubsection{Use of Alerters on requests: Summary}

Important similarities can be observed in the way that learners and BI NSs use Alerters. The two groups use Alerters with similar frequency, and have one main Alerter type in common. Morever, learners generally create an acceptable pragmatic effect through their Alerters, only occasionally using a form which is inappropriate. However, an important difference in use of Alerters is also evident. This is the fact that Alerters by learners contain or consist of a kinship term of address considerably less frequently than those of BI NSs. 


\subsubsection{4 'Scattering' of kinship TOAs by BI native speakers}

This is a suitable point at which to mention a difference between learner and BI NS requests which relates to all the request components examined so far. We have seen that BI NSs use kinship TOAs more frequently than learners do in all components of the request. Sometimes this feature has a powerful cumulative effect on the requests of BI NS subjects, who 'scatter' respectful kinship terms of address throughout the request, to modify various components. This conveys an impression of considerable effort by the speaker to make the request more polite. Two examples are below:

196 (asking a lecturer for an extension on an essay deadline)

NS: $\quad$ Selamat sore $\underline{B u}$ (.) uh (.) ini $\underline{B u}$ (.) saya mau (.) apa (.)

NS: saya sebetulnya kan harus memberi (.) tuh (.) uh (.)

NS: $\quad$ esainya harus di(.)kasih minggu depan $\underline{B u}$

P: $\quad Y a$ ?

NS: $\quad$ tapi saya nggak ini nggak bisa nyelesaiin deh $\underline{B u}$ (.) apa

NS: (.) bisa (.) di(.) diberi kelonggaran gitu $\underline{\mathrm{Bu}}$ ?

NS: Good afternoon 'mother' (.) uh (.) this 'mother' (.) I want

NS: (.) um (.) actually I have to give (.) that (.) uh (.) the

NS: essay has to be handed in next week 'mother.'

P: Yes?

NS: but I can't uh can't finish it 'mother' (.) can (.) I be (.) gi/

NS: given an extension 'mother'?

182 ("essay extension" situation above)

NS: $\quad$ Siang $\underline{\text { Pak }}$

P: $\quad$ Siang

NS: Uum (.) ini Pak (.) mengenai (.) esai (.) Kebudayaan

NS: Jawa itu Pak (.) [um

P: $\quad($ )]

NS: sepertinya saya bi/ (.) saya tidak mampu (.)

NS: menyelesaikannya hari ini Pak (.) kalau seandainya

NS: $\quad$ saya minta diperpanjang sampai hari (.) Sabtu bisa 
NS: Morning 'father'

P: $\quad$ Morning

NS: Uum (.) this 'father' (.) about (.) the essay (.) on Javanese

NS: Culture 'father' (.) [um

P: $\quad($ )]

NS: it looks like I can/ (.) I'm not able (.) to finish it today

NS: 'father' (.) if supposing I ask for it to be extended until (.)

NS: Saturday can it.

BI NSs tend to 'scatter' respectful kinship TOAs in this way when making requests to a hearer of relatively high status. It is a striking feature of their requests in three situations: asking a university lecturer for a copy of last week's handout, asking a lecturer for an essay extension, and asking a police officer where they should go to report their lost passport. Learners, however, never display this feature in their requests.

\subsubsection{Discussion}

In this section, important findings on use of Alerters are selected and discussed.

\subsubsection{Frequency of native-like Alerters by learners}

This section discusses the finding that learners regularly include an Alerter element in situations where BI NSs do, and that the basic formulas of these Alerters are native-like choices: Selamat + [time of day] and Maaf "Excuse me" (see 6.3.2.2).

Transfer of Ll pragmatic knowledge is likely to be important in enabling these learners to produce appropriate Alerters in their requests. English has a close equivalent for both of the common BI Alerter formulas above: the English greeting "Good + [time of day]" is a close formal, semantic and functional equivalent to the BI greeting Selamat + [time of day], and the English entreaty "Excuse me" is a close semantic and functional equivalent to the BI element Maaf. So a good deal of L1 pragmatic knowledge about Alerters can potentially be transferred to the L2. 
A similar finding by Harlow (1990) seems to support this claim for a strong L1 role. Her US English learners of French use Alerters on requests with much the same frequency and in the same situations as L2 natives, and, apparently, also use the same formulas as L2 natives: Excusez-moi or Pardon "Excuse me". It seems significant that these L2 Alerter formulas used so appropriately by Harlow's learners have a close equivalent in the $\mathrm{L} 1$ of these learners, in the form of the Alerter "Excuse me".

Formal instruction is also likely to play an important role in this feature of the learners' requests. The learners are given explicit pragmatic information about both the main Alerter formulas they use in "Cultural notes" in their main textbook (Johns 1977). They are told that the element Selamat + [time of day] is a greeting, and that its use is adapted from European usage; and that the element Maaf means "Excuse me," and that it is used when asking to be excused for imposing on someone (Johns 1977: 45-46). They are also exposed to examples of both formulas used with Alerter function in dialogues at various points in the textbook (and given limited practice in producing the two formulas with Alerter function, in the form of mini-dialogues to be rote-learned and performed aloud (Johns 1977: 58)). This information may form the basis of IL-specific knowledge about the function and distribution of these elements, or alert the learners to the fact that their L1 knowledge may be drawn upon successfully, or both.

While the fact that these learners have the requisite pragmatic knowledge to use these L2 Alerter elements can be explained by the factors above, the fact that they can actually use these elements on their requests in oral discourse, with its sociodynamic and processing constraints, is also worth discussing.

While two of the Low learners occasionally appear to omit Alerters inappropriately, generally all the learners, including the Low group, include an Alerter element when it is appropriate to do so. This suggests that the inclusion of an Alerter component on speech acts demands minimal processing effort for L2 learners. The likely reasons for this are twofold. Firstly, Alerters are formulaic in nature, so that they will require a minimum of verbal planning. Secondly, Alerters are, in a sense, separate from the 'real' request components that follow, and hence can probably be planned and even executed largely independently of these components, so their inclusion in the request will not cause processing overload for learners. Scarcella and Brunak (1981), in fact, find that even beginner Arabic learners of English 
manage quite regularly to include an Alerter component (a greeting) on their invitations and requests in spoken interaction. They conclude that the greeting may be a politeness feature that is acquired very early; it appears from the present data that this is probably true of Alerters in general.

\subsubsection{Frequency of kinship TOAs on Alerters by learners}

This section discusses the finding that learners in this study, unlike BI NSs, rarely use a bare kinship TOA (e.g. Pak "father") as an Alerter, and frequently do not include a kinship TOA on their main Alerter formulas of Selamat + [time of day] and Maaf "Excuse me" (see 6.3.2.2).

An important factor is that these learners cannot draw on $\mathrm{L} 1$ pragmatic knowledge to produce kinship TOAs in the L2 (see 5.3.1). Not only are the literal English semantic equivalents such as "Father" and "Mother" not used with Alerter function, but English TOAs such as "Sir" and "Madam" have highly restricted currency in Australian English (see 5.3.1), so they, too, are unlikely to be used in Alerters in these role play situations.

Again, Harlow's (1990) study seems to confirm the importance of the L1. While her US English speaking learners of French regularly used Alerters on requests, consisting of elements transferable from the L1, they - unlike L2 native speaker subjects - generally did not include a respectful term of address, such as Monsieur "Sir" (apparently either in Alerters or as internal modifiers).

It is interesting that these Australian learners sometimes, at least, use kinship TOAs in Alerters, while they never use them in the request head act. Two factors are likely to be crucial in explaining this difference. One is the fact that (as mentioned above) the 'head act' of an Alerter, unlike the head act proper, is a purely formulaic chunk (e.g. Maaf "Excuse me" or Selamat pagi "Good morning"), and so is likely to entail little or no verbal planning itself. As a result it will require miminal processing effort to produce, so the attention of the learner is 'freed up' to be concentrated on the addition of modifiers.

A second factor is that the learners receive considerably more instruction in the use of kinship TOAs on Alerters than on head acts. Learners are not exposed in their main textbook (Johns 1977) to any examples of head acts modified by kinship 
TOAs, but they are exposed to numerous instances of Alerters modified by this feature. For example, when the greeting Selamat + [time of day] is used in illustrative dialogues, it always occurs with an attached kinship TOA or given name (e.g. Selamat Pagi Bu "Good morning 'ㅆmother"” or Selamat Pagi Tom "Good morning Tom").

However, the attention of these learners is never explicitly directed in their teaching materials to the use of the kinship TOA on Alerters. And all groups of learners in the present study, including the High group, use Alerters with kinship TOAs considerably less frequently than BI native speakers. ${ }^{16}$ So it seems that even relatively advanced learners may not successfully acquire L2-specific Alerter forms without more systematic pragmatic instruction, involving active communicative practice and possibly metapragmatic information (see 7.4).

\subsubsection{Alerters: Summary and conclusion}

Important similarities can be observed in the way that learners and BI NSs use Alerters. The two groups add an Alerter element to requests with similar frequency, and also favour some of the same main types of Alerter. Morever, learners are generally able to use this element to create an acceptable pragmatic effect, only occasionally using a form which is inappropriate. However, one striking difference is that learners use Alerters that contain or consist of a kinship term of address considerably less frequently than BI NSs do. This underuse of kinship TOAs compared to BI NSs may also be regarded as a feature of requests by these learners more broadly.

The essentially native-like behaviour of the learners with respect to Alerters suggests an important role for positive transfer from the L1. It also suggests that quite minimal pragmatic instruction may be adequate in the case of features which are transferable from the $\mathrm{L} 1$. When a feature has the same form, function and distribution in the L1 and the L2 (e.g. the greeting Selamat + [time of day]), it may be enough to show learners that the feature does exist in the L2; after which they may successfully allow L1 pragmatic knowledge to 'take over'. The native-like inclusion of Alerters on requests by these learners also has implications for development of pragmatic competence, confirming the likelihood that this speech act component is acquired early by $\mathrm{L} 2$ learners. 
The non-native aspect of Alerter use by these learners, on the other hand, demonstrates a need for more explicit instruction - involving explicit information and active communicative practice - in pragmatic features which are not transferable from the L1. It appears that learners may need this type of instruction in the use of kinship TOAs on Alerters if they are to use this feature with comparable frequency to $\mathrm{BI}$ native speakers. 


\section{4 Notes to Chapter 6}

1 The classification of external modifiers used in the present paper is based on that of the CCSARP project (cf. Blum-Kulka et al 1989; CCSARP 1989), with certain adaptations. The CCSARP classification is in turn derived from the work of House and Kasper (1981), Edmondson (1981), and Edmondson and House (1981).

2 Blum-Kulka and Olshtain (1984: 210ff) prefer to call external modifiers 'adjuncts' rather than 'supportive moves', for the reason that these moves need not be hearer -supportive; they may aggravate the force of an FTA rather than mitigate it. However, elsewhere in the CCSARP literature (e.g. CCSARP 1989: 287), the term 'supportive move' is used to encompass both mitigating and aggravating external modifiers.

3 The notion of a Grounder is used broadly in the present study. It does not only refer to supportive reasons, strictly speaking, but also encompasses the type of move which House (1996; following Edmondson \& House 1981) calls an Expander; in which "the speaker ...gives more details than required about the state of affairs raised in the main move, whenever these details are deemed to increase the likelihood of the interlocutor's fulfilling the speaker's intent" (House 1996: 234).

4 cf. the supportive move of 'Preparator' in the CCSARP project (CCSARP 1989: 287).

5 House and Kasper (1981: 168) and Edmondson (1981: 155) propose a similar function for a type of gambit which they call the 'Cajoler.'

6 This analysis is based on Keller's (1981) identification of two possible functions of gambits in discourse: to signal "social context"; in the present case, by signalling that the speaker wants to be an active participant by taking a turn at speech, and to signal "semantic framing"; in this case, by signalling that the following message will be an account of a problem.

${ }^{7}$ I owe this observation to Emmy Oey (personal communication).

8 Questions of this kind (e.g. Numpang tanya? "May I ask a question?") are pre-requests. However, as Sifianou points out, "such pre-requests have become conventionalised and sometimes do not constitute a separate move on the part of the speaker that entails a response from the addressee" (Sifianou 1992: 183). 
${ }^{9}$ Some of this planning may in fact occur simultaneously with planning of head act constituents: see Levelt (1989: 24-25) on simultaneous processing of constituents in speech production.

10 Schegloff (1980) observes that questions of the type "Can I ask you a question?" are often used with a different function in English; as a preliminary to a speech act which is not a question at all. In such cases, these questions are regarded as "preliminaries to preliminaries" (Schegloff 1980: 116).

11 A similar 'compensatory' explanation for excessive use of Grounders by learners is proposed by Edmondson and House (1991: 284).

12 However, Rintell and Mitchell (1989) find (low advanced level, mixed nationality) learners of English to use more, and lengthier, supportive moves when making requests orally than when making the same requests in writing.

13 Bergman and Kasper (1993: 101), similarly, suggest that the verbose realisations of apologies produced by learners in DCT tasks are because the written elicitation method allows them to "waffle" in this way.

14 The tendency of CCSARP learners to include information from DCT cues in their responses is remarked on briefly by Blum-Kulka and Olshtain (1986) as a cause of these learners' verbosity in supporting speech acts. Blum-Kulka and Olshtain regard it as akin to learners' tendency to incorporate part of an interlocutor's previous move into their response (cf. Edmondson et al 1984), suggesting that both traits reflect a need for "contextual explicitness" (Blum-Kulka \& Olshtain 1986: 176).

15 An interesting piece of support for the notion that written cues are instrumental in eliciting Grounders is provided by Sifianou (1992: 185-186). She included potential Grounding information in the written cue for a request item for one set of subjects, but inadvertently omitted this information in the written cue for the same request item for another set of subjects. A number of the former group of subjects used Grounders on this item, consisting of the cue information supplied, while none of the latter group used Grounders at all. Siafanou (1992) suggests that the difference in the written cues accounts for the difference in Grounding behaviour on this item. 
16 A useful parallel can be observed in thanking by these learners (cf. Hassall 1996). They sometimes use kinship TOAs to modify the thanking head act (as with the Alerter head act), but do so considerably less frequently than BI NSs (as with Alerters). The probable causes are the same in both cases. The thanking head act (as with the Alerter head act) is a formulaic chunk (Terima kasih "Thank you"), requiring minimal processing effort to produce. The use of kinship TOAs on thanks (as on Alerters) is frequently modelled in dialogues in the learners' main textbook (e.g. Terima kasih $\underline{B u}$ "Thank you 'mother"'). Lastly, the use of kinship TOAs on thanks (as on Alerters) is never explicitly brought to the attention of the learners. 


\section{CHAPTER 7. CONCLUSION}

\subsection{Summary of findings}

This study reveals important similarities and differences in the requesting behaviour of Australian learner subjects and BI native speaker subjects.

In choice of head act strategy, the two groups exhibit important similarities and differences. Learners, like BI NSs, use mostly CI requests, in the form of the same sub-strategy: the QP modal request. However, the two groups generally select a different modal verb to realise this sub-strategy. Both groups use direct requests frequently. However, learners use a certain direct sub-strategy (the Want statement) a lot more frequently than BI NSs, and another direct sub-strategy (the imperative) a lot less frequently, as well as virtually never using several other direct request types which BI NSs sometimes use. Learners also use considerably more hints than BI NSs, especially statement hints.

Concerning situational variation in choice of strategy, learners show close similarities to BI NSs in their sensitivity to social variables, particularly in their use of the imperative and QP modal strategies; and consistently manage to choose a strategy that is acceptable for the situation.

However, learners do not manage so successfully to choose an appropriate strategy when their ability to do so depends on responsiveness to development of the discourse; specifically, on successful orientation to the interlocutor's previous contribution. In these cases, learners sometimes choose a strategy which (although inherently acceptable in terms of social variables) is not appropriate at that particular point, given the development of the interaction.

With regard to another main dimension of the head act, choice of perspective, learners show similarities with BI NSs as well as one major difference. In QP modal requests they favour the same perspective as BI NSs (speaker perspective). However, they use impersonal perspective less frequently than BI NSs for this sub-strategy, and in imperatives this contrast is more stark: learners never use impersonal perspective while BI NSs use it in a very high proportion of requests.

Learners have considerable difficulty in realising different head act types appropriately. They tend to express the goal of requests in highly unidiomatic and sometimes unclear ways. In addition, when they do not succeed initially in 
conveying the request goal clearly, they have trouble in clarifying the nature of the request goal in cooperation with the interlocutor. Moreover, they frequently use an inappropriate second person pronoun, and use markedly non-native intonation on a number of request types.

Follow-up 'requests' yield additional findings which confirm the picture provided by the main data. For these requests, too, learners use Want statements frequently while BI NSs prefer elided imperatives and Goal statements instead. And in performing these follow-up requests, as well, learners display a lack of sensitivity to interactional constraints. They do this by performing them with the same substrategy they use for the main request, while BI NSs select different sub-strategies for the two utterances.

With regard to internal modification, learner behaviour is very different from that of BI NSs. Learners generally use much less internal modification than BI NSs. On both the main request sub-strategy (QP modal) and the main Asking sub-strategy (direct question) IM is the norm for BI NS subjects, but the rare exception for learners. Only on imperatives do learners use IM with comparable frequency to BI NSs, and even on this request type, learners use much less compound internal modification than NSs do.

Learners also show striking differences in type of internal modifiers. In QP modal requests, the main BI NS modifiers are not used by learners at all; and in imperatives, learners favour a modifier which is never used by BI NSs (-lah).

With respect to the use of external modifiers, learners and BI NSs show some important similarities. Both groups frequently externally modify their main request type, the QP modal request, and do so using the same main type of supportive move: the Grounder. In addition, learners and BI NSs show close similarities in their choice of whether or not to use Grounders according to the situation, in all sub-strategies examined,

However, learners also differ importantly from BI NSs in their use of external modifiers. Firstly, unlike BI NSs, learners rarely use any type of supportive move other than Grounders. Most notably they rarely use Prefaces, which makes their pattern of external modification of direct questions, especially, strikingly different from that of BI NSs. Secondly, their realisation of their main move, the Grounder, is often problematic. A number of distinctly IL-specific pragmatic features (inclusion of excessive information, and overuse of overt discourse linkers and 
overt first person pronouns) makes many of their Grounders seem verbose or overexplicit.

With regard to Alerters, important similarities can be observed between learner and BI NS behaviour. The two groups use Alerters with similar frequency, and have main Alerter formulas in common (the formula Selamat + [time of day] and Maaf "Excuse me"). Morever, learners generally create an acceptable pragmatic effect through their Alerters, only occasionally using a form which is inappropriate. However, an important difference in the use of Alerters is also evident. This is the fact that the Alerters used by learners contain or consist of a kinship term of address considerably less frequently than those of BI NSs. This underuse of kinship TOAs by learners can also be regarded as a feature of their requests more broadly.

\subsection{Causes of learner pragmatic behaviour}

The requesting behaviour of these learner subjects has a number of implications for the causes of ILP behaviour. Most obviously, it confirms the contention (cf. Kasper 1992; S. Takahashi 1996) that a pluricausal explanation for ILP phenomena is the most convincing one. More than one causal factor can regularly be assigned to features of these learners' requests.

This study suggests an important role for certain factors in particular. It provides evidence that the simplicity or complexity of pragmalinguistic structures is an important determinant of learner pragmatic choices. The importance of formal simplicity as an enabling factor is suggested by the strong preference of these learners for QP request forms, and for direct questions in asking for information; and the ability to regularly include an Alerter element on their requests. The importance of formal complexity as a constraining factor is suggested by the infrequency with which they use indirect question forms to ask for information, their underuse of imperatives, and their non-use of impersonal imperatives in particular.

This factor of formal complexity is likely to be decisive in two main respects: it may make certain aspects of the pragmalinguistic input not salient enough to be noticed by the learners at their stage of grammatical competence, and hence, unable to be acquired (cf. Schmidt 1993); it may also mean that learners are unable to form stable representations of grammatical knowledge because the structure entails 
formal operations which at their stage of linguistic proficiency demand more processing capacity than is available to them (see 1.6.4).

This factor tends not to be identified as a major influence on learners' pragmatic choices in ILP studies; perhaps because the learner subjects in many studies have already reached a relatively advanced level of linguistic proficiency so that their pragmalinguistic competence is no longer severely curtailed by their grammatical competence. However, the present study suggests that for learners of intermediate linguistic ability, at least, grammatical proficiency is an important determinant of pragmalinguistic choices.

The processing effort required to produce complex pragmalinguistic structures is likely to be a major reason for an important feature of L2 requests generally, and confirmed in the present study: a tendency for learners to underuse internal modifiers (see 5.2), while using external modifiers frequently (see 6.3.1). Adding internal modifiers (of the lexical/phrasal kind) to a head act will tend to increase the structural complexity of the head act form, so that the modified head act requires increased processing capacity to produce. The contention that the processing effort required to add internal modifiers is an important reason for their underuse by learners is supported by the finding that the enclitic -lah is the one modifier which these Australian learners do regularly use - and that to add this modifier, due to its particular formal properties, very little processing effort is likely to be required (see 5.3.2).

The addition of external modifiers, unlike internal ones, can be expected not to increase the complexity of head act structures. This is because utterances tend to be verbally planned in small constituents, such as a noun or verb phrase or short clause (cf. Clark \& Clark 1977: 248, 260); so that supportive moves - which occur outside the head act - will tend to be planned in separate constituents to the head act (see 6.1.4.1). Therefore, increased processing complexity is likely to be an important obstacle to the addition by learners of internal modifiers but not of external ones.

This study also points to an important role in learner pragmatic behaviour for positive transfer from the $\mathrm{L} 1$. This factor tends to receive little attention in ILP studies (cf. Kasper 1992); however, it appears to be a major cause of a number of important features of requesting behaviour by these Australian learners. Their native-like selection of the $\mathrm{QP}$ request type as their main request strategy is probably largely explicable by transfer of L1 knowledge about the high frequency 
and the appropriacy in a wide range of contexts of this request type in English (see 4.2.2). The regular inclusion of Alerters, consisting of a native-like formula, on requests by these learners, also points to an important role for $\mathrm{L} 1 \mathrm{knowledge}$. The fact that these learners appropriately use two Alerter formulas, both of which have a common functional equivalent in the $\mathrm{L} 1$ (see 6.3.3.1,) suggests that their nativelike behaviour with respect to this feature is greatly facilitated by transfer of L1 knowledge.

At least two other important native-like features of requests by these Australian learners can largely be attributed to either L1 knowledge, or universal knowledge, or both. Their selection of a Grounder as their main type of supportive move on requests can plausibly be attributed to either knowledge source (see 6.1.4.1). Their ability to vary request strategies appropriately by situation seems attributable largely to transfer of L1 knowledge about the appropriacy or non-appropriacy of given request types in given contexts; however, at least one element of this ability, their native-like sensitivity to the factor of urgency in selecting imperatives, could be due to either L1 knowledge or universal knowledge (see 4.2.8). And in fact, in light of CCSARP findings (Blum-Kulka \& House 1989) that native speakers of a number of languages vary their choice of request strategy in similar ways, it appears that a large amount of knowledge about situational variation in strategy choice may be universal.

So, it appears that while positive L1 transfer plays a major role in shaping learner's pragmatic behaviour, universal pragmatic knowledge may as well. The difficulty of knowing which of the two knowledge sources is important for certain features of these Australian learners' behaviour demonstrates Kasper's (1992) observation that little is known about how much and what type of pragmatic knowledge is universal.

This study also highlights the powerful potential negative influence of formal instruction in causing non-native pragmatic behaviour. This is consistent with the claim in the Bochum study that instruction was an important cause for a large proportion of $\mathrm{L}$-specific features in the pragmatics of advanced German learners of English (cf. Kasper 1982), and confirms the likelihood that the nature of the instruction received by FL learners may be a major reason for non-native aspects of their pragmatic behaviour.

The present study confirms the claim (cf. Kasper 1982) that a powerful negative influence may be exerted by both primary and secondary induction from teaching 
materials. The influence of primary induction (i.e. from deviant input) is suggested by the strong preference of these Australian learners for the non-native modifier -lah on imperatives, in the light of the input they received on this feature in their main textbook (Johns 1977) (see 5.3.2). The marked overuse by these learners of Want statements in service encounters is also suggestive of this effect, in view of the unnatural frequency with which Want statements occur in illustrative dialogues in the learners' main textbook (Johns 1977: see 4.2.5).

The powerful negative effect of secondary induction (i.e. on the basis of correct input) from teaching materials is clearly suggested by the strong preference of these Australian learners for the less common BI NS choice of modal verb in QP requests: boleh "may/ be allowed" rather than bisa "can"; as these two modal verbs are presented contrastively in their main textbook (Johns 1977) in a way that implies that bisa "can" is not used to make requests (see 4.2.3). This study, then, supports the contention that both primary and secondary teaching induction are likely to be powerful factors in shaping the pragmatic behaviour of FL learners.

This study also confirms the likely negative role of an aspect of instruction other than teaching materials; namely, the classroom-specific interactional norms of traditional FL teaching. The finding that these Australian learners use rising intonation on a number of non-interrogative request forms, both at the end of utterances and within individual segments, together with the fact they received traditional teacher-centred FL instruction; support Kasper's (1982) contention that this feature (which she observed for German learners of English) is likely to be due to the question- response- feedback patterns typical of traditional classroom interaction. The presence of this finding in the speech act behaviour of these traditionally taught Australian learners, too, suggests that this feature may tend to be a characteristic pragmatic feature of FL learners and that the interactional norms of the traditional language classroom may indeed be a major cause for it.

The potential negative influence of L2 instruction is also suggested by the consistent use of overt discourse linkers and of overt personal pronouns by these Australian learners when BI NSs would tend to elide these features (see 6.1.3.1.2). A number of aspects of the instruction received by these learners may well have contributed to these features: the inclusion in their materials of examples of unnaturally explicit speech act realisation, a strong general emphasis in their materials on conveying propositional meaning clearly, and the interactional norm of the traditional FL classroom whereby learners are required to include in their responses elements which would normally be elided in speech (see 6.1.4.3). 
Learners in a number of other ILP studies, too, have been found to use overt discourse-linkers and personal pronouns in their L2 speech acts more than native speakers (see 6.1.4.3). The fact that these Australian learners do so supports the likelihood that these features will characterise learner pragmatics across a range of first and target languages; and in view of the type of L2 instruction these Australian learners have received, also supports the notion that formal instruction may be an important cause of these features.

The present study also provides support for the importance of one socialpsychological factor in shaping L2 pragmatic behaviour: uncertainty by learners about their ability to convey meaning clearly, manifested in a tendency to 'play it safe' by using a lot of words to realise speech acts, and to choose "explicit, transparent, unambiguous means of expression" (Faerch \& Kasper 1989: 245). A number of features of the requests by these Australian learners are probably influenced by this uncertainty about linguistic competence. One is the marked overuse of Want statements - a sub-strategy likely to appeal to learners because of its clarity and explicitness (cf. Koike 1989). Another is the marked underuse of elided imperatives, a sub-strategy which is likely to be perceived by learners as 'risky' because of its extreme brevity and elliptical nature. The tendency of these learners to include excessive information in requests, especially in supportive moves, but also in head acts (see 6.1.4.3); also appears to demonstrate this psychological need to opt for means of expression which are lengthy, explicit and transparent.

Not all studies support the claim of Faerch and Kasper (1989) that intermediate learners 'play it safe' by means of lengthy speech act realisations. Trosborg (1995: 432-433) finds no evidence of this tendency in the performance of various speech acts by Danish learners of English, and suggests that these findings cast some doubt on the claim that this tendency is a universal strategy of intermediate language learners. However, the present study supports the contention that 'playing it safe' due to uncertainty about linguistic competence may indeed be a major feature of learner pragmatic behaviour at intermediate level. 


\subsection{Development of pragmatic competence}

The study has certain implications for our understanding of the development of ILP competence generally. Firstly, it supports the theoretical processing model of pragmatic acquisition proposed by Bialystok (1993) (see 1.6.4). The important role for successful transfer of L1 pragmatic knowledge and/ or reliance on universal pragmatic knowledge in BI requesting by these Australian learners (discussed above) supports Bialystok's (1993) claim that for adult L2 learners, the task of forming representations of pragmatic knowledge is already largely accomplished, such that the most important task facing them is the development of control over attention in selecting knowledge when appropriate.

However, the present study also demonstrates that the task of learning new L2 pragmatic knowledge may itself be a substantial one for adult learners. A considerable amount of knowledge needed for native-like requesting behaviour is not available to these Australian learners from either L1 or universal pragmatic knowledge. This includes knowledge of the pragmalinguistic forms, or the distributional frequency, or both, of several direct request types (see 4.2.6) and of the main BI NS internal modifiers (see 5.3.1); as well as knowledge of the distributional frequency of Prefacing moves before direct questions (see 6.1.4.2) - all features which these learners underuse. This suggests that, as Bialystok (1993) acknowledges in her model, learners still have a certain amount of acquiring of new pragmatic knowledge to do.

This study also has implications for the likely relevance of the 'complexification hypothesis' (cf. Clahsen 1984) for the development of pragmatic competence. The apparent tendency for these learners to select pragmatic features which entail the use of structurally simple forms, and to eschew those which entail the use of structurally complex ones (discussed above), supports Trosborg's (1995) proposal that learners are likely to acquire pragmalinguistic structures in a sequence determined by their relative grammatical complexity (see 1.6.4). Thus, while grammatical competence is not in itself sufficient for pragmatic competence (cf. Bardovi-Harlig \& Hartford 1996), it is likely to greatly constrain the development of pragmatic competence, such that the 'complexification hypothesis' will have considerable explanatory power for ILP acquisition as well.

The present study supports a finding by Trosborg (1995) which (as she points out) confirms the likely relevance of the complexification hypothesis for L2 pragmatic 
acquisition: the finding that learners are increasingly able to add modifiers to speech acts as their control over the head act itself increases (Trosborg 1995: 430). These Australian learners add internal modifiers, in the form of kinship TOAs, to a relatively large number of Alerter 'head acts' (i.e. to the formulas Selamat + [time of day] and Maaf "Excuse me"), but virtually never add internal modifiers to a head act proper (e.g. to a QP request form or to a direct question). Part of the reason is likely to be that these Alerter 'head acts' are formulaic chunks which require little or no verbal planning and hence minimal processing effort to produce; while the main head acts, being more formally complex, demand considerably more processing capacity (see 6.3.3.2). This suggests a likely path in acquisition of the ability to internally modify L2 speech acts with lexical/ phrasal modifiers (which, as Trosborg (1995: 429) observes, are the type especially likely to require processing effort): learners will be able to use a given pragmalinguistic formula in its 'bare' form before they are able to use it with modifiers, and will be able to add modifiers to structurally simple pragmalinguistic formulas while they are still only able to use more complex formulas in their 'bare' form.

This study also demonstrates how another aspect of models of grammar acquisition can usefully be applied to the understanding of the development of pragmatics; namely, the multi-dimensional aspect of the model of Meisal, Clahsen and Pienemann (1981), whereby individual psychological factors influence the course of a learner through a sequence of ordered developmental stages. Comparison of the amount of support provided on requests by one Low learner (L-3), and other Low learners, in the light of the strikingly different interactional style of this Low learner ( $\mathrm{L}-3$ ) from the others, indicate how individual factors relating to confidence and 'risk-taking' orientation can cause a learner to embark 'early' on oversupportive behaviour, that is, at a level of linguistic proficiency at which learners would not normally display this feature (see 6.1.4.3).

This study also has implications for the role of grammatical proficiency in acquiring a particular type of pragmatic feature: those closely related to skill in conversational management. The fact that the Low group of learners show strikingly non-native performance with regard to these features, while the High group is much more native-like (see 4.2.10), suggests that learners' difficulties in this respect may largely be the result of processing overload during face-to-face interaction due to limited linguistic proficiency. This helps to put into perspective the findings in previous studies that advanced learners also have serious discourse-related pragmatic difficulties (see 1.6.3.3), and share some with these Australian learners: a tendency to select an inappropriate strategy when in a responding role 
(Edmondson et al 1984; House 1996), and to create a mechanical effect by repeating the same request strategy regardless of the stage of the interaction (Trosborg 1995). It suggests that we can probably reject the notion that increased linguistic proficiency has failed to bring about a significant improvement in such discourse-related aspects of requesting by those advanced learners, instead, they are probably much more competent at such discourse- management aspects of pragmatics than they were at a lower proficiency level by virtue of the reduced processing load which increased proficiency has brought about (see 4.2.10).

The present data contribute to understanding of one facet of the relationship between development of lingustic proficiency and pragmatic transfer. The High group of Australian learners in this study almost never select the modal verb bisa "can" in QP modal requests, while the Low group nearly always select this modal verb (see 4.2.3). This appears to confirm Kasper's (1995a) claim that learners at a high level of proficiency sometimes resist transferring a pragmatic feature which can be transferred (in this case the modal verb "can"), due to overcaution, while less proficient learners successfully transfer the same feature. A likely explanation can be suggested for this phenomenon, in the light of research about perceptions of transferability by learners (S. Takahashi 1996) and about the processes involved in acquiring pragmatic competence (Bialystok, 1993). High and low proficiency learners are likely to have similar knowledge about the likely non-transferability of the feature, but high level learners will be more able to attend to this knowledge while planning their speech acts because they are not under such a heavy processing load from the interactional demands of $\mathrm{L} 2$ discourse (see 4.2.3).

The present study also sheds some light on the likely earliness or lateness of acquisition of a number of individual pragmatic features.

With regard to Alerters, the present data confirms previous findings (Scarcella \& Brunak 1981; Harlow 1990) that learners regularly include these elements on L2 speech acts. The finding that even the Low group of learners uses Alerters regularly on their BI requests lends support to Scarcella and Brunak's (1981) contention that greetings are likely to be a politeness feature acquired very early, and suggests that this is likely to be true of Alerters more broadly (see 6.3.3.1).

Regarding Want statements, the finding that all members of the Low group use this request type heavily (especially the subject $L-2$, for whom it is the main request type); while the High group does not use it at all, confirms previous findings (Scarcella \& Brunak 1981; Trosborg 1995) that learners at lower levels of 
proficiency use this request type more than those at higher levels. These findings also support Scarcella and Brunak's (1981) assertion that Want statements may well be one of the first types of request forms to emerge in L2 pragmatic acquisition (see 4.2.5).

Regarding the elided imperative sub-strategy, the present finding that the only instances of this request type in the learner data are produced by the two High learners suggests the likelihood of a U-shaped curve of development (cf. Strauss 1982; Kellerman 1983) in the acquisition of this sub-strategy. Learners are likely to rely on this request type at beginner level (cf. Ellis 1992), because of their extremely limited linguistic competence; to eschew it at intermediate level, due to uncertainty about their ability to convey their meaning successfully with such a brief and elided form; and to use it again at a high level of proficiency, because they now feel more confident in their ability to convey meanings in the L 2 with few words (see 4.2.4).

As regards the amount of support provided by learners on requests, the present study provides partial support for a proficiency effect observed by Blum-Kulka and Olshtain (1986). The finding in this study that Low learners (L-1 and L-2) never provide excessive support on their requests is consistent with their finding that low -intermediate learners do not display this feature. However, the finding in this study that only the Middle group, and never the High group, provide excessive support, appears at odds with Blum-Kulka and Olshtain's (1986) finding that advanced learners regularly exhibit this feature. The different elicitation method used in the two studies may help to account for this apparent contrast in findings. Written discourse completion tasks may strongly encourage learners to include abundant information in their requests, due to a powerful 'cue-card effect' (see 6.1.4.3), so that even advanced learners - who are not naturally prone to oversupport their requests - will do so. Oral role play tasks, on the other hand, may not exert such a powerful 'cue-card effect', so that only learners most prone to oversupport their requests (in this study, the Middle group) will do so. Thus, the acquisition of a native- like amount of support on requests by learners may in fact follow a U-shape curve of development related to linguistic proficiency (see 6.1.4.3).

The fact that these learners greatly underuse impersonal perspective on requests has implications for the development of perspective on L2 speech acts, when considered together with previous findings. Impersonal perspective on speech acts may sometimes be difficult to use for various reasons: it may entail the use of 
relatively complex pragmalinguistic structures (as in the present study), or it may make considerable demands on socio-pragmatic competence (as in Trosborg's (1995) study). However, impersonal perspective does not appear to be inherently difficult for learners to acquire (suggested by the fact that intermediate learners in Blum-Kulka and Levenston's (1987) study use it frequently). And so, while it appears that learners will increase their range of perspective on speech acts as they become more linguistically proficient (cf. Ellis 1992), it seems doubtful that impersonal or any other perspective is inherently early- or late- acquired (see 4.2.9).

Regarding statement hints, the finding that these Australian learners frequently produce statement forms which are non-conventionally indirect but which do not seem to be motivated by strategic lack of transparency (see 4.2.7), confirms Trosborg's (1995) finding of the same feature in her study. The present finding that although these Australian learners overuse this request type in general, the High group never use it, is consistent with Trosborg's (1995) finding that learners use this request type less at a higher proficiency level, and lends support to the notion that use of this request type by L2 learners may often reflect difficulty in phrasing requests rather than a preference for highly indirect strategies.

\subsection{Teaching of $\mathbf{L} 2$ pragmatics}

An obvious implication of the present request data from BI native speakers is the need for FL teaching materials to be grounded in empirical data on how speech acts are performed, rather than (often unreliable) native intuitions about how speech acts are performed (cf. Bardovi-Harlig, Hartford, Mahan-Taylor, Morgan, \& Reynolds 1991; Kasper 1995b; Liddicoat 1997). A considerable amount of the pragmatic information about requesting conveyed explicitly or implicitly to these Australian learners in their main textbook (Johns 1977) appears to be at odds with the way native Indonesians carry out this speech act. For example, it is suggested to the learners that the enclitic -lah is a common modifier of imperative requests in speech, and that native speakers make query preparatory requests using the modal verb boleh "may/be allowed" but not bisa "can". As this kind of input in teaching materials may have a powerful effect upon learner pragmatic behaviour (discussed above), it highlights the need for data-based descriptions of common speech acts in languages such as Indonesian for which such descriptions have not yet been carried out, as a basis for development of teaching materials; if instruction is to aid learners significantly in the acquisition of pragmatic competence. 
This study also highlights one issue in presentation of pragmatic information in teaching materials: the need to balance the requirement to make pragmatic input salient enough for learners to notice it, and hence to be able to acquire it (cf. Schmidt 1993), with the requirement to make it natural. The technique used regularly in the learners' main textbook (Johns 1977) of presenting a given request form by showing it used repeatedly within a dialogue by the same speaker is likely to direct learners' attention effectively to this target form; however this input is at odds with the finding in this study that BI native speakers mark the stages of a request speech event by varying their request strategy. This deviant input may well have contributed to the $\mathrm{IL}$-specific tendency of the Australian learners to use the one request formula repeatedly within an interaction (see 4.1.9). So, this study highlights the fact that a widely used means of presenting a number of realisations of an L2 target form to learners in a concise way; namely, that of presenting multiple instances of it within a single dialogue, may contribute to IL-specific pragmatic behaviour.

Certain findings from this study demonstrate how the type of instruction needed for a particular pragmatic feature may vary considerably, depending on the extent to which L1 pragmatic knowledge is available to the learners.

These Australian learners have apparently acquired the ability to use query preparatory requests in the $\mathrm{L} 2$ in an essentially native-like way; that is, as their archetypal request strategy, across situations, despite far from 'ideal' pragmatic instruction. The input in their main textbook (Johns 1977) consisted mainly of isolated question forms, designed to demonstrate the range of formal permutations possible; practice consisted of highly controlled drills, and no metapragmatic information was provided about this request type. The reason this minimal instruction was effective is likely to be that it was adequate to alert learners to the fact that this request type existed in the L2. Then, on the basis of this initial knowledge, learners probably drew on L1 knowledge about this feature (see 4.2.2).

This suggests that L2 pragmatic features for which a parallel feature exists with the same form, function, and distribution in the L1 may, if necessary, be effectively taught with minimal input and minimal communicative practice, if learners are made aware of the extent to which L1 knowledge may be drawn upon. This awareness can be developed by metapragmatic information provided in teaching materials, ${ }^{1}$ the crucial information in this case being that the QP modal request type - in 
Indonesian, as in English - is a very common, polite request strategy, appropriate in a wide range of situations.

Conversely, this study demonstrates that much richer instruction is likely to be needed for features where L1 knowledge is not adequate or, particularly, where transfer of L1 knowledge is likely to result in non-native behaviour. This is illustrated by the virtual non-use by these Australian learners of Prefaces on direct questions, and their marked underuse of kinship TOAs on Alerters.

The instruction these learners received in these two features in their main textbook (Johns 1977) is comparable to that for the QP request type. Preface formulas were nearly always presented in isolation, with a focus on their formal permutations, and practice exercises consisted of drill practice of isolated forms (see 6.1.4.2). While kinship TOAs on Alerters were presented within dialogues, practice exercises were limited to rote repetition of mini-dialogues containing the feature (see 6.3.3.2). No metapragmatic information was provided about either feature. For both these features, unlike the case of $\mathrm{QP}$ requests, above, this instruction seems to have been inadequate. A major reason is probably that these learners cannot rely on L1 knowledge of when these two features are appropriate. In fact, use of L1 knowledge of when the equivalent English features (Prefaces of the type "May I ask a question?" and the polite TOAs "Sir" or "Madam") are appropriate may have actively inhibited selection of the two BI features by learners in these situations.

Thus, learners are likely to need rich input involving exposure to the feature in a variety of contexts, and also a good deal of communicative practice (for example, through roleplay) in producing these features in a range of situations, in order to develop stable, well-developed representations of knowledge of the contexts in which these features are appropriate. They are also likely once again to benefit a good deal from contrastive metapragmatic information, this time to raise their awareness of the fact that much L1 knowledge about such features cannot be transferred. For example, in the case of the two features above, learners should be made explicitly aware of the restricted nature of the contexts in which Prefaces before direct questions of the type "Can I ask a question?" are used in English (see 6.1.4.2), and of the highly restricted currency in English of the polite TOAs "Sir" or "Madam" (see 5.3.1), as well as of the broad range of contexts within which the Indonesian 'equivalents' occur.

On the whole, this study confirms the likely importance of elements such as exposure to input in a variety of contexts, and active communicative practice, in the 
teaching of pragmatics (see 1.6.3.4). It also suggests that the proportion of such components of instruction may be greatly varied according to the extent to which L1 pragmatic information can be used by the learner group. Furthermore, while a primarily contrastive approach to the teaching of pragmatics is not suggested, it appears that metapragmatic information of an explicitly contrastive nature may be valuable to enable learners to utilise L1 pragmatic knowledge optimally and selectively. ${ }^{2}$

\subsection{Methodology in ILP studies}

This study has several implications for the use of elicited data to investigate speech act performance.

It sheds some light on the likely relationship of elicitation method to the phenomenon of oversupport by learners on L2 requests. Importantly, it provides some evidence of oversupport on requests by learners in oral interaction. This suggests that the oversupport on requests by learners in a number of CCSARP studies (Blum-Kulka \& Olshtain 1986; House \& Kasper 1987; Faerch \& Kasper 1989; Blum-Kulka 1991) is probably not because written discourse completion tasks forced these learners to perform their request in one turn only, as suggested by Trosborg (1995; see 6.1.4.3). Rather, socio-psychological explanations, related to learners' uncertainty about their social competence (cf. House and Kasper 1987) and/ or their psychological need for self-assertion (cf. Faerch \& Kasper 1989) are likely to be important. However, examination of Grounders on certain requests by these Australian learners also suggests that one aspect of the elicitation procedure used in both the CCSARP project and the present study - the provision of written cue information to subjects - may be an important cause for this learner feature. Learners seem to have a tendency to incorporate information provided in these written cues into their own L2 speech acts, so that the phenomenon of oversupport may to some extent reflect a reliance by $\mathrm{L} 2$ learners on the language of written cues in formulating responses (see 6.1.4.3). This points to a strong need for natural data on requests by $\mathrm{L} 2$ learners, to help determine to what extent this feature is a phenomenon of elicited data only.

The present study also suggests that the phrasing of the written cue information provided to learners may influence learners' choice of speech act strategy. This is suggested by the fact that in some of the situations where these Australian learners overused Want statements, or statement hints, a segment of the cue information 
provided for the situation was phrased as a potential Want statement or statement hint respectively (see 4.2.5; see also 4.2.7). This suggests that care should be taken to phrase cue information in speech act elicitation tasks in such a way that the wording does not correspond to conventional formulas for performing that speech act; nor, as far as possible, to non-conventional forms which could plausibly be used in that situation to perform the speech act, in order to minimise likely influence of the cue information on choice of strategy.

This study also provides tentative support for the contention of Dahl (undated; cited in Kasper \& Dahl 1991) that role play speech act data may differ from natural data in the degree of directness with which speech acts are performed (see $2.8 \mathrm{ff} 7$ ). The fact that the BI native speakers in this study show a very strong preference for the query preparatory sub-strategy over any other request type is somewhat surprising, given that the strong preference of English speakers for this request type has been linked directly to Anglo-American cultural norms such as egalitarianism and regard for individual autonomy - norms which are in striking contrast to Indonesian cultural values (see 4.2.2). Therefore, one might suspect that this QP sub-strategy is overrepresented in the BI NS data. This seems consistent with the surprise expressed by a BI native speaker informant that two direct sub-strategies (Explicit Performative and Hedged Performative) did not occur more frequently in the BI NS data; she felt that both were very common request types in Indonesian. It seems possible that BI NS subjects in this study used QP requests somewhat more frequently than they would have in real-life, while using these two direct substrategies, in particular, somewhat less. This seems to support the conclusion that, although the role play method can reveal strategy preferences which go untapped by the DCT method (see 2.3), it may tend to elicit different strategy choices from natural interaction.

Lastly, this study reveals a potential limitation of the practice of explicitly probing sociopragmatic perceptions of situations by means of a questionnaire, as in the present study (see 2.5). It appears that native informants' willingness to give accurate reports of their perceptions of situations may sometimes be affected by sensitivity to the likelihood of negative judgements of a researcher from outside the culture. BI native speaker informants reported surprisingly small status differences between themselves and the interlocutor in many of the roleplay situations, particularly ones where they might be expected to perceive themselves as much higher in status than the interlocutor. For example, they assessed their own status as somewhat higher than that of a hotel servant whom they asked to wash their clothes, and of a waiter who brought them a meal in a restaurant, rather than as 
much higher (while Australian learner informants consistently reported larger differences in status between themselves and the interlocutor, assessing their own status in the situations above, for example, as much higher than the hotel servant and the waiter).

A likely reason for this finding is that these questionnaire informants, who are studying in Australia, would be well aware that Australians might perceive a hierarchical social ethos negatively, as being 'backward', and feudal. Therefore, they might well be unwilling to disclose to an Australian researcher that they perceive large status differences between themselves and others in everyday situations, because of likely negative judgments by the researcher about their culture and/ or about themselves. So, along with the more obvious limitation of questionnaires of this type; namely, that informants might not always be able to give accurate reports of their perceptions of social variables because these perceptions might not be wholly available to introspection; an additional limitation is that under certain circumstances, informants may be unwilling to provide accurate reports on their perceptions.

\subsection{Cross-cultural pragmatics}

This study has a number of implications for the way that requests - and speech acts in general - are performed across languages.

The finding that BI NSs use QP modal requests as a highly frequent request type is interesting. Although (as discussed above) subjects in this study may have used QP modal requests somewhat more frequently than they would in real life, this finding still indicates that this request type is an important one in Bahasa Indonesia. This lends support to the contention that this strategy is an important one for requesting across many languages, including non-Western ones (see 4.2.2).

The above finding that BI NSs use this QP request type so frequently also points to the possibility of systematic differences in speech act performances within cultures. The BI NS subjects in this study are from a highly educated middle-class Indonesian social 'elite', which is highly familiar with and to some extent adopts a Western life-style and attitudes. Thus, it is highly possible that they are influenced by Western cultural norms (specifically, Anglo-American ones) in their strong preference for this request type (see 4.2.2). ${ }^{3}$ The broader implication is that in Indonesia, as well as in other developing countries where a highly educated, urban 
middle-class 'elite' has emerged which increasingly does not identify with 'traditional' cultural values; striking differences may exist between the speech act behaviour of different speakers which directly reflect the extent to which their cultural orientation is 'Western' vs 'traditional'. This proposal is supported by Apte's (1974) study of thanking in South Asian languages. He claims that whether a speaker of Hindi or Marathi expresses thanks verbally in everyday interaction, and how frequently, depends directly on the extent to which he or she identifies with traditional cultural values vs Western ones ${ }^{4}$. Thus, the speech act behaviour of the 'elite' middle class group in many developing countries is likely to be relatively similar to that of Western cultures they are exposed to, while that of the majority of the population may diverge much more strongly from these Western norms.

The finding that BI NS subjects strongly favour direct questions as a strategy to ask for information has implications for speech act performance across cultures. It provides some counter-evidence to the suggestion by Blum-Kulka, Danet and Gherson (1985) that a request 'proper', rather than a question, is an inherently natural means of asking for information, such that even cultures with a general ethos of directness may tend to ask for information by means of requests rather than direct questions (see 4.2.12). The behaviour of these BI NS subjects suggests that this is unlikely to be so, and points to the likelihood that direct questions will be the dominant means of asking for information in most languages.

However, the behaviour of these BI NS subjects in asking for information also raises the interesting possibility that languages which favour direct questions may tend to incorporate a requestive element into the speech act by other means; namely, the inclusion of a prefacing move (see 4.2.12). Thus, possibly, the claim of theoreticians (e.g. Gordon \& Lakoff 1971) that the logical form of a question is that of a 'request to tell' may tend to be reflected in speech acts across languages by one means or another. 


\subsection{Notes to Chapter 7}

1 This is likely to be a minimal requirement for effective teaching - much better, as BardoviHarlig et al (1991) point out, is for learners to discover the relevant L1 pragmatic norms themselves, through discussion and reflection, in order to develop their awareness of pragmatic functions in language.

2 cf. Crozet and Liddicoat (1997), who claim that the development of contrastive metaknowledge by $\mathrm{L} 2$ learners may be highly beneficial for the learning of pragmatics

3 The thanking behaviour of these BI NS subjects strongly supports the contention that they are influenced in their speech act behaviour by Western norms. These BI NS subjects express verbal thanks very consistently in situations in which they are offered or given goods, services, or information; or done small favours, by a variety of interlocutors (Hassall 1996). This seems surprising in view of the numerous anecdotal reports (cf. also Soenarso 1988: 31) that Indonesians do not express verbal thanks nearly as frequently as Australians do in everyday interaction, and do not thank, for instance, in routine service encounters. It seems probable that these BI NS subjects thank so frequently in BI under influence from English-speaking culture - a claim consistent with Quinn's assertion that the frequency of terima kasih "thank you" in Indonesian seems to be rising, "probably under the influence of Anglo-American practice" (Quinn (1996d: 152).

4 More generally, D'Souza (1988: 168) asserts that "modernization" (including spread of education, and increasing industrialisation) is eroding the social values which underlie certain politeness features in South Asian languages, and that this is influencing pragmatic behaviour. 


\section{Appendix A. Role play situations}

\section{Request situations}

1. ask the shop assistant in a music store to let you listen to a cassette

2. ask the hotel receptionist when checking in to lend you a pen to fill in the registration form

3. ask a post office clerk to sell you two envelopes and stamps for letters to Australia.

4. ask a conductor on a city bus to let you know when you get to your stop

5. ask a university lecturer during class for a copy of last week's handout which you did not receive

6. ask a university classmate to let you look on at their textbook during a class

7. ask the ticket seller in a cinema for a ticket for the film "Four Seasons", AND

8. ask to be able to sit in the middle front of the cinema

9. ask a bank teller to change a large banknote into smaller notes

10. ask a stranger in a park for a light for your cigarette

11. ask a stranger in a crowded eating stall to move over a little so that you can sit down too

12. ask a hotel servant to have your dirty clothes washed

13. ask a magazine seller at a street stall for a copy of the magazine "Tempo"

14. ask a friend from your residential college whom you see at the shops for a lift home to college on their motor scooter

15. ask a university classmate to lend you a pen during a class 


\section{Appendix A (cont).}

Request situations (cont).

16. ask a friend while watching TV together to pass over some magazines which are beside him or her.

17. ask the manager of a clothes store to allow you to exchange a shirt you bought yesterday for one of a different colour

18. ask a waiter in a restaurant to give you a menu

AND

19. order a meal

20. order a drink from a waiter in a restaurant

21. ask your university lecturer for an extension on an essay deadline

22. ask a taxi driver to stop for a minute so you can buy cigarettes

23. ask the assistant in a shoe shoe to let you try on a pair of shoes

24. ask the official at the immigration office to give you the necessary forms to apply for a visa extension

25. ask a stranger on a railway platform if the train that has just arrived goes to Bandung

26. ask the conductor during a long coach journey when the coach will arrive in Denpasar

27. ask a police officer at the police station where to go to report your lost passport

28. ask a stranger in the street for directions to the Post Office

29. ask a stranger in the street for directions to the Language Centre 


\section{Appendix A (cont).}

\section{Non-request (i.e. 'distractor') role play situations}

30. a classmate offers to lend you a little money when you lose your wallet

31. a street vendor tries to sell you a newspaper which you do not want

32. a new acquaintance tells you that you speak Indonesian well

33. a shop assistant in a pharmacy hands you your parcel and asks you if you want anything else .

34. a stranger gives you your umbrella that you left behind on a park bench

35. a taxi driver stops at your destination, and when you pay, gives you your change

36. your lecturer offers to lend you a book to help with an essay you are writing

37. a hotel porter carries your bags to your room, and asks if you want anything else

38. a friend gives you a music cassette as a gift 


\section{Appendix B. Proportion of subjects who use each sub-strategy in each situation}

Top row of figures in bold type $\quad=\%$ of learner subjects

Bottom row of figures

$=\%$ of $\mathrm{BI}$ native speaker subjects

\begin{tabular}{|c|c|c|c|c|c|c|c|c|c|c|}
\hline & $\begin{array}{l}\text { Imperat } \\
\text { ive } \\
\text { (full) }\end{array}$ & $\begin{array}{l}\text { Imperat } \\
\text { ive } \\
\text { (elided) }\end{array}$ & \begin{tabular}{|l} 
Expl- \\
icit \\
per- \\
form- \\
ative
\end{tabular} & $\begin{array}{l}\text { Hedged } \\
\text { Perfrm } \\
\text { ative }\end{array}$ & $\begin{array}{l}\text { Goal } \\
\text { state- } \\
\text { ment }\end{array}$ & $\begin{array}{l}\text { Want } \\
\text { state- } \\
\text { ment }\end{array}$ & $\begin{array}{l}\text { Query } \\
\text { Prep: } \\
\text { modal }\end{array}$ & $\begin{array}{l}\text { Query } \\
\text { Prep: } \\
\text { availab } \\
\text { ility }\end{array}$ & $\begin{array}{l}\text { Hint: } \\
\text { quest- } \\
\text { ion }\end{array}$ & $\begin{array}{l}\text { Hint: } \\
\text { State- } \\
\text { ment }\end{array}$ \\
\hline $\begin{array}{l}\text { R1) try } \\
\text { cass } \\
\text { ette in } \\
\text { store }\end{array}$ & $\begin{array}{l}-\cdot \\
11\end{array}$ & & & & & $\begin{array}{c}\mathbf{5 0} \\
11\end{array}$ & $\begin{array}{l}50 \\
66\end{array}$ & & $\begin{array}{l}-- \\
11\end{array}$ & \\
\hline \begin{tabular}{l|} 
R2) \\
borrow \\
pen \\
frm \\
hotel \\
recept.
\end{tabular} & & & & & $\begin{array}{l}-\cdot \\
11\end{array}$ & & $\begin{array}{r}20 \\
77\end{array}$ & $\begin{array}{l}10 \\
\ldots\end{array}$ & & $\begin{array}{r}70 \\
11\end{array}$ \\
\hline \begin{tabular}{|l|} 
R3) \\
buy \\
stamps \\
in post \\
office
\end{tabular} & & $\begin{array}{c}-- \\
12.5\end{array}$ & & $\begin{array}{c}-- \\
25\end{array}$ & & $\begin{array}{c}70 \\
50\end{array}$ & $\begin{array}{c}20 \\
12.5\end{array}$ & & $\begin{array}{l}10 \\
--\end{array}$ & \\
\hline \begin{tabular}{|l|} 
R4) \\
bus \\
cndctr \\
tell \\
when \\
is your \\
stop \\
\end{tabular} & $\begin{array}{l}-- \\
55\end{array}$ & & & $\begin{array}{l}-- \\
11\end{array}$ & & $\begin{array}{l}11 \\
-.\end{array}$ & $\begin{array}{l}55 \\
22\end{array}$ & & $\begin{array}{l}22 \\
-\end{array}$ & $\begin{array}{c}11 \\
11\end{array}$ \\
\hline \begin{tabular}{|l|} 
R5) get \\
last \\
week's \\
hndout \\
from \\
lect.'r
\end{tabular} & $\begin{array}{c}- \\
12.5\end{array}$ & & & $\begin{array}{l}-- \\
25\end{array}$ & & & $\begin{array}{c}40 \\
50\end{array}$ & $\begin{array}{c}20 \\
12.5\end{array}$ & & 40 \\
\hline
\end{tabular}


Appendix B (cont.)

\begin{tabular}{|c|c|c|c|c|c|c|c|c|c|c|}
\hline & $\begin{array}{l}\text { Imp. } \\
\text { (full) }\end{array}$ & $\begin{array}{l}\text { Imp. } \\
\text { (elided) }\end{array}$ & $\begin{array}{l}\text { Per- } \\
\text { form } \\
\text { ative }\end{array}$ & $\begin{array}{l}\text { Hedged } \\
\text { Perf. }\end{array}$ & $\begin{array}{l}\text { Goal } \\
\text { state. }\end{array}$ & $\begin{array}{c}\text { Want } \\
\text { state. }\end{array}$ & $\begin{array}{l}\mathrm{QP}: \\
\text { modal }\end{array}$ & \begin{tabular}{|l|}
$\mathrm{QP}:$ \\
availab \\
ility
\end{tabular} & $\begin{array}{r}\text { Hint: } \\
\text { Quest }\end{array}$ & $\begin{array}{l}\text { Hint: } \\
\text { State- } \\
\text { ment }\end{array}$ \\
\hline \begin{tabular}{|l|} 
R6) \\
look \\
on \\
class \\
mate's \\
book
\end{tabular} & & & & & $\begin{array}{l}\cdots \\
22\end{array}$ & & $\begin{array}{l}90 \\
66\end{array}$ & & $\begin{array}{c}10 \\
--\end{array}$ & $\begin{array}{l}-\cdot \\
11\end{array}$ \\
\hline $\begin{array}{l}\text { R7 buy } \\
\text { cinema } \\
\text { ticket } \\
\text { AND }\end{array}$ & & $\begin{array}{l}10 \\
44\end{array}$ & $\begin{array}{l}- \\
11\end{array}$ & $\begin{array}{c}-- \\
11\end{array}$ & $\begin{array}{c}10 \\
--\end{array}$ & $\begin{array}{l}80 \\
11\end{array}$ & $\begin{array}{l}\cdots \\
11\end{array}$ & $\begin{array}{l}\cdots \\
11\end{array}$ & & \\
\hline $\begin{array}{l}\overline{R 8)} \\
\text { ask for } \\
\text { seat in } \\
\text { centre } \\
\text { front }\end{array}$ & $\begin{array}{c}-- \\
12.5\end{array}$ & $\begin{array}{l}10 \\
25\end{array}$ & $\begin{array}{l}- \\
12.5\end{array}$ & $\begin{array}{l}-- \\
25\end{array}$ & $1--$ & 70 & $\begin{array}{l}20 \\
25\end{array}$ & & & \\
\hline $\begin{array}{l}\mathrm{R} 9 \text { ) } \\
\text { change } \\
\text { large } \\
\text { note in } \\
\text { bank }\end{array}$ & & & & & & $\overline{70}$ & $\begin{array}{l}20 \\
88\end{array}$ & $\begin{array}{l}-- \\
11\end{array}$ & & $\begin{array}{c}10 \\
--\end{array}$ \\
\hline $\begin{array}{l}\text { R10) } \\
\text { get } \\
\text { light } \\
\text { from a } \\
\text { strang } \\
\text { er }\end{array}$ & & & $\begin{array}{l}11 \\
--\end{array}$ & $\begin{array}{l}-- \\
22\end{array}$ & & -- & $\begin{array}{l}44 \\
55\end{array}$ & $\begin{array}{l}22 \\
22\end{array}$ & & $\begin{array}{r}22 \\
-\end{array}$ \\
\hline \begin{tabular}{|l|} 
R11) \\
strngr \\
move \\
over \\
in \\
eating \\
stall \\
\end{tabular} & & & & & & & $\begin{array}{l}70 \\
100\end{array}$ & & $\begin{array}{l}20 \\
--\end{array}$ & $\begin{array}{l}10 \\
--\end{array}$ \\
\hline $\begin{array}{l}\text { R12) } \\
\text { hotel } \\
\text { servnt } \\
\text { have } \\
\text { your } \\
\text { clothes } \\
\text { washed }\end{array}$ & $\begin{array}{l}20 \\
33\end{array}$ & & & $\begin{array}{l}-- \\
11\end{array}$ & & $\begin{array}{l}20 \\
-\end{array}$ & $\begin{array}{l}40 \\
22\end{array}$ & & $\begin{array}{l}20 \\
22\end{array}$ & $\begin{array}{l}-\cdot \\
11\end{array}$ \\
\hline
\end{tabular}


Appendix B (cont.)

\begin{tabular}{|c|c|c|c|c|c|c|c|c|c|c|}
\hline & $\begin{array}{l}\text { Imp. } \\
\text { (full) }\end{array}$ & $\begin{array}{l}\text { Imp. } \\
\text { (elided) }\end{array}$ & Perf. & $\begin{array}{l}\text { Hedged } \\
\text { Perf. }\end{array}$ & $\begin{array}{l}\text { Goal } \\
\text { state. }\end{array}$ & $\begin{array}{l}\text { Want } \\
\text { state. }\end{array}$ & $\begin{array}{l}\mathrm{QP} \\
\text { modal }\end{array}$ & $\begin{array}{c}\mathrm{QP} \\
\text { avail. }\end{array}$ & $\begin{array}{l}\text { Hint: } \\
\text { Quest- } \\
\text { ion }\end{array}$ & $\begin{array}{l}\text { Hint: } \\
\text { State- } \\
\text { ment }\end{array}$ \\
\hline $\begin{array}{l}\text { R13) } \\
\text { buy } \\
\text { mag. } \\
\text { from } \\
\text { street } \\
\text { stall }\end{array}$ & & $\begin{array}{l}\cdot- \\
44\end{array}$ & $\begin{array}{l}\cdot- \\
11\end{array}$ & & $\begin{array}{c}-- \\
11\end{array}$ & $\overline{\overline{50}}$ & & $\begin{array}{l}\mathbf{5 0} \\
22\end{array}$ & $\begin{array}{l}-- \\
11\end{array}$ & \\
\hline $\begin{array}{l}\text { R14) } \\
\text { lift } \\
\text { home } \\
\text { with } \\
\text { fellow } \\
\text { college } \\
\text { resid't }\end{array}$ & & & & & $\begin{array}{l}-- \\
11\end{array}$ & $\begin{array}{l}10 \\
--\end{array}$ & $\begin{array}{l}60 \\
66\end{array}$ & -- & $\begin{array}{c}30 \\
22\end{array}$ & \\
\hline $\begin{array}{l}\text { R15) } \\
\text { borrow } \\
\text { pen in } \\
\text { class }\end{array}$ & & & & & $\begin{array}{l}\cdots \\
11\end{array}$ & & $\begin{array}{c}60 \\
66\end{array}$ & $\begin{array}{c}30 \\
22\end{array}$ & $\begin{array}{c}10 \\
--\end{array}$ & \\
\hline $\begin{array}{l}\text { R16) } \\
\text { ask } \\
\text { friend } \\
\text { to pass } \\
\text { mags }\end{array}$ & $\begin{array}{l}10 \\
22\end{array}$ & $\begin{array}{l}-\cdot \\
11\end{array}$ & & $\begin{array}{l}-\cdots \\
11\end{array}$ & 11 & 11 & $\begin{array}{c}70 \\
22\end{array}$ & & $\begin{array}{c}20 \\
11\end{array}$ & \\
\hline $\begin{array}{l}\text { R17) } \\
\text { exchge } \\
\text { shirt in } \\
\text { shop }\end{array}$ & & & & & & $\begin{array}{l}30 \\
11\end{array}$ & $\begin{array}{l}70 \\
88\end{array}$ & & & \\
\hline $\begin{array}{l}\text { R18) } \\
\text { ask for } \\
\text { menu } \\
\text { AND }\end{array}$ & & $\begin{array}{l}-- \\
22\end{array}$ & $\begin{array}{l}\cdots \\
11\end{array}$ & $\begin{array}{l}-\cdot- \\
22\end{array}$ & & $\begin{array}{l}20 \\
--\end{array}$ & $\begin{array}{l}30 \\
33\end{array}$ & $\begin{array}{l}40 \\
11\end{array}$ & & \\
\hline $\begin{array}{l}\mathrm{R} 19) \\
\text { order } \\
\text { a meal }\end{array}$ & & $\begin{array}{c}10 \\
22\end{array}$ & $\begin{array}{l}-\cdot \\
11\end{array}$ & $\begin{array}{l}-- \\
11\end{array}$ & & $\begin{array}{l}70 \\
22\end{array}$ & $\begin{array}{l}20 \\
33\end{array}$ & & & \\
\hline $\begin{array}{l}\mathrm{R} 20 \text { ) } \\
\text { order a } \\
\text { drink } \\
\text { in a } \\
\text { restaua } \\
\text { nt }\end{array}$ & $\begin{array}{l}20 \\
11\end{array}$ & $\begin{array}{l}-- \\
22\end{array}$ & & $\begin{array}{l}-- \\
33\end{array}$ & & $\begin{array}{l}\mathbf{1 0} \\
11\end{array}$ & $\begin{array}{l}40 \\
22\end{array}$ & $\begin{array}{l}30 \\
-\end{array}$ & & \\
\hline
\end{tabular}


Appendix B (cont.)

\begin{tabular}{|c|c|c|c|c|c|c|c|c|c|c|}
\hline & $\begin{array}{l}\text { Imp. } \\
\text { (full) }\end{array}$ & $\begin{array}{l}\text { Imp. } \\
\text { (elided) }\end{array}$ & Perf. & $\begin{array}{l}\text { Hedged } \\
\text { Perf. }\end{array}$ & $\begin{array}{l}\text { Goal } \\
\text { state }\end{array}$ & Want & $\begin{array}{l}\mathrm{QP} \\
\text { modal }\end{array}$ & $\begin{array}{l}\mathrm{QP} \\
\text { availab } \\
\text { ility }\end{array}$ & $\begin{array}{l}\text { Hint: } \\
\text { Quest- } \\
\text { ion }\end{array}$ & $\begin{array}{l}\text { Hint: } \\
\text { State- } \\
\text { ment }\end{array}$ \\
\hline $\begin{array}{l}\text { R21) } \\
\text { essay } \\
\text { extnsn } \\
\text { from } \\
\text { lcturer }\end{array}$ & & & $\begin{array}{l}-\cdot \\
11\end{array}$ & & $\begin{array}{l}10 \\
22\end{array}$ & & $\begin{array}{l}\mathbf{3 0} \\
66\end{array}$ & & & $\begin{array}{l}60 \\
--\end{array}$ \\
\hline $\begin{array}{l}\text { R22) } \\
\text { taxi to } \\
\text { stop so } \\
\text { can } \\
\text { buy } \\
\text { cig's }\end{array}$ & $\begin{array}{l}50 \\
55\end{array}$ & & & & & $\begin{array}{r}10 \\
-\end{array}$ & $\begin{array}{l}30 \\
44\end{array}$ & & $\begin{array}{l}10 \\
-\end{array}$ & \\
\hline $\begin{array}{l}\text { R23) } \\
\text { try on } \\
\text { shoes } \\
\text { in } \\
\text { store }\end{array}$ & & & & $\begin{array}{l}-\cdot \\
11\end{array}$ & $\begin{array}{l}-- \\
11\end{array}$ & $\begin{array}{l}30 \\
11\end{array}$ & $\begin{array}{l}70 \\
55\end{array}$ & & $\begin{array}{l}-\cdot \\
11\end{array}$ & \\
\hline $\begin{array}{l}\text { R24) } \\
\text { ask } \\
\text { official } \\
\text { for } \\
\text { visa } \\
\text { forms }\end{array}$ & & & $\begin{array}{l}-- \\
11\end{array}$ & $\begin{array}{c}11 \\
22\end{array}$ & & $\begin{array}{l}11 \\
33\end{array}$ & $\begin{array}{l}33 \\
11\end{array}$ & $\begin{array}{r}33 \\
-\end{array}$ & $\begin{array}{l}11 \\
22\end{array}$ & \\
\hline
\end{tabular}

\begin{tabular}{|c|c|c|c|c|c|c|}
\hline & \begin{tabular}{|l|} 
Direct \\
question
\end{tabular} & $\begin{array}{l}\text { Hedged } \\
\text { perform. }\end{array}$ & $\begin{array}{l}\text { Want } \\
\text { statement }\end{array}$ & $\begin{array}{l}\text { Query Prep: } \\
\text { modal }\end{array}$ & $\begin{array}{l}\text { Query Prep: } \\
\text { availab- } \\
\text { ility }\end{array}$ & $\begin{array}{l}\text { Hint: } \\
\text { statement }\end{array}$ \\
\hline $\begin{array}{l}\text { A25) ask } \\
\text { stranger on } \\
\text { platform if } \\
\text { train goes to } \\
\text { Bandung } \\
\end{array}$ & $\begin{array}{l}70 \\
77\end{array}$ & & & & $\begin{array}{l}10 \\
11\end{array}$ & $\begin{array}{l}20 \\
11\end{array}$ \\
\hline $\begin{array}{l}\text { A26) ask } \\
\text { conductor } \\
\text { on coach } \\
\text { when will } \\
\text { arrive } \\
\end{array}$ & $\begin{array}{l}80 \\
100\end{array}$ & & $\begin{array}{r}20 \\
-\end{array}$ & & & \\
\hline $\begin{array}{l}\text { A27) ask } \\
\text { police } \\
\text { officer } \\
\text { where to } \\
\text { report lost } \\
\text { passport } \\
\end{array}$ & $\begin{array}{l}60 \\
44\end{array}$ & & $\begin{array}{l}30 \\
22\end{array}$ & $\begin{array}{l}10 \\
-\end{array}$ & & 33 \\
\hline $\begin{array}{l}\text { A28) ask } \\
\text { stranger in } \\
\text { street the } \\
\text { way to P.O. }\end{array}$ & $\begin{array}{l}60 \\
66\end{array}$ & & & $\begin{array}{l}10 \\
33\end{array}$ & & $\begin{array}{l}30 \\
-\end{array}$ \\
\hline $\begin{array}{l}\text { A29) ask } \\
\text { stranger in } \\
\text { street the } \\
\text { way to } \\
\text { Language } \\
\text { Centre } \\
\end{array}$ & $\begin{array}{l}70 \\
77\end{array}$ & $\begin{array}{l}-- \\
11\end{array}$ & & $\begin{array}{l}-- \\
11\end{array}$ & $\begin{array}{l}20 \\
-\end{array}$ & $\begin{array}{r}10 \\
-\end{array}$ \\
\hline
\end{tabular}




\section{Appendix C. Assessment of social variables by native Bahasa Indonesia informants and Australian learner informants}

-The first number in each cell is a ranking (e.g. $6=$ means that respondents ranked this situation equal 6th highest out of the 26 situations].

-The number in brackets is the mean raw score (e.g. 3.47 means that on a five-point scale, with lowest possible value of 1.00 and highest of 5.00, respondents awarded a mean score of 3.47).

- BI informants: $n=15$; Australian learner informants: $n=20$.

\begin{tabular}{|c|c|c|c|c|c|c|}
\hline \multirow[b]{2}{*}{$\begin{array}{c}\text { Request } \\
\text { situation }\end{array}$} & \multicolumn{2}{|c|}{$\begin{array}{c}\text { Status of } \mathrm{S} \\
\text { (in relation to } \mathrm{H} \text { ) }\end{array}$} & \multicolumn{2}{|c|}{ Size of imposition } & \multicolumn{2}{|c|}{$\begin{array}{l}\text { How comfortable } \\
\text { making request }\end{array}$} \\
\hline & $\begin{array}{l}\text { BINS } \\
\text { rating }\end{array}$ & $\begin{array}{l}\text { Learner } \\
\text { rating }\end{array}$ & $\begin{array}{l}\text { BINS } \\
\text { rating }\end{array}$ & $\begin{array}{l}\text { Learner } \\
\text { rating }\end{array}$ & $\begin{array}{l}\text { BI NS } \\
\text { rating }\end{array}$ & $\begin{array}{l}\text { Learner } \\
\text { rating }\end{array}$ \\
\hline $\begin{array}{l}\mathrm{R} 18,19) \text { ask for } \\
\text { menu, order meal }\end{array}$ & $\begin{array}{l}6= \\
(3.47) \\
\end{array}$ & $\begin{array}{l}5= \\
(3.70)\end{array}$ & $\begin{array}{c}19= \\
(3.00)\end{array}$ & $\begin{array}{l}19= \\
(2.15)\end{array}$ & $\begin{array}{l}8= \\
(3.47)\end{array}$ & $\begin{array}{l}3 \\
(4.55)\end{array}$ \\
\hline $\begin{array}{l}\text { R15) borrow pen } \\
\text { in class }\end{array}$ & $\begin{array}{l}16= \\
(2.93)\end{array}$ & $\begin{array}{l}16= \\
(2.90)\end{array}$ & $\begin{array}{l}14= \\
(3.20)\end{array}$ & $\begin{array}{l}18 \\
(2.20)\end{array}$ & $\begin{array}{l}11= \\
(3.20)\end{array}$ & $\begin{array}{l}11 \\
(3.70)\end{array}$ \\
\hline $\begin{array}{l}\text { R21) ask for } \\
\text { essay extension }\end{array}$ & $\begin{array}{l}26 \\
(1.73)\end{array}$ & $\begin{array}{l}26 \\
(1.45)\end{array}$ & $\begin{array}{l}5= \\
(3.47) \\
\end{array}$ & \begin{tabular}{|l|}
1 \\
$(4.50)$ \\
\end{tabular} & $\begin{array}{l}26 \\
(1.93) \\
\end{array}$ & $\begin{array}{l}26 \\
(1.60)\end{array}$ \\
\hline $\begin{array}{l}\text { R3) buy stamps, } \\
\text { envelopes } \\
\text { in PO }\end{array}$ & $\begin{array}{l}12= \\
(3.13)\end{array}$ & $\begin{array}{l}9= \\
(3.40)\end{array}$ & \begin{tabular}{|l}
$5=$ \\
$(3.47)$ \\
\end{tabular} & $\begin{array}{l}19= \\
(2.15)\end{array}$ & $\begin{array}{l}1 \\
(3.80) \\
\end{array}$ & $\begin{array}{l}6= \\
(4.30)\end{array}$ \\
\hline $\begin{array}{l}\text { A28, 29) ask } \\
\text { directions } \\
\text { in street }\end{array}$ & $\begin{array}{l}23 \\
(2.60)\end{array}$ & $\begin{array}{l}19= \\
(2.85)\end{array}$ & $\begin{array}{l}4 \\
(3.53)\end{array}$ & $\begin{array}{l}11 \\
(2.75)\end{array}$ & $\begin{array}{l}17= \\
(2.87)\end{array}$ & $\begin{array}{l}15 \\
(3.35)\end{array}$ \\
\hline $\begin{array}{l}\text { R4) ask } \\
\text { conductor to } \\
\text { tell right stop }\end{array}$ & $\begin{array}{l}6= \\
(3.47)\end{array}$ & $\begin{array}{l}13 \\
(3.20)\end{array}$ & $\begin{array}{l}1 \\
(3.67)\end{array}$ & $\begin{array}{l}9 \\
(3.05)\end{array}$ & $\begin{array}{l}10 \\
(3.27)\end{array}$ & $\begin{array}{l}19 \\
(2.85)\end{array}$ \\
\hline $\begin{array}{l}\text { R11) ask stranger } \\
\text { to move over in } \\
\text { eating stall }\end{array}$ & $\begin{array}{l}24 \\
(2.53)\end{array}$ & $\begin{array}{l}22 \\
(2.55)\end{array}$ & $\begin{array}{l}2= \\
(3.60)\end{array}$ & $\begin{array}{l}5= \\
(3.40)\end{array}$ & $\begin{array}{l}21= \\
(2.53)\end{array}$ & $\begin{array}{l}25 \\
(2.20)\end{array}$ \\
\hline $\begin{array}{l}\text { R12) ask hotel } \\
\text { servant to have } \\
\text { clothes washed }\end{array}$ & $\begin{array}{l}1 \\
(3.80)\end{array}$ & $\begin{array}{l}1 \\
(4.15)\end{array}$ & $\begin{array}{l}10 \\
(3.40)\end{array}$ & $\begin{array}{l}13= \\
(2.40)\end{array}$ & $\begin{array}{l}3= \\
(3.67)\end{array}$ & $\begin{array}{l}8= \\
(3.75)\end{array}$ \\
\hline $\begin{array}{l}R 24 \text { ) ask official } \\
\text { for forms for visa }\end{array}$ & $\begin{array}{l}19= \\
(2.87)\end{array}$ & $\begin{array}{l}23 \\
(2.15) \\
\end{array}$ & $\begin{array}{l}16= \\
(3.13)\end{array}$ & $\begin{array}{l}2 \\
(4.00)\end{array}$ & $\begin{array}{l}11= \\
(3.20)\end{array}$ & $\begin{array}{l}21= \\
(2.55)\end{array}$ \\
\hline $\begin{array}{l}\mathrm{R} 13) \text { buy } \\
\text { magazine from } \\
\text { stall owner }\end{array}$ & $\begin{array}{l}6= \\
(3.47)\end{array}$ & $\begin{array}{l}8 \\
(3.50)\end{array}$ & $\begin{array}{l}19= \\
(3.00)\end{array}$ & $\begin{array}{l}23= \\
(1.60)\end{array}$ & $\begin{array}{l}3= \\
(3.67)\end{array}$ & $\begin{array}{l}4 \\
(4.50)\end{array}$ \\
\hline $\begin{array}{l}\text { R16) ask friend } \\
\text { to pass } \\
\text { magazines }\end{array}$ & $\begin{array}{l}15= \\
(3.00)\end{array}$ & $\begin{array}{l}14 \\
(3.00)\end{array}$ & $\begin{array}{l}19= \\
(3.00)\end{array}$ & $\begin{array}{l}23= \\
(1.60)\end{array}$ & $\begin{array}{l}7 \\
(3.53)\end{array}$ & $\begin{array}{l}5 \\
(4.45)\end{array}$ \\
\hline $\begin{array}{l}\text { R22) stop taxi to } \\
\text { buy cigarettes }\end{array}$ & $\begin{array}{l}11 \\
(3.33)\end{array}$ & $\begin{array}{l}5= \\
(3.70)\end{array}$ & $\begin{array}{l}16= \\
(3.13)\end{array}$ & $\begin{array}{l}12 \\
(2.70)\end{array}$ & $\begin{array}{l}20 \\
(2.73)\end{array}$ & $\begin{array}{l}16 \\
(3.15)\end{array}$ \\
\hline $\begin{array}{l}\text { A27) ask police } \\
\text { officer where to } \\
\text { report lost } \\
\text { passport } \\
\end{array}$ & $\begin{array}{l}14 \\
(3.00)\end{array}$ & $\begin{array}{l}24 \\
(2.10)\end{array}$ & $\begin{array}{l}5= \\
(3.47)\end{array}$ & $\begin{array}{l}3 \\
(3.70)\end{array}$ & $\begin{array}{l}14 \\
(3.07)\end{array}$ & $\begin{array}{l}24 \\
(2.50)\end{array}$ \\
\hline
\end{tabular}


Appendix C (cont.)

\begin{tabular}{|c|c|c|c|c|c|c|}
\hline & $\begin{array}{r}\text { Status } \\
\text { (in relat }\end{array}$ & $\begin{array}{l}\mathrm{S} \\
\text { to } \mathrm{H} \text { ) }\end{array}$ & Size of $i$ & position & $\begin{array}{l}\text { How co } \\
\text { making }\end{array}$ & $\begin{array}{l}\text { fortable } \\
\text { quest }\end{array}$ \\
\hline $\begin{array}{l}\text { Request } \\
\text { situation }\end{array}$ & $\begin{array}{l}\text { BI NS } \\
\text { rating }\end{array}$ & $\begin{array}{l}\text { Learner } \\
\text { rating }\end{array}$ & $\begin{array}{l}\text { BI NS } \\
\text { rating }\end{array}$ & $\begin{array}{l}\text { Learner } \\
\text { rating }\end{array}$ & $\begin{array}{l}\text { BI NS } \\
\text { rating }\end{array}$ & $\begin{array}{l}\text { Learner } \\
\text { rating }\end{array}$ \\
\hline $\begin{array}{l}\text { R1) ask to listen } \\
\text { to cassette in } \\
\text { store }\end{array}$ & $\begin{array}{l}9 \\
(3.40)\end{array}$ & $\begin{array}{l}7 \\
(3.55)\end{array}$ & $\begin{array}{l}14= \\
(3.20)\end{array}$ & $\begin{array}{l}15 \\
(2.35)\end{array}$ & $\begin{array}{l}8= \\
(3.47)\end{array}$ & $\begin{array}{l}8= \\
(3.75)\end{array}$ \\
\hline $\begin{array}{l}\text { A25) ask stranger } \\
\text { if train goes to } \\
\text { Bandung. }\end{array}$ & $\begin{array}{l}16= \\
(2.93)\end{array}$ & $\begin{array}{l}21 \\
(2.80)\end{array}$ & $\begin{array}{l}23= \\
(2.87)\end{array}$ & $\begin{array}{l}16= \\
(2.30)\end{array}$ & $\begin{array}{l}16 \\
(2.93)\end{array}$ & $\begin{array}{l}13 \\
(3.55)\end{array}$ \\
\hline $\begin{array}{l}\text { R2) borrow pen } \\
\text { from hotel } \\
\text { receptionist }\end{array}$ & $\begin{array}{l}4= \\
(3.60)\end{array}$ & $\begin{array}{l}3= \\
(3.80)\end{array}$ & $\begin{array}{l}26 \\
(2.73)\end{array}$ & $\begin{array}{l}26 \\
(1.45)\end{array}$ & $\begin{array}{l}2 \\
(3.73)\end{array}$ & $\begin{array}{l}1= \\
(4.65)\end{array}$ \\
\hline $\begin{array}{l}\text { R17) ask store } \\
\text { manager to } \\
\text { exchange shirt }\end{array}$ & $\begin{array}{l}12= \\
(3.13)\end{array}$ & $\begin{array}{l}16= \\
(2.90)\end{array}$ & $\begin{array}{l}2= \\
(3.60)\end{array}$ & $\begin{array}{l}4 \\
(3.50)\end{array}$ & $\begin{array}{l}24 \\
(2.40)\end{array}$ & $\begin{array}{l}21= \\
(2.55)\end{array}$ \\
\hline $\begin{array}{l}\text { R7, 8) buy } \\
\text { cinema ticket for } \\
\text { middle-front row }\end{array}$ & $\begin{array}{l}4= \\
(3.60)\end{array}$ & $\begin{array}{l}9= \\
(3.40)\end{array}$ & $\begin{array}{l}12= \\
(3.27)\end{array}$ & $\begin{array}{l}10 \\
(2.80)\end{array}$ & $\begin{array}{l}11= \\
(3.20)\end{array}$ & $\begin{array}{l}12 \\
(3.60)\end{array}$ \\
\hline $\begin{array}{l}\mathrm{R} 20 \text { ) order drink } \\
\text { in restaurant }\end{array}$ & $\begin{array}{l}2= \\
(3.67)\end{array}$ & $\begin{array}{l}3= \\
(3.80)\end{array}$ & $\begin{array}{l}22= \\
(2.93)\end{array}$ & $\begin{array}{l}23= \\
(1.60)\end{array}$ & $\begin{array}{l}3= \\
(3.67)\end{array}$ & $\begin{array}{l}1= \\
(4.65)\end{array}$ \\
\hline $\begin{array}{l}\text { R10) ask stranger } \\
\text { for a light }\end{array}$ & $\begin{array}{l}21 \\
(2.73) \\
\end{array}$ & $\begin{array}{l}19= \\
(2.85)\end{array}$ & $\begin{array}{l}23= \\
(2.87)\end{array}$ & $\begin{array}{l}13= \\
(2.40)\end{array}$ & $\begin{array}{l}15 \\
(3.00)\end{array}$ & $\begin{array}{l}20 \\
(2.70)\end{array}$ \\
\hline $\begin{array}{l}\text { A26) ask coach } \\
\text { conductor when } \\
\text { arrive in } \\
\text { Denpasar }\end{array}$ & $\begin{array}{l}4= \\
(3.60)\end{array}$ & $\begin{array}{l}11= \\
(3.35)\end{array}$ & $\begin{array}{l}25 \\
(2.80)\end{array}$ & $\begin{array}{l}21 \\
(2.10)\end{array}$ & $\begin{array}{l}3= \\
(3.67)\end{array}$ & $\begin{array}{l}14 \\
(3.45)\end{array}$ \\
\hline $\begin{array}{l}\text { R5) ask lecturer } \\
\text { for last week's } \\
\text { handout }\end{array}$ & $\begin{array}{l}25 \\
(2.40)\end{array}$ & $\begin{array}{l}25 \\
(1.75)\end{array}$ & $\begin{array}{l}5= \\
(3.47)\end{array}$ & $\begin{array}{l}5= \\
(3.40)\end{array}$ & $\begin{array}{l}25 \\
(2.33)\end{array}$ & $\begin{array}{l}21= \\
(2.55)\end{array}$ \\
\hline $\begin{array}{l}\text { R9) change large } \\
\text { note in bank }\end{array}$ & $\begin{array}{l}19= \\
(2.87)\end{array}$ & $\begin{array}{l}11= \\
(3.35)\end{array}$ & $\begin{array}{l}12= \\
(3.27)\end{array}$ & $\begin{array}{l}16= \\
(2.30)\end{array}$ & $\begin{array}{l}17= \\
(2.87)\end{array}$ & $\begin{array}{l}8= \\
(3.75)\end{array}$ \\
\hline $\begin{array}{l}\text { R6) ask to look } \\
\text { on at textbook in } \\
\text { class* }\end{array}$ & $\begin{array}{l}22 \\
(2.67)\end{array}$ & $\begin{array}{l}18 \\
(2.88)\end{array}$ & $\begin{array}{l}5= \\
(3.47)\end{array}$ & $\begin{array}{l}8 \\
(3.12)\end{array}$ & $\begin{array}{l}23 \\
(2.47)\end{array}$ & $\begin{array}{l}18 \\
(2.88)\end{array}$ \\
\hline $\begin{array}{l}\text { R23) ask to try } \\
\text { on shoes* }\end{array}$ & $\begin{array}{l}2= \\
(3.67)\end{array}$ & $\begin{array}{l}2 \\
(3.82)\end{array}$ & $\begin{array}{l}18 \\
(3.07)\end{array}$ & $\begin{array}{l}22 \\
(1.76)\end{array}$ & $\begin{array}{l}21= \\
(2.53)\end{array}$ & $\begin{array}{l}6= \\
(4.35)\end{array}$ \\
\hline $\begin{array}{l}\text { R14) ask friend } \\
\text { for lift home }\end{array}$ & $\begin{array}{l}16= \\
(2.93)\end{array}$ & $\begin{array}{l}15 \\
(2.95) \\
\end{array}$ & $\begin{array}{l}11 \\
(3.33) \\
\end{array}$ & $\begin{array}{l}7 \\
(3.25) \\
\end{array}$ & $\begin{array}{l}17= \\
(2.87)\end{array}$ & $\begin{array}{l}17 \\
(2.95) \\
\end{array}$ \\
\hline
\end{tabular}

* Only 17 , not 20 , learner informants assessed these two situations (due to defective questionnaire copies distributed) 


\section{Appendix D. Role play cues for Australian learner subjects}

Key:

$\mathrm{R}(1)=$ Request situation (No 1)

$\mathrm{A}(25)=\quad$ Asking situation (No 25)

$\mathrm{D}(30)=\quad$ Distractor situation (No 30)

\section{Cues for learner subjects: Group A}

R1. You are in a cassette store, and you would like to listen to a cassette that you see (for example the latest Iwan Fals cassette). Approach the assistant at the counter.

[Anda berada di toko kaset, dan Anda ingin mencoba sebuah kaset yang Anda lihat (misalnya, kaset Iwan Fals yang terbaru). Dekatilah pelayan yang sedang berdiri di belakang meja pajangan.]

D30. You are feeling rather worried because you have just lost your wallet/purse with all your money in it. You are with a classmate who you know well, who notices that you look worried.

[Anda baru saja kehilangan dompet yang berisi semua uang Anda. Anda sedang bersama seorang teman sekelas yang sudah Anda kenal dengan baik, yang memperhatikan bahwa Anda kelihatan agak cemas.]

R2. You have just arrived at your hotel. The hotel receptionist will give you a check-in form to fill out. (You do not have a pen).

[Anda baru saja tiba di hotel. Resepsionis akan memberi Anda selembar formulir untuk diisi. (Anda tidak mempunyai pulpen).]

R3. You are in a post office, and you want to buy two envelopes with stamps for Australia. Approach the clerk at the counter.

[Anda berada di kantor pos. Anda ingin membeli dua amplop yang ditempeli perangko untuk dikirim ke Australia. Dekatilah pegawai di belakang meja pajangan.] 


\section{Appendix D (cont.).}

\section{Cues for learner subjects Group A (cont.)}

D32. You meet someone who asks you a few social questions. After answering all their questions, take your leave with an excuse; for example, that you have to meet someone.

[Anda bertemu dengan seseorang yang mengajukan beberapa pertanyaan dengan ramah-tamah. Sesudah Anda selesai menjawab semua pertanyaan, mintalah permisi dengan memberi alasan (misalnya, bahwa Anda sudah ada janji).]

R4. You are on a local city bus. You don't know which is the right stop for Jalan Kartini (Kartini Street). You would like the conductor to tell you when you reach the stop closest to it.

[Anda sedang naik bis kota. Anda mau ke Jalan Kartini, dan Anda tidak tahu harus turun di mana. Anda ingin kondektur memberitahu Anda ketika sampai pada pemberhentian bis yang terbaik]

D33. You are in a pharmacy. You have already been served by a shop assistant, and they are now wrapping your parcel for you. (You don't want anything else, if they ask).

[Anda berada di apotek. Anda sudah dilayani dan sekarang pelayan toko sedang membungkus barang-barang Anda. (Jika dia bertanya sesuatu, beritahulah dia bahwa Anda tidak perlu yang lain lagi.)]

A25. You are waiting on Jakarta railway platform for a train to Bandung. A train has just arrived, but you do not know if it is the right one. There is a person standing next to you.

[Anda berada di setasiun kereta api di Jakarta, menunggu kereta api ke Bandung. Sebuah kereta api baru saja tiba, tetapi Anda tidak tahu apakah kereta api itu adalah yang Anda tunggu. Ada seseorang yang berdiri di samping Anda.]

R5. You are a student at university, sitting in class. You were away sick last week, so you didn't get a handout that was distributed. The lecturer is approaching you now this is a good chance to talk to them.

[Anda adalah seorang mahasiswa di sebuah universitas, sedang duduk di ruangan kelas. Anda tidak hadir minggu yang lalu karena sakit, sehingga tidak diberi latihan. Sekarang dosen mendekati Anda - inilah kesempatan baik untuk berbicara dengan dia.] 


\section{Appendix D (cont).}

\section{Cues for learner subjects: Group A (cont.)}

R6. You are sitting in class. You realise that you have left your textbook at home. The student sitting next to you has their textbook open in front of them and is following the lesson.

[Anda sedang duduk di kelas. Anda baru menyadari bahwa buku pelajaran Anda tertinggal di rumah. Mahasiswa yang duduk di samping Anda sudah ada buku pelajaran terbuka di depannya, dan dia sedang mengikuti pelajaran.]

D34. You are in a park. You get up from the bench, and start to walk away.

[Anda sedang duduk di atas bangku di kebun raya. Anda bangkit dari tempat Anda dan mulai pergi.]

R7 and 8. You are in a cinema to buy a ticket for the film "Four Seasons". You want a seat near the front, in the middle. Approach the ticket seller.

[Anda berada di bioskop untuk membeli sebuah karcis untuk film "Four Seasons". Anda ingin tempat duduk di bagian tengah depan ruangan bioskop. Dekatilah penjual karcis.]

R9. You have some 10,000 rupiah notes and nothing else, and you want to change them for smaller notes. You go into a bank and approach the bank teller.

[Anda mempunyai sejumlah uang kertas Rp10.000-an tetapi tidak mempunyai uang kecil. Anda ingin menukar uang kertas Rp10.000-an itu dengan uang kertas yang lebih kecilan. Anda masuk ke bank dan mendekati kasir.]

A28. You have just arrived in a new city, and you want to find the main post office. Approach someone in the street.

[Anda baru saja tiba di sebuah kota yang tidak Anda kenal, dan Anda mau mencari Kantor Pos utama. Dekatilah seseorang di jalan.]

D35. You are a passenger in a taxi. You arrive at your destination and the driver tells you how much the fare is. Give them a 5,000 rupiah note and wait for the change.

[Anda adalah penumpang taksi. Taksi tiba di tempat tujuan, dan sopir memberitahu Anda tentang ongkosnya. Berilah dia sehelai uang kertas Rp 5.000-an, dan tunggulah sampai sisanya dikembalikan.] 


\section{Appendix D (cont.).}

\section{Cues for learner subjects: Group A (cont.)}

R10. You are walking in a park. You feel like a cigarette, but you do not have any matches. There is someone sitting smoking on a bench nearby. Approach them.

[Anda sedang berjalan-jalan di kebun raya. Anda ingin merokok, tetapi tidak mempunyai korek api. Ada seseorang yang duduk di bangku dekat Anda sementara merokok. Dekatilah dia.]

A27. You come to the police station to report your lost passport. You want to know which section to go to to report it. Approach a police officer working at their desk.

[Anda datang ke kantor Polisi untuk melaporkan bahwa paspor Anda sudah hilang. Anda ingin tahu tempat untuk melaporkannya. Dekatilah seorang polisi yang sedang bekerja di meja kerjanya.]

R11. You enter a roadside eating stall (warung ). The benches are almost full, but if someone moves a little there will be room for you. Approach someone.

[Anda masuk ke sebuah warung. Walaupun semua bangku sudah hampir penuh, tetapi jika orang yang duduk bergeser sedikit, maka masih ada sedikit tempat. Dekatilah seseorang.]

\section{Cues for learner subjects: Group B}

R12. You are a guest in a hotel. There is a servant in your room who has just finished making your bed. You have a lot of dirty clothes that you would like laundered.

[Anda adalah tamu di hotel. Ada seorang pelayan di kamar Anda, yang baru saja selesai membereskan tempat tidur. Anda mempunyai banyak pakaian kotor untuk dicuci.]

R13. You want to buy the latest TEMPO magazine, and you stop at a roadside magazine stall, where the owner is sitting and reading.

[Anda ingin membeli majalah TEMPO yang terbaru. Anda berhenti di sebuah kios majalah di tepi jalan. Pemilik kios sedang duduk sambil membaca.] 


\section{Appendix D (cont.)}

\section{Cues for learner subjects: Group B (cont.)}

D31. You are walking in the street. A newspaper vendor approaches you. You don't want a newspaper.

[Anda sedang berjalan-jalan. Seorang penjual koran mendekati Anda. Anda tidak mau membeli koran.]

R14. You are about to walk home from the shops when you see a friend getting on their motorbike. They live in the same residential college (asrama) as you, and you could get a lift with them. Call out to them to attract their attention.

[Anda baru saja mau pulang dari pertokoan dengan berjalan kaki, ketika Anda melihat seorang teman yang mulai menaiki sepeda motornya. Dia juga tinggal di asrama dengan Anda, sehingga mungkin Anda bisa ikut pulang dengan dia. Panggillah dia.]

D38. You are in a friend's room in your college (asrama), talking about Indonesian music. Ask them which Indonesian pop singers they like most.

[Anda berada di kamar teman Anda di asrama sedang mengobrol tentang musik Indonesia. Tanyakanlah padanya siapakah penyanyi pop Indonesia yang paling dia sukai.]

R15. You are sitting in a lecture theatre at university. The lecture is about to start. You realise you do not have a pen. A student who you know is sitting near you.

[Anda sedang duduk di ruangan kuliah. Kuliah baru saja mau mulai. Tiba-tiba Anda sadar bahwa Anda tidak mempunyai pulpen. Seorang mahasiswa yang sudah Anda kenal sedang duduk di dekat Ânda.]

R16. You are sitting with a friend, casually watching TV. There is a pile of magazines beside your friend and you want to have a look at a couple.

[Anda sedang duduk bersama seorang teman, iseng menonton TV. Ada tumpukan majalah di samping teman Anda, dan Anda ingin membaca-baca sedikit.] 


\section{Appendix D (cont.)}

\section{Cues for learner subjects: Group B (cont.)}

R17. You bought a shirt yesterday. Now you have brought it back to exchange it for one of a different colour (you haven't unwrapped it). Approach the manager of the store.

[Anda membeli sebuah kemeja kemarin. Sekarang Anda membawa kemeja itu kembali ke toko pakaian untuk menukarkannya dengan kemeja yang berwarna lain. (Kemeja itu masih dibungkus). Dekatilah manajernya.]

R18 and 19. You are sitting in a cheap restaurant (rumah makan) and you want a menu. Get a menu from the waiter/waitress nearby, then order a dish (for example nasi goreng).

[Anda sedang duduk di sebuah rumah makan, dan Anda ingin melihat daftar makanan. Dapatkanlah daftar makanan dari pelayan yang berada di dekat Anda itu, kemudian pesanlah makanan (misalnya nasi goreng).]

R20 You are a customer in a cheap restaurant (rumah makan). When the waiter brings you your meal, order a beer too.

[Anda adalah langganan di sebuah rumah makan. Ketika pelayan membawa makanan Anda, pesanlah sebotol bir]

R21. You are a student at university, and you have an essay for your Javanese culture course due on Friday. You don't think you can finish it before next Monday. You go to see your lecturer and knock on their door.

[Anda adalah mahasiswa di sebuah universitas. Anda harus menyerahkan sebuah esai untuk matakuliah "Kebudayaan Jawa" pada hari Jumat, tetapi rasanya tidak mampu menyelesaikannya sebelum hari Senin minggu depan. Anda pergi ke kantor dosen dan mengetok pintunya.]

A26. You are a passenger in the middle of a long-distance bus trip to Denpasar. You want to know how much longer until the bus arrives in Denpasar. The conductor is standing beside you.

[Anda adalah penumpang di bus jarak jauh yang sedang menempuh perjalanan ke Denpasar. Anda ingin tahu berapa lama lagi busnya akan tiba di Denpasar. Kondektur sedang berdiri di samping Anda.] 


\section{Appendix D (cont.)}

\section{Cues for learner subjects: Group B (cont.)}

D37. You have just arrived at your hotel. A porter takes your bags and carries them to your room - give them a tip. (If they ask you, you don't want anything else).

[Anda baru saja tiba di hotel. Seorang portir membawa koper-koper Anda ke kamar Anda - berilah dia uang tip. (Jika dia bertanya sesuatu, beritahulah dia bahwa Anda tidak perlu apa-apa lagi.)]

R22. You are a passenger in a taxi, on a long journey across the city.

You would like the taxi to stop for a minute so you can buy some cigarettes.

[Anda sedang naik taksi melintasi kota (sebuah perjalanan yang panjang). Anda ingin taksi berhenti sebentar sehingga Anda dapat membeli rokok.]

A29. You are lost in the street. Approach someone and ask them for directions to "Pusat Bahasa" (The Language Centre).

[Anda tersesat di jalan. Dekatilah seseorang dan tanyakanlah jalan ke "Pusat Bahasa."]

R23. You are in a shoe shop and see a pair of shoes that you like. You want to try on a pair. Approach a sales assistant.

[Anda berada di toko sepatu. Anda melihat sepatu yang Anda sukai, dan Anda ingin mencoba sepasang. Dekatilah pelayan toko.]

R24. You are studying in Indonesia and you want to extend your visa. You have come to the Immigration Department office to pick up the necessary form. Approach the clerk responsible.

[Anda sedang kuliah di Indonesia, dan Anda ingin memperpanjang visa. Anda berada di kantor Imigrasi untuk mengambil formulir yang seperlunya. Dekatilah pegawai yang membidanginya.] 


\section{Appendix E. Role play cues for partners of Australian learner subjects}

\section{Cues for partners of Group A subjects}

R1. Anda adalah pelayan di toko kaset, yang sedang berdiri di belakang meja pajangan. Seorang langganan asing mendekati Anda.

D30. Seorang teman sekelas dari luar negeri yang sudah Anda kenal dengan baik kelihatan agak cemas. Tanyakanlah padanya apa masalahnya. Sesudah dia menjelaskan masalahnya, pinjamilah dia sedikit uang. (Jika dia ragu-ragu, desaklah supaya dia terima).

R2. Anda adalah resepsionis di hotel. Seorang tamu asing baru saja tiba di hotel. Berilah dia selembar formulir dan mintalah dia untuk mengisi formulir itu.

R3. Anda adalah pegawai di kantor pos. Seorang langganan asing mendekati meja pajangan.

D32. Anda bertemu dengan orang asing. Ajukanlah beberapa pertanyaan biasa (misalnya "Dari mana?" "Sudah berapa lama di Indonesia?" "Sudah ke mana saja?"). Kemudian, beritahulah dia bahwa Bahasa Indonesiannya baik sekali.

R4. Anda adalah kondektur di bis kota. Anda sedang berdiri di bagian belakang bis. Ada seorang penumpang asing yang berdiri di samping Anda.

D33. Anda adalah pegawai apotek. Anda sudah melayani seorang langganan asing. Bungkuslah barang-barang yang baru saja dia beli dan berikanlah bungkusan itu kepadanya. Tanyakanlah padanya apa lagi yang mau dia beli.

A25. Anda sedang menunggu kereta api di sebuah setasiun kereta api di Jakarta. Kereta api ke Bandung yang Anda tunggu baru saja tiba. Ada orang asing yang berdiri di samping Anda.

R5. Anda adalah dosen di sebuah universitas. Anda sedang membagikan sebuah latihan kepada setiap mahasiswa, seorang demi seorang.

Anda mendekati tempat duduk seorang mahasiswa asing.

R6. Anda sedang duduk di kelas. Buku pelajaran Anda sudah terbuka di depan Anda dan Anda sedang mengikuti pelajaran. Ada seorang mahasiswa asing yang sedang duduk di samping Anda. 


\section{Appendix E (cont.)}

\section{Cues for partners of Group A subjects (cont.)}

D34. Anda sedang berjalan-jalan di kebun raya. Anda melihat orang asing bangkit dari tempatnya dan mulai pergi. Dia lupa payungnya. Ambillah payungnya dan panggillah dia.

R7and 8. Anda adalah penjual karcis di bioskop. Seorang langganan asing mendekati Anda.

R9. Anda adalah kasir di bank. Ada orang asing masuk ke bank dan mendekati Anda.

A28. Anda sedang berjalan kaki di kota Anda sendiri. Ada orang asing mendekati Anda.

D35. Anda adalah sopir taksi. Hentikanlah taksi dan beritahulah penumpang asing Anda tentang ongkos perjalanannya: Rp 4.200. Sesudah dia membayar, berikanlah kembaliannya kepadanya.

R10. Anda sedang duduk di kebun raya sementara merokok. Ada orang asing mendekati Anda.

A27. Anda adalah seorang polisi. Anda sedang duduk di kantor polisi sementara bekerja. Orang asing masuk ke kantor dan mendekati Anda.

R11. Anda sedang duduk di atas bangku di sebuah warung sementara makan. Walaupun warung itu hampir penuh dengan langganan, mungkin Anda bisa bergeser sedikit. Ada orang asing masuk ke warung.

\section{Cues for partners of Group B subjects}

R12. Anda adalah pelayan di hotel. Anda berada di kamar seorang tamu asing. Anda baru saja selesai membereskan tempat tidur.

R13. Anda adalah pemilik kios majalah di tepi jalan, yang sedang duduk sambil membaca. Seorang langganan asing mendekati Anda. 


\section{Appendix E (cont.)}

\section{Cues for partners of Group B subjects (cont.)}

D13. Anda adalah penjual koran di jalan. Anda melihat orang asing. Dekatilah dia dan tawarilah dia koran-koran apa saja yang mungkin mau dia beli.

R14. Ketika Anda mulai menaiki sepeda motor Anda untuk pulang dari pertokoan, ada orang yang memanggil. Ternyata dia seorang teman asing yang juga tinggal di asrama Anda.

D38. Anda berada di kamar Anda di asrama bersama seorang teman asing, sedang mengobrol tentang musik Indonesia. Jawablah pertanyaannya. Kemudian Anda ingat bahwa Anda tadi membelikan dia sebuah kaset sebagai kado kecil- berikanlah kaset itu kepadanya.

R15. Anda sedang duduk di ruangan kuliah. Kuliah baru saja mau mulai. Seorang mahasiswa asing yang sudah Anda kenal sedang duduk di dekat Anda.

R16. Anda sedang duduk bersama seorang teman asing, iseng menonton TV. Ada tumpukan majalah di samping Anda.

R17. Anda adalah manajer sebuah toko pakaian. Seorang langganan asing masuk ke toko membawa sebuah bungkusan, dan mendekati Anda.

R18 and 19. Anda adalah pelayan di rumah makan. Anda sedang berdiri di dekat seorang langganan asing yang sedang duduk.

R20. Anda adalah pelayan di sebuah rumah makan. Bawakanlah makanan kepada seorang langganan asing: gado-gado dan nasi putih.

R21. Anda adalah dosen di sebuah universitas sedang bekerja di kantor. Seorang mahasiswa asing, yang ikut matakuliah Anda: "Kebudayaan Jawa", baru saja mengetok pintu.

A26. Anda adalah kondektur di bus jarak jauh yang sedang menempuh perjalanan ke Denpasar. Bus itu akan tiba di Denpasar dalam waktu kurang lebih 45 menit kemudian. Anda sedang berdiri di samping seorang penumpang asing. 


\section{Appendix E (cont.)}

\section{Cues for partners of Group B subjects (cont.)}

D37. Anda baru saja membawa koper-koper seorang tamu asing ke kamarnya. Letakkanlah koper-koper itu, dan tanyakanlah kepadanya apakah dia memerlukan yang lain lagi.

R22. Anda adalah sopir taksi. Anda sedang membawa seorang penumpang asing melintasi kota (sebuah perjalanan yang panjang).

A29. Anda sedang berjalan kaki di jalan. Ada orang asing mendekati Anda untuk menanyakan jalan. Jalannya agak sulit diterangkan, tetapi kebetulan saja Anda sendiri sedang berjalan ke tempat yang sama.

R23. Anda adalah pelayan di toko sepatu. Seorang langganan asing mendekati Anda.

R24. Anda adalah pegawai di kantor Imigrasi. Anda membidangi bagian visa. Ada orang asing mendekati meja pajangan. 
Appendix F. Excerpt from questionnaire on values of social variables in role play situations.

\section{Version given to Australian learner informants}

Imagine you are in Indonesia. Here are a number of situations in which you ask for something.

For each situation, decide:

* How high is your status, in relation to the other person?

* How big a thing is it that you are asking?

* How comfortable do you feel making this request?

Circle the most appropriate number (from 1 to 5)

Important: there are no right or wrong answers! Please just give your own opinion.

1. You are in a city bus, and you want to get off at Kartini Street. You ask the conductor to let you know when the bus gets to the right stop.

Your status (in relation to the other person)

1

2

3

4 5

lowest

highest

How big a thing you are asking

$\begin{array}{llllll}1 & 2 & 3 & 4 & 5\end{array}$

smallest

biggest

How comfortable you feel making this request

$\begin{array}{llllll}1 & 2 & 3 & 4 & 5\end{array}$

least most

comfortable

comfortable 


\section{Appendix F (cont).}

Version given to Bahasa Indonesia native informants

Bayangkanlah bahwa Anda berada di Indonesia. Berikut adalah sejumlah situasi di mana Anda meminta sesuatu.

Untuk setiap situasi, berikanlah evaluasi Anda:

* Berapa tinggi status Anda, dibandingkan dengan orang yang dimintai?

* Berapa besar jasa yang Anda minta?

* Bagaimana perasaan Anda ketika Anda mengajukan permintaan ini?

Lingkari angka yang paling tepat (dari $1 \mathrm{~s} / \mathrm{d} 5$ )

Penting: Tidak ada jawaban yang benar atau yang salah! Tolong beri pendapat Anda $\underline{\text { sendiri. }}$

1. Anda berada di bus kota. Anda mau turun di Jalan Kartini. Mintalah kepada kondektur, agar Anda diberitahu nanti kalau bus sudah sampai pada tempat pemberhentian yang terdekat.

Status Anda (dibandingkan dengan orang yang dimintai)

$\begin{array}{lllll}1 & 2 & 3 & 4 & 5 \\ \begin{array}{l}\text { paling } \\ \text { rendah }\end{array} & & & & \begin{array}{l}\text { paling } \\ \text { tinggi }\end{array}\end{array}$

Besarnya jasa yang diminta

$\begin{array}{llllll}1 & 2 & 3 & 4 & 5\end{array}$

paling paling

kecil besar

Enak/tidaknya perasaan Anda ketika meminta

$\begin{array}{lllll}1 & 2 & 3 & 4 & 5 \\ \begin{array}{l}\text { paling tidak } \\ \text { enak }\end{array} & & & & \begin{array}{l}\text { paling } \\ \text { enak }\end{array}\end{array}$




\section{REFERENCES}

Aijmer, K. (1996) Conversational routines in English: Convention and creativity, London, Longman

Allen, J. and H. Widdowson (1979) Teaching the communicative use of English. In $\mathrm{C}$. Brumfit and $\mathrm{K}$. Johnson (eds) The communicative approach to language teaching, Oxford, Oxford University Press

Apte, M. (1974) "Thank you" and South Asian languages: A comparative sociolinguistic study. International Journal of the Sociology of Language 3: 67-90

Aston, G. (1993) Notes on the interlanguage of comity. In G. Kasper and S. Blum-Kulka (eds) Interlanguage pragmatics, 224-250, New York, Oxford University Press

Aston, G. (1995) Say 'Thank you': Some pragmatic constraints in conversational closings. Applied Linguistics 16 (1): 57-86

Austin, J. (1955) How to do things with words. Reprinted in 1976, edited by J. Urmson and M. Sbisà, Oxford, Oxford University Press

Bachman, L. (1990) Fundamental considerations in language testing, Oxford, Oxford University Press

Badudu, J. (1986) Inilah Bahasa Indonesia yang benar II, Jakarta, Gramedia.

Bardovi-Harlig, K. and B. Hartford (1990) Congruence in native and non-native conversations: Status balance in the academic advising session. Language Learning 40: 467-501

Bardovi-Harlig, K., B. Hartford, R. Mahan-Taylor, M. Morgan and D. Reynolds (1991) Developing pragmatic awareness: closing the conversation. ELT Journal 45 (1): 4-15

Bardovi-Harlig, K. and B. Hartford (1996) Input in an institutional setting. Studies in second language acquisition 18: 171-188

Béal, C. (1990) 'It's all in the asking': A perspective on problems of crosscultural communication between native speakers of French and native speakers of English in the workplace. Australian Review of Applied Linguistics Series S, 7: 16-32

Beebe, L. and T. Takahashi (1989) Do you have a bag?: Social status and patterned acquisition in second language acquisition. In S. Gass, C. Madden, D. Preston and L. Selinker (eds) Variation in second language acquisition Volume 1: Discourse and pragmatics, Clevedon, Multilingual Matters

Beebe, L., T. Takahashi and R. Uliss-Weltz (1990) Pragmatic transfer in ESL refusals. In R. Scarcella, E. Andersen and S. Krashen (eds) Developing communicative competence in a second language, Boston, Heinle and Heinle.

Bergman, M. and G. Kasper (1993) Perception and performance in native and nonnative apology. In G. Kasper and S. Blum-Kulka (eds) Interlanguage pragmatics, 82-107, New York, Oxford University Press 
Bialystok, E. (1991) Achieving proficiency in a second language: A processing description. In R. Phillipson, E. Kellerman, L. Selinker, M. Sharwood Smith and M. Swain (eds) Foreign/second language pedagogy research, 63-78, Clevedon, Multilingual Matters

Bialystok, E. (1993) Symbolic representation and attentional control in pragmatic competence. In G. Kasper and S. Blum-Kulka (eds) Pragmatic interlanguage, New York, Oxford University Press

Bilbow, G. (1995) Requesting strategies in the cross-cultural business meeting. Pragmatics 5 (1): 45-55

Blum-Kulka, S. (1982) Learning to say what you mean in a second language: A study of the speech act performance of learners of Hebrew as a second language. Applied Linguistics 3 (1): 29-59

Blum-Kulka, S. (1983) Interpreting and performing speech acts in a second language - a cross-cultural study of Hebrew and English. In N. Wolfson and E. Judd (eds) Sociolinguistics and language acquisition, 36-55, Rowley, Massachusetts, Newbury House

Blum-Kulka, S. (1987) Indirectness and politeness in requests: Same or different? Journal of Pragmatics 11: 131-46

Blum-Kulka, S. (1989) Playing it safe: The role of conventionality in indirect requests. In S. Blum-Kulka, J. House and G. Kasper (eds) Cross-cultural pragmatics: Requests and apologies, 37-70, Norwood, New Jersey, Ablex

Blum-Kulka, S. (1991) Interlanguage pragmatics: The case of requests. In $R$. Phillipson, E. Kellerman, L. Selinker, M. Sharwood Smith and M. Swain (eds) Foreign/second language pedagogy research, 255-272, Clevedon, Multilingual Matters

Blum-Kulka, S., B. Danet and R. Gherson (1985) The language of requesting in Israeli society. In J. Forgas (ed) Language and social situations, 113-139, New York, Springer-Verlag

Blum-Kulka, S. and J. House (1989) Cross-cultural and situational variation in requesting behaviour. In S. Blum-Kulka, J. House and G. Kasper (eds) Crosscultural pragmatics: Requests and apologies, Ablex, New Jersey

Blum-Kulka, S., J. House and G. Kasper (1989) Investigating Cross-Cultural Pragmatics: An Introductory Overview. In S. Blum-Kulka, J. House and G. Kasper (eds) Cross-Cultural Pragmatics: Requests and Apologies, Ablex, New Jersey.

Blum-Kulka, S. and E. Levenston (1987) Lexical-grammatical pragmatic indicators. In Studies in Second Lnguage Acquisition 9: 155-170

Blum-Kulka, S. and E. Olshtain (1984) Requests and Apologies: A Cross-Cultural Study of Speech Act Realization Patterns. Applied Linguistics 5(3): 196-213

Blum-Kulka, S. and E. Olshtain (1986) Too many words: Length of utterance and pragmatic failure. Studies in Second Language Acquisition 8: 165-180 
Blum-Kulka, S. and H. Sheffer (1993) The metapragmatic discourse of AmericanIsraeli families at dinner. In G. Kasper and S. Blum-Kulka (eds) Interlanguage pragmatics, 196-223, New York, Oxford University Press

Bodman, J. and M. Eisenstein (1988) May God increase your bounty: The expression of gratitude in English by native and non-native speakers. CrossCurrents 15 (1): 1-21

Bongaerts, T., E. Kellerman and A. Bentlage (1987) Perspective and proficiency in L2 referential communication. Studies in Second Language Acquisition 9: 171-199

Brown, H. (1987) Principles of language learning and teaching, New Jersey, Prentice Hall Regents

Brown, P. and C. Fraser (1979) Speech as a marker of situation. In K. Scherer and H. Giles (eds) Social markers in speech, Cambridge, Cambridge University Press

Brown, P. and S. Levinson (1978) Universals in language usage: Politeness phenomena. In E. Goody (ed) Questions and politeness: Strategies in social interaction, Cambridge University Press, Cambridge

Brown, P. and S. Levinson (1987) Politeness: some universals in language usage, Cambridge, Cambridge University Press

Brumfit, C. and K. Johnson (eds) (1979) The communicative approach to language teaching, Oxford, Oxford University Press

Bryant, B. (1980) Australian questioning intonation: An addition to speakers' response-seeking repertoire. Unpublished BA Honours thesis, Department of Linguistics, Faculty of Arts, Australian National University, Canberra

Campbell, R. and R. Wales (1970) The study of language acquisition. In J. Lyons (ed) New horizons in linguistics, Harmondsworth, Penguin

Canale, M. (1983) From communicative competence to communicative language pedagogy. In J. Richards and R. Schmidt (eds) Language and communication, 125, London, Longman

Canale, M. and M. Swain (1980) Theoretical bases of communicative approaches to second language teaching and testing. Applied Linguistics 1: 1-47

Carroll, B. (1980) Testing communicative performance, Oxford, Pergamon Press

Cartier, A. (1989) Kalimat berverba transitif yang mengalami pemudaran diatesis di dalam Bahasa Indonesia ragam formal. In B. Kaswanti Purwo (ed) Serpih-serpih telaah pasif Bahasa Indonesia, 85-146, Yogyakarta, Kanisius

CCSARP (1989) The CCSARP Coding Manual. In S. Blum-Kulka, J. House and G. Kasper (eds) Cross-cultural pragmatics: Requests and apologies , 273-289, Ablex, New Jersey

Charters, H. (1997) Ellipsis in Mandarin: Places where learners don't use. Australian Review of Applied Linguistics 20(1): 57-82

Chomsky, N. (1965) Aspects of the theory of syntax, Massachusetts, MIT Press 
Chung, S. (1989) Ihwal dua konstruksi pasif di dalam Bahasa Indonesia. In B. Kaswanti Purwo (ed) Serpih-serpih telaah pasif Bahasa Indonesia, 3-84, Yogyakarta, Kanisius

Clahsen, H. (1984) The acquisition of German word order: A test case for cognitive approaches to L2 development. In R. Andersen (ed) Second languages: A cross-linguistic perspective, 219-242, Massachusetts, Newbury House

Clark, H. (1979) Responding to indirect speech acts. Cognitive Psychology 11: 430-477

Clark, H. and E. Clark (1977) Psychology and language: An introduction to psycholinguistics, New York, Harcourt Brace Jovanovich

Cohen, A. (1996) Developing the ability to perform speech acts. Studies in Second Language Acquisition 18: 253-267

Cohen, A. and E. Olshtain (1981) Developing a Measure of Sociocultural Competence: The Case of Apology. Language Learning 31(1): 113-34

Cohen, A. and E. Olshtain (1993) The production of speech acts by EFL learners. TESOL Quarterly 27 (1): 33-56

Cohen, A., E. Olshtain and D. Rosenstein (1986) Advanced EFL apologies: What remains to be learned? International Journal of the Sociology of Language 62: 5175

Cook, V. (1985) Language functions, social factors, and second language learning and teaching. IRAL 23(3): 177-198

Crozet, C. (1996) Teaching verbal interaction and culture in the language classroom. Australian Review of Applied Linguistics 19 (2): 37-58

Crozet, C. and A. Liddicoat (1997) The place of culture in language teaching: An introduction. In $\mathrm{T}$. Liddicoat and $\mathrm{C}$. Crozet (eds) Teaching language, teaching culture, 1-22, Canberra, Applied Linguistics Association of Australia

D. P. and K. [Departemen Pendidikan dan Kebudayaan] (1993) Tatabahasa Baku Bahasa Indonesia, Jakarta, Balai Pustaka

Draine, C. and B. Hall (1990) Culture Shock Indonesia, Times Editions, Singapore.

Dreyfuss, J. (1978) “men-, di- and ber-:[three analyses]”. NUSA 6(5):1-6

D'Souza, J. (1988) Interactional strategies in South Asian languages: their implications for teaching English internationally. World Englishes 7 (2): 159-171

Edmondson, W. (1981) Spoken discourse: A model for analysis, Longman, New York

Edmondson, W. and J. House (1981) Let's talk and talk about it: A pedagogical interactional grammar of English, Urban and Schwarzenberg, Munich 
Edmondson, W. and J. House (1991) Do learners talk too much? The waffle phenomenon in interlanguage pragmatics. In R. Phillipson, E. Kellerman, L. Selinker, M. Sharwood Smith and M. Swain (eds) Foreign/second language pedagogy research, 273-286, Clevedon, Multilingual Matters

Edmondson, W., J. House, G. Kasper and B. Stemmer (1984) Learning the Pragmatics of Discourse: A Project Report. Applied Linguistics 5(2): 113-27

Eisenstein, M. and J. Bodman (1986) 'I very appreciate': Expressions of gratitude by native and non-native speakers of American English. Applied Linguistics 7(2): $167-85$

Eisenstein, M. and J. Bodman (1993) Expressing gratitude in American English. In G. Kasper and S. Blum-Kulka (eds) Interlanguage pragmatics, 64-81, New York, Oxford University Press

Ellis, R. (1992) Learning to communicate in the classroom: A study of two language learners' requests.Studies in Second Language Acquisition 14: 1-23

Ervin-Tripp, S. (1976) Is Sybil there? the structure of some American English directives. Language in Society 5: 25-66

Faerch, C. and G. Kasper (1983) Plans and strategies in foreign language communication. In C. Faerch and G. Kasper (eds) Strategies in interlanguage communication, 20-59, London, Longman

Faerch, C. and G. Kasper (1989) Internal and external modification in interlanguage request realization. In S. Blum-Kulka, J. House and G. Kasper (eds) Cross-Cultural Pragmatics: Requests and Apologies, 221-247, New Jersey, Ablex

Fraser, B. (1978) Acquiring social competence in a second language. $R E L C$ Journal 9 (2): 1-21

Fraser, B. (1990) Perspectives on politeness. Journal of Pragmatics 14: 219-236

Fraser, B. and W. Nolen (1981) The association of deference with linguistic form. International Journal of the Sociology of Language 27: 93-109

Fraser, B., E. Rintell and J. Walters (1980) An approach to conducting research on the acquisition of pragmatic competence in a second language. In D. LarsenFreeman (ed) Discourse analysis in second language research, Massachusetts, Newbury House

Fukushima, S. (1996) Request strategies in British English and Japanese. Language Sciences 18 (3-4): 671-688

Geertz, C. (1976) The Religion of Java, Chicago, The University of Chicago Press

Goffman, E. (1967) Interaction ritual: Essays on face-to-face behaviour, New York, Anchor Books

Goody, E. (1978) Towards a theory of questions. In E. Goody (ed) Questions and Politeness: Strategies in social interaction, 17-43, Cambridge, Cambridge University Press 
Gordon, D. and G. Lakoff (1971) Conversational postulates. Papers from the Seventh Regional Meeting of the Chicago Linguistic Society, 63-84.

Green, G. (1975) How to get people to do things with words: The whimperative question. In P. Cole and J. Morgan (eds) Syntax and semantics Volume 3: Speech acts, New York, Academic Press

Grice, P. (1975) Logic and Conversation. Reprinted in P. Grice (ed) (1989) Studies in the Way of Words, Massachusetts, Harvard University Press

Gu, Y. (1990) Politeness phenomena in modern Chinese. Journal of Pragmatics 14: $237-257$

Gunarwan, A. (1993) The politeness rating of English and Indonesian directive types among Indonesian learners of English: Towards contrastive pragmatics. Paper presented at 4th International Pragmatics Conference, Kobe, Japan

Harlow, L. (1990) Do they mean what they say? Sociopragmatic competence and second language language learners. The Modern Language Journal 74 (3): 328351

Hassall, T. (1996) Thanking by Australian learners of Indonesian. Paper presented at the 21 st Conference of the Applied Linguistics Association of Australia (ALAA), University of Western Sydney, October 3-6, 1996.

Hill, B., S. Ide, S. Ikuta, A. Kawasaki and T. Ogino (1986) Universals of linguistic politeness. Journal of Pragmatics 10: 347-71

Hinkel, E. (1994) Pragmatics of interaction: Expressing thanks in a second language. Applied Language Learning 5(1): 73 - 92

Hinkel, E. (1997) Appropriateness of advice: DCT and multiple choice data. Applied Linguistics 18(1): 1-26

Horvath, B. (1985) Explorations into the meaning of HRT. In B. Horvath (ed) Variations in Australian English: The sociolects of Sydney, 118-132, Cambridge, Cambridge University Press

House, J. (1989) Politeness in English and German: The functions of "please" and "bitte". In S. Blum-Kulka, J. House and G. Kasper (eds) Cross-Cultural Pragmatics: Requests and Apologies, 96-119, Ablex, New Jersey

House, J. (1993) Towards a model for the analysis of inappropriate responses in native/nonnative interactions. In G. Kasper and S. Blum-Kulka (eds) Interlanguage pragmatics, 161-183, New York, Oxford University Press

House, J. (1996) Developing pragmatic fluency in English as a second language. Studies in Second Language Acquisition 18: 225-252

House, J. and G. Kasper (1981) Politeness markers in English and German. In F. Coulmas (ed) Conversational routine, 157-185, The Hague, Mouton

House, J. and G. Kasper (1987) Interlanguage pragmatics: Requesting in a foreign language. In W. Lörscher and Rainer Schulze (eds) Perspectives on language in performance, 1250-1288, Tübingen, Narr 
Hymes, D. (1972a) On communicative competence. In J. Pride and J. Holmes (eds) Sociolinguistics: Selected readings, London, Penguin Books

Hymes, D. (1972b) Models of the interaction of language and social life. In J. Gumperz and D. Hymes (eds) Directions in Sociolinguistics: The Ethnography of Communication, 35-71, New York, Holt, Rinehart and Winston

Ide, S. (1989) Formal forms and discernment: Two neglected aspects of universals of linguistic politeness. Multilingua 8 (2/3): 223-248

Janicki, K. (1986) Accommodation in native speaker-foreigner interaction. In J. House and S. Blum-Kulka (eds) Interlingual and intercultural communication, 169178, Tübingen, Narr

Jenson, K. (1988) Forms of address in Indonesian. I.T.L: Review of Applied Linguistics 81/82: 113-138

Johns, Y. (1977) Bahasa Indonesia: Langkah Baru Book 1, Canberra, Australian National University Press

Kasper, G. (1979) Communication strategies: Modality reduction. Interlanguage Studies Bulletin Utrecht 4: 266-283

Kasper, G. (1982) Teaching-induced aspects of interlanguage discourse. Studies in Second Language Acquisition 4: 99-113

Kasper, G. (1989) Variation in interlanguage speech act realisation. In S. Gass, C. Madden, D. Preston and L. Selinker (eds) Variation in second language acquisition Volume 1: Discourse and Pragmatics, 37-58, Clevedon, Multilingual Matters

Kasper, G. (1990) Linguistic politeness: Current research issues. Journal of Pragmatics 14: 193-218

Kasper, G. (1992) Pragmatic Transfer. Second Language Research 8: 203-231

Kasper, G. (1995a) Interlanguage pragmatics. In G. Kasper Pragmatics in language teaching and teacher education (Pre-readings for LIFT teacher inservice session at the Australian National University, Sept. 23-23 1995). To appear in H. Byrnes (ed) Perspectives on research and scholarship in second language learning, Modern Language Association

Kasper, G. (1995b) The role of pragmatics in language teacher education. In G. Kasper Pragmatics in language teaching and teacher education (Pre-readings for LIFT teacher inservice session at the Australian National University, Sept. 23-23 1995). To appear in K. Bardovi-Harlig and B. Hartford (eds) Beyond methods, New York, McGraw-Hill

Kasper, G. and S. Blum-Kulka (1993) Interlanguage pragmatics: An introduction. In G. Kasper and S. Blum-Kulka (eds) Interlanguage pragmatics, 3-15, New York, Oxford University Press

Kasper, G. and M. Dahl (1991) Research methods in interlanguage pragmatics. Studies in Second Language Acquisition 13: 215-247

Kasper, G. and R. Schmidt (1996) Developmental issues in interlanguage pragmatics. Studies in Second Language Acquisition 18: 149-169 
Kaswanti Purwo, B. (1984) Deiksis dalam Bahasa Indonesia, Jakarta, Balai Pustaka

Kaswanti Purwo, B. (1990) Pragmatik and pengajaran bahasa: Menyibak kurikulum 1984, Yogyakarta, Kanisius

Keller, E. (1981) Gambits: Conversational strategy signals. In F. Coulmas (ed) Conversational routine, 93-113, The Hague, Mouton

Kellerman, E. (1983) If at first you do succeed... In S. Gass and C. Madden (eds) Input in second language acquisition, Rowley, Massachusetts, Newbury House.

Koike, D. (1989) Pragmatic competence and adult L2 acquisition: Speech acts in interlanguage. The Modern Language Journal 73 (3): 279-289

Kramsch, C. (1981) Discourse analysis and language teaching (Vol. 37 of Language in Education series), Washington, Centre for Applied Linguistics

Labov, W. (1972) Sociolinguistic patterns, Oxford, Basil Blackwell

Lakoff, R. (1973) The logic of politeness, or, minding your p's and q's. In C. Corum, T. Smith-Stark and A. Weiser (eds) Papers from the ninth regional meeting of the Chicago Linguistic Society, 292-305, Chicago, Chicago Linguistics Society

Larsen-Freeman, D. and M. Long (1991) An introduction to second language research, New York, Longman

Leech, G. (1983) Principles of Pragmatics, London, Longman

Le Pair, R. (1996) Spanish request strategies: A cross-cultural analysis from an intercultural perspective. Language Sciences 18 (3-4): 651-670

Lee-Wong, S. (1994) Imperatives in requests: Direct or impolite - Observations from Chinese. Pragmatics 4 (4): 491-515

Levelt, W. (1989) Speaking: From intention to articulation, Massachusetts, MIT Press

Levinson, S. (1983) Pragmatics, Cambridge, Cambridge University Press

Liddicoat, A. (1997) Everyday speech as culture: Implications for language teaching. In A. Liddicoat and C. Crozet (eds) Teaching language, teaching culture, Canberra, Applied Linguistics Association of Australia

Littlewood, W. (1981) Communicative language teaching: An introduction, Cambridge, Cambridge University Press

Mao, L. (1994) Beyond politeness theory: 'Face' revisited and renewed. Journal of Pragmatics 21: $451-486$

Matsumoto, Y. (1988) Reexamination of the universality of face. Journal of Pragmatics 12: 403-26

McCune, K. (1979) Passive function and the Indonesian passive. Oceanic Linguistics 18(2): 119-169 
McCune, K. (1989) Fungsi pasif dan pasif Bahasa Indonesia. In B. Kaswanti Purwo (ed) Serpih-serpih telaah pasif Bahasa Indonesia, 283-344, Yogyakarta, Kanisius

McDonough, S. (1981) Psychology in foreign language teaching, Allen and Unwin, London

Meisal J., H. Clahsen and M. Pienemann (1981) On determining developmental stages in natural second language acquisition. Studies in Second Language Acquisition 3 (2): 109-135

Merritt, M. (1976) On questions following questions in service encounters. Language in Society 5 (3): 315-357

Mintz, M. (1994) A student's grammar of Indonesian, Singapore, EPB

Morrow, K. (1979) Communicative language testing: Revolution or evolution? In C. Brumfit and K. Johnson (eds) The communicative approach to language teaching, Oxford, Oxford University Press

Mulder, N. (1989) Individual and Society in Java: A Cultural Analysis, Gadjah Mada University Press, Yogyakarta

Nababan, P. (1991) Language in Education: The case of Indonesia. International Review of Education 37 (1): 117-31

Nguyen, T. (1990) Politeness formulae: Thanking. In U. Nixon (ed) Discourse analysis papers (Centre for Teaching English to Speakers of Other Languages Occasional Papers Series), 81-98, Canberra, University of Canberra

Nguyen, X. (1990) Requests. In U. Nixon (ed) Discourse analysis papers (Centre for Teaching English to Speakers of Other Languages Occasional Papers Series), 117, Canberra, University of Canberra

Nwoye, O. (1992) Linguistic politeness and socio-cultural variations of the notions of face. Journal of Pragmatics 18: 309-28

Odlin, T. (1989) Language transfer, Cambridge, Cambridge University Press

Olshtain, E. and S. Blum-Kulka (1985) Crosscultural Pragmatics and the testing of communicative competence. Language Testing 2(1): 16-30

Olshtain, E. and A. Cohen (1983) Apology: a speech-act set. In N. Wolfson and E. Judd (eds) Sociolinguistics and Second Language Acquisition., 18-35, Rowley, Massachusetts, Newbury House.

Olshtain, E. and L. Weinbach (1987) Complaints: A Study of Speech Act Behaviour among Native and Nonnative Speakers of Hebrew. In J. Verschueren and M. Bertuccelli-Papi (eds) The Pragmatic Perspective: Selected papers from the 1985 international pragmatics conference, 195-208, John Benjamins, Amsterdam.

Olshtain, E. and L. Weinbach (1993) Interlanguage features of the speech act of complaining. In G. Kasper and S. Blum-Kulka (eds) Interlanguage pragmatics, 108-122, New York, Oxford University Press 
Psathas, G. (1991) The structure of direction-giving in interaction. In D. Boden and D. Zimmerman (eds) Talk and social structure, Cambridge, Polity

Quinn, G. (1996a) The Indonesian Way: Book 1, Canberra, Southeast Asia Centre, Faculty of Asian Studies, Australian National University

Quinn, G. (1996b) The Indonesian Way: Book 3, Canberra, Southeast Asia Centre, Faculty of Asian Studies, Australian National University

Quinn, G. (1996c) The Indonesian Way: Book 4, Canberra, Southeast Asia Centre, Faculty of Asian Studies, Australian National University

Quinn, G. (1996d) The Indonesian way: Readings and Wordlist, Canberra, Southeast Asia Centre, Faculty of Asian Studies, Australian National University

Reeve, D. (1995) Introductory Indonesian: Cultural notes. In Issues in the teaching of Indonesian 2 [Pre-readings for LIFT teacher inservice session at Australian National University, Canberra, April 8-9 1995], The Australian National University

Rintell, E. (1981) Sociolinguistic variation and pragmatic ability: A look at learners. International Journal of the Sociology of Language 27: 11-34

Rintell, E. and C. Mitchell (1989) Studying Requests and Apologies: An Inquiry into Method. In S. Blum-Kulka, J. House and G. Kasper (eds) Cross-Cultural Pragmatics: Requests and Apologies, 248-273, Ablex, New Jersey.

Robinson, M. (1992) Introspective methodology in interlanguage pragmatics research. In G. Kasper (ed) Pragmatics of Japanese as native and target language (Second Language Teaching and Curriculum Centre Technical Report No 3), 2782, Honolulu, University of Hawaii Press

Rose, K. (1994) On the validity of discourse completion tests in non-Western contexts. Applied Linguistics 15 (1): 1-14

Sacks, H. (1992) Lectures on conversation Volume 1, edited by G. Jefferson, Oxford, Blackwell

Sacks H., E. Schegloff and G. Jefferson (1974) A simplest systematics for the organization of turn-taking for conversation. Language 50: 696-735

Sadock, J. (1974) Towards a linguistic theory of speech acts, New York, Academic Press

Sarumpaet, J. (1977) The structure of Bahasa Indonesia, Melbourne, Sahata

Sawyer, M. (1992) The development of pragmatics in Japanese as a second language: the sentence-final particle ne. In G. Kasper (ed) Pragmatics of Japanese as native and target language (Second Language Teaching and Curriculum Centre Technical Report No 3), 83-125, Honolulu, University of Hawaii Press

Scarcella, R. (1983) Developmental trends in the acquisition of conversational competence by adult second language learners. In N. Wolfson and E. Judd (eds) Sociolinguistics and language acquisition, Rowley, Massachusetts, Newbury House 
Scarcella, R. and J. Brunak (1981) On speaking politely in a second language. International Journal of the Sociology of Language 27: 59-75

Schegloff, E. (1980) Preliminaries to preliminaries: 'Can I ask you a question'. Sociological Inquiry 50: 104-152

Schegloff, E. (1995) Sequence organization. Unpublished manuscript, Department of Sociology, UCLA

Schegloff, E., G. Jefferson and H. Sacks (1977) The preference for self-correction in the organisation of repair in conversation. Language 53(2): 361-382

Schegloff, E. and H. Sacks (1973) Opening up closings. Semiotica 8: 289-327

Schmidt, R. (1983) Interaction, acculturation, and the acquisition of communicative competence: A case study of an adult. In N. Wolfson and E. Judd (eds) Sociolinguistics and language acquisition, 137-174, Rowley, Massachusetts, Newbury House

Schmidt, R. (1993) Consciousness, learning and interlanguage pragmatics. In G. Kasper and S. Blum-Kulka (eds) Interlanguage pragmatics, 21-42, New York, Oxford University Press

Schmidt, R. and J. Richards (1980) Speech Acts and Second Language Learning. Applied Linguistics 1(2): 129-57

Searle, J. (1969) Speech Acts: An Essay in the Philosophy of Language, Cambridge, Cambridge University Press

Searle, J. (1971) A classification of illocutionary acts. Reprinted in D. Carbaugh (ed) (1990) Cultural communication and intercultural contact, New Jersey, Lawrence Erlbaum

Searle, J. (1975) Indirect speech acts. In P. Cole and J. Morgan (eds) Syntax and semantics Volume 3: Speech acts, New York, Academic Press

Selinker, L. (1969) Language transfer. General Linguistics 9: 67-92

Selinker, L. (1972) Interlanguage. IRAL 10 (3): 209-231

Sharwood Smith, M. (1994) Second language learning: Theoretical foundations, London, Longman

Sifianou, M. (1992) Politeness phenomena in England and Greece, Oxford, Clarendon Press

Skehan, P. (1989a) Language Testing: Survey article, Part 1. Language Teaching Abstracts 21 (4): 211-221

Skehan, P. (1989b) Language Testing: Survey article, Part 2. Language Teaching Abstracts 22 (1): 1-13

Sneddon, J. (1996) Indonesian reference grammar, Sydney, Allen and Unwin

Soebardi, S. (1989). Learn Bahasa Indonesia Book Two, Jakarta, Bhratara 
Soenarso, L. (1988) Developing social competence in complimenting behaviour among Indonesian learners of English. Unpublished MA thesis, University of Canberra

Stern, H. (1982) Fundamental concepts of language teaching, Oxford, Oxford University Press

Strauss, S. (1982) U-shaped behavioural growth, New York, Academic Press

Takahashi, S. (1996) Pragmatic transferability. Studies in Second Language Acquisition 18: 189-223

Takahashi, T. and L. Beebe (1993) Cross-linguistic influence in the speech act of correction. In G. Kasper and S. Blum-Kulka (eds) Interlanguage pragmatics, 138158, New York, Oxford University Press

Tanaka, N. (1986) An investigation of politeness: two request situations in English and Japanese. Unpublished MA field study report, University of Canberra

Tanaka, N. (1988) Politeness: Some problems for Japanese speakers of English. JALT Journal 9 (2): 81-101

Thomas, J. (1983) Cross-Cultural Pragmatic Failure. Applied Linguistics 4: 91112

Trosborg, A. (1995) Interlanguage pragmatics: Requests, complaints and apologies, Berlin, Mouton de Gruyter

Tsui, A. (1994) English conversation, Oxford, Oxford University Press

Van der Wijst, P. (1995) The perception of politeness in Dutch and French indirect requests. Text 15(4): 477-501

Van Mulken, M. (1996) Politeness markers in French and Dutch requests. Language Sciences 18 (3/4): 689-702

Verhaar, J. (1984) The categorial system in contemporary Indonesian: Verbs. NUSA 18: 27-63

Verhaar, J. (1989) Keergatifan Sintaktis di dalam Bahasa Indonesia Modern. In B. Kaswanti Purwo (ed) Serpih-serpih telaah pasif Bahasa Indonesia, 201-282, Yogyakarta, Kanisius

Verschueren, J. (1985) What people say they do with words: Prolegomena to an empirical-conceptual approach to linguistic action, Norwood, New Jersey, Ablex

Weizman, E. (1989) Requestive hints. In S. Blum-Kulka, J. House and G. Kasper (eds) Cross-Cultural Pragmatics: Requests and Apologies, 71-95, Ablex, New Jersey

Weizman, E. (1993) Interlanguage requestive hints. In G. Kasper and S. BlumKulka (eds) Interlanguage pragmatics, 123-137, New York, Oxford University Press

White, I. (1994) Bahasa Tetanggaku: A notional-functional course in Bahasa Indonesia: Coursebook, Stage 1, Melbourne, Longman 
Wierzbicka, A. (1985) Different Cultures, Different Languages, Different Speech Acts. Journal of Pragmatics 9(1): 145-78

Wierzbicka, A. (1987) English speech act verbs, Academic Press, Sydney

Wierzbicka, A. (1991) Cross Cultural Pragmatics: The Semantics of Human Interaction, Mouton de Gruyter, Berlin

Wolff, J. (1972) Beginning Indonesian Part One, Ithaca, Cornell University Press

Wolfson, N. (1983) Rules of speaking. In J. Richards and R. Schmidt (eds) Language and communication, New York, Longman

Wolfson, N. (1986) Research methodology and the question of validity. TESOL Quarterly 20 (4): 689-699

Wolfson, N., T. Marmor and S. Jones (1989) Problems in the comparison of speech acts across cultures. In S. Blum-Kulka, J. House and G. Kasper (eds) Cross cultural pragmatics: Requests and apologies, Ablex, New Jersey

Worsley, P. (1993) Unlocking Australia's Language Potential: Profile of 9 key languages in Australia: Volume 5 - Indonesial Malay, Canberra, The National Languages and Literacy Institute of Australia

Zhang, Y. (1995a) Strategies in Chinese requesting. In G. Kasper (ed) Pragmatics of Chinese as native and target language (Technical report No 5, Second Language Teaching and Curriculum Centre, University of Hawai' $i$ ), Honolulu, University of Hawai'i Press

Zhang, Y. (1995b) Indirectness in Chinese requesting. In G. Kasper (ed) Pragmatics of Chinese as native and target language (Technical report No 5, Second Language Teaching and Curriculum Centre, University of Hawai'i), Honolulu, University of Hawai'i Press

Zimin, S. (1981) Sex and politeness: factors in first- and second- language use. International Journal of the Sociology of Language 27: 35-58 